\title{
Kapitel 2: Ausstellen
}

\section{"Die Zerschlagung vor Moskau". Eine Sonderausstellung in der Frontstadt}

Das Bewusstsein, in einer historischen, das heiß bewahrenswerten Zeit zu leben, motivierte die muzejščiki, an der Front Erinnerungsstücke für künftige Ausstellungen zu sammeln. Die Museumsmitarbeitenden nahmen den Krieg von Beginn an als gegenwärtige, lebendige und "gerade entstehende Geschichte« wahr. ${ }^{1}$ Es entstanden Museumssammlungen und in der Folge Sonderausstellungen, die nicht wie üblich die Vergangenheit oder zukünftig zu erreichende (politische) Ideale dokumentierten, sondern das Hier und Heute des Museumspublikums als historisch aufgeladene Gegenwart repräsentierten. Lisa Kirschenbaum hat dieses Phänomen eines Gedenkens, das simultan zu den Ereignissen konstruiert wird, im belagerten Leningrad beobachtet und als "contemporary commemoration « beschrieben. ${ }^{2}$ Sie bezieht sich bei ihrer Beobachtung auf Pierre Nora, der die Deutung von Ereignissen, die bereits während ihrer Entwicklung kommemoriert und mit großem symbolischen Wert verbunden wurden, als "commémoration anticipée« beschrieb. ${ }^{3}$ Die rantizipierte Kommemoration< setzt bei den gestaltenden Akteuren immer auch die Gewissheit um ein »danach « voraus. So adressieren diese vvorgegriffenen Erinnerungsprojekter nicht nur die Zeitgenossinnen und Zeitgenossen, sondern auch die Nachkommen, die verstehen wollen und sollen, wie es zu den dargestellten Ereignissen kam. Damit wird die Lektüre aktiv vorweggenommen und eine spätere Lesart festgelegt, um die Kontrolle über das zukünftige Geschichtsverständnis zu behalten, die nicht aus zufällig hinterlassenen Zeugnissen bestehen soll.

Auch in Moskau wurde die Verteidigung der Hauptstadt im ersten Kriegswinter 1941/42 als Erinnerungsprojekt in Form einer »antizipierten Kommemoration« in-

Lisa Kirschenbaum beschrieb dieses historische Gegenwartsbewusstsein in den Medien während des Krieges als»History in the making«. Vgl. Kirschenbaum, Lisa: The Legacy of the Siege of Leningrad, S. 77.

2 Ebd. S. 79.

3 Nora, Pierre : Les lieux de mémoire, La République, Paris 1984, S. XXXI. 
szeniert. Der Entstehungsprozess der Sonderausstellung im Armeemuseum zeigt die spezifische Situation der Gleichzeitigkeit von Gegenwart, Vergangenheit und Zukunft. Der Entstehungskontext der Ausstellung eröffnet Einblicke in die Motivationen der muzejščiki, in deren Ausstellungsnarrativen erlebte und gedeutete Erinnerung ineinander übergingen.

Die Kriegsausstellungen der Hauptstadt waren Bestandteil eines öffentlichen Kriegsdiskurses, den verschiedenene populäre Medien gemeinsam formten und auf den sie bei ihren Darstellungen zurückgriffen. Den Ton gab Stalin vor, der in seiner Rede zum 24. Jahrestag der Oktoberrevolution am 7. November 1941 der sowjetischen Bevölkerung die »vollständige Zerschlagung der deutschen Eroberer « (Razgrom nemeckich zachvatčikov) versprochen hatte. ${ }^{4}$ Die epische Rhetorik, mit der der Krieg in Museen, im Kino und in der Presse dargestellt werden sollte, war bereits vor den Ereignissen festgeschrieben. Insbesondere den visuellen Medien wurde von Kriegsbeginn an eine vitale Rolle und Wirkung zugesprochen. ${ }^{5}$ Deswegen beobachteten die Moskauer muzejščiki die Veränderungen in der Tonlage genau und reagierten unmittelbar. Als der sowjetische Gegenangriff im Dezember 1941 bekannt wurde, änderten die Kuratorinnen und Kuratoren des GIM den Titel ihrer Sonderausstellung »Die Verteidigung von Moskau« über Nacht zu »Die Zerschlagung der deutsch-faschistischen Truppen vor Moskau«. ${ }^{6}$ Zur gleichen Zeit beauftragte der Chefideologe Aleksandr Ščerbakov, der dem einflussreichsten Informationskanal "Sowjetisches Informationsbüro« (Sovetskoe informacionnoe bjuro, kurz: Sovinformbüro) vorstand, das »Zentrale Kinostudio« in Moskau, die Gegenoffensive in einem Dokumentarfilm mit dem Titel »Die Zerschlagung der deutschen Truppen vor Moskau « festzuhalten. ${ }^{7}$ Bald trug auch die erste Ausstellung des Moskauer Armeemuseums zum »Großen Vaterländischen Krieg« den Titel der allgegenwärtigen Devise »Zerschlagung der deutschen Truppen vor Moskau«.

Stalin, Josef: Werke, Bd. 14, Dortmund 1976, S. 259-261. Hier wurde »razgrom« mit »Zerschmetterung« übersetzt. Zur besseren Lesbarkeit wird hier der Begriff »Zerschlagung« synonym verwendet.

Youngblood, Denise: Russian War Films, On the Cinema Front, 1914-2005, Lawrence 2007, S. 56.

6 Zaks, Anna: Kak my žili, S. 14. Es ist anzunehmen, dass Kontakte zwischen den muzejščiki beider Häuser bestanden und die Mitarbeiterinnen und Mitarbeiter des Armeemuseums sich am Ausstellungsplan des CIM orientierten.

7 Das Sovinformbüro hatte die Kontrolle über die gesamte Presse, den Rundfunk und die zentrale Kriegsberichterstattung. Auch die »Organisation der Gegenpropaganda gegen die deutsche und sonstige feindliche Propaganda« gehörte zum Aufgabenbereich des Büros. Ausschlaggebend für diese Anweisung war vermutlich die Direktive »Über die Beseitigung von Unzulänglichkeiten in der mündlichen Propaganda und Agitation«, die die GlavPURKKA im Dezember verabschiedete. Die Maßnahme sollte der deutschen Propaganda entgegenwirken und die Effizienz der eigenen erhöhen. Vgl. Perepelicyn, Aleksandr/Timofeeva, Natalja: Das Deutschen-Bild, S. 271. 
Insbesondere der Dokumentarfilm der ausgezeichneten sowjetischen Regisseure Leonid Varlamov und Il'ja Kopalin, der eine Woche vor Ausstellungseröffnung in allen großen Kinos der Stadt gezeigt wurde, bot den muzejščiki inhaltliche Anknüpfungspunkte. Die Kameras an der Front filmten jene Objekte, die die $m u-$ zejščiki später in ihren Sälen präsentierten. ${ }^{8}$

Welche Implikationen hatte eine solche Ausstellung, die die konstruierte Gegenwart der Menschen zeigte? Was bedeutete es, wenn Kuratorinnen und Kuratoren von Bombenangriffen und Verteidigung in Ausstellungen erzählten, die sie selbst gerade erst erlebt hatten? Boten ihnen die offiziellen Berichte von Heldenmut und Standhaftigkeit Orientierung, eine Möglichkeit, die traumatischen Erlebnisse mit Sinn zu versehen und zu verarbeiten, wie es Lisa Kirschenbaum für die Kulturschaffenden in Leningrad vorschlägt? In der belagerten Stadt führte die »antizipierte Kommemoration « zu einer Verschmelzung von individuellem und offiziellem Gedächtnis an die Blockade und es formierte sich eine gemeinsame Erzählung vom »Großen Vaterländischen Krieg«. In dem so entstandenen Mythos waren Erinnerung und Ideologie nicht mehr zu trennen. ${ }^{9}$

Mit der Übertragung dieser These auf die Frontstadt Moskau kann die Forschung, die bislang davon ausgeht, dass die Erinnerung an diese Kriegsperiode von offizieller Seite unterdrückt wurde, hinterfragt und erweitert werden. Nach dieser Lesart erinnerte der Kampf um Moskau Stalin an die Katastrophen der ersten Kriegsmonate und seine eigenen Fehleinschätzungen und die Menschen an ihre Panik vor einer drohenden Einnahme der Stadt im Oktober 1941. Deswegen hätten er und die entsprechenden Parteiorgane keinen Anlass dafür gesehen, die Erinnerung an die Verteidigung von Moskau, die international zudem als Verdienst seines besten Generals Georgij Žukov gelobt wurde, wachzuhalten. ${ }^{10}$ In der Retrospektive erweist sich diese These der »Unterdrückung« als eine zu oberflächliche und zu stark auf Stalin zugespitzte Zuschreibung, denn die erfolgreiche Verteidigung von Moskau und der sowjetische Gegenangriff waren zentrale Bestandteile der frühen und sehr populären (musealen) Kriegserinnerung.

Gleichzeitig war diese frühe Kriegsphase von einer Lockerung der Vorschriften im Kulturbereich geprägt, die Freiräume nicht nur für die schriftliche, sondern auch für die visuelle Dokumentation der Ereignisse schuf. Die Filmhistorikerin Denise Youngblood sprach von einer »small oasis of freedom«, die sich für Kunstschaffende während des Krieges auftat. Der Fotohistoriker David Shneer stellte das gleiche Studio im April 1943 den Dokumentarfilm »Stalingrad «produzierte, belegen. Der Sammlungsleiter Pëtr Loginov bestellte Fotos der einzelnen Filmszenen, die in den Vitrinen des Museums ausgestellt wurden. In: CMVS: op. 3, d. 18/1, I. 28-29, hier I. 28. 
fest, dass »[a]lthough photographers were told in general terms what to photograph, they were not neccessarily told how to photograph « (kursiv D.S.). ${ }^{11}$ Der Historiker und Spezialist für sowjetischen Film Peter Kenez bescheinigte den Filmen, die während des Krieges produziert wurden, eine Authentizität, die sie weder vor noch nach dem Krieg erlangt hätten. Ironischerweise sei der Krieg, trotz der Zerstörung und dem Leid, eine »befreiende Erfahrung« (liberating experience) für die Filmschaffenden gewesen. ${ }^{12}$ Die Glaubwürdigkeit der Kriegsdokumentationen liege in der simplen Tatsache begründet, dass die Regisseurinnen und Regisseure sich Themen angenommen hätten, die sie selbst beschäftigten, und dabei echte und tief empfundene Gefühle ausdrückten. Sie glaubten an das, was sie zeigten. ${ }^{13}$ Auch Kenez deutet die Gleichzeitigkeit von Ereignis und medialer Darstellung und die personelle Überschneidung von Erfahrungsgeneration und >Erinnerungsproduzenten als Gründe für die überzeugende Transformation der Gegenwart in ein »antizipiertes Gedenken«. Ein Prozess, der Analogien zu der Ausstellungsentstehung aufweist.

Neben inhaltlichen Parallelen teilten Film und Ausstellung methodische Gemeinsamkeiten, die sich für das Verständnis von sowjetischen Kriegsausstellungen als instruktiv erweisen. Die Regisseure von »Die Zerschlagung der deutschen Truppen vor Moskau « setzten den Dokumentarfilm aus verschiedenen Wochenschauen zusammen. Diese Suggestion von größtmöglicher Aktualität spiegelte sich auch in der Sonderausstellung, die ständig mit »frischen« Objekten von der Front versorgt wurde.

\section{Der Dokumentarfilm über die Verteidigung von Moskau}

Nach Kriegsausbruch wurden Wochenschauen als »reinste Form der Kriegspropaganda bevorzugt. ${ }^{14}$ Die Wochenschauen der ersten Kriegsmonate waren jedoch weder gute Propaganda noch enthielten sie interessantes historisches Material. ${ }^{15}$

11 Youngblood, Denise: Russian War Films, S. 81. Shneer, David: Through Soviet Jewish Eyes, S. 91.

12 Kenez, Peter: Cinema and Soviet Society, 1917-1953, Cambridge 1992, S. 204.

13 Kenez, Peter: Black and White, The War on Film, in: Stites, Richard (Hg.): Culture and Entertainment in Wartime Russia, S. 157-175, hier S. 173.

14 Kenez, Peter: Black and White, S. 160.

15 Die ersten Aufnahmen und längeren Reportagen, die im Juni/Juli 1941 in dem »Unionsfilmjournal« (Sojuskinožurnal) erschienen, zeigten beispielsweise die Sprengung einer Brücke über den Dnistr oder die Evakuation der ukrainischen Bevölkerung. Sergej Dobrašenko betont die fehlende Ausbildung und technische Ausrüstung, die unter den Frontkameramännern zu großen menschlichen Verlusten, Improvisationen und neuen Erfindungen geführt hätte. Vgl. Dobraschenko, Sergej: Der sowjetische Dokumentarfilm im Großen Vaterländischen Krieg, in: Wehling, Will (Hg.): Der Kampf gegen das nationalsozialistische Deutschland, Filme aus der UdSSR und aus den USA, Oberhausen 1972, S. 24-27. 
Dokumentationen, unabhängig von dem Grad ihrer Verzerrung und Täuschung, brauchten die Realität, und bis zur erfolgreichen Verteidigung von Moskau gab es kaum Themen, die dem Publikum als glaubhaft und zugleich erbaulich präsentiert werden konnte. Anfang Dezember, als es der Stavka (Oberkommando der sowjetischen Streitkräfte) gelang, neue Truppen aus Sibirien an die Front vor Moskau zu bringen und die Rote Armee den nicht für den Winter gerüsteten deutschen Armeeverbänden eine erste entscheidende Niederlage zufügte, fiel der Wendepunkt des Krieges mit dem Wendepunkt im sowjetischen Kriegsdokumentarfilm zusammen. ${ }^{16}$ Der Film »Die Zerschlagung der deutschen Truppen vor Moskau« gilt bis heute als eine der einflussreichsten sowjetischen Kriegsdokumentationen. ${ }^{17}$

Die ideologische Öffentlichkeitsarbeit Ščerbakovs konzentrierte die mediale Informationskampagne auf den Tag der Roten Armee am 23. Februar 1942, an dem auch die gleichnamige Ausstellung im Armeemuseum eröffnen sollte. Am Mittwoch, dem 18. Februar, fünf Tage vor dem Feiertag, zeigten die 16 größten Kinos der Stadt und die zwei bekanntesten Arbeiterklubs den im Vorfeld aufwendig beworbenen Dokumentarfilm. ${ }^{18}$

16 Gerhard Paul spricht in diesem Zusammenhang von einer »Zäsur«, die »für einen Moment das wahre Gesicht des modernen Krieges « zeigte und die in der Filmhistorie wenig beachtet sei. Vgl. ders.: Krieg und Film im 20. Jahrhundert, Historische Skizzen und methodologische Überlegungen in: Chiari, Bernhard/Rogg, Matthias/Schmidt, Wolfgang: Krieg und Militär im Film des 20. Jahrhunderts, München 2003, S. 3-76, hier S. 38. Youngblood, Denise: Russian War Films, S. 56.

18 Bereits drei Tage vor der Premiere hatte die Tageszeitung »Moskovskij Bol'ševik« den Film täglich angekündigt und Vorverkaufsstellen eingerichtet. Vgl. Moskovskij Bol'ševik, 15. Februar 1942, S. 2. Auf den Plätzen der Stadt waren Ständer mit dem Filmplakat, das der Künstler Vasilij Jakovlev entworfen hatte, aufgestellt. Vgl. Ohne Autor: Fil'm »Razgrom nemeckich voijsk pod Mosvkvoj « vychodit na èkrany, in: Moskovskij Bol'ševik, 17. Februar 1942, S. 3. Stills aus dem Film, die den Cegenangriff der Roten Armee zeigten, wurden regelmäßig an den unteren Seitenrand der Zeitung gedruckt. Vgl. Moskovskij Bol'ševik, 17. Februar 1942, S. 1., Moskovskij Bol'ševik, 19. Februar 1942, S. 2., Moskovskij Bol'ševik, 21. Februar 1942, S. 3. 
Abbildung 11: Kinoeingang mit Plakat des Dokumentarfilms »Die Zerschlagung der deutschen Truppen vor Moskau«, Moskau Februar 1942.

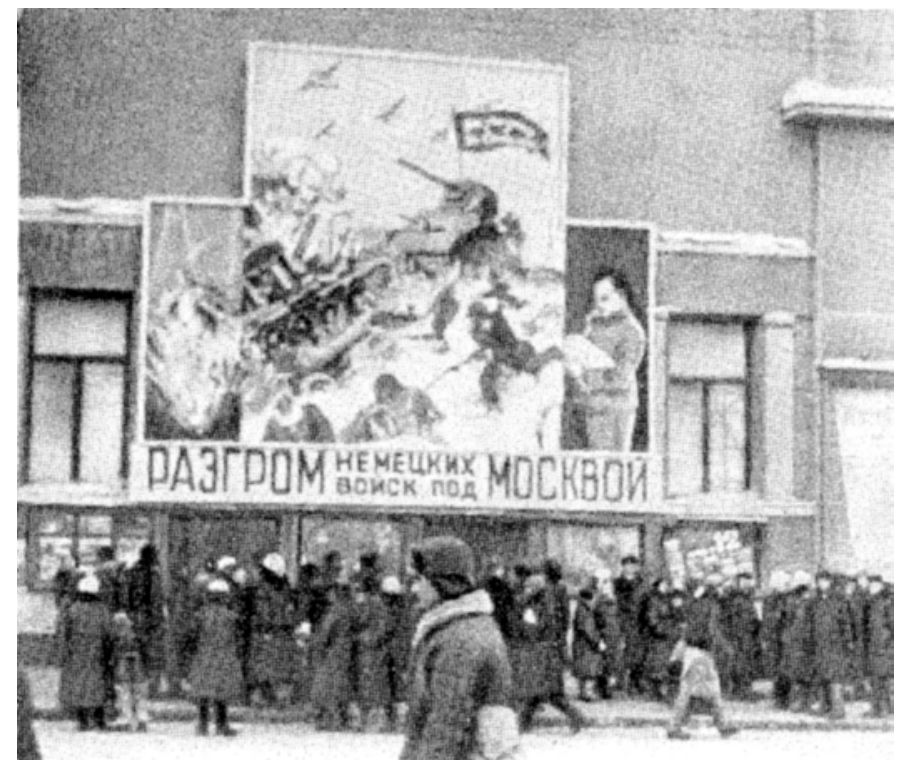

Die Abbildung (Abb. 11) zeigt eine Menschenmenge, die in Winterkleidung und zum Teil mit ihren Kindern vor dem Kino auf den Einlass wartet. ${ }^{19}$ Ein großes Plakat kündigt den einzigen Film an, der zu laufen scheint. Angeordnet wie ein Triptychon lockt das Plakat mit Szenen des Filmes. Das größte Bild in der Mitte zeigt, wie ein von oben kommender sowjetischer Panzer mit einer überdimensional großen Fahne einen deutschen Panzer nach unten zurückdrängt. Begleitet wird er von vorwärts stürmenden Rotarmisten und nach Westen fliegenden sowjetischen Flugzeugen. Das linke Plakat zeigt Suchscheinwerfer, die die deutschen Flieger im Luftraum über Moskau ins Visier nehmen. Das rechte Bild stellt interessanterweise nicht den Kriegsstrategen Stalin dar, sondern seinen General Georgij Žukov, der mit einer Karte in der Hand die militärische Offensive leitet. Dieses Plakat ist ein Hinweis auf das Verschwinden der Stalin-Bilder aus dem öffentlichen Raum im

19 Nauka (Hg.): Sovetskaja kul'tura v gody Velikoj Otečestvennoj vojne, Moskva 1976, S. 160. Die Urherberrechte der Abbildung konnten trotz Recherchen seitens der Autorin nicht abschließend abgeklärt werden. 
ersten Kriegsjahr. ${ }^{20}$ Die Regisseure Il'ja Petrovič Kopalin (1900-1976) und Leonid Vasil'evič Varlamov (1907-1962) betonten, dass sie in dem Bewusstsein arbeiteten, aus ihrem reichhaltigen Material Aufnahmen auszuwählen, die besonders treffend, einfach und klar waren. ${ }^{21}$ Die Menschen, die sich vor den Kinos drängten, wollten unbedingt Beweise sehen, dass die deutsche Armee geschlagen werden konnte. Sie bezeichneten die Szenen mit den deutschen Gefangenen und dem zerstörten deutschen Kriegsgerät nach dem Kinobesuch als die eindrücklichsten. ${ }^{22}$

Erbeutetes deutsches Kriegsgerät und gefangene Wehrmachtssoldaten gaben Anlass zur Hoffnung, dass die Rote Armee den Krieg gewinnen könnte - ein tröstender Gedanke, der der Panik vom Herbst 1941 gegenübergestellt werden konnte. Die Wirkung des Filmes strahlte über die Grenzen der Sowjetunion hinaus. Unter dem Titel »Moscow Strikes Back« war der Film in den USA und in Großbritannien ein großer Erfolg und stärkte die öffentliche Unterstützung für den sowjetischen Alliierten. $^{23}$

Die von der Forschung beschriebene »Authentizität« des Kriegsdokumentarfilmes liegt z.T. in der tatsächlichen Lebensgefahr begründet, in der sich die Filmer befanden. Insgesamt starben über 40 Kameramänner während der Dreharbeiten an der Front. Der Kameramann Lebedev, der auch an dem Film über die Verteidigung von Moskau beteiligt war, erinnerte sich an das Nebeneinander von dem "großem Glück«, einen Beitrag zur Geschichte des »Großen Vaterländischen Krieges« geleistet $\mathrm{zu}$ haben und an die "psychologische Barriere«, die er als Zivilist, der »noch nie Pulverdampf gerochen hatte, überwinden musste«, als er mit den Einheiten der Roten Armee in den Kampf zog, um den Angriff zu filmen. ${ }^{24}$

Der Film mit einer Länge von 70 Minuten beginnt mit Aufnahmen der Kriegsvorbereitungen in Moskau im Oktober 1941 und endet mit der Befreiung des letzten Dorfes des Moskauer Gebietes im Januar 1942. ${ }^{25}$ Der Inhalt besteht aus drei Teilen mit unterschiedlicher thematischer Gewichtung. Während die ersten zwei Kapitel

20 Jeffrey Brooks hat das gleiche Phänomen für die Presseberichterstattung beobachtet. Vgl. Brooks, Jeffrey: Pravda goes to war, in: Stites, Richard: Culture and Entertainment in Wartime Russia, S. 9-27.

21 Kopalin, Ilja: Naš tvorčeskij raport, in: Moskovskij Bol'ševik, 19. Februar 2018, S. 3.

22 Kenez, Peter: Cinema and Soviet Society, S. 190.

23 Eine gekürzte Version wurde mit einem englischen Sprecher produziert. Rezension in der New York Times vom 17. April 1942: T. S.: >Moscow strikes back«, Front-Line Camera Men's story of Russian Attack is seen at the Clobe: https://www.nytimes.com/1942/08/17/archives/mosco W-strikes-back-frontline-camera-mens-story-of-russian-attack.html (Stand: 31.07.2021). 1943 wurde diesem Film als erstem sowjetischen Dokumentarfilm der Oscar verliehen. Lebedev, Aleksej: Frontovaja Kinochronika, in: Nauka (Hg.): Sovetskaja kul'tura v gody Velikoj Otečestvennoj vojny, Moskva 1976, S. 255-261, hier S. 255-256.

25 Dokumentarfilm, s/w (1:09): Razgrom nemeckich vojsk pod Moskvoj, Central'nij studii kinochroniki, 1942, in: https://www.youtube.com/watch?v=ImwG_WaqaFc (Stand: 31.07.2021). 
eine kampfbereite Moskauer Bevölkerung und den Angriff der Roten Armee vor der Stadt zeigen, steht der dritte Teil ganz im Zeichen der Befreiung der Dörfer, der Gefangennahme von Wehrmachtssoldaten, der anklagenden Demonstration ihrer Verwüstungen und Gräueltaten und der Freude der Bevölkerung über die Befreiung. Die Szenen in der Hauptstadt von Oktober 1941 suggerierten eine städtische Geschäftigkeit, die mit den tatsächlichen Zuständen im >Panikmonat « nur wenig zu tun hatte. Durch die Aufnahmen vom Bau der Verteidigungsanlagen, von der Arbeit in den Munitionsfabriken und der Rekrutierung neuer Rotarmistinnen und Rotarmisten fahren Trams und Busse, die dem Publikum glaubhaft machen wollten, dass die Ordnung des zivilen Lebens nicht bedroht sei. Der Dokumentarfilm überträgt diese Ordnung auf die Front. Nahaufnahmen von Generälen, die über Pläne gebeugt Strategien entwerfen und die Verleihung von Orden, die mit einem Kuss der Roten Fahne endet, bewiesen die Einigkeit von Militär und Partei. Aufnahmen vom Feind zeigten seine scheinbare Unterlegenheit. Deutsche Soldaten wurden entweder als erfrorene Leichen im Schnee oder als frierende Gefangene gezeigt, deren teilnahmslose Gesichter in die Kamera blicken. Im starken Kontrast dazu rennen, reiten, fahren, fliegen die Rotarmistinnen und Rotarmisten mit Flugzeugen und Fallschirmen und überbrücken dabei weite Schneelandschaften. Eile ist geboten, so stellt es der dritte Teil dar, da in den Dörfern im Moskauer Gebiet deutsche Soldaten morden, vergewaltigen, Häuser in Brand stecken und sowjetische Kulturdenkmäler zerstören. In diesem Teil sind Menschen in emotionalem Aufruhr zu sehen: Weinende alte Frauen zeigen verzweifelte Trauer über tote Verwandte, vor Freude winkende junge Frauen begrüßen die Rote Armee, voller Wut halten Politoffiziere auf einem erbeuteten Panzer vor einem Galgen eine Ansprache, und vor Glück strahlende Kinder klatschen und laufen mit einem Hund in ihre befreiten Holzhäuser zurück. Die letzten Szenen des Films vermitteln die Botschaft eines Kampfes, der weitergehen muss. Hier wiederholen sich die Bilder: Luftaufnahmen zeigen die Zerstörungen, die die Wehrmacht auf ihrem Rückzug hinterlassen hat. Szenen aus der Stadt Istra demonstrieren das zerstörte Kloster (ein Anblick, den auch die Kuratorin des GIM, Anna Zaks, auf ihrer ersten Fahrt an die Front als schockierende Erfahrung beschrieb) und in Jasnaja Poljana das verwüstete Anwesen des Schriftstellers Leo Tolstoj. Zahlreiche Bilder mit zerstörtem, russgeschwärztem deutschem Kriegsgerät wechseln sich ab mit Aufnahmen von gefrorenen Leichen deutscher Soldaten im Schnee. Am Ende des Films stellt eine Nahaufnahme des Kutuzow-Denkmals in Borodino die Analogie zum »Vaterländischen Krieg« 1812 her und nimmt damit den siegreichen Ausgang des »Großen Vaterländischen Kriegs« vorweg. ${ }^{26}$

26 Für eine Rezension des Filmes von April 1973 anlässlich einer Retrospektive der 19. Westdeutschen Kurzfilmtage in Oberhausen, vgl. Dobraschenko, Sergej: Warlamovs und Kopalins 
Dem Film wurde in der gegenwärtigen verzweifelten Lage motivierende Wirkung zugesprochen. Bereits vor der Premiere schickte das "Zentrale Kinostudio« Kopien in die Städte des Moskauer Gebietes, dessen Befreiung der Film zeigte. Die Vorführungen wurden hier von Vorträgen und Diskussionen begleitet, bei denen Teilnehmerinnen und Teilnehmer der Kämpfe sprachen und das Gezeigte bezeugten. ${ }^{27}$ Diese kombinierte Aufführungspraxis unterstützte die Glaubwürdigkeit der dargestellten Ereignisse.

Die ausführliche Rezension, die die Tageszeitung »Moskauer Bolschewik« (Moskovskij Bol'ševik) einen Tag vor der Premiere veröffentlichte, vermittelt einen lebendigen Eindruck von dem emotionalen Kinoerlebnis. ${ }^{28}$ In dem Artikel vermischten die Autoren ihre künstlerische Bewertung der »Kino-Front-Reportage« mit ihrer Deutung der Ereignisse. Die Journalisten A. Vetrov und S. Indurskij beschrieben die Verteidigung Moskaus als "großen Kampf« und drückten ihre Überzeugung aus, dass sich ihre Generation dank dieses Filmes in den kommenden Jahrzehnten »mit Ergriffenheit« (s volnenija) an die gegenwärtigen Tage erinnern werde. Die Rezensenten betonten die Authentizität der Aufnahmen. Den Kameramännern sei es gelungen, »die gigantische Schlacht um Moskau so ausdrucksstark (tak vyrazitel'no), so wahr und lebendig (tak pravdivo i žiznenno) « auf den Bildschirm zu bannen. ${ }^{29}$ Dabei verschwieg der Film die Panik der Moskauer Bevölkerung vor einer drohenden Einnahme ihrer Stadt und die Fehleinschätzungen der sowjetischen Führung nicht. Für die Rezensenten war der Film eine Bestätigung dieser Erfahrung: »Da erscheinen sie vor uns, die Monate Oktober und November [...], die Stadt bereit für den Straßenkampf [...]. Eine schreckliche Gefahr (groznaja opasnost') lag über der Hauptstadt [...]. Hitler hatte vor Moskau eine ungeahnte (nevidannoe) Anzahl an Armeen zusammengezogen. ${ }^{30}$

Die Topoi, die bis heute Teil der kulturellen Erinnerung an den »Großen Vaterländischen Krieg« sind, entnahmen die Regisseure im Winter 1941/42 zum Teil aus dem bereits vorhandenen diskursiven Feld oder formten sie neu. An erster Stelle stand die Zerstörung des Mythos der deutschen Unbesiegbarkeit. Zum ersten Mal war es einer europäischen Armee gelungen, die deutsche Taktik des »Blitzkrieges« zu schlagen. Der Erzähler sprach mit ernster Stimme den Text eines bekannten sowjetischen Schriftstellers und Kriegskorrespondenten. Seine Worte, die

Film, in: Wehling, Will (Hg.): Der Kampf gegen das nationalsozialistische Deutschland, Filme aus der UdSSR und aus den USA, Oberhausen 1972, S. 48-50.

Ohne Autor: Fil'm »Razgrom nemeckich vojsk pod Moskvoj « vychodit na èkrany, in: Moskovskij Bol'ševik, 17. Februar 1942, S. 3. Der Artikel nennt zwei Städte des Moskauer Cebietes: Solnečnogorsk und Klin.

Vetrov, An./Indurskij, S.: »Razgrom nemeckich voijsk pod Moskvoj«, Kinoletopis' o velikoj bitve, in: Moskovskij Bol'ševik, 17. Februar 1942, S. 2.

29 Ebd. S. 2.

30 Ebd. 
von energischer Orchestermusik begleitet wurden, beschrieben die militärischen Manöver, die der »deutschen Armee die berauschende Überzeugung ihrer Unverwundbarkeit « entzogen haben. ${ }^{31}$ Peter Kenez sieht in dem gesprochenen Text eine Besonderheit, die den sowjetischen Kriegsdokumentarfilm von Dokumentationen der anderen kriegsführenden Staaten unterschied. »American breeziness and flippancy or British understatements would have been completely out of place in a Soviet product. The voice of the Soviet commentator was always solemn and often bombastic - as if a human observer were not commenting on pictures, but history itself was speaking. «22 Der Schwarzweissfilm untermalt diese Aussage mit großen Kameraschwenks, die aus der Vogelperspektive scheinbar unendlich viel zerschossenes und aufgegebenes deutsches Militärgerät zeigten.

Eigens für den Film wurde der Dichter Aleksej Surkov beauftragt, ein Lied über die »Verteidiger von Moskau« zu dichten. Dieses Lied (Pesnja zaščitnikov Moskvy), dessen Zeilen unter der Rezension im »Moskauer Bolschewiken« abgedruckt wurden, hinterließ bei dem Kinopublikum einen nachhaltigen Eindruck und ist bis heute fester Bestandteil der postsowjetischen Erinnerungskultur an den »Großen Vaterländischen Krieg «. ${ }^{33}$ Der Regisseur Ilja Kopalin erklärte seine dramaturgische Absicht beim Einsatz der Musik:

»Die Filmmusik soll [...] den Reichtum der geistigen Kräfte unseres Volkes spiegeln. Wenn die Zuschauer zum Beispiel [...] das von den Deutschen ausgeraubte und verunstaltete Häuschen von Tschaikowski sehen, die zerstörte Büste des Komponisten, seine zerfetzten Noten und die weggeworfenen Bücher [...], dann hören sie in dieser Minute die unsterbliche Fünfte Symphonie. $^{34}$

Die Regisseure trafen das Gefühl der Zeit: Sowohl die Fünfte Symphonie Tschaikowskis als auch das Bild der die Kultur zerstörenden, barbarischen Deutschen wurden zum festen Bestandteil des sowjetischen Erinnerungskanons an den Krieg. Ein weiteres wirkmächtiges und langlebiges Argument, das der Film aufgriff, war die Darstellung der Wehrmachtssoldaten als Opfer des russischen Winters:

»Die Kälte macht den Deutschen Angst. Der Film gibt eine anschauliche Vorstellung davon, wie sie sich in ihren dünnen Soldatenmänteln krümmen, wie ausgeturpolitik war. Vgl. Schenk, Frithjof Benjamin: Aleksandr Nevskij, S. 297-302.

32 Kenez, Peter: Cinema and Soviet Society, S. 192.

33 Ponikarova, N.: Moskva, Ispytanie vojnoj, in: Moskovskij žurnal, Nr. 5, 1999, S. 33-38, hier S. 37. 
stopfte Vogelscheuchen sehen die in Halstücher und Halbschuhe der Kolchosbauern gekleideten Krieger der nordischen Rasse aus. «35

Diese Beschreibung der nicht für den Winter gerüsteten Wehrmachtssoldaten wurde von den Satirezeitschriften des Landes und anderen Medien unter der Metapher des »Winter-Fritz« aufgenommen und weiterentwickelt. ${ }^{36}$ Auch die Kriegsverbrechen, die die Deutschen am sowjetischen Volk verübten, waren ein zentraler Topos. Das Leid und der Tod auf sowjetischer Seite wurde in der Darstellung nicht ausgespart, sondern von der GlavPURKKA explizit gefordert. ${ }^{37}$ Die Kunst der Filmemacher lag dabei in dem Balanceakt, Bilder zu zeigen, die einerseits plastisch genug waren, um Wut zu schüren, andererseits jedoch nicht so grausam waren, dass sie die Menschen in Panik versetzten. Sie zeigten einen rauchenden Scheiterhaufen mit Leichen von Rotarmisten, Körper von getöteten Bauern und gehängte Partisaninnen und Partisanen. Die eindrücklichsten Bilder waren jedoch die Aufnahmen von Frauen, die vergewaltigt und umgebracht worden waren. Insbesondere da die Darstellung von Gewalt an der eigenen Bevölkerung ein bislang wenig verbreiteter Bestandteil der visuellen Massenberichterstattung war. Die Forschung betont diese Dimension des Leides und des Schmerzes, die den sowjetischen Wochenschauen bis heute eine Suggestion von Realität vermittelt, und die den nationalsozialistischen Produktionen fehlte. ${ }^{38}$ Die deutschen Kriegsverbrechen und die sowjetischen Heldentaten, die ihnen gegenübergestellt wurden, bildeten die

Vetrov, An./Indurskij, S.: »Razgrom nemeckich voijsk pod Moskvoj«, in: Moskovskij Bol’ševik, 17. Februar 1942, S. 2.

Diverse Satire-Plakate mit Karikaturen zum Thema »Zimnij fric« (Winter-Fritz) des KünstlerKollektivs Kukryniksy, in: Kukryniksy (Hg.): Grafika 1941-1945, Moskva 2006. Hinter dieser Satire stand ein neues Feindbild, das sich in der Hochphase des Gegenangriffs nach Wiedererlangung des eigenen Selbstwertgefühls und der Siegeszuversicht gebildet hatte. Mit Blick auf die deutschen Kriegsgefangenen schrieb Konstantin Simonov: WWie haben sich diese Soldaten der >unbesiegbaren ‘ Armee in den ersten sechs Monaten des Krieges verändert. Im Juli war unklar, wer von ihnen tapfer und wer feige ist. Alle menschlichen Eigenschaften waren bei ihnen unterdrückt, überdeckt vom Dünkel, den man allgemein als Unverfrorenheit von Eroberern kennt. [...] Jetzt aber ist nichts mehr davon übrig. Einige von ihnen zittern und weinen [...]. Die Armee der Unverschämten hat sich in den Tagen der Niederlage verändert.«Zitiert nach: Senjavskaja, Elena: Deutschland und die Deutschen, S. 253-254. Zu den sowjetischen Feindbildern im Deutsch-Sowjetischen Krieg, die eher sozialistische als nationale Feindbilder waren, vgl. Ganzenmüller, Jörg: >Polnischer Pan< und `deutscher Faschist<, Die nationale Komponente sowjetischer Feindbilder im Krieg, in: Satjukow, Silke/Gries, Rainer: Unsere Feinde, Konstruktionen des Anderen im Sozialismus, Leipzig 2004, S. 421-436. Die GlavPURKKA erinnerte die Herausgeber der Zeitungen daran, Berichte und Fotografien über nationalsozialistische Gräueltaten zu publizieren. Zitiert nach: Shneer, David: Through Soviet Jewish Eyes, S. 96. 
dualen Narrative, die laut David Shneer den Krieg für die sowjetische Bevölkerung visuell prägten. ${ }^{39}$

Der Film hatte in der sowjetischen Kriegsgesellschaft enormen Erfolg. Bereits am ersten Tag sahen ihn in Moskau über 83.000 Menschen. ${ }^{40}$ Kopien des Filmes wurden an die Einheiten der Roten Armee und in alle Gebiete der Sowjetunion verschickt. ${ }^{41}$ Der Film weckte das Verlangen nach mehr Informationen. Wann würde der Krieg zu Ende sein? Das war die Frage, die den Rezensenten zufolge die Menschen am meisten beschäftigte. ${ }^{42}$ Vetrov und Indurskij sprachen für ihre Leserinnen und Leser, als sie schrieben: »Und jetzt [...] ist es unser ganz natürlicher Wunsch, dieses herausragende Ereignis in der Geschichte des Großen Vaterländischen Krieges stärker und tiefer zu begreifen und zu beurteilen. « ${ }^{43}$

Einen ersten bildhaften Eindruck und ein Verständnis von dem gegenwärtigen Krieg versprach auch die gleichnamige Ausstellung im Armeemuseum, die wenige Tage nach der Filmpremiere eröffnete.

\section{Die Sonderausstellung über die Verteidigung von Moskau im Armeemuseum}

Am ehemaligen »Platz der Kommune«, im Zentrum von Moskau, befindet sich noch heute das »Haus der Armee«. Bevor dem Museum der Roten Armee nach dem Sieg im »Großen Vaterländischen Krieg« ein eigenes Gebäude zugeteilt wurde, befand es sich in den Räumlichkeiten dieses Hauses. ${ }^{44}$ Das klassizistische Gebäude (Abb. 12), das vor der Revolution eine »Höhere Mädchenschule« beherbergte, schließt an den Katharinengarten (Ekaterinskij sad) an. ${ }^{45}$ Im linken Flügel des zweistöckigen

39 Shneer, David: Through Soviet Jewish Eyes, S. 96. Shneer betont, dass diese Bilder in erster Linie den Vernichtungskrieg abbilden und erst in zweiter Linie den spezifisch gegen die Jüdinnen und Juden gerichteten Holocaust, von dem die sowjetischen Fotografen 1941 keine Bilder hatten.

40 Ohne Autor: 83 tysjači zritelej na prosmotrach kinofil'ma »Razgrom nemeckich vojsk pod Moskvoj, in: Moskovskij Bol'ševik, 20. Februar 1942, Nr. 44, S. 1. Vor Ausbruch des Krieges lebten ca. 4.215.800 Menschen in Moskau. Bis zum Januar 1942 hatte sich die Zahl aufgrund von Evakuierungen in das Hinterland und Mobilisierungen an die Front um die Hälfte verringert (2.027.818). Vgl. Gorinov, Mikhail M.: Muskovites' Moods, 22 June 1941 to May 1942, in: Thurston, Robert W./Bonwetsch, Bernd (Hg.): The People's War, Chicago 2000, S. 108-134, hier S. 108-109.

41 Ohne Autor: 800 kopij fil'ma »Razgrom nemeckich vojsk pod Moskvoj«, in: Moskovskij Bol'ševik, 19. Februar 1942, Nr. 44, S. 3.

42 Chlewnjuk, Oleg: Stalin, Eine Biographie, München 2015, S. 346.

43 Ebd. S. 2.

44 Ohne Autor: Istorija Central'nogo Doma Rossijskoj Armii, in: http://kcvs.ru/istoria.htm (Stand: 31.07.2021).

45 Ohne Autor: Central'nij dom Rossijskoj Armii, Istorija, http://kcvs.ru/istoria.htm (Stand: 31.07.2021). 
Gebäudes, der ehemaligen Mensa der Schule, stellte das Armeemuseum seit 1928 auf ca. $430 \mathrm{~m}^{2}$ in 10-15 Sälen die Geschichte der Roten Armee aus. ${ }^{46}$

Abbildung 12: Das Haus der Roten Armee, festlich geschmückt für den 18. Tag der Roten Armee, Moskau 23. Februar 1935, Fotografin/Fotograf unbekannt (C) CMVS.

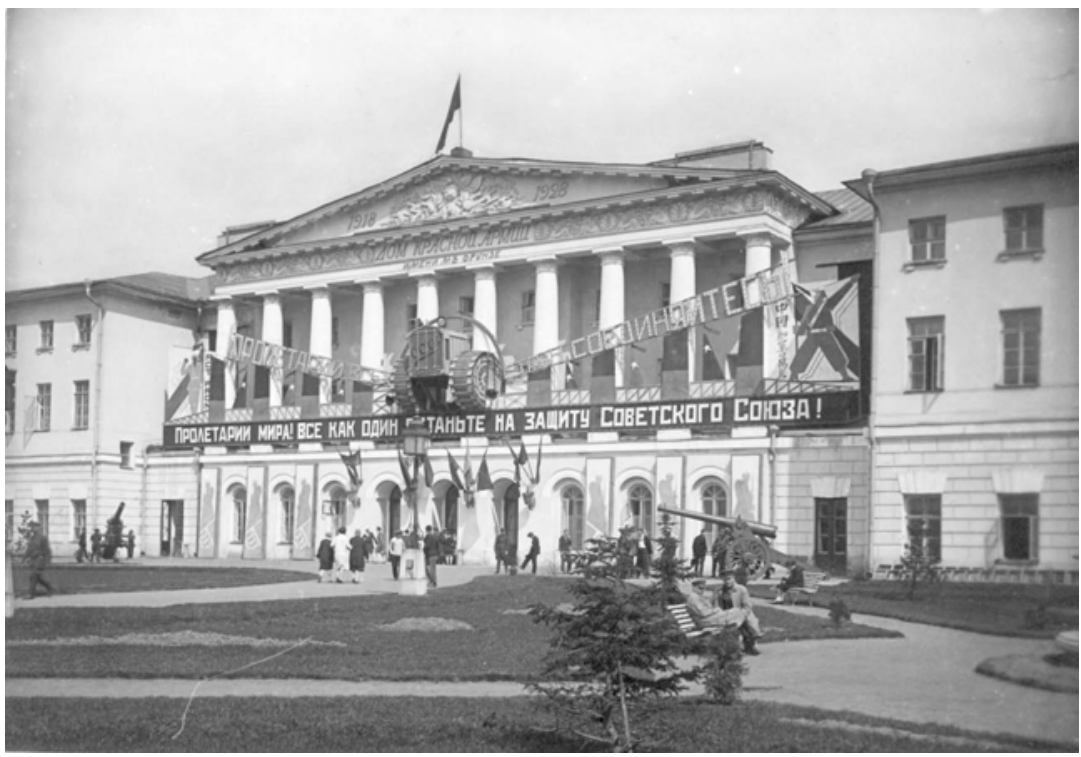

Das Haus der Roten Armee und damit auch das Armeemuseum unterstanden als Kulturabteilungen der GlavPURKKA. Dementsprechend waren die leitenden Stellen mit Offizieren der Roten Armee besetzt. Nach der Evakuation des Museums nach Kazan im Dezember 1941 arbeiteten von den vormals ca. 40-60 Mitarbeitenden nur noch sechs Personen im Museum: der Regimentskommissar Vladimir Fedjanin und seine zwei engsten Mitarbeiter, die Politoffiziere Pëtr Loginov und I. Pankov sowie die Museumsführerin Marija Nazarova, die die Offiziere auf ihren Sammlungsexpeditionen an die Front begleitete, die Sammlungsleiterin Nina Moskaleva und eine Fotografin. ${ }^{47}$ Den sechs muzejščiki, die den Auftrag bekamen, die Sonderausstellung »Die Zerschlagung der deutschen Truppen vor Moskau« zu inszenieren, fehlte es im Januar 1942 an allem. Die Stadt befand sich im Belagerungszustand, die Baumaterialien wurden für Verdunklungsschutz und Verteidigungsanlagen gebraucht. Die muzejščiki mussten improvisieren und das fehlende Holz für Rahmen oder Vitrinen durch Bodenleisten und Bretter von Objektkisten

46 Pečen, N./Povesmo, P.: V gody surovych ispitanij, S. 84. 
ersetzen. ${ }^{48}$ Nicht nur Personal und Materialien, sondern vor allem auch das spezifische Wissen über die Objekte, die täglich in den Museumsdepots eintrafen und mit denen sie die gegenwärtigen militärischen Ereignisse ausstellen sollten, fehlte den Kuratorinnen und Kuratoren. Der Beginn der Ausstellungsarbeit war unter diesen Umständen chaotisch. Von der Front trafen scheinbar wahllos unbekannte Objekte ein. Häufig konnten die muzejščiki die fremden erbeuteten Dinge weder identifizieren noch inventarisieren. Die Museumsführerin Marija Nazarova erinnert sich: »Die Museumsarbeiter säuberten die Waffen von Schnee, Eis und Dreck in dem praktisch unbeheizten Gebäude. Von der ständigen Berührung mit dem vereisten Metall schwollen die Hände. Besonders schwer war es für Nina Moskaleva, die Leiterin der Waffensammlung. «49 Die eklatante Unterbesetzung führte dazu, dass die muzejščiki, die mit der Lagerung der neuen Exponate und dem Zimmern von Vitrinen beschäftigt waren, keinen Ausstellungsplan anfertigen konnten. So folgten die Inszenierung der Exponate und der Ausstellungsrundgang der grundlegenden Frage: Wie kann die Besiegbarkeit der deutschen Armee am besten gezeigt werden?

Eindrücke von Inhalt und Inszenierung der Sonderausstellung vermitteln drei Rezensionen. Diese Textgattung muss im Kontext der Sowjetunion, in der es keine Pressefreiheit gab, als Lese- bzw. Sehanleitung und weniger als Ausdruck einer eigenen kritischen Meinung verstanden werden. Da alle drei Rezensenten ähnliche Exponate und Topoi beschrieben, können die Texte jedoch als Quelle für die Schwerpunktsetzung der Ausstellung und ihre gewünschte take-home-message herangezogen werden. Eine der Rezensionen stammt von dem Journalisten, der auch die Rezension des Dokumentarfilms in der Tageszeitung "Moskauer Bolschewik « verfasst hatte. Eine zweite wurde in der Armeezeitung »Roter Stern« veröffentlicht und eine dritte schrieb Pëtr Loginov, der Kurator der Ausstellung, selbst. Die eingangs beschriebene Methode der "antizipierten Kommemoration« zeigt sich exemplarisch in den Worten des Rezensenten Vetrov:

»Es scheint, als ob sich die Bande der dunklen Bösewichte [...] unter den Säulen des Museums im unbeweglichen Starrkrampf versammelt hätte [sobralas' i zastyla $v$ stolbnjake]. Im Grunde genommen ist es genauso: Es ist noch überhaupt nicht lange her, da haben die Objekte, die im Katalog unter ihrer friedlichen ExponatsBezeichnung aufgeführt sind, noch Kugeln, Granaten, Bomben und Minen ausgespien und vor den Toren von Moskau gerasselt und geklirrt. Jetzt sind sie in einer Reihe in den Museumssälen aufgestellt und ihr einziges Mittel, Angst zu verbreiten, ist das Schild >Nicht berühren $<.{ }^{50}$

\footnotetext{
48 Ebd. S. 68.

49 Ebd. S. 62

50 Vetrov, An.: Vzjato na poljach sraženij ... Vystavka boevych trofeev v muzee central'nogo doma krasnoj armii, in: Moskovskij Bol'ševik, 22. Februar 1942, Nr. 44, S. 4.
} 
In der Schilderung des Journalisten verkörperte die deutsche Militärtechnik den Feind. Die gerade noch >lebendigen « Waffen wurden im Kampf >versteinert unschädlich gemacht. Ihrer todbringenden Macht beraubt, sind sie sgetötet< im Museum zusammengekommen.

Der Rezensent offenbarte kuratorische Fachkenntnisse. In seiner Ausstellungsbeschreibung vollzog er den Musealisierungsprozess nach. Durch die museale Inszenierung wurden die Objekte ihrer ursprünglichen Funktion entzogen und erhielten den erhabenen Status eines Museumsexponates. Der Journalist reflektierte diesen Prozess und drückte sein Erstaunen über den Kontrast aus, der durch diesen Funktionswandel entstanden war: Irgendwie wurden die Tafeltexte, die diese gefährlichen Geräte nüchtern als Artilleriewaffen bezeichneten, und der warnende Hinweis, die Exponate nicht zu berühren, der furchteinflößenden Vorstellung, die der Museumsbesucher von der deutschen Militärtechnik hatte, nicht gerecht.

Einen zentralen Platz in der Sonderausstellung nahm ein erbeutetes, in den Worten des Journalisten »sperriges Stabs-Vehikel« ein. Auf der Saalansicht (Abb. 13) ist das Wehrmachtsauto zu sehen, das dem Journalisten aufgefallen war. ${ }^{51}$ Mit platten Reifen und offenem Kofferraum stand es auf einem Teppich, der das wertvolle Parkett des Museums schützen sollte. Hier zitierte der Journalist den Objekttext, um das Ausstellungsstück zu kommentieren: „Ein Stabsauto der faschistischen Räuberarmee mit geraubten Gütern der sowjetischen Bürger. « ${ }^{52}$ 
Abbildung 13: Saalansicht der Sonderausstellung »Die Zerschlagung der deutschen Truppen vor Moskau im Zentralmuseum der Roten Armee, Moskau Februar 1942 bis März 1945, Fotografin/Fotograf unbekannt (c) CMVS.

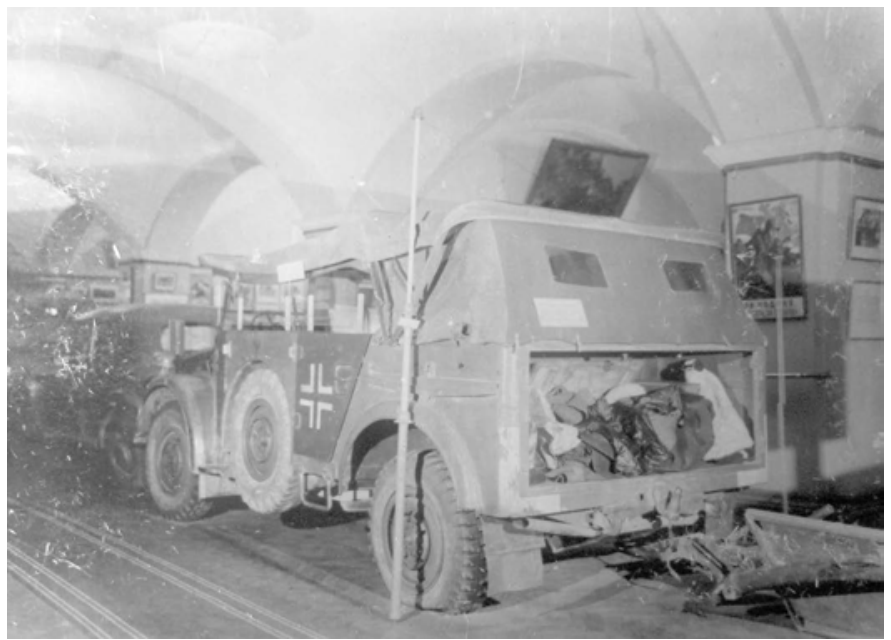

Vetrov beschreibt die gestohlenen Waren im Kofferraum des Autos: Hemden und Hüte sowie Kopftücher und Damenblusen. Die Saalansicht verdeutlicht den Eindruck von der irritierenden Gleichzeitigkeit von Vergangenheit, Gegenwart und Zukunft. Die Inszenierung des Autos als Museumsexponat verweist auf seine Historizität, die es als Erinnerungsstück des »Großen Vaterländischen Krieges« darstellt. Gleichzeitig steht es stellvertretend für alle anderen Wehrmachtsautos, deren Fahrer in diesem Augenblick den Menschen der Sowjetunion ihren Besitz rauben. Die Methode der »antizipierten Kommemoration« hatte jedoch den Nachteil der potentiellen Vieldeutigkeit der Objekte. Diese Ambivalenz wird in der Beschreibung der deutschen Militärtechnik, die in dem Park rund um das Haus der Roten Armee ausgestellt war, deutlich: ${ }^{53}$ hatte, Platz zwischen den Säulen der Museumshallen. Vgl. Pečen, N./Povesmo, P.: V gody surovych ispitanij, hier S. 62. 
»Das Auge fällt auf die schwere >Büssing< in der Kolonne von Schlachtkörpern, die Elefanten gleichen [kolonna slonovnoj tiša], und auf das hässliche Geländefahrzeug von >Daimler Mercedes Benz‘, ein gepanzertes Auto für den Transport von Soldaten, das so sehr einem Sarg aus Metall ähnelt. ${ }^{54}$

Die in dem Elefanten-Vergleich durchscheinende Aufwertung der militärischen Ausrüstung des Feindes wird in der Metapher des >Metall-Sargs` wieder aufgelöst. Die Trophäen waren in der Stadt Jachroma (ca. $70 \mathrm{~km}$ nördlich von Moskau) erbeutet worden, wo die Wehrmacht eine Niederlage gegen die Rote Armee erlitten hatte, die der Dokumentarfilm gezeigt hatte. Die ausgestellte unzerstörte deutsche Artillerie bewies zwar die erfolgreiche Verteidigung vor Moskau, gleichzeitig war sie jedoch auch ein Hinweis, wie nah und scheinbar unbehelligt die deutsche Wehrmacht an die Stadtgrenze Moskaus vorgerückt war. Vetrov drückte seine Bewunderung für die »Waffen-Meisterwerke der Krupp-Konstrukteure« (orudyešedevr konstruktorov Kruppa) aus. Nach der Beschreibung der deutschen Haubitze, deren "nigelnagelneuer Lauf zeigte, dass sie noch nie in Gebrauch gewesen war", ergänzte der Journalist, dass der Plan des Feindes, Moskau von dieser Stelle aus zu erobern, gescheitert war. ${ }^{55}$ Die Darstellung der leistungsfähigen feindlichen Militärtechnik wurde hervorgehoben, um den eigenen Sieg noch beeindruckender wirken zu lassen.

Das Foto (Abb. 14) zeigt Artilleriegeschosse und ein zurückgelassenes deutsches Flugzeug, die als Ergänzung der Ausstellung im Museumspark präsentiert wurden. ${ }^{56}$ Die Ausstellungsfläche im Park des Hauses der Roten Armee wurde von einer hohen Bretterwand begrenzt, die als zusätzliche Inszenierungsfläche genutzt wurde und gemalte Plakate eines Artillerieangriffs zeigte. Darauf war eine Exponatstafel angebracht, die die deutsche Militärtechnik erklärte. Vor den Fahrzeugen stand ein Hocker, den die Museumsmitarbeitenden dort stehengelassen hatten.

Auch in der Rezension des »Roten Sterns « nahm der Topos der Besiegbarkeit der deutschen Armee in der Beschreibung der zerstörten und eroberten deutschen Militärtechnik einen prominenten Platz ein. Der größte mediale Vorteil des Museums gegenüber dem Film war die Dreidimensionalität der Exponate, anhand derer die Verteidigung von Moskau besonders anschaulich dargestellt werden konnte. Am eindrücklichsten war die Materialität des zerstörten deutschen Kriegsgerätes, das sogar berührt werden konnte. Wie bereits der Journalist vom »Moskauer Bolschewik« war auch der Reporter des »Roten Sterns" von der deutschen Haubitze beeindruckt. Er sprach aus der Perspektive der Besucherinnen und Besucher:

54 Vetrov, An.: Vzjato na poljach sraženij ..., S. 4.

55 Ebd.

56 CMVS, V. 95, Nr. 42500. 
Abbildung 14: Trophäen in der Sonderausstellung »Die Zerschlagung der deutschen Truppen vor Moskau« im Park des Hauses der Roten Armee, Moskau Februar 1942 bis März 1945, Fotografin/Fotograf unbekannt (C) CMVS.

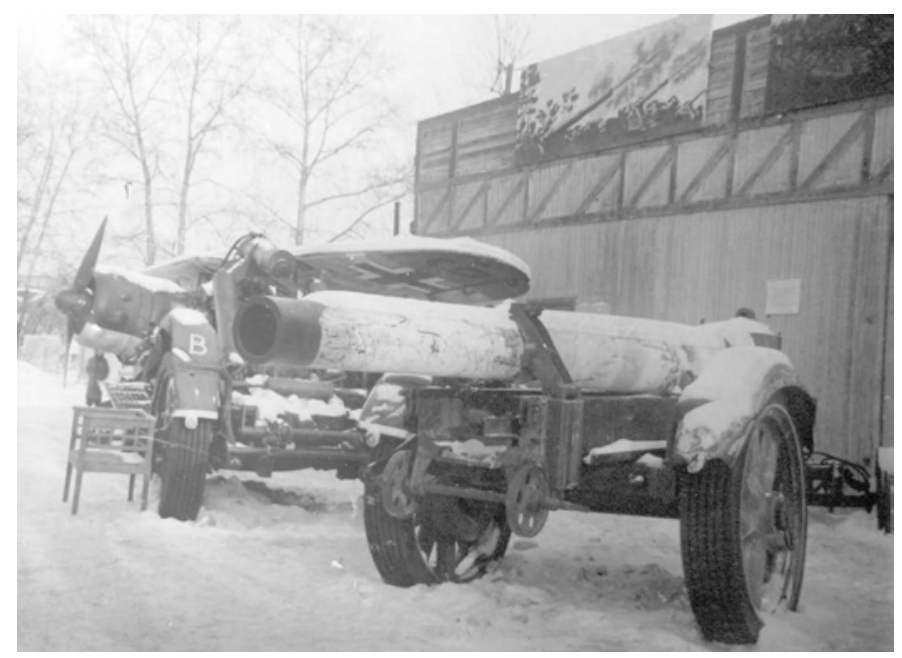

»Wenn Du Dir diese Todesmaschine anschaust, denkst du: Sie stand vor Warschau, sie stand vor Paris und jetzt steht sie im Park des Hauses der Roten Armee und die Kinder klopfen ihr vertrauensvoll auf ihr trauriges Rohr. ${ }^{57}$

Hier zeigt sich erneut eine sorgenvolle Ungläubigkeit über die schnelle Verwandlung der Militärgeräte in Museumsobjekte. Genau wie in Warschau und Paris hätte diese Waffe den Deutschen beinahe geholfen, die Stadt Moskau einzunehmen. Nun stand sie, ihres Zwecks beraubt, im Park und diente den Kindern als Spielzeug, während in anderen Landesteilen die gleiche Artillerie weiterhin Tod und Zerstörung anrichtete. In diesem Erstaunen wird die zeitliche Einheit zwischen Dargestelltem und Erlebtem deutlich. Eine Simultanität, die das Museumspublikum beeindruckte.

Ein weiteres Thema, das sowohl im Dokumentarfilm als auch in der Ausstellung eine große Rolle spielte, waren die Maßnahmen, die die Bevölkerung zur Verteidigung der Hauptstadt trafen. Während der Dokumentarfilm den Vorteil bewegter Aufnahmen nutzen konnte, stellten die muzejščiki Fotos aus, die, so die Interpretation des zweiten Rezensenten, die »ernsten Gesichter« der Frauen beim Bau der

57 Dangilov, S.: Razgrom nemeckich okkupantov pod Moskvoj, Na vystavke v Central'nom dome Krasnoj Armii, in: Krasnaja Zvezda, 28. Februar 1942, S. 4. 
Verteidigungsanlagen und den »prüfenden Blick« der Bürgerwehren zeigten. ${ }^{58} \mathrm{Da}$ die junge, männliche Bevölkerung an die Front geschickt worden war, mussten die Frauen und Kinder wie auch die Alten und Kranken in Moskau Gräben ausheben, Straßenbarrikaden errichten und auf Häuserdächern die Brände der Luftangriffe löschen. Diese Darstellung einer in erster Linie weiblichen Kriegserfahrung erweitert das klassische, männlich konnotierte Bild des Widerstandes in der sowjetischen Kriegserinnerung. ${ }^{59}$

Unter den Fotos befand sich auch die berühmte Aufnahme Evgenij Chaldejs von einer Gruppe von Menschen, die am Straßenrand stehengeblieben waren, um mit erhobenen Köpfen der Rundfunkrede Molotovs zuzuhören, die über Lautsprecher den Kriegsausbruch verkündete. ${ }^{60}$ Das Foto ist ein Beispiel für die Rolle der Fotografen als Begründer und der muzejščiki als Multiplikatorinnen und Multiplikatoren einer bis heute wirkmächtigen Kriegserinnerung. ${ }^{61}$ Bereits im Februar 1942 stellen die Kuratorinnen und Kuratoren das Foto aus, das heute unter dem Titel "Der erste Tag des Krieges« als Ikone der Kriegserinnerung gilt. ${ }^{62}$ David Shneer hat darauf aufmerksam gemacht, dass das Foto entgegen seiner klassischen Deutung nicht primär Tapferkeit, Konzentration und Bereitschaft für den Kampf zeigt, sondern dass es Chaldej gelungen war, individuelle Reaktionen auf den Kriegsausbruch einzufangen. ${ }^{63}$ Die Gesichter zeigen eine ganze Reihe von Emotionen, die von Ungläubigkeit, Sorge, Missbilligung, Nachdenklichkeit bis zu Erschütterung reichten.

Die muzejščiki inszenierten Fotos, auf denen bekannte Orte und Szenen erkannt werden konnten. Sie sollten dabei auf zwei Ebenen wirken: Einerseits evozierten sie persönliche Assoziationen und Erinnerungen an die eigene Erfahrung, andererseits hob die museale Inszenierung diese Gefühle in eine offizielle Sphäre und wertete das Erlebnis zum Bestandteil einer Geschichte auf, die größer war als das individuelle Erlebnis. Dieses Gefühl sollte auch von Plakaten aufgegriffen werden, die neben den Fotos im Museum hingen. Ebenso wie das Foto Chaldejs wurden auch die ersten Kriegsplakate fester Bestandteil der sowjetischen Kriegserinne-

58 Ebd.

59 Für die Erinnerungen an ein stark von Frauen geprägtes Stadtbild, in der viele zuvor männlich kodierte Berufe und Tätigkeiten (Arbeit in der Rüstungsindustrie/Bau von Verteidigungsanlagen) von Frauen ausgeübt wurden, vgl.: Bukov, K./Gorinov, M./Ponomarev, A. (Hg.): Moskva voennaja 1941-1945, Memuary i archivnye dokumenty, Moskva 1995, insb. S. 311-354.

60 Pečen, N./Povesmo, P.: V gody surovych ispitanij, hier S. 69.

61 Volland, Ernst/Krimmer, Heinz (Hg.): Von Moskau nach Berlin, Bilder des russischen Fotografen Evgenij Chaldej, 2. Aufl. Berlin 1995, S. 12.

62 Volkova, Bèlla: Kilometry plenki i tycjači dnej, Žiyn' i rabota fotografa efgenija chaldeja, in: $\mathrm{h}$ ttps://tass.ru/spec/yevgeny_khaldei (Stand: 31.07.2021).

63 Shneer, David: Through Soviet Jewish Eyes, S. 88. 
rung. ${ }^{64}$ Die Moskauer muzejščiki ermöglichten diese Kanonisierung, indem sie bereits im Februar 1942 die Popularität der Plakate erkannten und sie von den Straßen ins Museum holten. ${ }^{65}$ Das bekannteste Beispiel ist das bis heute populäre Plakat des Künstlers Iraklij Toidze, das eine Frau im roten Kleid und mit dem Text des Fahneneids in der Hand zeigt. Mit dem erhobenen Arm führt sie die unzähligen Bajonette hinter sich an, die für Soldaten stehen. Über dem Plakat steht der berühmte Satz »Mutter Heimat ruft! « (Rodina-mat' zovet). ${ }^{66}$

Der dritte Rezensent, der Politoffizier und muzejščik Pëtr Loginov war maßgeblich an der Inszenierung dieser ersten Moskauer Ausstellung über den Krieg beteiligt ${ }^{67}$ Er arbeitete bereits seit 1928 im Museum und zählte zu den erfahrensten und angesehensten Kuratoren des Hauses. Nach Kriegsausbruch wurde er als einer der ersten zum >Exponatesammeln die Befreiung der Dörfer im Moskauer Gebiet erlebt. Er hatte mit der Bevölkerung Gespräche geführt und mit seiner Kamera die Folgen der deutschen Besatzung

64 Am bekanntesten sind die sogenannten »Okna Tass «(Tass-Fenster), ein Studio, das kurz nach dem Überfall der Wehrmacht auf die Sowjetunion gegründet wurde und beinahe täglich ein neues Plakat herausgab. Das Künstlerkollektiv Kukryniksy und zahlreiche weitere bekannte Zeichner, Maler und Schriftsteller (wie der Autor des Satiremagazins »Krokodil« Samuil Maršak) arbeiteten an den Plakaten mit. Für die Erinnerungen des Studioleiters und Künstlers von über 300 »Fenstern« Pavel Sokolov-Skalja vgl: Bukov, K./Gorinov, M./Ponomarev, A. (Hg.): Moskva voennaja 1941-1945, S. 598-603.

65 Pečen, N./Povesmo, P.: V gody surovych ispitanij, hier S. 69.

66 Dieses Plakat, das I. Toidze bereits im Juni 1941 anfertigte, wurde zur Vorlage für die gleichnamige Skulptur einer schwertschwingenden rufenden Frau auf dem Mamaev Kurgan in Wolgograd. Das Plakat hing gemeinsam mit der Fotografie von einer Gruppe von Soldaten auf dem Weg zur Front, die im Juni 1941 an einem Schild mit dem Aufdruck »Unsere Sache ist gerecht, wir werden siegen « vorbeizogen, am Ende des Krieges in fast jeder Ausstellung zum »Großen Vaterländischen Krieg«, vgl. Lupalo, I.: Vklad muzeev, S. 147. Ulrike Schmiegelt hat auf die Vorlage des Plakates hingewiesen. Der Künstler war von dem bekannten Bürgerkriegsplakat von Dmitri Moor inspiriert, das einen Rotarmisten vor rauchenden Fabrikschloten zeigt. Der Soldat deutet mit dem Zeigefinger direkt auf den Betrachter und fragt: »Hast du Dich als Freiwilliger eingeschrieben?« Bei Toidze hat sich der Bürgerkriegssoldat zur »Mutter Heimat« verwandelt. Vgl. Schmiegelt, Ulrike: »Mutter Heimat ruft!«, in: Czech, Hans-Jörg/Doll, Nikola: Propaganda, S. 238. Der Begriff »Rodina«, dessen Cebrauch in den sowjetischen Medien im Verlauf des Krieges stetig anstieg, war bis Mitte der 1930er Jahre ein »distinctly un-Bolshevik word«. In den Worten der Literaturwissenschaftlerin Vera Sandormirsky bedeutete es etwas wie »native place«, verbunden mit einer nicht zu übersetzenden »emotion, with a peculiarly Russian warmth and tenderness«. Zitiert nach: Chatterjee, Choi/Kirschenbaum, Lisa/Field, Deborah: Russia's Long Twentieth Century, Voices, Memories, Contested Perspectives, London/New York 2016, S. 134.

67 Der Museumsdirektor Vladimir Fedjanin hatte den Kurator und Politoffizier P. Loginov mit der Suche nach weiteren Materialien für die Ausstellung und mit der Beschriftung der neu eintreffenden Exponate beauftragt. In: CMVS, op. 3, d. 18/1, I. 1-2. 
dokumentiert. Vor Ort hatte er Kriegsrelikte sammeln lassen, die ihm als aussagekräftige Museumsexponate erschienen. Kurzum, er kannte die Verhältnisse an der Front und den Kontext bzw. die Provenienz der Ausstellungsstücke aus eigener Erfahrung.

Drei Monate nach der Ausstellungseröffnung publizierte er im Mai 1942 in der prestigeträchtigen »Historischen Zeitschrift« eine ausführliche Rezension, die ihn als Experten und Kenner der Ausstellung identifizierte. Der Text erschien in der Kategorie »Chronik«, was den dokumentierenden Charakter der Ausstellung unterstrich. ${ }^{68}$ Welche Ausstellungselemente schienen dem erfahrenen Kurator, der im Gegensatz zu den Journalisten über eine Innensicht auf die Arbeitsprozesse im Museum verfügte, erwähnenswert? Loginov, der als Oberst selbst ein ranghohes Mitglied der Roten Armee war, eröffnete seinen Bericht mit einem Dank für die erfolgreiche Zusammenarbeit mit der Roten Armee, im Besonderen mit den Truppenteilen der Westfront, die zu der reichhaltigen Sammlung von deutschem Kriegsgerät geführt hatte. Das Lob war strategisch geschickt platziert, da das $\mathrm{Mu}$ seum dank der GlavPURRKA über einen direkten, exklusiven und ertragreichen Zugang zu den kämpfenden Truppen verfügte. Anschließend erklärte der Militärexperte die verschiedenen Waffengattungen der Trophäen. Waffen waren und sind traditioneller Bestandteil von militärhistorischen Museen. Doch der gegenwärtige Krieg brachte neue Objekte in die Vitrinen, die die meisten sowjetischen Besucherinnen und Besucher noch nie gesehen hatten. Während sich die beiden Rezensenten zuvor auf die großformatigen Trophäen konzentriert hatten, beschrieb Loginov französische, tschechoslowakische und österreichische Gewehre und Pistolen, die die Deutschen bei ihrem Angriff auf Moskau eingesetzt hatten. ${ }^{69}$ Dabei verschob er den Fokus von Exponaten, die die Besiegbarkeit der Deutschen belegten, auf den Eroberungscharakter des deutschen Feldzuges.

Im Vergleich zu den Journalisten war die Ausstellungsbeschreibung des muzejščik Loginov sehr viel emotionsärmer und nüchterner. Dafür ergänzte er viel Kontextwissen. Während, ebenso wie Waffen, auch eigene und fremde Uniformen traditionelle Exponate eines Armeemuseums sind, waren die Kleidungsstücke in der Moskauer Kriegsausstellung aufsehenerregend. Bereits der Journalist des »Roten Sterns « hatte die Vitrine mit den Sommeruniformen der Wehrmacht beschrieben. In den hämischen Worten des Journalisten hatten sich nach der Niederlage und Gefangennahme der deutschen Soldaten im Winter »diese Paradeuniformen mit den vielen Auszeichnungen in dreckige Lumpen verwandelt $"{ }^{70}$ Das Bild des unterlegenen, weil nicht für den Winter gerüsteten deutschen Soldaten war ein

Loginov, Pëtr: Vystavka >Razgrom nemeckich okkupantov nad podstupach k Moskve $<$ Ventral'nom muzee Krasnoj Armii«, in: Istoričeskij Žurnal 1942, Nr. 5, S. 169-171.

69 Loginov, Pëtr: Vystavka, S. 169.

70 Ebd. S. 4. 
bekanntes Argument des Winters als Verbündetem der russischen Armee. Eine Facette des deutschen Feindbildes, das der Film und die Ausstellung zu Beginn des Jahres 1942 aufgriffen. Wie seine Vorgänger nahm auch Loginov den Topos des deutschen "Winter-Fritzen« auf. Neben den zerrissenen deutschen Sommeruniformen waren selbstgenähte Westen aus Zeitungspapier und aus Stroh geflochtene Bastschuhe ausgestellt. Bei der Beschreibung der Vitrine erklärte Loginov, dass die Deutschen im Winter mit Sommeruniformen gefangen genommen worden waren, weil die deutsche Heeresleitung von einem weiteren »Blitzsieg« ausgegangen sei und ihren Soldaten im anbrechenden Winter den hilflosen Rat gegeben habe, sich übergangsweise selbst »Ersatz-Kleidung« anzufertigen. Der historische Kontext der Ausstellungsstücke wurde hier differenzierter dargestellt als bei den Journalisten: Die deutsche Selbstüberschätzung stand an erster, der russische Winter an zweiter Stelle. ${ }^{71}$

Ein weiteres Ausstellungselement, das bereits unter dem zeitgenössischen $\mathrm{Pu}$ blikum große Aufmerksamkeit erweckte und in gleicher Inszenierung bis heute einen zentralen Platz in der Dauerausstellung einnimmt, waren die erbeuteten Orden und Auszeichnungen der Deutschen. ${ }^{72}$ Auch diese Objekte waren dem Publikum von Armeemuseen prinzipiell vertraut. Im Kontext des gegenwärtigen Krieges bekam die deutsche Auszeichnung des »Eisernen Kreuzes« in den Moskauer Vitrinen jedoch eine be(un)ruhigende Dimension. Loginov erklärte, dass die hier ausgestellten »Eisernen Kreuze« I. und II. Ranges von den vor Moskau gefallenen deutschen Soldaten stammten. Die noch in ihrer aufwendigen Verpackung befindlichen »Eisernen Kreuze« seien für die Auszeichnung derjenigen Soldaten bestimmt gewesen, die sich bei der geplanten Einnahme Moskaus auszeichnen würden. ${ }^{73}$

In der Mitte des Raums war eine Trommel aus dem Bestand der zarischen Armee ausgestellt. Wehrmachtsverbände hatten sie für die Siegesparade in der eroberten Hauptstadt mitgeführt. Im Zuge der fortschreitenden Winterkampagne fanden Rotarmisten die Trommel in einer aufgegebenen Stellung westlich von Moskau und hatten sie dem Museum geschickt. ${ }^{74}$ Der Kontext dieser Inszenierung verweist auf eine interessante Gemeinsamkeit der Kriegsgegner: Auch die deutsche Seite konstruierte offenbar Tradition und Kontinuität deutsch-russischer Waffengänge und hatte sich dafür den Symbolcharakter solcher Objekte zunutze

71 Ebd. S. 169

72 Im Zentrum des »Siegessaales« befindet sich heute eine Installation, die die »Fahne des Sieges«über einem zerbrochenen deutschen Reichsadler auf einem Haufen von »Eisernen Kreuzen« ausstellt. VgI. Dauerausstellung des Zentralmuseums der Streitkräfte der Russländischen Föderation. Ausstellungsbesuch der Autorin: 5. Juni 2014.

73 Ebd. S. 169.

74 Pečen, N./Povesmo, P.: V gody surovych ispitanij, hier S. 69. 
gemacht. Diese Exponate, die so eindeutig die Siegesgewissheit des Feindes repräsentierten, unterstützten die grundlegende Botschaft der muzejščiki, die in der Widerlegung der allgegenwärtigen, lähmenden Angst vor der Unbesiegbarkeit der deutschen Armee lag. ${ }^{75}$

Auch die ausgestellten deutschen Briefe von und an die Front, die den deutschen Gefangenen abgenommen worden waren, sollten das Scheitern der deutschen »Blitzkriegtaktik « beweisen. Von den deutschen Originalen, die mit ihren Handschriften eine emotional ansprechende visuelle Quelle für die Betrachterinnen und Betrachter darstellten, waren russische Übersetzungen angefertigt worden, aus denen Loginov in seiner Ausstellungsbeschreibung zitierte:

»Lotta, die Frau des Cefreiten Heinrich schrieb: >Bring mir einen Pelzmantel mit.く Der Cefreite Martin Leichner beschwerte sich bei seiner Verlobten: >Die vor uns haben alle Ceschäfte bereits ausgeraubt. Ich werde trotzdem versuchen, Dir irgendetwas zu klauen.< Der Soldat Hans Lampert schrieb seinem Freund Bernhard: >Treffen wir uns am Kreml in Moskau, den genauen Zeitpunkt vermag ich noch nicht zu sagen .... $\ll^{76}$

Die Briefe vermittelten den Eindruck einer erschreckend überheblichen und wie selbstverständlich erscheinenden deutschen Vorstellung vom Sieg. Dies mag der Hintergrund gewesen sein, warum an dieser Stelle in der Ausstellung das Zitat Stalins über die Deutschen, die »auf das Niveau von wilden Tieren herabgefallen seien«, angebracht war. ${ }^{77}$ Für die Übersetzungen dieser sorgfältig ausgewählten Briefe konnten die muzejščiki auf eine Einrichtung zurückgreifen, die sich praktischerweise gegenüber dem Museum befand und mit der das Museum gute Kontakte pflegte. Eine Abteilung der GlavPURKKA war für Propaganda und Gegenpropaganda zuständig. ${ }^{78}$ Nach den Bombenangriffen auf das Marx-Engels-Institut

75 Laut Elena Senjavskaja wirkte die Diskrepanz zwischen der Vorkriegsvorstellung vom zukünftigen Gegner, die dem erlebten Gegner in keiner Weise entsprach, und das Eingeständnis dieser Illusion zuerst lähmend und wurde dann zu einer weitverbreiteten Bedrücktheit und Angst. Vgl.: Senjavskaja, Elena: Deutschland und die Deutschen in den Augen sowjetischer Soldaten und Offiziere des Großen Vaterländischen Krieges, in: Scherstjanoi, Elke: Rotarmisten schreiben aus Deutschland, S. 247-266, hier S. 252.

76 Loginov, Pëtr: Vystavka, S. 169.

77 Hier zitiert Loginov aus der Rede Stalins zum 24. Jahrestag der Oktoberrevolution am 7. November 1941. Vgl. Loginov, Pëtr: Vystavka, S. 170.

78 Die 7. Verwaltung hatte ein besonderes Interesse an einem institutionellen Zugriff auf die Kriegsgefangenen. Bereits im Juni 1941 schuf sie die Unterabteilung »Arbeit mit den Kriegsgefangenen«. Sie unterstand einer für die sowjetische Bürokratie typischen Doppelzuständigkeit. Einerseits war sie der ClavPURKKA und andererseits dem »Sowjetischen Büro für militärische Propaganda « verpflichtet, das am 25. Juni 1941 als Koordinierungsstelle zwischen der Roten Armee und der Partei geschaffen wurde. Vgl. Morré, Jörg: Hinter den Kulissen des Nationalkomitees, S. 28-34. 
zog diese in das gerade fertiggestellte Theater der Roten Armee, das sich bis heute gegenüber des Museums befindet. Die »Deutsche Unterabteilung« der Behörde wertete mit der Hilfe von deutschen politischen Emigrantinnen und Emigranten feindliche Radiosendungen aus, verhörte Kriegsgefangene und übersetzte abgefangene Dokumente und Briefe. ${ }^{79}$

Genauso wie die muzejščiki das Feindbild mitprägten, formten sie gleichzeitig Selbst- und Heldenbilder, die bis heute Teil des Mythos vom »Großen Vaterländischen Krieg«sind. Die Erinnerung an die berühmteste Märtyrerin des Krieges, Zoja Kosmodem'janskaja, wurde von den Moskauer muzejščiki mitbegründet. Im Januar 1942 publizierte der »Pravda«-Korrespondent Pëtr Lidov einen Artikel über die junge Partisanin, die im November 1941 angeblich bei einem Brandanschlag auf eine von Deutschen besetzte Scheune gefangen genommen wurde. Sie hatte im Verhör keinerlei Informationen preisgegeben und wurde von Wehrmachtsoldaten gehängt. ${ }^{80}$ Vor ihrem Auftrag soll sie gesagt haben: »Weine nicht, Mutter, wenn ich nicht als Heldin zurückkomme, denn dann sterbe ich als Heldin. " ${ }^{81}$ Am 17. Februar 1942 hielt die Mutter Ljubov Kosmodem'janskaja eine Radioansprache, in der sie ihre große Trauer ausdrückte und gleichzeitig ihren Stolz über ihre wahrhaft außergewöhnlich loyale Tochter betonte und ihre Zuhörerinnen und Zuhörer zur Rache für Zoja aufrief. ${ }^{82}$ Die Zeitung "Pravda« trug mit der Publikation des Radiobeitrages einen Tag später zur weiteren Verbreitung dieser Erzählung bei. Es ist nachvollziehbar, dass das Ergebnis und das Leid der Mutter Bilder evozierten, die im gegenwärtigen Krieg auf Verständnis stiessen und zugleich den Hass auf den Feind nährten. Die muzejščiki erkannten und nutzten die Wirkung der Erzählung. Die Ausstellung im Armeemuseum zeigte Briefe an Zojas Mutter aus den Verbänden der Roten Armee und den Partisaneneinheiten. ${ }^{83}$ Darin schworen sie der Mutter, den Tod der Tochter zu rächen, und drückten ihre »tiefen und unauslöschlichen Gefühle aus, die die Heldentat der jungen Partisanin in ihnen hervor-

79 Stelzl-Marx, Barbara: Der Wandel des Feindbildes. Sowjetische Propaganda für Rotarmisten 1941-1945, in: Mattl, Siegfried/Botz, Gerhard/Karner, Stefan u.a. (Hg.): Krieg, Erinnerung, Geschichtswissenschaft, Wien 2009, S. 195-217, hier S. 199.

80 Für eine englische Übersetzung des Pravda-Artikels von Pëtr Lidov: vgl. Tanya, ediert von Bryan Bean, in: Raduga Publishers (Hg.): Password Victory, Recollections, Stories, Reports, Vol. I., Moskau 1985, S. 92-100.

81 Lidov, Pëtr: Tanya, Pravda, 25. Januar 1942, zitiert nach: Sartorti, Rosalinde: On the Making of Heroes, Heroines, and Saints, in: Stites, Richard (Hg.): Culture and Entertainment in Wartime Russia, S. 176-193, hier S. 183.

82 Vystuplenie po radio L. T. Kosmodem'janskoj-materi geroja Sovetskogo Sojuza Z. A. Kosmodem'ianskoj, in: Lidov, Pëtr (Hg.): Tania, Ceroj Sovetskogo Sojuza Zoija Anatol'evna Kosmodem'janskaja, Moscow 1942, zitiert nach Sartorti, Rosalinde: On the Making, S. 192.

83 Ljubov Kosmodem'janskaja übergab dem Museum 15 Briefe, die den Mut ihrer Tochter rühmten und weitere Dokumente aus dem Leben von Zoja Kosmodem'janskaja. Vgl. Pečen, N./Povesmo, P.: $V$ gody surovych ispitanij, S. 59. 
gerufen hatte.$^{84}$ Ein Foto des »Pravda«-Kriegsfotografen Sergej Strunnikov, das vermutlich auch in der Ausstellung gezeigt wurde, bewegte die Betrachterinnen und Betrachter besonders. Es zeigte Zojas erfrorenen Körper im Schnee, die Brust unbedeckt, mit der Schlinge um den Hals. ${ }^{85}$ Während die Darstellung vom Opfertod kein Novum der Kriegszeit war, so war ihre nackte Darstellung ein Bruch mit der traditionellen Ikonographie von sowjetischen Frauen, die gemeinhin entweder als martialische Kämpferinnen oder Mutterfiguren dargestellt wurden. In der Schönheit der jungen Frau, deren Gesicht keine Anzeichen von Gewalt trug und eine gelassene Ruhe ausstrahlte, lag etwas, das die Menschen bewegte. Eine universelle, menschliche Qualität, die den konstruierten Erzählungen eine unideologische und zeitlose Dimension gab, die die offiziellen Heldinnen und Helden zu Hoffnungsträgern für die sowjetischen Menschen im Krieg machte. ${ }^{86}$

Die Heldinnen und Helden sollten der Gegenwart voller Verzweiflung Sinn verleihen. Der Grund für ihre Persistenz weit über den Krieg hinaus liegt in der kollektiven Erschaffung ihres Mythos. ${ }^{87}$ Die mediale Rhetorik, ihre Bilder und Erzählungen wurden von den Menschen aufgenommen und in ihre individuellen Lebenswelten integriert. Sowohl die leidtragende Mutter als auch die Kämpferinnen und Kämpfer übernahmen die offiziellen Narrative und wurden zu glaubwürdigen Vermittlerinnen und Vermittler einer Heldenerzählung, die dem klassischen Muster des Sozialistischen Realismus mit hagiographischen Zügen folgte. Die Halbwaise Zoja schien schon in ihrer Kindheit kommunistische und traditionell christliche Züge aufzuweisen, die sich in ihrer Ergebenheit, Selbstlosigkeit, Gewissenhaftigkeit, Liebe zu ihren Kameraden, Loyalität zu ihren Führern, zu ihrer Mutter, der Partei und dem Land ausdrückten. Dieses vorbildhafte Verhalten, unterbrochen von Kämpfen gegen die eigenen Schwächen, fand seine Erfüllung in der Selbstaufopferung, die Zoja zur sowjetischen »Heiligen« und Märtyrerin der frühen Kriegserinnerung machte. 88

84 Loginov, Pëtr: Vystavka, S. 170.

85 Die entblößte Brust hat zu dem Verweis auf die französische Liberté und zu der Bezeichnung »sowjetische Jeanne d'Arc« geführt. Vgl. Tumarkin, Nina: The Living and the Death, S. 76.

86 Sartorti, Rosalinde: On the Making, S. 191.

87 Das Erinnerungsprojekt über Zoja Kosmodem'janskaja wurde im Krieg fortlaufend weiterentwickelt. Noch im Jahr 1942 wurde ein Cedicht und ein Lied über die Heldin verfasst, das von Pioniergruppen auswendig gelernt wurde. Im März 1943 wurde ihr posthum der Orden »Held der Sowjetunion« verliehen und ein Film verewigte ihre Biografie im Jahr 1944. Bis zum Kriegsende erschienen mindestens 20 verschiedene Publikationen über Zoja, die als Broschüren im Taschenformat als ständiger Begleiter mitgetragen werden sollten. Vgl. Sartorti, Rosalinde: On the Making, S. 184.

88 Zur Erzählstruktur des Sozialistischen Realismus vgl. Clark, Katerina: The Soviet Novel, History as Ritual, Dritte Auflage, Indiana 2000. 
Die geschilderten Ausstellungselemente zeigen die agency der muzejščiki bei der Gestaltung der Kriegserinnerung. Dabei wahrten sie jedoch unausgesprochene Grenzen und thematisierte beispielsweise die Kollaboration mit der deutschen Besatzungsmacht, von der sie vermutlich im Zuge der Befreiung des Moskauer Gebietes erfuhren, nicht.

Sie banden ihre Ausstellungsnarrative immer wieder an die oberste Deutungshoheit des Krieges, an Stalin, zurück. Interessanterweise gelang es ihnen auch in diesem politischen Diskurs, Topoi aufzugreifen, die bis heute Bestandteil der kulturellen Kriegserinnerung sind. Mit dem berühmt gewordenen Ausspruch »die Hitler kommen und gehen, aber das deutsche Volk, der deutsche Staat bleibt « unterschied Stalin zwischen der auf sowjetischem Territorium kämpfenden deutschen Armee, die bei ausbleibender Kapitulation zerstört werden würde, und der unter Hitler leidenden deutschen Bevölkerung. ${ }^{89}$ Damit wandte er sich gegen ausländische Korrespondenten, die der Sowjetunion unterstellten, die Deutschen zu hassen und deutsche Soldaten nicht gefangen $\mathrm{zu}$ nehmen, sondern sie direkt $\mathrm{zu}$ töten. ${ }^{90}$ Eine direkte Folge des Befehls war die massenhafte Publikation und Verteilung von Flugblättern, die sich in deutscher Sprache an die Wehrmachtssoldaten richteten. Für die Museumsbesucherinnen und Museumsbesucher waren die Stalin-Zitate auf den Flugblättern ins Russische zurückübersetzt: »Unter den Rotarmisten herrscht kein Hass gegen das deutsche Volk«, »Das Oberkommando der Roten Armee garantiert den Kriegsgefangenen das Leben und die Rückkehr in die Heimat «, »Wir kämpfen nicht gegen das deutsche Volk, sondern gegen die Eroberer Hitlers«. Der Kurator Loginov machte darauf aufmerksam, dass auf jedem Flugblatt ein »Passierschein « gedruckt war, der den deutschen Soldaten den Einlass in die russische Kriegsgefangenschaft erlaubte. ${ }^{91}$

Damit gelangte der Rundgang wieder in der Gegenwart an. Die Ausstellung bestätigte den Krieg der Roten Armee als gerecht. Im Gegensatz zum Feind, der einen rassenideologisch motivierten Vernichtungskrieg verfolgte, verteidigte sie die Freiheit. Die ständig neu in der Sonderausstellung eintreffenden Trophäen und Kriegsrelikte von der Front bewiesen den Erfolg dieses Vorhabens. Dabei vermischte sich die objektive Beurteilung der Ausstellung erneut mit einer Bewertung der politischen Gegenwart, wie das Resumé der Rezension zeigt:

89 Der Wortlaut des Befehls wurde in der Presse und in den Periodika vielfach wiederholt. Vgl.: Prikaz Narodnogo Komissara Oborony, 23 fevralja 1942 g. Nr. 55 g. Moskva, in: Moskovskij Bol'ševik, Nr. 45, Montag, 23. Februar 1942, S. 1. Übersetzung des Befehls vgl. Stalin, Josef: Über den Großen Vaterländischen Krieg der Sowjetunion, 3. Auflage, Moskau 1946, S. 21-24. 
»Die Rote Armee hat den Deutschen vor Moskau eine Niederlage zugefügt und den Beginn der Zerschlagung der Hitler-Armee eingeleitet. Die lebendige Ausstellung erzählt einfallsreich von diesem Sieg. Ihre Stärke liegt in ihrer großen moralischen Bedeutung. [...] Sie erlaubt es, die historischen Tage der berühmten Kämpfe um Moskau mit tiefer Ergriffenheit noch einmal zu erleben. ${ }^{92}$

Loginov betonte die kommemorative Funktion der Ausstellung. Ihr Wert lag in ihrem Vermögen, die Betrachterinnen und Betrachter $\mathrm{zu}$ »sekundären Zeugen« $\mathrm{zu}$ machen, die beim Ausstellungsrundgang das Gezeigte noch einmal durchlebten und durch die Verinnerlichung des Zeugnisses die Weitergabe der Erfahrung an zukünftige Generationen gewährleisten sollten. ${ }^{93}$

\section{Erforschen. Von der Sonderausstellung zur Meistererzählung}

Seit die Archivarin Vinogradova mit den übrigen muzejščiki im Frühjahr 1942 aus der Kazaner Evakuation zurückkehrt war, wurde im Moskauer Armeemuseum wieder Buch geführt. ${ }^{94}$ Auf inhaltlicher Ebene zeigen die Arbeitspläne des Museumsdirektors das Streben nach Wiedererlangung der fachlichen Professionalität der Vorkriegszeit und seine ehrgeizigen Ambitionen, das führende Kriegsmuseum der Sowjetunion zu werden. Dabei sollte die erfolgreiche Sonderausstellung über die Verteidigung von Moskau die zentrale Rolle spielen. ${ }^{95}$ Denn die muzejščiki, die in den ersten Kriegsmonaten nach neuen Inszenierungen gesucht und verschiedene Varianten der Vermittlung ausprobiert hatten, hatten das Potential, das in dieser improvisierten und innovativen ersten Kriegsausstellung lag, erkannt. ${ }^{96}$

92 Im ersten Jahr ihrer Laufzeit besichtigten 304.000 Menschen die Ausstellung, und das Vermittlungspersonal mussten bis zu fünf Führungen pro Tag leiten. So hoch war die Besucherzahl während der restlichen Kriegsjahre nicht mehr. Vgl.: Ebd. S. 4.

93 Die Forschung zur Erinnerungskultur an die Shoah hat den Begriff des »sekundären Zeugen« entwickelt. Hierbei handelt es sich um die Rezipienten des Zeugnisses. Vgl. Laub, Dori: Zeugnis ablegen oder die Schwierigkeit des Zuhörens, in: Baer, Ulrich (Hg.): »Niemand zeugt für den Zeugen«, Erinnerungskultur nach der Shoah, Frankfurt a.M. 2000, S. 68.

Das erste interne Dokument ist der Arbeitsplan für den April 1942, unterschrieben von dem Museumsdirektor und Regimentskommissar Vladimir Fedjanin. CMVS, op. 3, d. 18/1, I. 1-2. Der Arbeitsplan ist als Durchschlag im Museumsarchiv überliefert. Das zweiseitige, schwer lesbare Dokument spiegelt das Anliegen des Museumsdirektors und Regimentskommissars Vladimir Fedjanin, den Museumsbetrieb zu professionalisieren. Die Aufträge des Arbeitsplans bestätigten und erweiterten bestehende Praktiken in der Sammlungs-, Inventarisierungs-, und Ausbildungsarbeit der Mitarbeitenden. 1943 verzeichnete das Museum 126.000 Eintritte. Vgl. Pečen, N./Povesmo, P.: V gody surovych ispitanij, S. 69. 
Seit dem deutschen Überfall auf die Sowjetunion hatte sich das Haus der Roten Armee und damit auch das Museum zum wichtigsten Propagandamedium der GlavPURKKA entwickelt. Der Auftrag lag in der Sicherstellung einer militärisch und politisch ausgerichteten Erziehung und der künstlerischen Betreuung (Kino, Theater, Lesungen ect.) von Armee und Hinterland. ${ }^{97}$ Die Forschung spricht der GlavPURKKA die allumfassende Verantwortung für die Moral, Motivation und politische Erziehung der Rotarmistinnen und Rotarmisten zu. Sie habe eine wichtige Rolle bei der Gestaltung der heroischen Bilder und Mythen des »Großen Vaterländischen Krieges « gespielt und gemeinsam mit anderen zentralen Organisationen und sogar Stalin selbst entschieden, welche Heldentaten veröffentlicht und zur Nachahmung gepriesen wurden. Dabei prägte sie nicht nur das offizielle Selbstbild, sondern auch das deutsche Feindbild. Die Behörde habe den Krieg politisiert, indem sie die Diskurse über den Feind formte, schreibt Roger Reese. ${ }^{98}$ Während dies für eine normative Ebene zutrifft, bleibt die GlavPURKKA im Forschungsdiskurs jenseits ihrer Leitungsebene (Aleksander Ščerbakov und Lev Mechlis) akteurslos und ihre Handlungsfelder unkonkret. ${ }^{99}$ Innerhalb der GlavPURKKA erteilte der »Rat für militärpolitische Propaganda « (Sovet voenno-političeskoj propagandy) dem Museum Befehle zur ideologischen Ausrichtung seiner Arbeit. Die Korrespondenz gibt Einblicke in die tatsächliche Umsetzung der Propaganda, deren Ton Stalin in seinen Reden setzte.

Im Frühjahr 1942 leitete der Direktor des Hauses der Roten Armee Oberst Vladimir Maksimov einen tiefgreifenden Umbau ein, von dem auch das Armeemuseum betroffen war. Die Maßnahmen sind im Kontext von Stalins Rede zum 1. Mai und der 46 Losungen zu verstehen, die das ZK der KPdSU bei dieser Gelegenheit im

97 Voennoe izdatel'stvo ministerstvo oborony SSSR (Hg.): CDKA imeni M. V. Frunze, S. 38. Dieses breite Bildungs- und Kulturprogramm für die Soldatinnen und Soldaten an der Front scheint eine sowjetische Spezifik zu sein. Zum Stellenwert der (politischen) Bildung innerhalb der Roten Armee vgl.: Reese, Roger: The Soviet Military Experience. Zukünftige Forschung müsste darüber hinaus in einem Vergleich verifizieren, ob sich auch westliche Museen wie das Imperial War Museum (London) oder das Heeresmuseum (Berlin) im Verband mit der Armeeführung in der Truppenbetreuung engagierten.

98 Reese, Roger: Why Stalin's Soldiers Fought, The Red Army's Effectiveness in World War II, Kansas 2011, S. 190-191.

99 Eine aufschlussreiche Ausnahme stellt die Studie von Jörg Morré über das Nationalkomitee »Freies Deutschland «(NKFD) dar. Hier werden die Kooperationen und Konkurrenzen der drei Instanzen, die für die Bildung dieses Komitees und die sowjetische Deutschlandpolitik zwischen 1941-1946 verantwortlich waren (»Verwaltung des NKVD für die Angelegenheiten von Kriegsgefangenen und Internierten«, die GlavPURKKA, und das Exekutivkomitee der Kommunistischen Internationale) anschaulich beschrieben. Siehe: Morré, Jörg: Hinter den Kulissen. 
Frühjahr 1942 erließ. ${ }^{100}$ Die Losungen forderten jede und jeden auf, einen persönlichen Beitrag zum Kampf gegen den Feind zu leisten. ${ }^{101}$ Die Arbeitspläne, die der Museumsdirektor Vladimir Fedjanin in der Folg schrieb, zeigen, dass die Umbaumaßnahmen auf eine Intensivierung der Forschungsarbeit im Museum zielten. ${ }^{102}$ Fedjanin sah seine Aufgabe in der größtmöglichen geistigen Unterstützung der Roten Armee. Konkret versuchte er dieses Ziel zu erreichen, indem er Wanderausstellungen für die Front und für die Spitäler im Hinterland erstellen ließ. Außerdem erhöhte er die Qualität in der didaktischen Arbeit bei den Ausstellungsführungen für Angehörige der Roten Armee. Diese »Frontausstellungen« (frontovaja vystavka), die die muzejščiki bei ihren sSammel-Exkursionen zu den kämpfenden Einheiten mitnahmen, bestanden in der Regel aus zweidimensionalen Objekten: Fotos, Plakate oder Dokumente, die auf Pappe in handlichem Format geklebt wurden. Reduzierte Versionen der Sonderausstellung »Die Zerschlagung der deutschen Truppen vor Moskau« nahm die Ausstellungsführerin Marija Nazarova mit zu ihren Einsätzen an der Front:

»Ich habe über einen Monat lang mit der Ausstellung gearbeitet. Zu den einzelnen Einheiten fuhr man mich zuerst mit dem Auto, dann mit dem Boot und dann, begleitet von einem Maschinengewehr, von einer Zemljanka [Erdhütte, A.H.] zur anderen. Nur am Kragenspiegel konnte ich erkennen, bei wem, das heißt bei welchem Regiment der Streitkräfte ich mich befand ... Wie einen Stafettenstab reichte man mich von einer Einheit zur nächsten. Am Morgen wusste ich nicht, wo ich am Abend sein würde ... ${ }^{103}$

Diese Arbeit der muzejščiki, die mit einem hohen Risiko für das eigene Leben verbunden war, konnte nur überzeugend sein, wenn das Vermittlungspersonal didaktisch gut ausgebildet und immer auf dem neusten Stand der aktuellen militärischen Ereignisse war. Häufig war ein Teil ihrer vorbereiteten Materialien bereits veraltet und damit wertlos geworden, wenn sie die Einheiten erreichten. Dann mussten sie improvisieren können und das Material benutzen, das sie vor Ort vorfanden. Für die Soldatinnen und Soldaten wiederrum konnten die Treffen mit den muzejščiki nicht nur eine Möglichkeit sein, Informationen aus Moskau und dem Hinterland zu erhalten, sondern stellten immer auch erholsame Pausen zwischen den Kämpfen dar. ${ }^{104}$

Stalin, Josef: Befehl des Volkskommissars für Verteidigung, Nr. 130, Moskau, 1. Mai 1942, in: ders.: Über den Großen Vaterländischen Krieg der Sowjetunion, 3. Aufl. Moskau 1946, S. 2529.

Stelzl-Marx, Barbara: Der Wandel des Feindbildes, S. 201-202.

CMVS, op. 3, d. 18/1, I. 3-6.

Nazarova, Marija: Vospominanija, zitiert nach: Pečen, N./Povesmo, P.: V gody surovych ispitanij, S. 74-75.

Pečen, N./Povesmo, P.: V gody surovych ispitanij, S. 75. 
In Moskau animierte Museumsdirektor Fedjanin seine Mitarbeitenden, sich noch stärker für die Erfüllung ihrer Aufgaben einzusetzen. Er appellierte an ihren Teamgeist, um gemeinsam und entschlossen den Plan zu erfüllen. Auf einer Generalversammlung im Mai 1942 diskutierte er mit ihnen darüber, wie der »Kampf um noch größere Organisiertheit, Klarheit und Geschlossenheit in der Museumsarbeit « zu verstärken sei. ${ }^{105}$ Im Rahmen eines speziell entwickelten Ausbildungsprogramms forderte er von seinen Untergebenen umfassende Kenntnisse der Exponate. $\mathrm{Zu}$ diesem Zweck lernten sie auf dem Schießplatz die deutschen Waffen zusammenzusetzen und mit ihnen zu schießen. Ein gefangen genommener deutscher Offizier erklärte mit Hilfe eines Übersetzers die Unterschiede der deutschen Abzeichen und Orden. ${ }^{106}$ Das Museumspersonal wurden fachlich immer kompetenter und war in der Lage, den Rotarmistinnen und Rotarmisten die Stärken und Schwächen der deutschen Waffen zu erklären. Dieses Wissen wurde in Schulungen mit dem Titel »Wie können die Waffen des Feindes im Kampf benutzt werden« an Einheiten vermittelt, die für den Einsatz im deutsch besetzten Gebiet vorbereitet wurden. ${ }^{107}$

Das Beispiel zeigt, dass das gesammelte Wissen nicht nur für die geistige Mobilisierung, sondern auch für die praktische Ausbildung genutzt wurde. Dabei griffen die muzejščiki auf die Erfahrungen berühmter Kriegsteilnehmerinnen und Kriegsteilnehmer zurück. Sie luden die Heldinnen und Helden zu ihren Führungen ein, damit diese das Gesagte bezeugen konnten. ${ }^{108}$

Im Sommer 1942, als sich die 25-jährige Scharfschützin Ljudmila Pavličenka in Moskau von ihrer Kriegsverletzung erholte, wurde sie von den muzejščiki gebeten, eine Führung von Soldaten zu begleiten. Bei dem anschließenden Gespräch im Park des Armeemuseums wurde ein Foto aufgenommen (Abb. 15). Vier junge Soldaten, von denen nur der dritte von links die Heldin Pavličenka anschaut, hören den Ausführungen der jungen Frau zu, die für ihre Kriegsverdienste in den Rang eines Leutnants erhoben wurde. Links neben der Scharfschützin steht im weißen Kleid, die Arme genau wie Pavličenka hinter dem Rücken zusammengenommen, die Museumsführerin Marija Nazarova. Sie hatte ein Aufnahmegerät vor die Referentin gestellt, um deren Erzählungen für eine spätere Wiederverwendung aufzuzeichnen. Ljudmila Pavličenka - die »Frau, die 300 Faschisten tötete« - wurde als Vorbild der jungen Kriegsgeneration stilisiert. Die »Komsomol'skaja Pravda«

105 CMVS, op. 3, d. 18/1, I. 3.

106 Pečen, N./Povesmo, P.: V gody surovych ispitanij, S. 63. Auch hier konnten die muzejščiki vermutlich auf die 7. Verwaltung der GlavPURKKA zurückgreifen. Ihre Unterabteilung »Arbeit mit den Kriegsgefangenen «setzte die deutschen Kriegsgefangenen ab dem Frühjahr 1943 an der Front bei Propagandaeinsätzen ein. Vgl. Morré, Jörg: Hinter den Kulissen, S. 28.

107 Pečen, N./Povesmo, P.: V gody surovych ispitanij, S. 63.

108 CMVS, V. 98, Nr. 33876p. 
Abbildung 15: Marija Nazarova zeichnet das Gespräch zwischen der Scharfschützin Ljudmila Pavličenka mit Soldaten der Roten Armee im Park des Hauses der Roten Armee auf, Moskau Sommer 1942, Fotografin/Fotograf unbekannt ( C CMVS.

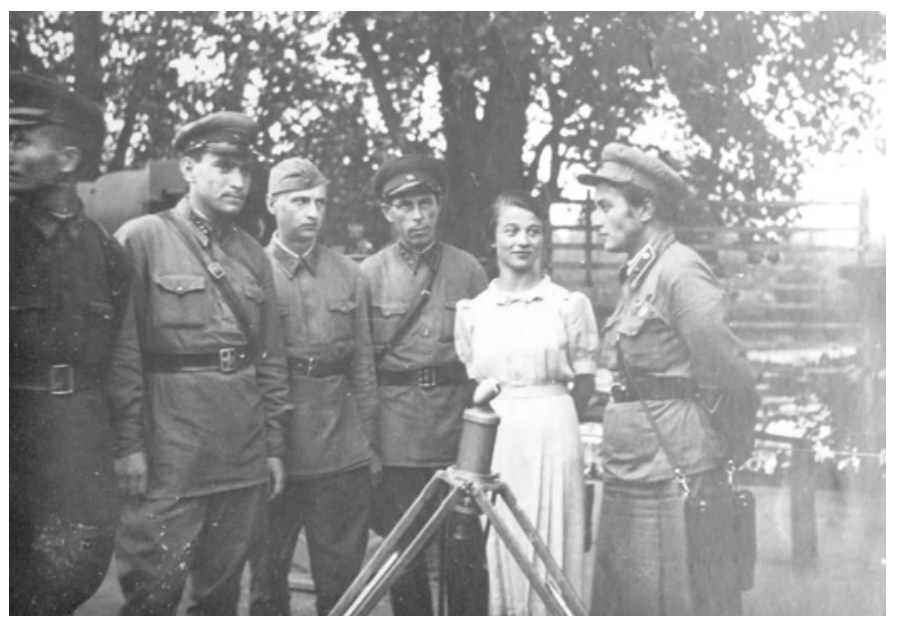

publizierte im Juni 1942 einen Artikel mit der Überschrift »Schieße wie Ljudmila Pavličenka«. ${ }^{109}$

Die muzejščiki sollten selbst zu Expertinnen und Experten des Krieges werden. Ein Resultat war die Dokumentation der Ausstellung »Die Zerschlagung der deutschen Truppen vor Moskau« in Form eines sogenannten »Thematischen Plans «. ${ }^{110}$ Der Ausstellungsplan, in dem die oben beschriebenen Objekte wiederzufinden sind, war weit mehr als nur eine Niederschrift der bestehenden Inszenierung. Die formale Struktur des Plans verlangte eine Systematisierung und Zuordnung der Exponate, die bei der chaotischen Inszenierung zu Beginn des Jahres ohne methodischen Hintergrund quasi wahllos in die Räume gestellt worden waren. Nun war zu erkennen, dass der Rundgang chronologisch angelegt war und das Publikum durch insgesamt zehn Säle führte. Die räumliche Struktur der zehn Säle bildete die Grundlage der thematischen Einteilung der Ausstellung. ${ }^{111}$ Jeder Saal

109 »Streliaj, kak Ljudmila Pavličenka«in: Komsomolzkaja Pravda, 2. Juni 1942, zitiert nach: Chatterjee, Choi/Kirschenbaum, Lisa/Field, Deborah: Russia's Long Twentieth Century, S. 134.

110 CMVS, op. 3, d. 25/8, I. 32-35. Dieser Plan ist nicht vollständig überliefert. Es fehlen zwei der insgesamt fünf Seiten.

111 Für einen thematischen und räumlichen Grundriss der Ausstellungsfläche des Museums vor dem Krieg vgl.: Plan-ukazatel' osmotra central'nogo muzeja RKKA, in: Pečen, N./Povesmo, P. (Hg.): 80 let na službe Otčestvu, Zentral'nij Muzej vooružennych sil, Moskva 1999, S. 18. 
der Sonderausstellung entsprach einem Ausstellungskapitel. Spezifische »Zielsetzungen « (celevaja ustanovka) bestimmten den thematischen und didaktischen Kontext seiner Objekte. In der Niederschrift dieser Zielsetzungen zeigte sich exemplarisch die Deutungsmacht der muzejščiki. Die Inszenierung der Ausstellung »Die Zerschlagung der deutschen Truppen vor Moskau« sollte vermitteln, dass »die Niederlage der Deutschen vor Moskau das entscheidende Ereignis der ersten Kampagne des Großen Vaterländischen Krieges und die erste große Niederlage der Deutschen im Zweiten Weltkrieg war «. Mit dieser begrifflichen Unterscheidung (»Großer Vaterländischer Krieg«, »Zweiter Weltkrieg«) integrierten die muzejščiki die Moskauer Episode in den internationalen Zusammenhang des Weltkrieges. Hierbei spielte die Rote Armee eine entscheidende Rolle, denn ihr war es als erster kriegsführender Partei gelungen, den Deutschen eine Niederlage zuzufügen.

Dabei, und das war die zweite wichtige Botschaft, wurde die Kraft des deutschen Angriffes entscheidend geschwächt. Drittens habe die Rote Armee die militärische Offensive übernommen und so die Legende von der »unbesiegbaren deutschen Armee« zerstört. Die Ereignisse würden das Scheitern der deutschen »Blitzkriegtaktik « zeigen. ${ }^{112}$

Die erfolgreiche Vermittlung der Überzeugung vom sowjetischen Sieg hatte im Frühjahr und Sommer 1942 eine nicht zu überschätzende Bedeutung. Die sowjetischen Truppen hatten die Wehrmacht im Winter 1941 zwar vor Moskau gestoppt, aber Stalins überambitionierte Pläne und seine strategischen Fehleinschätzungen führten zu mehreren militärischen Niederlagen mit extrem hohen menschlichen Verlusten auf sowjetischer Seite. Als im Frühjahr 1942 die im Januar abgebauten Straßenbarrikaden in Moskau wieder errichtet wurden, kehrten auch die Angst und das Bedürfnis nach Informationen nach Moskau zurück. Am 9. April 1942 schrieb die Ärztin E. Sacharova in ihr Tagebuch: »Die Nachrichten der vergangenen zwei Wochen berichten nichts über die wirkliche Lage der Dinge. Sie beginnen immer mit den Worten: >An dem und dem Tag hat sich an den Fronten nichts ereignet $\ll$. Das bedeutet nichts Gutes. ${ }^{113}$

Während Stalin von einem weiteren Angriff Hitlers auf Moskau ausging, konzentrierte sich das deutsche Oberkommando auf den Zugang zu den Ölfeldern am Kaspischen Meer. Nachdem die Wehrmacht im Mai 1942 den Brückenkopf auf der Halbinsel Kertsch im Schwarzen Meer zurückerobert hatte, nahm sie im Juli die Festung in Sewastopol und die Stadt Rostow am Don ein. Die unkoordinierten

CMVS, op. 3, d. 25/8, I. 34.

Dnevnik vrača Sacharovoj E. I., zitiert nach: Ponikarova, N.: Moskva, Ispytanie vojnoj, in: Moskovskij žurnal, Nr. 5, 1999, S. 33-38, hier S. 38. Das Tagebuch befindet sich im Wissenschaftlichen Archiv des Instituts für Russländische Geschichte (RAN). Ein Auszug, der die Einträge vom 25. August 1941-31. Mai 1942 umfasst, findet sich in: Bukov, K./Gorinov, M./Ponomarev, A. (Hg.): Moskva voennaja 1941-1945, S. 657-687. 
Rückzüge der Roten Armee ließen die militärische Disziplin einbrechen, und Ende August wehte auf dem höchsten Berg des Kaukasus, dem Elbrus, die deutsche Reichskriegsflagge. Die Wehrmacht stand kurz vor Stalingrad. ${ }^{114}$ Das militärische Versagen konnte nicht vor der sowjetischen Öffentlichkeit verborgen werden, und in Moskau brach wieder Panik aus, die von Wut und Entsetzen über den scheinbar unaufhaltsamen Vormarsch der deutschen Armee begleitet war. ${ }^{115}$

Die Moskauer muzejščiki wussten um die Wirkmacht, die ihrer Arbeit in dieser aussichtslosen Lage zugesprochen wurde. Sie nutzten die allgemeine Ratlosigkeit, um ihre Ausstellung den Vorgesetzten gegenüber als »mächtiges Medium« (moščnoe sredstvo) in der militärischen und politischen Erziehung der Roten Armee und der sowjetischen Bevölkerung zu präsentieren. ${ }^{116}$

Im Frühjahr 1942 hatten die zerstörten deutschen Waffen eine nachhaltige emotionale Wirkung ausgeübt. Im Herbst 1942 wurden die Waffen und persönlichen Überbleibsel der sowjetischen Helden zu auratisch aufgeladenen Exponaten. Im Diskurs der zeitgenössischen muzejščiki wurden sie als »Reliquien« bezeichnet. Damit wurden sie zu symbolischen Opfergaben, die einen guten Ausgang der bedrohlichen Situation beschwören sollten. John Horne hat in seiner Forschung zu den Museen des Ersten Weltkrieges festgestellt, dass eine sakrale Inszenierung dann eine Lösung darstellte, wenn die Kosten des Krieges in keinem Verhältnis zu seinem Ergebnis zu stehen schienen und das Massensterben den Sinn des Krieges in Frage stellte. Dies erkläre, warum »sogar in den Gesellschaften der sogenannten Siegermächte die Trauer und das Gedenken eher symbolische als didaktische Formen angenommen habe. ${ }^{117}$ Laut den muzejščiki des Armeemuseums verspürten die Soldatinnen und Soldaten vor ihrem Einsatz an der Front oft das Bedürfnis, an diesen Reliquien im Museum "teilhaben « (priobščit'sja k relikvijam) zu wollen. ${ }^{118}$ Die von den muzejščiki vorgenommene Klassifizierung der Objekte als Reliquien und der Wunsch der Soldatinnen und Soldaten, die sich von dem Anblick Kraft und Mut erhofften, erinnern an das christliche Verständnis von Heiligenreliquien. Bereits im Mittelalter, als man von einer Unteilbarkeit von Körper und Geist

Für eine detaillierte Übersicht des Kriegsverlaufs im Frühjahr und Sommer 1942 vgl.: Beevor, Antony: The Second World War, S. 327-343.

Overy, Richard: Russia's War, A History of the Soviet War Effort, 1941-1945, New York 1997, S. 158.

116 CAMO RF, f. 32, op. 11302, d. 95, I. 477-479, hier I. 477.

117 Horne, John: Von Museen im Weltkrieg, S. 45. Diese grundsätzliche Überlegung verweist auf den allgemeinen Umgang der kriegführenden Cesellschaften (also auch Deutschlands), die unabhängig vom momentanen Kriegsglück mit sinnlos erscheinenden Todeszahlen konfrontiert waren. Es gilt demnach zu überprüfen, ob auch in den nationalsozialistischen Ausstellungen eine sakralisierende Inszenierung vorgenommen wurde. 
ausging, wurde den Überresten der Heiligen postmortale Wundertätigkeit zugesprochen. ${ }^{119}$ Diese Sakralisierung der Objekte fügte sich in die Konzeption des »Großen Vaterländischen Kriegs « als »Heiligen Krieg« ein. ${ }^{120}$ Während vor dem Museum die Einheiten auf dem Weg zur Front über den »Platz der Kommune« marschierten und das Lied »Heiliger Krieg« (Svjaščennaja Vojna) sangen, stellten die muzejščiki in ihren Vitrinen den Dirigentenstab und die Handschrift der Partitur von Aleksandr Aleksandrov aus. ${ }^{121}$ Der Krieg hatte die muzejščiki zu Hüterinnen und Hütern von kraftbringenden Heiligtümern gemacht. Diese Position verlieh der Institution eine bislang unerreichte Machtfülle.

Selbstbewusst betonten die Direktoren des Museums und des Hauses der Roten Armee gegenüber der GlavPURKKA deren Abhängigkeit von dem Museum, die sich aus dem Bedarf an wirkmächtigen Ausstellungen ergäbe. Sie stellten weitreichende Forderungen: Das Museum sollte vom Haus der Roten Armee institutionell unabhängig werden. Die politische Behörde sollte das Museums zum `Zentralmuseum`aller militärhistorischen Museen der Sowjetunion erklären und ihm ein eigenes, neues Gebäudes zuteilen. ${ }^{122}$ Fedjanin verlieh seinen Forderungen Nachdruck, indem er auf die Konsequenzen hinwies, die bei der Unterlassung dieser Kompetenzausweitung des Museums eintreten würden: Das Museum würde weiterhin seinen »dilettantischen und verwahrlosten Charakter « (kustarnij u besprizornij charakter) behalten, während Objekte von großem historischen Wert »einfach verloren gehen würden «. ${ }^{123}$ Diese selbstkritische Reflexion konnte nur geäußert werden, weil sich die gesellschaftliche Position der muzejščiki verändert hatte. Als Bewahrerinnen und Bewahrer von historisch wertvollen Propagandamaterialien hatten sich die muzejščiki als dokumentierende Expertinnen und Experten des »Großen Vaterländischen Kriegs« unverzichtbar gemacht.

Während man annehmen könnte, dass die Forderungen des Museumsdirektors nach zusätzlichen finanziellen und räumlichen Ressourcen im Angesicht einer weiteren drohenden militärischen Niederlage keine Priorität hätten, ist das Gegenteil der Fall. Im August 1942, einen Monat später, leitete Šikin das Anliegen der muzejščiki an seinen Vorgesetzten, den Leiter der GlavPURKKA Aleksandr

Angenendt, A.: Reliquien, in: Lexikon des Mittelalters, http://apps.brepolis.net/lexiema/test/ Default2.aspx (Stand: 31.07.2021).

Elena Polyudova hat auf das komplexe semantische Begriffsfeld des Wortes »svjaščennij《 (heilig) hingewiesen, das im sowjetischen Kontext der 1940er Jahre die zusätzlichen Bedeutungsfelder von »Spiritualität«, »Ehre«, »Pflicht« und »Schutz« implizierte, was einen Teil der großen Popularität des Liedes ausmachte. Vgl. Polyudoda, Elena: Soviet War Songs in the Context of Russian Culture, Newcastle upon Tyne 2016, S. 62-73. 
Ščerbakov weiter. ${ }^{124}$ Er verwandelte die Forderungen der muzejščiki in eine Staatsangelegenheit und warf seinem Chef vor, »dieser derart wichtigen staatlichen Aufgabe [damit ist die Museumsarbeit gemeint, A.H.] viel zu wenig Aufmerksamkeit zu widmen «. ${ }^{125}$ Einen Monat später griff der Leiter der Kulturaufklärungsbehörde (Abteilung zwischen dem Haus der Roten Armee und der GlavPURKKA) das Anliegen der muzejščiki erneut auf und bezeichnete die Forderung nach der Vereinigung aller militärhistorischen Museen der Sowjetunion unter der Führung des Museums der Roten Armee als »berechtigte Frage«, deren Lösung jedoch auf einen "günstigeren Zeitpunkt« (bolee blagoriatnoj obstanovke) verschoben werden müsste. Gemeinsam mit den Vorsitzenden der Kommission zur Geschichte des Großen Vaterländischen Krieges und in Übereinstimmung mit der Militärhistorischen Abteilung des Generalstabs sei er jedoch der Meinung, dass das Museum dringend ein größeres Gebäude benötige und schlug vor, die Sammlung in dem Gebäude des ehemaligen Museums der Völker der UdSSR auf den Sperlingsbergen bei Moskau unterzubringen. ${ }^{126}$

Auch wenn die Forderungen in Anbetracht der desaströsen Entwicklungen an der Front aufgeschoben wurden, zeigt die Korrespondenz den Einfluss der muzejščiki auf die übergeordneten Instanzen. Vor dem Hintergrund der militärischen Niederlagen im Sommer und Herbst 1942 konzentrierte sich die GlavPURKKA auf eine neue Form der geistigen Mobilisierung der Roten Armee. Als psychologische Taktik, um die Motivation und Moral der Armee zu heben, wurde die sogenannte »Hass-Kampagne« initiiert. Der auf den Feind geschürte Hass wurde mit dem Drang nach Rache verknüpft, um die Hemmschwelle zum Töten zu senken. In seiner Rede zum 1. Mai 1942 beschrieb Stalin den Hass auf die deutschen Soldaten als unerlässliche Bedingung für den Sieg über die deutsche Armee. ${ }^{127}$ Diese Rede löste eine Welle der »Hasspropaganda« aus, die von Journalistinnen und Journalisten mit zahlreichen Artikeln und Gedichten in den Tageszeitungen gefördert wurde und im Sommer 1942 ihren Höhepunkt erreichte. ${ }^{128}$

Im Museum sollte sich dieser Diskurs in den Ausstellungsobjekten niederschlagen. Mitte Juli 1942 forderte die GlavPURKKA jene Politarbeiter an der Front, die in engem Kontakt mit dem Museum standen, dazu auf, explizit nach Objekten $\mathrm{zu}$ suchen, die als Beweise für Kriegsverbrechen dienen konnten. ${ }^{129}$ Die materiellen Relikte des Leids sollten bei den Menschen Wut und Hass sowie den Wunsch

CAMO RF, f. 32 , op. 11302 , d. 96, I. 20-22.

Ebd. I. 20.

Ebd. I. 12-13.

Befehl des Volkskommissars für Verteidigung, Nr. 130, Moskau, 1. Mai 1942, in: Stalin, Josef: Über den Großen Vaterländischen Krieg der Sowjetunion, 3. Auflage, Moskau 1946, S. 28.

Stelzl-Marx, Barbara: Der Wandel des Feindbildes, S. 204.

Zolotarev, V. u.a. (Hg.): Velikaja Otečestvennaja, Moskva 1996, S. 161. 
nach Rache auslösen. Die entsprechenden neuen Exponate wurden umgehend in die Ausstellung integriert. Die ständige Aktualisierung der Ausstellung weckte das Interesse der Presse, die über die »Neuen Exponate im Zentralmuseum der Roten Armee« berichtete. Unter dem Titel »Eine Anklageschrift gegen die faschistischen Henker« berichtete der »Rote Stern« über neue Museumsobjekte, die den brutalen Umgang der Wehrmacht mit gefangen genommenen Rotarmistinnen und Rotarmisten bezeugten. ${ }^{130}$ Der Artikel zitierte aus dem ausgestellten Bericht über den Fund von drei toten Rotarmisten und beschrieb das Schaudern beim Anblick des abgenagten Birkenzweiges, der in der Ausstellung als »materieller Beweis« für den Hungertod in deutscher Kriegsgefangenschaft, präsentiert wurde. ${ }^{131}$

Museumsdirektor Fedjanin nannte in den Arbeitsplänen für Juli und August 1942 »die noch stärkere Bewaffnung der Soldaten und des sowjetischen Volkes mit brennendem Hass gegenüber dem Feind « als Hauptaufgabe der Museumsarbeit. ${ }^{132}$ Laut Fedjanin konnte dieses Ziel am ehesten mit Führungen und Ausstellungen erreicht werden. Diese Führungen sollten von »harten Fakten, flammender Leidenschaftlichkeit und Überzeugung « bestimmt sein, und die Ausstellungen sollten das Material so präsentieren, dass es »stechend und überzeugend für jeden Besucher« sei. ${ }^{133}$ Die Integration von stark emotional aufgeladenen Objekten und die entsprechende Anpassung der Führungen machten das Museum zum Protagonisten der staatlichen Hasskampagne.

Die Gefühle von Hass und Rache, die der Anblick von misshandelten, gequälten und getöteten Menschen an der Front auslöste, sollte in den Museen hinter der Front reproduziert werden. Dem Fotohistoriker David Shneer zufolge hatte sich die Interpretation der nationalsozialistischen Gräueltaten verschoben: Im Winterhalbjahr 1941/42 stand sie für das Entsetzen über das Ausmaß der feindlichen Gewalt, im Sommer 1942 sollte sie Rache an einem Feind auslösen, der sich nicht an die Kriegskonventionen hielt. ${ }^{134}$

In den Monaten Oktober und November 1942, als die Einnahme Stalingrads durch die deutsche Armee kurz bevorstand, erhielt die Ausstellung über die Verteidigung von Moskau neue Relevanz und Wirkmacht. Die Arbeitspläne dieser Monate sind voller Aufträge, weitere Objekte zu den militärischen Ereignissen des Vorjahrs zu sammeln: Es sollten Interviews mit den Gardedivisionen geführt werden, die sich bei der Verteidigung der Hauptstadt ausgezeichnet hatten, auch sollten

Ohne Autor: Obvinitel'nij akt protiv fašistskich palačej, Novye èksponaty Central'nogo muzeja Krasnoj Armii, in: Krasnaja Zvezda, 2. August 1942, S. 3. Ebd.

132 CMVS, op. 3, d. 18/1, I. 8-10, hier I. 8; CMVS, op. 3, d. 18/1, I. 11-14, hier I. 11.

133 Ebd.

134 Shneer, David: Through Soviet Jewish Eyes, S. 111. 
weitere Objekte über den Einsatz der Moskauer Bevölkerung beim Bau der Verteidigungsanlagen gesammelt werden. ${ }^{135}$ Museumsdirektor Fedjanin beschrieb das "Studium und die Vermittlung der Kriegserfahrung « und die »Demonstration der militärischen Kriegskunst auf der Grundlage der Erfahrung der Moskauer Operation« als wichtigste Aufgaben der muzejščiki im Herbst $1942 .{ }^{136}$ Die Ausstellung über die Verteidigung von Moskau wurde entsprechend angepasst. Dabei zogen die Kuratorinnen und Kuratoren bewusst Parallelen zwischen der militärischen Situation im Herbst 1941, als die Hauptstadt von der Einnahme bedroht war, und der gegenwärtigen Situation in Stalingrad. Sie vertieften und erweiterten das Kapitel über die »Oktoberperiode 1941«, indem sie die deutschen Pläne zum Angriff auf die Hauptstadt und die militärischen Operationen der Gegenoffensive der Roten Armee ausgestellten. ${ }^{137}$

In Anbetracht der verzweifelten Lage der Roten Armee vor Stalingrad versprach die Sonderausstellung über die erfolgreiche Verteidigung von Moskau eine ermutigende und vorbildhafte Episode des vergangenen Jahres zu werden. Die muzejščiki hatten die Anforderungen an die geistige Mobilisierung ihres Stammpublikums richtig erfasst: Stalingrad sollte nun die Rolle einnehmen, die Moskau ein Jahr zuvor gespielt hatte. ${ }^{138}$ Natürlich sollte auch die Schlacht um Stalingrad selbst ausgestellt werden. Aufgrund von fehlenden Objekten war zu diesem Zeitpunkt jedoch nur eine »Foto-Ausstellung« möglich, die als weiteres Kapitel der Moskauer Sonderausstellung angefügt wurde. Die Analogie zwischen den Ausstellungsteilen zeigt sich auch im gleichlautenden Titel der Fotoausstellung. Nur der Name der Stadt war ausgetauscht worden: "Die Zerschlagung der deutschen Eroberer vor Stalingrad « (Razgrom nemeckich zachvatčikov pod Stalingradom). ${ }^{139}$

Neben der GlavPURKKA beauftragten die politischen Frontoffiziere das Museum damit, Wanderausstellungen für ihre Einheiten zu reproduzieren und Material für die sogenannten »Agitationsautos « (agitmašiny) bereitzustellen. ${ }^{140}$ Diese unmittelbare Verbindung zur Front ermöglichte den muzejščiki einen noch direkteren Zugang zu den Themen, die die Darstellung der akuten militärischen Situation erforderte. Für ihre Agitationsautos wünschten sich die Offiziere beispielsweise Stellwände mit dem Titel »Nicht einen Schritt zurück. Bleibt standhaft bis zum Ende des Kampfes «. ${ }^{141}$ Diese Losung stammt aus dem unmittelbaren Kontext der militärischen Niederlagen im Sommer 1942, als am 28. Juli nach der kampflosen 
Aufgabe der Stadt Rostow der von Stalin persönlich ausgearbeitete Befehl Nr. 227 "Keinen Schritt zurück « an alle Truppenteile verlesen wurde. ${ }^{142}$ Nach Kriegsende wurde die Veröffentlichung dieses brutalen Befehls, der Rückzug mit der Erschießung durch Sperrabteilungen hinter der Front bestrafte, verboten und bis 1988 vor der sowjetischen Öffentlichkeit geheim gehalten. ${ }^{143}$ Die Veröffentlichung des Befehls im Januar 1943 zeigt, dass die Grenzen der Darstellung des »Großen Vaterländischen Krieges « während des Krieges noch nicht gezogen waren und an die jeweiligen Bedürfnisse der sowjetischen Kriegsführung angepasst wurden. ${ }^{144} \mathrm{Da}$ bei hatte die Verbreitung der disziplinarischen Anordnungen über das Medium Museum höchste Priorität. Unabhängig von diesen späteren Ereignissen zeigt dieses Beispiel die unmittelbare Koordinierung der ideologischen Erziehungsarbeit zwischen den Führungsoffizieren an der Front und den muzejščiki im Hinterland der Front.

Im Frühjahr 1943, als der Generalstab der Roten Armee in Antizipation einer deutschen Offensive die Verteidigung am Kursker Bogen verstärkte, intensivierten auch die Moskauer muzejščiki ihre Arbeit und erweiterten ihre beruflichen Netzwerke. ${ }^{145}$ Ihre Qualifikation als militärhistorische Expertinnen und Experten verschaffte den muzejščiki die Möglichkeit, ihre Handlungsräume im Krieg auszubauen. Sammlungsleiter Loginov, der den an die Front abkommandierten Museumsdirektor Vladimir Fedjanin vertrat, vereinbarte mit den sogenannten »TrophäenAbteilungen «, die wegen der wachsenden Anzahl von aufgegebenem deutschem Kriegsgerät als reguläre Einheiten innerhalb der Roten Armee gegründet worden waren, eine ständige Kooperation. ${ }^{146}$ Die Abteilungen sollten dem Museum re-

142 Für den Befehl im Wortlaut vgl. Prikazy narodnogo komissara oborony SSSR, 22. ljunija 1941 g.-1942, in: Russkij archiv (Hg.): Velikaja Otečestvennaja, Bd. 13, Moskva 1997, S. 276-279.

143 Overy, Richard: Russia's War, S. 158. Jochen Hellbecks Forschung zu den StalingradProtokollen zeigt die unterschiedliche Auslegung und Anwendung des Befehls. Während einige Generäle zur Abschreckung den Befehl umsetzten und fliehende Soldaten erschossen, betonten andere die erzieherische Wirkung des Befehls, der zu größerer Standfestigkeit und Effektivität geführt habe. Grundsätzlich zeigen bekannt gewordene Angaben aus den Geheimarchiven, dass die Zahl der erschossenen Deserteure deutlich niedriger liegt als bisher angenommen und 92 Prozent der festgenommenen Soldaten in die Einheiten zurückgeschickt wurden. Vgl. Hellbeck, Jochen: Die Stalingrad-Protokolle, S. 66-75.

144 Auch die Presse setzte Fotos von deutschen Gräueltaten zur Unterstützung des Befehls ein. Das Titelblatt des »Ogonek « vom August 1942 trug die Überschrift: »Don't forget what the Germans are doing. This is your fate if you allow them to advance. Therefore, do not take another step backward, and get revenge for these crimes.«Zitiert nach: Shneer, David: Through Soviet Jewish Eyes, S. 111.

145 Zum Kontext und Verlauf der Schlacht am Kursker Bogen vgl. Overy, Richard: Russia's War, S. 186-222.

146 Trophäenbrigaden wurden bereits im März 1942 in Anbetracht der großen Anzahl von aufgegebenem Kriegsgerät nach der Verteidigung von Moskau gegründet. Am 5. Januar 1943 erließ 
gelmäßig eine Auswahl der an der Front gesammelten Waffen schicken. ${ }^{147} \mathrm{Da}$ mit auch die anderen Sammlungsbereiche des Museums (Plakatsammlung, Dokumentensammlung, Fotosammlung, Kunstsammlung) mit den aktuellsten Materialien versorgt wurden, etablierte Loginov die Verbindung $\mathrm{zu}$ jener Abteilung der GlavPURRKA, die für die Feindpropaganda zuständig war und vereinbarte eine ständige Übergabe ihrer zweidimensionalen Materialien an das Museum. Die gleiche Vereinbarung traf er mit der staatlichen Nachrichtenagentur TASS und mit den größten Zeitungsredaktionen. ${ }^{148}$

Offiziere des Generalstabs der Roten Armee und Mitglieder der Militärakademie unterstützten die muzejščiki bei der Erstellung von Militär- und taktischen Manöverkarten. Diese Karten waren bei dem Museumspublikum außerordentlich beliebt: Das Vermittlungspersonal erinnerte sich, dass sie ihre Führungen bei den Karten immer unterbrechen mussten, um die vielen Fragen zu beantworten. Manche seien nur wegen der Karten ins Museum gekommen, um sich eine anschauliche Vorstellung von den Veränderungen an der Front zu machen. ${ }^{149}$ Hier zeigt sich die bedeutende Rolle der Museen bei der Visualisierung des Krieges, mit der sie in Zeiten ohne Fernsehen ihren medialen Konkurrenten wie beispielsweise dem Radio überlegen waren. Das Interesse der Menschen war besonders groß, weil diese Karten eine Neuheit in den Museen waren. Zuvor waren sie mit der Begründung, Panik zu vermeiden, verboten gewesen. Seit dem Sommer 1942 konnte sich die Moskauer Bevölkerung nun ein Bild vom Kriegsverlauf in ihrer Region machen; was jedoch fehlte, war ein Überblick über die internationale Kriegssituation. Nur über die Frontverlaufskarten konnte man sich die Dimension des Krieges erschließen und Mutmaßungen über den Zeitpunkt des Sieges anstellen. Die Aktualität der Karten sollte durch ihre kombinierte Inszenierung mit den jeweils neuesten Ausgaben des Sovinformbüros gewährleistet werden. Diese theoretisch ideale Präsentation, die das Museumsinstitut empfahl, warf jedoch praktische Probleme auf, da die Überblickskarten meist einen zu großen Ausschnitt präsentierten, auf dem die detaillierten Nachrichten der einzelnen Verbände und Divisionen verloren gingen. ${ }^{150}$

Die Arbeitspläne der Museumsdirektoren zeigen, dass sie sich bei der Weiterentwicklung ihrer Arbeit an der ersten Sonderausstellung »Die Zerschlagung der

das Verteidigungskomitee eine Neuauflage dieses Befehls und organisierte die Sicherstellung der Materialien. Dabei wurden die Soldaten darauf hingewiesen, dass die von ihnen gesammelten Materialien Staatseigentum seien. Diese Hinweise zu den Trophäenbrigaden verdanke ich Brandon Schechter. Vgl. Schechter, Brandon: The Stuff of Soldiers, A History of the Red Army in World War II through Objects, Ithaca 2019, S. 215-218. Ebd. 
deutschen Truppen vor Moskau« vom Februar 1942 orientierten. Das Museumsinstitut hatte im Februar in einem Brief an die Direktoren ebenjene gleichnamige Ausstellung im GIM als Vorbild empfohlen. ${ }^{151}$ Mit diesem Schreiben bestätigten die Behörden nicht nur offiziell die innovative Ausstellungspraxis der Kriegssonderausstellungen, sondern lobten das Konzept explizit. Obwohl das Armeemuseum nicht dem Narkompros, sondern der GlavPURKKA unterstellt war, nahmen die Kuratorinnen und Kuratoren die Empfehlungen wahr. Die Übernahme des Ausstellungstitels vom GIM hatte sich bereits bewährt. Nun galt es, die eigene Ausstellung über die »Zerschlagung der deutschen Truppen vor Moskau« weiterzuentwickeln. Die kommemorative Ausstellung diente den muzejščiki als >Lernort‘, an dem sie forschen und sich zu Expertinnen und Experten des »Großen Vaterländischen Krieges« qualifizieren konnten.

Im Juni 1943 formulierte der inzwischen von der Front zurückgekehrte Museumsdirektor Oberst Fedjanin folgendes Ziel im Arbeitsplan: »Vertiefung des Inhaltes und Verbesserung der Qualität der Ausstellung >Die Zerschlagung der deutschen Truppen vor Moskau« «. ${ }^{152}$ Dieses Ziel sollte über eine Kombination von theoretischen und praktischen Maßnahmen erreicht werden. Idealerweise erarbeiten die Ausstellungsabteilung gemeinsam mit der Abteilung Bildung und Vermittlung ihre Themen auf der Basis von wissenschaftlichen Grundlagen. Dafür konnte der Museumsdirektor auf seine guten Verbindungen zu allen wichtigen Institutionen der Stadt und seine angesehene Position als Oberst der Roten Armee zurückgreifen. Er etablierte den Kontakt mit der »Kommission zur Geschichte des Großen Vaterländischen Krieges« an der Akademie der Wissenschaften. Sie stellte den $m u$ zejščiki ihr dokumentarisches Material zur Verteidigung von Moskau zur Verfügung. ${ }^{153}$ Außerdem wurden regelmäßige »methodisch-didaktische Versammlungen« für die Angestellten organisiert, bei denen beispielsweise Vorträge zum Thema »Wie leitet man eine Kinder-Führung durch die Ausstellung >Die Zerschlagung der deutschen Truppen vor Moskau« " gehalten wurden. ${ }^{154}$ Auch die materiellen Arbeitsbedingungen verbesserten sich und trugen zur Außenwirkung des Museums bei. Während die muzejščiki zu Jahresbeginn 1942 ihre Vitrinen noch selbst zimmern mussten und die Ausstellung einen improvisierten Eindruck machte, konnten sie nun in der hausinternen Tischlerei einheitliche Vitrinen bestellen und die szenische Inszenierung aufwerten. ${ }^{155}$

Manevksij, Aleksej/Krjažin, Ivan: O dal'nejšem razvitii muzejno-ėkspozicionnoj raboty po tematike velikoj otečestvennoj vojny, 27. Februar 1943, Moskva 1943, S. 1-8. 
Bei allen Bemühungen sind die Einträge im Arbeitsplan zugleich ein Hinweis auf den immer noch mangelhaften Zustand der Ausstellung. Diesen Eindruck bestätigt auch ein bemerkenswert offenherziges Schreiben von zwei wissenschaftlichen Mitarbeitern an die GlavPURKKA:

»In der Ausstellung >Die Zerschlagung der deutschen Truppen vor Moskau< sind alle Trophäen ohne jeden Plan, ohne Geschmack und ohne Beschriftungen ausgestellt: Wer hat [wen A.H.] abgeschossen und vernichtet, wann, wo und wie viele? Es sind Uniformen aufgehängt und persönliche Waffen, aber es ist nicht bekannt, wem sie persönlich gehört haben, welchem deutschen Soldaten oder Offizier? Ohne jeden politischen Sinn [bez vsjakogo političeskogo smysla] liegen Kreuze und Medaillen auf einem aufgeschütteten Haufen, dort wo sie überhaupt nicht gebraucht werden. ${ }^{156}$

Diese chaotische und dilettantische Inszenierung war der Grund für die Appelle des Museumsdirektors zur Verbesserung der Arbeitsqualität. Das Foto der Ausstellung (Abb. 16) veranschaulicht die Kritik. ${ }^{157}$

Abbildung 16: Inszenierung in der Sonderausstellung »Die Zerschlagung der deutschen Truppen vor Moskau« im Zentralmuseum der Roten Armee, Februar 1942 bis März 1945, Fotografin/Fotograf unbekannt (c) CMVS.

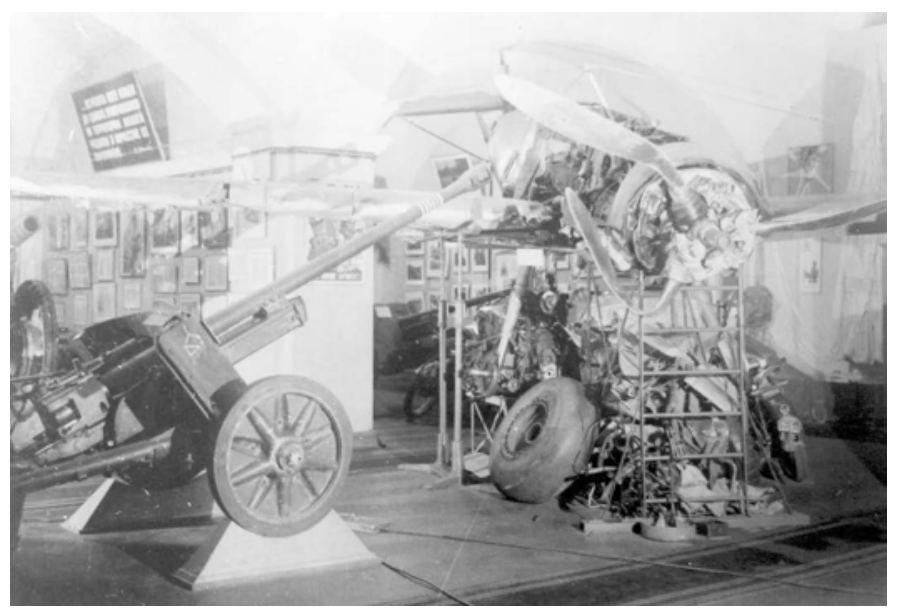

Die Beschriftung »Zerschossener faschistischer Aasgeier« war weder den am Detail interessierten Besucherinnen und Besuchern noch dem Vermittlungsperso- 
nal eine Hilfe bei der Interpretation der Inszenierung. Die spärlichen Informationen der Beschriftung waren offensichtlich. Ein sowjetisches Flakgeschütz richtete sein Rohr auf ein offensichtlich abgeschossenes deutsches Flugzeug. Dieses schien in seinen Einzelteilen ins Museum gebracht worden zu sein und hier von den muzejščiki zwischen behelfsmäßigen Stangen und Leitern, die den Rest der Pilotenkabine und den Propeller trugen, notdürftig zusammengeschoben worden zu sein. Am rechten Rand der Installation lehnte ein deutsches Motorrad, das offenbar nichts mit der Szene des Absturzes zu tun hatte und wahrscheinlich aus Ermangelung an Informationen bei dem Flugzeug abgestellt worden war.

Welchen Anlass hatten die Kuratoren, ihrem direkten Vorgesetzten einen derart selbstkritischen Einblick in ihre Arbeit zu geben? Im Hintergrund dieser vermeintlichen Diskreditierung der Kolleginnen und Kollegen stand eine wohlüberlegte Taktik: Die Schreiber waren sich der großen politischen Relevanz ihrer Sammlung zum »Großen Vaterländischen Krieg« bewusst. Sie betonten ihr Alleinstellungsmerkmal, Besitzer von Objekten zu sein, »die es möglich machten, in zehn, ja hundert Jahren das ganze Ausmaß des Titanenkampfes zu zeigen, den das sowjetische Volk in diesem Augenblick um seine Heimat führt«. ${ }^{158}$ Auf dieser argumentativen Grundlage knüpften sie an ihre Forderungen vom Vorjahr an und brachten ihr Hauptanliegen vor: die institutionelle Herauslösung aus dem Haus der Roten Armee, die Beförderung zum wichtigsten Armeemuseum der Sowjetunion und die Zuteilung eines eigenen Hauses. ${ }^{159}$

Die Kuratoren erhoben ihre neuerlichen Forderungen in einer Situation, in der die von der Roten Armee gewonnene Schlacht am Kursker Bogen den letzten deutschen Hoffnungen auf einen Sieg im Osten ein Ende gesetzt hatte. In der sowjetischen Bevölkerung hingegen, erwartete man das baldige Kriegsende. ${ }^{160}$ Die endgültige militärische Wende zugunsten der Sowjetunion im Jahr 1944 hatte für das Museum verschiedene Folgen. Auf materieller Ebene kamen mit dem Vorrücken der Roten Armee eine Vielzahl neuer Objekte in die Sammlungen, die das Platzproblem des Museums massiv verschärfte. Auf personeller Ebene sollte das $\mathrm{Mu}$ seum wieder in den Vorkriegszustand versetzt werden. Das bedeutete, dass die Stellen, die bislang mehrheitlich von Frauen ohne militärische Ausbildung ausgeübt wurden, wieder von Offizieren besetzt wurden und dass der Personalstand massiv aufgestockt wurde. In den Augen der GlavPURKKA war das Armeemuseum ein idealer Arbeitsort für demobilisierte Offiziere, die dort häufig in Leitungsfunktionen eingesetzt wurden. ${ }^{161}$ Auch auf der Führungsebene gab es einen Wechsel. 
Oberst Fedjanin wurde zur Trophäenabteilung abkommandiert, wo er dafür sorgte, dass die begehrten Objekte in die Museumssammlung gelangten, und Oberst Ivan Gorjuškin übernahm im Juli 1944 die Leitung des Armeemuseums. Diese Entwicklungen ermöglichte dem neuen Museumsdirektor die Durchsetzung der Forderungen seiner Vorgänger: Das Museum wurde institutionell vom Haus der Roten Armee getrennt und als Leitmuseum der Roten Armee anerkannt. Damit hatte sich das Museum gegen seine vier direkten Konkurrenten (Historisches Artilleriemuseum, Zentralmuseum der Marine, Museum für Kriegsmedizin, Zentralmuseum des NKVD) durchgesetzt. ${ }^{162}$ Das Sammlungsmonopol, über das die muzejščiki nun verfügten, brachte eine Vielzahl neuer Objekte in die Sammlungen. Diese Bestände und die Beförderung zum Leitmuseum der Armee verpflichteten die muzejščiki zu einer Gesamtdarstellung des »Großen Vaterländischen Krieges«, im Rahmen derer die Moskauer Sonderausstellung von 1942 den Auftakt bildete. ${ }^{163}$

\section{Das Museum der Roten Armee im Spätstalinismus}

Am 9. Februar 1946, ein halbes Jahr nach Kriegsende, hielt Stalin eine Rede, in der er die erinnerungspolitische Leitlinie des »Großen Vaterländischen Krieges« festlegte. In dieser Rede beschrieb er den »Ursprung und Charakter des Zweiten Weltkrieges«, sowie seine drei zentralen »Ergebnisse « für die Sowjetunion. ${ }^{164}$ In diesem ersten Teil der langen Rede, die Stalin im vollbesetzten Bolschoj-Theater hielt, stellte er den Krieg als »unvermeidliche« Folge des Kapitalismus dar, der aufgrund seiner ungerechten Güterverteilung zwangsläufig zu Konflikten geführt habe. ${ }^{165}$ Die Hauptergebnisse des Krieges sah Stalin erstens in dem Beweis für die Überlegenheit der sowjetischen Gesellschaftsordnung, zweitens in dem Beweis für den Zusammenhalt des sowjetischen Vielvölkerstaats und drittens in dem Beweis der Unbesiegbarkeit der Roten Armee. ${ }^{166}$

Die zeitgenössische amerikanischen Öffentlichkeit las diesen ersten Teil der Rede als Angriff auf die westliche Gesellschaftsordnung, der Richter des Supreme Court of the United States deutete sie gar als "Deklaration des Dritten Welt-

Diese Museen bestehen bis heute unter folgenden Namen: Voenno-istoričeskij muzej artillerii, inženernych voijsk i vojsk slavy (Militärhistorisches Museum der Artillerie und des Ingenieurwesens), Central'nij voenno-morskoj muzej (Zentralmuseum der Marine), Voennomedicinskij muzej (Museum für Kriegsmedizin), Central'nij pograničnij muzej FSB Rossii (Zentralmuseum des FSB).

Für eine detaillierte Beschreibung der Ausstellungsinhalte der 15 Museumssäle im Jahr 1946 vgl. Loginov, Pëtr: Kratkij putevoditel' po zalam èkspozicii, Moskva 1946. Stalin, Josef W.: Rede in der Wählerversammlung des Stalinwahlbezirks der Stadt Moskau, 9. Februar 1946, in: ders.: Werke 15, Mai 1945-Dezember 1952, Dortmund 1979, S. 33-41. 
krieges«. Der zweite, für die stalinistische Erinnerungspolitik weitaus aufschlussreichere Teil der Rede wurde, wie der Historiker Frank Costigliola betont, infolge der Fixierung auf die vermeintliche Drohgebärde Stalins von der Forschung lange vernachlässigt. ${ }^{167}$ In diesem Teil, den auch die Moskauer muzejščiki in ihrer Ausstellungs- und Vermittlungsarbeit aufgriffen, wendete sich Stalin mit folgender Mahnung an das Volk: »Es wäre falsch zu glauben, dass man einen solchen historischen Sieg ohne vorhergehende Vorbereitung des ganzen Landes für die aktive Verteidigung erringen könnte. ${ }^{168}$ In den nun folgenden statistischen Ausführungen Stalins zu den Erfolgen der zurückliegenden drei Fünfjahrespläne sieht Costigliola die eigentliche Bedeutung der Rede: »It was an effort to establish myths that would justify the brutality of the forced collectivization, industrialization, and purges of the 1930s; erase memories of the nearly fatal defeats and divisions of World War II; and justify the future role of the Communist Party. ${ }^{169}$ Um deutlich zu machen, dass all die Entbehrungen und das Leid des Volkes für den Sieg notwendig gewesen waren, verglich Stalin die wirtschaftliche Produktivität der Sowjetunion mit jener des Zarenreiches und zog folgendes Fazit: »Wie Sie sehen, gleicht dieses Bild nicht dem Bild, das die Versorgung unserer Armee im Ersten Weltkrieg bot, als die Front unter einem chronischen Mangel an Geschützen und Geschossen litt, als die Armee ohne Panzer und Flugzeuge kämpfen musste, als je drei Soldaten ein Gewehr ausgehändigt wurde. ${ }^{170}$

Die maßgebliche Führungsrolle der Kommunistischen Partei bei diesen Errungenschaften diente Stalin zur Überleitung zu seinem dritten Schwerpunkt: dem Blick in die Zukunft und dem damit verbundenen Aufruf zur Arbeitsmobilisierung. Nach vagen Versprechen auf eine baldige Aufhebung des Rationierungssystems, eine Preissenkung von Bedarfsgütern und die allgemeine Hebung des Lebensstandards kündigte Stalin das Vorhaben der Partei an, in den kommenden drei Fünfjahresplänen das industrielle Niveau des Landes um das Dreifache im Vergleich zum Vorkriegsstand zu heben. Der Widerspruch lag in der gleichzeitigen Ankündigung von sozialstaatlichen Reformen und dem Wiederaufbau der zerstörten Industrie und Wirtschaft. Eine doppelte Herausforderung, die das vom Krieg stark versehrte Land unmöglich leisten konnte und die das Lavieren Stalins spiegelte. Einerseits musste er den Erwartungen der Nachkriegsgesellschaft nach einem besseren Leben

167 Costigliola, Frank: The Creation of Memory and Myth, Stalin's 1946 Election Speech and the Soviet Threat, in: Medhurst, Martin ]./Brands, H. W. (Hg.): Critical Reflections on the Cold War, Linking Rhetoric and History, College Station, 2000, S. 38-54.

168 Stalin, Josef W.: Rede in der Wählerversammlung, S. 36.

169 Costigliola, Frank: The Creation of Memory and Myth, S. 41.

170 Stalin, Josef W.: Rede in der Wählerversammlung, S. 39. 
entgegenkommen und andererseits sollte die Mobilisierungspolitik der Vorkriegszeit wiederhergestellt werden. ${ }^{71}$

Hochstimmung, ausgelöst durch den Wiederaufbau, sollte die Traumata der Kriegsgesellschaft verdrängen. Stalins Angabe von nur rund sieben Millionen sowjetischer Kriegsopfer war ein eindeutiges Zeichen für die Herabsetzung des hohen Preises, den die sowjetische Bevölkerung an der Front, in den besetzten Gebieten und im Hinterland für den Sieg gezahlt hatte. ${ }^{172}$ Auch wenn den Menschen unter Stalins Herrschaft die heutigen Schätzungen, die mit über 27 Millionen Toten beinahe das Vierfache dieser Zahl angeben, nicht bekannt sein konnten, so muss diese Angabe doch den sowjetischen Familien, die fast alle jemanden im Krieg verloren hatten, unglaubwürdig oder gar respektlos gegenüber den Toten erschienen sein. ${ }^{173}$

Wie verhielten sich die Moskauer muzejščiki zu diesen geschichtspolitischen Kampagnen der Nachkriegszeit? Pëtr Loginov, der stellvertretende Direktor des Moskauer Armeemuseums, hatte im Januar 1946, also einen Monat vor Stalins Rede, den Arbeitsplan für das erste Nachkriegsjahr ganz unter das Motto "Studieren, studieren, bis wir die wertvollste militärische Erfahrung des Großen Vaterländischen Krieges beherrschen " gestellt. ${ }^{174}$ Konkret bedeutete dies, dass die muzejščiki neue Ausstellungen konzipieren sollten (zum Beispiel »Die Zerstörung des japanischen Imperialismus und die Kapitulation Japans«) und bestehende Ausstellungen (wie zum Beispiel »Die aktiven Verteidigungskämpfe der Roten Armee im Sommer und Herbst 1941 und die Zerstörung der Deutschen vor Moskau«) verbessern und umbauen sollten. ${ }^{175}$ Der erfahrene wissenschaftliche Mitarbeiter Ju. Skotnikov, der

171 Zu den Erwartungen, Hoffnungen und Stimmungen der Nachkriegsgesellschaft vgl. Zubkova, Elena: Russia after the War, Hopes, Illusions and Disappointements, 1945-1957, übersetzt von Hugh Ragsdale, New York 1998.

Stalin nannte diese Zahl im Rahmen eines Interviews, in dem er zur Rede von Winston Churchill befragt wurde, die dieser am 9. März 1946 in Fulton (MO) gab und die als »Iron Curtain Speech « in die Geschichte einging. Sowohl für die Rede Churchills als auch für das Interview Stalins, das am 14. März 1946 in der »Pravda «abgedruckt wurde, vgl.: Seventeen Moments in Soviet History, an on-line archive of primary sources: http://soviethistory.msu.edu/1947-2/col d-war/cold-war-texts/ (Stand: 31.07.2021).

Zu den russischen Schätzungen der Todesopfer im Krieg, die von über 27 Millionen Opfer ausgehen vgl. Isupov, Vladimir: Demografičeskie katastrofy i krizisy v pervoj polovine XX veka, Novosibirsk 2000, S. 195.

Loginov, Pëtr: Osnovnye zadači Central'nogo Muzeja Krasnoj Armii na 1946 god, 10. Januar 1946, in: CMVS, op. 3, d. 8/1, I. 59. Das Motto »Vsja Krasnaja Armii dolžna učit'sja i učit'sja nastojčivo osvaivaja cennejšij boevoj opyt Velikoj Otečestvennoj vojny« ist von einem Zitat aus dem Stalin-Befehl Nr. 75 vom 7. November 1945 abgeleitet, vgl. Krasnoe Znamja, 7. November 1945, S. 1. 
während des Krieges mit seiner Arbeitskollegin Marija Nazarova und dem Museumsdirektor Vladimir Fedjanin an den verschiedenen Fronten der Roten Armee nach Ausstellungsobjekten gesucht hatte, war verantwortlich für dieses Ausstellungskapitel, das aus der ersten Kriegsausstellung des Museums im Februar 1942 hervorgegangen war und sich der kritischen Anfangsphase des Krieges widmete. Anfang April 1946, zwei Monate nach der Rede Stalins, erhielt Skotnikov konkrete Arbeitsaufträge, dieses Ausstellungskapitel zu verbessern. ${ }^{176}$ Insbesondere das Thema »Die Vorbereitung des Landes für die aktive Verteidigung «, ein direktes Zitat aus Stalins Rede am 9. Februar 1946, sollte auf Grundlage des Redetextes in die Ausstellung integriert werden. ${ }^{177}$ Der Kurator Pëtr Loginov widmete der Rede also nicht ein eigenes Ausstellungskapitel, sondern ordnete sie in der Dauerausstellung zum »Großen Vaterländischen Krieg« der Anfangsphase zu. Diese Entscheidung war politisch nachvollziehbar, da so dem Trauma des Überraschungsangriffs, der zu Zweifeln an einer strategisch erfolgreichen militärischen Vorbereitung auf den Kriegsfall geführt hatte, eine offizielle Darstellung gegenübergestellt werden konnte.

Von der Forschung wird die Rede Stalins im Februar 1946 als Beginn des Kalten Krieges gedeutet. ${ }^{178}$ Für die Menschen und insbesondere für die Arbeiterinnen und Arbeiter im Kultur- und Bildungsbereich markiert sie aus der Retrospektive den Beginn einer immer repressiver werdenden ideologischen Kontrolle. Im Herbst desselben Jahres kündigte der Arbeitsplan im Armeemuseum eine umfassende Kontrolle aller Ausstellungspläne an. ${ }^{179}$ Jedes einzelne Ausstellungskapitel wurde auf seinen Inhalt geprüft, allfällige Mängel sollten festgehalten werden. Ein für alle spürbares Zeichen einer zunehmenden ideologischen Kontrolle war auch die Wiederaufnahme der Arbeit der »Primären Parteiorganisation« (Partijnoe bjuro partorganizacii) im Dezember 1946. Diese Parteibasisorganisation, über die jeder größere Betrieb in der Sowjetunion verfügen musste und die als Zelle der Kommunistischen Partei direkt dem ZK untergeordnet war, hatte die Aufgabe, die ideologische Erziehung sicherzustellen und Angelegenheiten von Parteimitgliedern der jeweiligen Institutionen zu regeln. Ihre Beschlüsse, die die Museumsarbeit dokumentierten, wurden in der Regel an das Institut für Parteigeschichte der Kommunistischen Partei weitergeleitet, wo sie geprüft und Fehlverhalten verfolgt wurde. ${ }^{180}$ Am 13. Dezember 1946 versammelte sich die militärische Führungsriege des

176 Loginov, Pëtr: Plan Raboty naučno-ekspozicionnogo otdela CMKA na aprel', maj i ijun' mesjac 1946, 10. April 1946, in: CMVS, op. 3, d. 8/1, I. 81-84.

177 Ebd. I. 83.

178 Costigliola, Frank: The Creation of Memory, S. 38.

179 Zubanov, Plan raboty Naučno-Ekspozicionnogo otdela CMKA na oktjabr'-nojabr'-dekabr' mecjacy 1946 goda, 4. Oktober 1946, CMVS, op. 3, d. 8/1, I. 77-85, hier I. 77.

180 Im Museumsarchiv sind die Originale von zwölf Sitzungsprotokollen (5. Dezember 1946 bis 8. August 1947) der Primären Parteiorganisation (PPO) überliefert. Dabei handelt es sich mög- 
Museums (die Oberstleutnante Chromin, Loginov und Koljupanov, der Leutnant und Museumsdirektor Gorjuškin sowie der Major und Leiter der Exkursionsabteilung Belousov und die zwei höchsten wissenschaftlichen Mitarbeiter Skotnikov und Jasen'), um die Mitglieder des Parteibüros zu wählen und die Arbeitspläne für die bevorstehende Zeit zu besprechen. ${ }^{181}$ Die erste Maßnahme, die das Parteibüro ergriff, war, Vorbereitungen für die Wahlen des Obersten Sowjets in den Unionsrepubliken der UdSSR im Februar des kommenden Jahres zu treffen. ${ }^{182}$ Die »besten und gelehrtesten Arbeiter" (lučsich i gramotnych rabotniky) des Museums wurden als »Agitatoren « des Wahlbezirkes ausgewählt, wo sie die Bürgerinnen und Bürger zu den bevorstehenden Wahlen mobilisieren sollten. ${ }^{183}$ Zur Vorbereitung dieser politischen Bildungsarbeit beschloss das Parteibüro, mit den muzejščiki »systematische« Gespräche über die »Fragen der gegenwärtigen politischen Lage« und die Aufgaben des neuen Fünfjahresplans zu führen. ${ }^{184}$

Die materiellen Anreize, die diese ehrgeizigen Wirtschaftspläne versprachen, schienen den Mitgliedern des Parteibüros in Anbetracht der vom Krieg völlig erschöpften Bevölkerung und den ärmlichen Umständen, unter denen die Menschen auch anderthalb Jahre nach Kriegsende selbst in Moskau noch lebten, dringend notwendig. ${ }^{185}$ Die Missernte infolge der Dürre von 1946 hatte zu einer landesweiten Hungersnot geführt, unter der insbesondere die ländliche Dorfbevölkerung

licherweise um einen Zufallsfund, da ihre fehlende Archivierung (keine Laufnummern) auf die Praxis hinweisen könnte, dass diese Protokolle in der Regel an die entsprechenden Organe des ZK weitergereicht wurden. Weiteren Aufschluss könnten hier Recherchen in den Archiven des Instituts für Parteigeschichte bei dem Zentralkomitee der Kommunistischen Partei oder im Stadtarchiv Moskau (CGA Moskau) geben, Stellen, die die Protokolle der PPO archivierten.

Ohne Autor, Protokol Nr. 1, Zasedanija partijnogo bjuro partorganizacii Central'nogo Muzeja Krasnoj Armii ot 13. Dekabrja 1946, in: CMVS, Mappe mit 12 Protokollen (Dez. 1946 - Aug. 1947, I. 1-21), keine Signatur (Opus/Delo), I. 1-2.

Ebd. I. 1.

Edb. I. 1-2. Zum Ablauf der Wahlen in der ukrainischen Unionsrepublik im Februar 1947 und zur Rolle der lokalen Agitatoren bei der Mobilisierung der Bevölkerung vgl. Yekelchyk, Serhy: Stalin's Citizens, Everyday Politics in the Wake of Total War, Oxford 2014, s. insb. Kapitel 6 »Election Day«, S. 179-217.

Ohne Autor, Protokol Nr. 1, I. 2.

Bernd Bonwetsch betont, dass das Realeinkommen 1945 bei etwa 40 Prozent von 1940 erst 1947 etwa 50 Prozent des Vorkriegsniveaus erreichte. Auch der Wiederaufbau von Wohnungen wurde zugunsten des Industriebaus zurückgestellt. Selbst in der Hauptstadt blieb der Wohnraum katastrophal überfüllt, führte zu Verschleiß (bei Kriegsende waren 90 Prozent der Zentralheizungen und 48 Prozent der Wasser- und Abwasserleitungen außer Betrieb). Vgl. Bonwetsch, Bernd: Sowjetunion, Triumph im Elend, in: Herbert, Ulrich/Schildt, Axel (Hg.): Kriegsende in Europa, Vom Beginn des deutschen Machtzerfalls bis zur Stabilisierung der Nachkriegsordnung 1944-1948, Essen 1998, S. 52-88, insb. S. 82-88. 
litt. ${ }^{186}$ Aber auch die grundsätzlich privilegierte Stadtbevölkerung war von den Preiserhöhungen der Lebensmittel stark betroffen. Die ungleiche staatliche $\mathrm{Zu}$ teilung der raren Konsumgüter war durch die Bevorzugung besonderer Gruppen geprägt, zu denen auch die muzejščiki des Armeemuseums gehörten. Das Parteibüro des Museums ordnete an, dass »in Anbetracht der Schwierigkeiten des Winters 1946/47 Unterstützung (pomošč) « für das Museumspersonal, unter ihnen bevorzugt die Kriegsinvaliden und demobilisierten Soldaten, sichergestellt wurde. ${ }^{187}$

Das Regime hatte der kriegsversehrten Bevölkerung wenig anzubieten. Die Referenz auf ein lobenswertes, ja heldenhaftes Verhalten im Krieg konnte zwar nicht den Hunger stillen, jedoch die Menschen mit Stolz erfüllen. So wurden auch 18 muzejščiki des Armeemuseums, darunter 14 Frauen, im Jahre 1946 mit der Medaille »Für die heldenhafte Arbeit im Großen Vaterländischen Krieg« ausgezeichnet. ${ }^{188}$

Abbildung 17: Mitarbeiterinnen und Mitarbeiter des Zentralmuseums der Roten Armee vor der »Fahne des Sieges«, Moskau 1946, Fotografin/Fotograf unbekannt (c) CMVS.

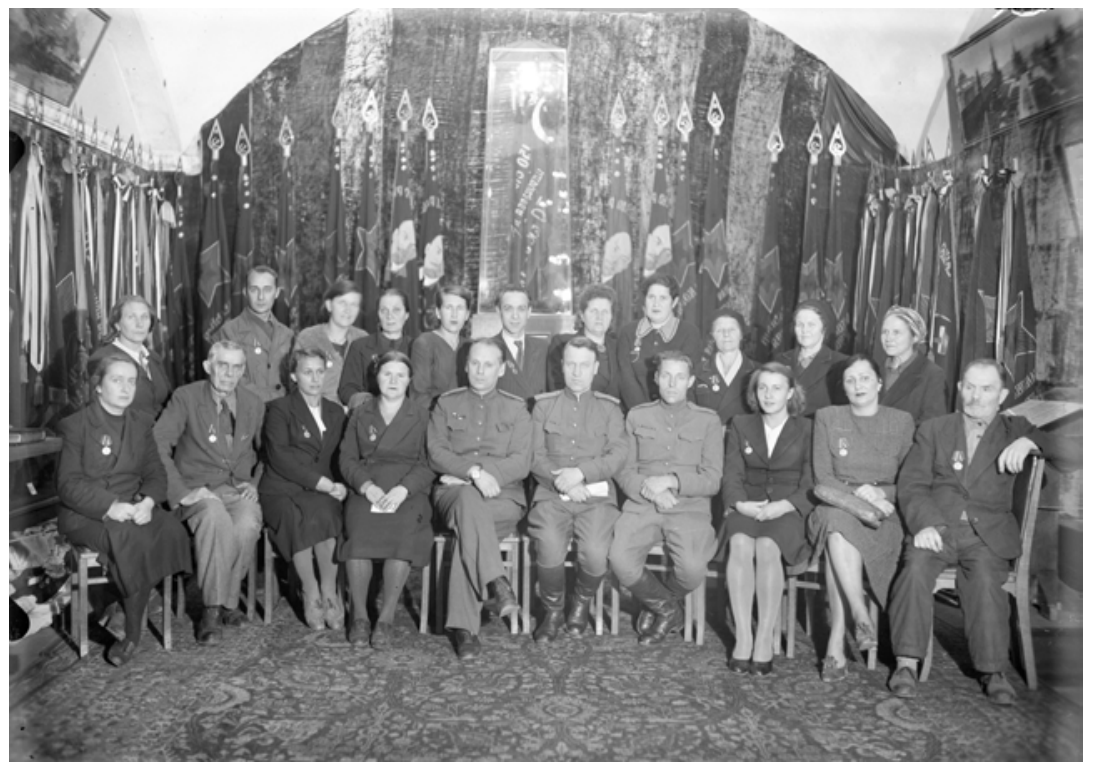

186 Ebd.

187 Ohne Autor, Protokol Nr. 1, I. 2.

188 Pechen, N./P. Povesmo, P.: 80 let na sluzhbe Otechestvu, Zentral'nii Muzei vooruzhennykh sil, Moskva 1999. 
Das Foto (Abb. 17) spiegelt die demographische Realität der sowjetischen Nachkriegsgesellschaft, die sich selbst im von Männern dominierten Museum der Roten Armee abbildete. Rund zwei Drittel der ca. 28 Millionen Menschen, die im Krieg ihr Leben verloren hatten, waren Männer, die meisten von ihnen im arbeitsfähigen Alter. 8,6 Millionen Rotarmistinnen und Rotarmisten fielen in einem Krieg, der mehr als 18 Millionen Opfer in der Zivilbevölkerung forderte. ${ }^{189}$ Die Witwen, Halb- und Vollwaisen und die mehreren Millionen Invaliden, Verletzten und Kranken fanden nach Kriegsende nur schwer in ein geordnetes Leben zurück. ${ }^{190}$ Insbesondere für die in den Museumsunterlagen bedachten Kriegsinvaliden, schätzungsweise rund zwei Millionen demobilisierter Soldaten, viele von ihnen mit amputierten Gliedmaßen, erblindet oder mit anderen schweren Beeinträchtigungen, war es praktisch, unmöglich Arbeit $\mathrm{zu}$ finden, so dass sie ohne ausreichende medizinische Versorgung und finanzielle Hilfe aufs Betteln angewiesen waren. ${ }^{191}$ Über die Menschen, die seelische Erkrankungen von ihrem Kriegserlebnis davontrugen, gibt es keine offiziellen Angaben.

Die offizielle Propaganda wurde angepasst. Anstelle des Versprechens auf ein besseres Leben wurde nun von unvermeidlichen Opfern und temporären Schwierigkeiten gesprochen. Die Schuld an der Lebensmittelkrise von 1946/47 trugen entweder »Saboteure« innerhalb der Sowjetunion oder die »Imperialisten«, die der Sowjetunion mit einem neuen Krieg drohten. ${ }^{192}$ Stalin nutzte das Trauma von 1941 und das daraus folgende Sicherheitsbedürfnis, um die Fortsetzung seiner Politik zu legitimieren. Die Erfahrung des gerade erst überlebten Krieges schürte eine permanente Angst vor einem weiteren Krieg: »Der Krieg bildete im kollektiven Bewusstsein noch lange den wichtigsten Maßstab für die Schwierigkeiten des Lebens, und die beschwörende Redensart >Wenn es nur keinen Krieg gibt! ‘ diente als stete Rechtfertigung für alle Zumutungen und Entbehrungen der Nachkriegszeit, selbst dann noch, wenn es darüber hinaus keinerlei vernünftige Erklärung gab.« ${ }^{193}$

189 Grüner, Frank: Patrioten und Kosmopoliten, Juden im Sowjetstaat 1941-1953, Köln/Weimar/Wien 2008, S. 184-185.

190 Zu den sowjetischen Invaliden des Zweiten Weltkrieges vgl. Fieseler, Beate: Arme Sieger, Die Invaliden des Großen Vaterländischen Krieges, Köln/Weimar/Wien 2006.

Zu den Kriegsinvaliden der Roten Armee vgl. Fieseler, Beate: The Bitter Legacy of the »Great Patriotic War«, Red Army Disabled Soldiers under Late Stalinism, in: Fürst, Juliane: Late Stalinist Russia, Society between Reconstruction and Reinvention, New York 2006, S. 46-61.

Zubkova, Elena: The Soviet Regime and Soviet Society in the Postwar Years, in: Journal of Modern European History, Vol. 2, Nr. 1, Communist Regimes and Parties after the Second World War, 2004, S. 134-152, hier S. 149. 
Im Armeemuseum drehte das Parteibüro in Zusammenarbeit mit der GlavPURKKA unterdessen die ideologischen Schrauben fest. In den Sitzungsprotokollen $\mathrm{zu}$ Beginn des Jahres 1947 dominierten die Beschwerden über die politische »Unzulänglichkeit« der Museums-Agitatoren und der Arbeitsplan schrieb den muzejščiki eine eindeutige ideologische Ausrichtung der Ausstellungsarbeit vor. Um den Anforderungen der GlavPURKKA zu entsprechen, musste das Museum dem Autor des Arbeitsplans vom 3. Januar 1947 gemäß folgendes leisten:

»Unermüdliche Erziehung der Angehörigen der sowjetischen Streitkräfte im Sinne des kommunistischen Bewusstseins, der selbstlosen Hingabe an die Heimat, die sowjetische Regierung, die Sache der Partei Lenins und Stalins; unermüdliche Erläuterung der welthistorischen Bedeutung des Sieges des sowjetischen Volkes und seiner vereinigten Streitkräfte im Großen Vaterländischen Krieg, [Erläuterung A.H.] des Ursprungs der Kraft und der Stärke des sowjetischen Staates, seiner Armee und Flotte, [Erläuterung A.H.] der Aufgaben, die der neue Fünfjahresplan Stalins beinhaltet und der zur Sicherstellung der zukünftigen Verbesserung der Verteidigungsfähigkeit der UdSSR führen wird; [Erläuterung A.H.] der planenden und inspirierenden Rolle, die die allrussische kommunistische Partei und ihre großen Führer Lenin und Stalin bei den Siegen des sowjetischen Volkes gespielt hatten; Erziehung kraftvoller sowjetischer Soldaten, die keine Schwierigkeiten fürchten und an den Triumph unserer Sache glauben. ${ }^{194}$

Was diese abstrakten ideologischen Vorgaben konkret für die muzejščiki bedeuteten, machte Loginov im zweiten Teil des Arbeitsplans deutlich: Innerhalb von drei Monaten sollte die ganze Ausstellung überprüft werden, um »die unbedingt notwendigen Anpassungen und Ergänzungen« vorzunehmen, die »zum Ziel der Steigerung eines ideologischen Ausstellungsinhaltes « führen sollten. ${ }^{195}$ Während die Kuratorinnen und Kuratoren des Museums nach bestem Wissen und Gewissen Ausstellungstexte neu verfassten oder korrigierten, Exponate hinzufügten oder aus den Vitrinen entfernten, stand die Abteilung Bildung und Vermittlung vor der Aufgabe, die pädagogische Arbeit zu intensivieren. Das Parteibüromitglied Pëtr Loginov hatte ihnen die Vorgabe gemacht, die Besucherzahl bis zum Jahresende um das 1,5-fache im Vergleich zum Vorjahr zu erhöhen. ${ }^{196}$ Diese Kontrolle des Ausstellungsinhaltes und der erzieherischen Vermittlungsarbeit durch die oberste politi-

194 Loginov, Pëtr: Plan Raboty Central'nogo Muzeja Krasnoj Armii, 3. Januar 1947, in: CMVS, op. 3, d. 8/1, I. 121-134, hier I. 121-122.

195 Ebd. 122-123.

196 Hier gab P. Loginov folgende konkrete Handlungsanweisungen: Die muzejščiki sollten nicht nur Kontakt zu allen militärischen Ausbildungsstätten aufnehmen, sondern auch zu allen städtischen Schulen, Bibliotheken und Ausbildungsbetriebe, damit diese ihre obligatorische politische Bildungsarbeit fortan im Museum in Zusammenarbeit mit dem Museumspersonal abhielten. 
sche Behörde der Streitkräfte im Frühjahr 1947 hatte nachhaltige Folgen und führte zu einer Neuauflage der "Leitlinien « (položenie) des Museums. ${ }^{197}$

Die ideologische Neuausrichtung des Moskauer Armeemuseums muss im $\mathrm{Zu}$ sammenhang mit der wachsenden repressiven Kontrolle und politischen Ausrichtung der Künste und Wissenschaften im Spätstalinismus sowie der beginnenden Systemkonkurrenz des Kalten Krieges gesehen werden. Die sogenannte »Ždanovščina« (wörtlich »die Sache Ždanovs«), benannt nach dem zweiten Sekretär der Kommunistischen Partei und engen Vertrauten Stalins Andrej Ždanov (1896-1948), war die ideologisch und xenophob gegen den Westen gerichtete Kulturpolitik der Nachkriegszeit. Sie zielte auf die Unterdrückung und Verurteilung sowjetischer experimenteller Kunstschaffende, Schriftstellerinnen und Schriftsteller und Wissenschaftlerinnen und Wissenschaftler von denen sie parteikonforme, patriotisch ausgerichtete Ausdrucksformen verlangte. »The Zhdanovshchina [...] reiterated the condemnation of experimentation with form, artistic introspection, a preoccupation with the emotional turmoil of the individual [...].«198

Für die Moskauer muzejščiki stellte die innovative Praxis der kommemorativen Ausstellungen während des Krieges einen Wendepunkt in ihrer Arbeitspraxis dar, dem zwar im Spätstalinismus ein vorläufiges Ende gesetzt wurde, aber auf den sie sich in den 1980er Jahren positiv bezogen. Laut dem späteren Direktor des GIM war es der Krieg, der einen "grundlegenden Umbau« (korennaja perestrojka) der $\mathrm{Mu}$ seumsarbeit verlangt hatte und $\mathrm{zu}$ den schnell zu konzipierenden Sonder- und Wanderausstellungen führte. ${ }^{199}$ Auch die Kuratorin und Museologin Anna Zaks sah rückblickend den Erkenntnisgewinn, den die Arbeit an den >Ausstellungen der Gegenwart « den muzejščiki gebracht hatte:

»Die Ausstellungen wurden nicht mehr mechanisch errichtet. [...] Es wurden Fehler ausgebessert, die im Zusammenhang mit der Unterschätzung der Wirkung der historischen Erinnerungsstücke auf die Besucher und mit der hypertrophen Verwendung von didaktischen Mitteln in der Inszenierung der Ausstellung standen. Ein gutes Beispiel für die Kombination von >Musealität und die den Ausbau der wissenschaftlichen Kompetenz ist die Ausstellung > Die Zerschlagung der deutschfaschistischen Streitkräfte vor Moskau<. [...] die gesellschaftliche Verantwortung unserer Arbeit wurde in den Jahren des Krieges offensichtlich. «00

Ohne Autor: Istorija Muzeja, in: Offizielle Webseite des Museums: www.cmaf.ru/history/ (Stand: 31.07.2021). Levykin, Konstantin: Perestroijka raboty, S. 148. 


\section{Zwischen Widerstand und Leiderfahrung. Ausstellungen im befreiten Minsk}

\section{Eine Museumsgründung im Krieg}

Die Geschichte des Minsker Kriegsmuseums beginnt im November 1942 in Moskau. Hier, im staatlichen historischen Museum am Roten Platz (GIM), hatten die Mitglieder der belarussischen »Kommission zur Geschichte des Großen Vaterländischen Krieges« ihre gesammelten Materialien in der Sonderausstellung »Belarus lebt, Belarus kämpft, Belarus war und wird sowjetisch sein« inszeniert. Ein knappes Jahr später verfügte die Historikerkommission, dass die erfolgreiche Ausstellung als Grundlage für die Neugründung eines nationalen Museums im bald befreiten Minsk dienen sollte.

Der erste Sekretär und Partisanenführer der sowjetischen Republik Belarus Pantelejmon Ponomarenko, der die Historikerkommission während des Krieges eng betreute, verlieh der Museumsgründung höchste Priorität. Bereits im Mai 1944, zwei Monate vor der Schlacht um Minsk, wurde der »Museumsapparat «, gemeint ist das Büro, von Moskau nach Gomel' in den bereits befreiten süd-östlichen Teil von Belarus gebracht. ${ }^{201}$ Unmittelbar nach der Flucht der deutschen Truppen aus Minsk befahl Ponomarenko am 27. Juli 1944, dass dem zukünftigen Museum Ausstellungssäle, Sammlungsdepots, Büros und ein Labor sowie Wohnräume und eine Mensa für die Mitarbeitenden im ehemaligen Gewerkschaftshaus zugeteilt werden sollten (Abb. 18). ${ }^{202}$

NARB, f. 1246, op. 1, d. 3, I. 1. Voronkova, Irina: Sozdanie i sostanovlenie Belorusskogo gosudarstvennogo muzeja istorii Velikoj Otečestvennoj vojne, Minsk 2001, S. 14.

202 NARB, f. 4p, op. 47, d. 23, I. 200. Im heutigen kulturellen Gedächtnis der Stadt wird das Haus als »Cewerkschaftshaus« (Dom Profsojuzov), erinnert - nach dem Umzug des Museums in einen Neubau (1969) diente das Haus erneut diesem Zweck. Das ursprünglich vorgesehene Gebäude des Staatlichen Historischen Museums kam nicht mehr in Frage, da es bei den Kämpfen um Minsk zerstört wurde. Die Aufnahme stammt aus dem sozialen Netzwerk pikabu.ru. Es handelt sich dabei um eine deutsche »Beutefotografie«. Die Urherberschaft und die Rechtefrage konnte trotz Bemühen der Autorin nicht abschliessend geklärt werden.Vgl.: https://pikabu.ru/story/povsednevnaya_zhizn_minska_vo_vremya_okkupatsii_na_f otografiyakh_7983909 (Stand: 31.07.2021). 
Abbildung 18: Das »Generalkommissariat Weißruthenien«, Minsk Mai 1943 bis Mai 1944, Fotografin/Fotograf unbekannt.

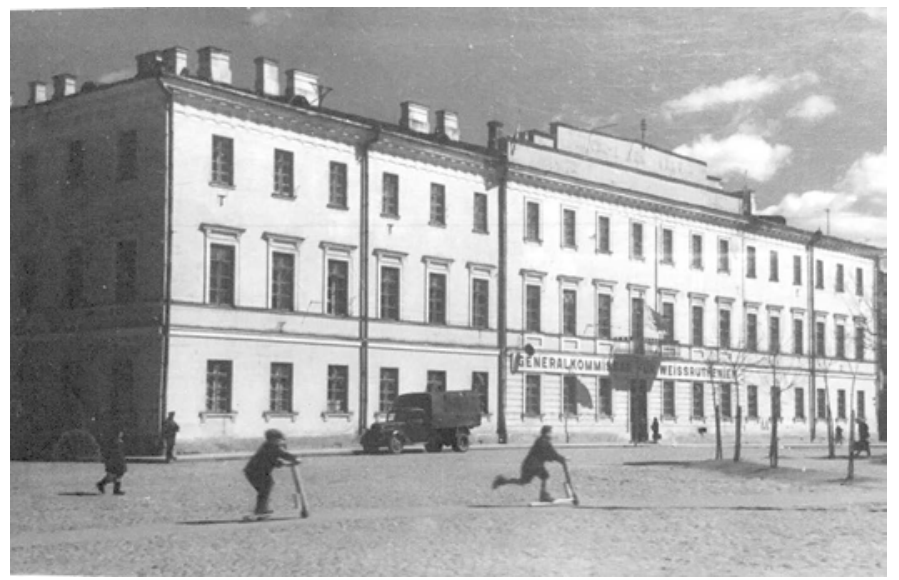

Das war ein unvorstellbares Privileg in der fast vollständig zerstörten Stadt. ${ }^{203}$ Die deutsche Besatzung und der Kampf um die Befreiung von Belarus hatten enorme wirtschaftliche Schäden verursacht, unter denen die Nachkriegsgesellschaft stark litt. Die Schäden wurden auf 75 Billionen Rubel geschätzt, was dem 35-fachen des staatlichen Gesamtbudgets der sowjetischen Republik im letzten Vorkriegsjahr entsprach. ${ }^{204}$ Insbesondere der eklatante Wohnungsmangel führte in den ehemals besetzten Gebieten, wo das Ausmaß der Zerstörungen am größten war, dazu, dass Zehntausende von Familien in Erdhütten, Ruinen, Kellern, Baracken oder ähnlichen behelfsmäßigen Unterkünften leben mussten. ${ }^{205}$ Immer wieder brachen in

203 Bohn, Thomas: Das »neue« Minsk - Aufbau einer sozialistischen Stadt nach dem Zweiten Weltkrieg, in: Beyrau, Dietrich/Lindner, Rainer (Hg.): Handbuch der Geschichte Weißrusslands, Göttingen 2001, S. 319-333, hier S. 321.

204 Smilovitsky, Leonid: Jewish Life in Belarus, The Final Decade of the Stalin Regime, 1944-53, Budapest/New York, 2014, S. 199.

205 Zubkova, Elena: Die sowjetische Gesellschaft nach dem Krieg, S. 369-370. Über drei Millionen Menschen waren nach dem Krieg in Belarus obdachlos. Sie wohnten in Bunkern, zerfallenen Gebäuden und Baracken. Von den $10.773 .000 \mathrm{~m}^{2}$ Wohnraum der Städte und Dörfer waren nur $2.762 .000 \mathrm{~m}^{2}$ intakt geblieben. Die prekäre Situation in den Städten wurde durch den Zuzug von Kriegsflüchtlingen, demobilisierten Soldatinnen und Soldaten, Partisaninnen und Partisanen und vor der Armut auf dem Land geflohenen Bäuerinnen und Bauern verstärkt. Vgl. Kashtalian, Iryna: The Repressive Factors of the USSR's Internal Policy and Everyday Life of the Belarusian Society, 1944-1953, Wiesbaden 2016, S. 191-193. 
der ganzen Stadt öffentliche Konflikte über die Besitzverhältnisse aus, selbst politisch sehr gut vernetzte Minskerinnen und Minsker hatten massive Probleme, geeigneten Wohnraum zu finden. ${ }^{206}$ Die Stadt war zu 85 Prozent zerstört. Nur wenige Gebäude standen noch unversehrt in dem riesigen Trümmerfeld. Eines davon war das dreistöckige Gewerkschaftshaus am »Platz der Freiheit«, das die deutschen Besatzungsbehörden ab 1943 als Sitz des »Generalkommissariats Weißruthenien« genutzt hatten. ${ }^{207}$ Laut dem Minsker Korrespondent der »Pravda« war es das am besten erhaltene Gebäude der Stadt, das nun dem neuen Museum zugeteilt wurde. $^{208}$

Die Gründungsdokumente belegen weitere Privilegien, die dem Museum, das bereits vor Eröffnung die staatliche Kategorie Nr. 1 erhalten hatte, zugesprochen wurden: Es wurden 167 Planstellen bewilligt, die neben der Ausstellungsarbeit die technische Ausstattung und die administrative Verwaltung des Museums gewährleisten sollten. 25 Säle mit insgesamt $1.248 \mathrm{~m}^{2}$ Ausstellungsfläche dieses großzügigen Gebäudes wurden für das Museum reserviert; daneben gab es Wohnräume und eine Kantine für die Angestellten. Zudem wurde eine militärische Bewachung der Liegenschaft angeordnet. In Anbetracht der großen Armut und Zerstörung der Stadt ist das Ausmaß des Projektes beeindruckend und bezeichnend für die erinnerungspolitischen Prioritäten und Ambitionen der Parteiführung. ${ }^{209}$ Mit der Befreiung der sowjetischen Republik Belarus durch die Rote Armee sollte Minsk $\mathrm{zu}$ einem zentralen Erinnerungsort des Krieges werden. Als neu aufgebautes administratives, kulturelles und industrielles Zentrum sollte die Stadt den Triumph über den Faschismus demonstrieren. Dieses neue Selbstverständnis zeigte sich auch in der Bezeichnung »Museum der Geschichte des Vaterländischen Krieges«, wie das Museum in dem Schreiben zur Gebäudeübertragung genannt wurde. Das

206 Exemplarisch für andere belarussische Städte beschreibt Iryna Kashtalian, dass in den Wochen nach der Befreiung die Menschen in Minsk aus Not leerstehende Häuser illegal besetzten, für die ihnen später das Wohnrecht zugesprochen wurde, sofern der ehemalige Eigentümer keinen Einspruch einlegte. Vgl.: Kashtalian, Iryna: The Repressive Factors, S. 194. Insbesondere Jüdinnen und Juden, die den Holocaust in Belarus überlebt hatten, waren mit großen Schwierigkeiten konfrontiert, als sie ihre Häuser und ihr Eigentum zurückforderten. Vgl. Smilovitsky, Leonid: The Struggle of Belorussian Jews for the Restitution of Possessions and Housing in the First Postwar Decade, in: East European Jewish Affairs 30, 2, S. 53-70. Lyvčavko, Aleksandr: Vtoraja mirovaja: ploščad' Svobody v Minske vo vremja okkupacii i segodnja, 23. Juni 2014 in: https://news.tut.by/society/404240.html(Stand: 21. September 2017).

208 Zemcov, A.: Dve vystavki, posvjaščennye narodnoj bor'be, in: Pravda, Nr. 274, 15. November 1944, S. 3.

209 Auch Aljaksandr Hužaloŭski, der mit seiner Forschung die Grundlagen einer belarussischen Museumsgeschichte gelegt hat, drückte sein Erstaunen über die finanziellen und materiellen Dimensionen aus, die dem neuen Museum zugesprochen wurden. Vgl. Hužaloŭski, Aljaksandr: Cistorija muzejnaj spravy belarusi, S. 222. 
im wörtlichen Sinne "wiederauferstandene « sozialistische Minsk sollte als Symbol in die ganze Sowjetunion ausstrahlen. Dementsprechend musste das örtliche Kriegsmuseum nicht nur die lokale, sondern auch die übergeordnete Erzählung vom »Großen Vaterländischen Krieg« ausstellen. Das Kriegsmuseum war das erste Projekt der Planungen für das "neue« Minsk. ${ }^{210}$ Der politische Entschluss, dem Museum das »beste Gebäude der Stadt « zu widmen, muss Missgunst hervorgerufen haben. ${ }^{211}$ Die Museumsangestellten hingegen erinnerten sich stolz, dass sie das Gebäude in den chaotischen Wochen nach der Befreiung vor dem "Übergriff" durch andere Institutionen bewahrt hatten. ${ }^{212}$ Für die Nachkriegsgesellschaft war die Museumseröffnung zugleich ein Zeichen der wiederkehrenden Normalität, des Friedens, der wiederhergestellten Kultur und des Wiederaufbaus. Das hohe Tempo und der Nachdruck, mit dem Ponomarenko die Museumseröffnung vorantrieb, signalisierte den Kommissionsmitgliedern die hohe Relevanz, die der ehemalige Partisanenführer dem Museum zusprach und bestärkte sie in ihrer Arbeit.

Die riesige Ausstellungsfläche des Museums musste mit Objekten gefüllt werden, und die Leitung des Partisanenstabs verschickte Ende Juli einen Aufruf an alle Kommandeure und Kommissare der Einheiten und Brigaden, innerhalb einer Dreitagesfrist alle infrage kommenden Objekte und Materialien bei der Museumsdirektion abzugeben. ${ }^{213}$ Bereits vor der Eröffnung bestand also ein republikweiter Führungsanspruch des Minsker Kriegsmuseums in der Kriegskommemoration. Auch alle Kommandeure und Kommissare der Regionen außerhalb von Minsk hatten dem Museum in der Hauptstadt "charakteristische Exponate $z u r$ Verfügung zu stellen. Es wurde an das Pflichtgefühl der Partisanenführer appelliert, die selbst dafür verantwortlich seien, dass die Tätigkeiten ihrer Einheiten möglichst umfassend in dem neuen Museum dokumentiert würden. ${ }^{214}$

Doch Ponomarenko war nicht der einzige, der sich für eine unmittelbare $\mathrm{Mu}$ seumseröffnung in der befreiten Hauptstadt einsetzte: Die 1907 in der Nähe von Brest geborene Minsker Kunsthistorikerin Elena Aladova (Belarussisch: Alena Aladava) befand sich mitten in den Vorbereitungen für die Gründung einer Minsker Gemäldegalerie, als die »Heeresgruppe Mitte« die sowjetische Republik Bela-

210 Bohn, Thomas M.: Das »neue« Minsk, S. 319.

211 Während die hohen Mieten für die bereits von Steuern und Abgaben stark belastete Bevölkerung das Überleben zusätzlich erschwerten, musste das Museum keine Miete für seine Räumlichkeiten zahlen. NARB, f. 1246, op. 1, d. 8, I. 4.

Voložinskij, Vladimir: Muzej Velikoj Otečestvennoj vojny (staryj), 14. Dezember 2015, in: https://minsk-old-new.com/places/muzei/muzej-velikoj-otechestvennoj-vojny-staryj (Stand: 31.07.2021). 
rus überfiel. ${ }^{215}$ Gemeinsam mit den Beständen der Minsker und Witebsker Museen wurde Elena Aladova nach Saratow an der Wolga evakuiert, wo sie als wissenschaftliche Mitarbeiterin im Radyšev-Kunstmuseum arbeitete. Im Januar 1944 berief man sie in die Außerordentliche Staatliche Kommission (ČGK) nach Moskau, wo sie die Verluste, die die belarussischen Museen durch die Plünderungen der Achsenmächte erlitten hatten, dokumentierte und die Sonderausstellung »Belarus lebt, Belarus kämpft ...« im GIM betreute. ${ }^{216}$ Dank ihren Beziehungen zu der staatlichen Kommission wurden ihr mehrere Räume im Minsker Gewerkschaftshaus zugeteilt, um hier ihre Pläne für ein Kunstmuseum zu verwirklichen. ${ }^{217}$ Jedoch zeigte sich bereits in der Verteilung der Räume die Hierarchie unter den Minsker Museen: Während dem Kriegsmuseum 25 Ausstellungssäle zugesprochen wurden, musste sich die zukünftige Gemäldegalerie mit fünf Sälen begnügen. ${ }^{218}$

Die Gründung des Kriegsmuseums im Sommer 1944 ist von einem Mythos umgeben, der von offizieller Seite mitgeschaffen wurde. Bis heute zitieren die Museumspublikationen aus der »Pravda« vom 15. November 1944, wenn sie die Geschichte des Hauses erzählen:

»Am 16. Juli fand in Minsk eine Parade der bewaffneten Partisanen statt. Wenige Tage später gingen die Partisanen zu dem Cebäude [gemeint ist das Museum, A.H.] und legten ihre Waffen ab, um das Handwerk des Maurers, die Arbeit des Stuckateurs und des Malers aufzunehmen ... Ausstellungsleiter wurde der Schriftsteller Sablin, der zwei Jahre in den Reihen der Minsker Partisanenvereinigung gekämpft hatte. Unter den wissenschaftlichen Mitarbeitern befanden sich der ehemalige Kommandeur der Einheit `Für die Heimat` Genosse Gončarov, der Leiter des Stabes `Sturmvoge`Cenosse Loveckij, der Brigadeleiter von `Eisenerz« Cenos-

215 NCHM BR [Nacional'nyj chudožestvennyj muzej Respubliki Belarus'], f. 2, op. 6, d. 16, I. 1-11. Nacyjanal'ny mastacki muzej respubliki belarus (Hg.): Elena Aladova, dvenadcat' mgnovenij žizni, k 110-letiju so dnja roždenija, in: https://www.artmuseum.by/ru/vyst/virt/elena-aladova -dvenadcat-mgnovenij-zhizni-k-110-letiyu-so-dnya-rozhdeniya (Stand: 01.10.2018). Zu ihrem 110. Geburtstag widmete die Gemäldegalerie ihrer Gründerin Elena Aladova eine virtuelle Fotoausstellung.

216 Ebd. I. 1.

217 NCHM BRf. 2, op. 6, d. 16, I. 1-2. Im November 1947 eröffnete die Cemäldegalerie ihre erste Nachkriegsausstellung in fünf Sälen im zweiten Stock des Gebäudes. Vgl. Homepage des Staatlichen Kunstmuseums, Nacyjanal'ny mastacki muzej respubliki belarus (Hg.): Istorija Muzeja, in: www.artmuseum. by/ru/aboutmuseum/istmus (Stand: 25.09.2017). Als drittes Museum war das Erinnerungsmuseum Janka Kupala (Dom Muzej Ja. Kupaly) in dem Cewerkschaftshaus untergebracht.

218 Karasëva, N. (Hg.): Belaruski Dzjaržaŭny muzej gistory vjalikaŭ ajčynnaŭ vajny, Minsk 2015, S. 12-13. 
se Peregrugov, der Kommandeur der Sabotagegruppe Abramov und viele andere. ${ }^{219}$

Nach der Parade hatte Pantelejmon Ponomarenko die führenden Partisaninnen und Partisanen zu einem Empfang geladen und betraute sie mit zivilen Aufgaben, die in diesem Fall in der Renovation des Gewerkschaftshauses und dem Aufbau einer Ausstellung bestanden. ${ }^{220}$ Für die Zeitung »Pravda« lief dieser personelle und berufliche Übergang vom Partisanen zum Kurator oder von der Partisanin zur Kuratorin reibungslos. Der Berichterstattung zufolge legten die Kämpferinnen und Kämpfer ihre Waffen nieder und wurden über Nacht zu Handwerkerinnen und Handwerker bzw. zu muzejščiki. Dabei unterschlägt die Zeitung, dass die Überlebenden der dreijährigen Besatzungszeit in erster Linie junge Frauen oder ältere Menschen waren, die keinerlei Erfahrung oder gar eine Ausbildung im Museumswesen hatten. Der wahre Kern der Gründungslegende des Museums liegt in der partiellen personellen Überschneidung von Partisaninnen und Partisanen und $m u$ zejščiki. Diese Kontinuität war keine Besonderheit des Museumskontextes. Im Gegenteil, führende Politiker des städtischen Parteikomitees förderten den Mythos von Untergrundkämpferinnen und Untergrundkämpfer, die nach dem Krieg an der Arbeitsfront weiterkämpften: »Gestern noch Partisanen und heute schon Ingenieure, Lokführer, Schlosser, Stuckateure, [sie A.H.] arbeiten mit dem gleichen Heldentum des bewaffneten Kampfes an der Arbeitsfront. ${ }^{221}$ Diese Politik führte dazu, dass ehemalige Partisanen insbesondere in den ersten zwei Nachkriegsjahren viele Parteipositionen besetzten. ${ }^{222}$ Zum Gründungsdirektor des Museums ernannte die Kommission aus naheliegenden Gründen den Sekretär der Belarussischen Historikerkommission Vasilij Stal'nov (Abb. 19).

219 Zemcova, A.: Dve vystavki, posvjašennye narodnoj bor'be, Pravda, 15.11.1944.

220 Voronkova, Irina: Sozdanie i sostavlenie Belorusskogo Gosudarstvennogo Muzeja, S. 13.

221 Bel'skij, losif: Vozroždajuščijsja gorod, in: Pravda, 5. November 1944, S. 3.

222 Am 1. April 1945 hatten beispielsweise $40 \%$ der Führungspositionen in regionalen Verwaltungen sowie Kreis- und Stadtverwaltungen ehemaligen Partisanen inne. Vgl. Exeler, Franziska: What Did You Do During the War? Personal Responses to the Aftermath of Nazi Occupation, in: Kritika, 17,4, Herbst 2016, S. 805-835, hier S. 821. 


\section{Abbildung 19: Museumsdirektor Vasilij Dem'janovič Stal'nov, Minsk August 1944 bis Januar 1946, Fotografin/Fotograf unbekannt @ BDMGVAV.}

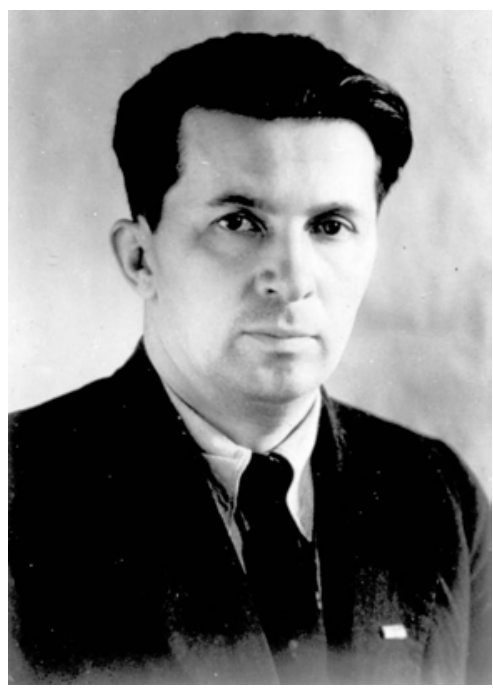

Vasilij Parfimovič, dessen genaue Lebensdaten unbekannt sind, wuchs südlich von Minsk im Starodorožsker Kreis in einer armen Bauernfamilie auf. In den 1930er Jahren arbeitete er als Journalist unter dem Pseudonym "Stal'nov« bei verschiedenen belarussischen Zeitungen, unter anderem auch beim »Stern«, der größten Zeitung der sowjetischen Republik. Für Reportagen wurde er an die russisch-chinesische Grenze nach Chabarowsk, auf die Krim und nach Kasachstan geschickt. Im Jahr 1940, als der östliche Teil Polens im Zuge des MolotovRibbentrop-Paktes von der Sowjetunion annektiert wurde, schrieb Stal'nov in Białystok als Korrespondent für die »Pravda«. Nach Kriegsausbruch gelangte er mit einem Evakuationszug nach Almaty, von wo aus er nach Moskau in die Kommissionsarbeit gerufen wurde. Als Sekretär koordinierte er die Sammelarbeit der Kommission, bis er Anfang August 1944 zum Museumsdirektor ernannt wurde. ${ }^{223}$

Die Anstellung von ehemaligen Partisaninnen und Partisanen als zukünftige muzejščiki lässt sich anhand der Anordnung des Museumsdirektors vom Oktober 1944 verfolgen, als er die ersten Ausstellungen plante und seine Angestellten auswählte. Von den 33 Mitarbeitenden, die unter der Direktion Vasilij Stal'novs an den 
Gründungsausstellungen des Minsker Museums mitarbeiteten, lassen sich neben Pëtr Gončarov bislang acht weitere ehemalige Partisanen und Untergrundkämpferinnen bestimmen. ${ }^{224}$

Abbildung 20: Wissenschaftliche Mitarbeiterinnen und Mitarbeiter im Museum zur Geschichte des »Großen Vaterländischen Krieg", Minsk 1944, Fotografin/Fotograf unbekannt (C) BDMGVAV.

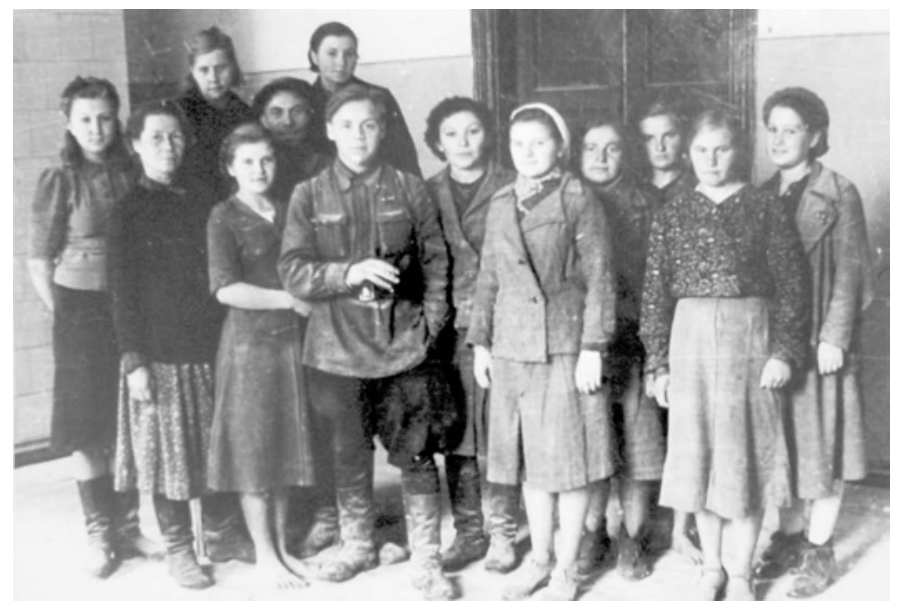

Das Foto des ersten Mitarbeiterstabes im Minsker Museum (Abb. 20), aufgenommen ebendort im Jahr 1944, gibt wertvolle Aufschlüsse über die soziale Zusammensetzung der ersten Generation von muzejščiki, die die Aufgabe der musealen Kriegskommemoration von der Historikerkommission übernahm. ${ }^{225}$ Laut der handschriftlichen Bezeichnung zeigt das Foto eine Gruppe »wissenschaftlicher Mitarbeiter«. Unter den 13 Personen befanden sich elf Frauen und zwei Männer. Mit Ausnahme der zweiten Person, links in der ersten Reihe, wirken die Angestellten ausgesprochen jung. Der Krieg hatte den Geschlechter- und Altersdurchschnitt stark verzerrt. ${ }^{226}$ Die enormen Anstrengungen des allgemeinen Wiederaufbaus mussten von einer physisch erschöpften und demoralisierten Gesellschaft geleistet werden, wobei in der »männerlosen Gesellschaft« eine außergewöhnlich

224 NARB, f. 1246, op. 1, d. 3, I. 22.

225 BDMGVAV, ND 26319.

2261947 waren nur 25 Prozent der Bevölkerung zwischen 16 und 60 männlich. Ungeachtet der Gleichstellungspropaganda wurden Frauen schlechter bezahlt. Vgl. Kashtalian, Iryna: The Repressive Faktors, S. 181-185. 
große Belastung auf den Frauen sowie den Kindern und Jugendlichen lag. Letztere mussten trotz Mangelerscheinungen, Krankheit oder seelischer Verletzungen vielfach zum Broterwerb beitragen. ${ }^{227}$ Die Zusammensetzung der muzejščiki entsprach der Nachkriegsrealität. Gleichzeitig stellte die Anstellung eine der wenigen Möglichkeiten zu überleben dar - insbesondere wenn der Arbeitsplatz mit Kost und Logis und der Ausgabe von Konsumgütern verbunden war. ${ }^{228}$ Der Abgleich mit anderen Archivquellen zeigt, dass die Mehrheit des ersten Mitarbeiterstabes unter 30 Jahre jung war. Auf dem Foto sticht ein junger Mann in Uniform aus der Mitte der Gruppe hervor. Selbstbewusst blickt er mit einer Zigarette in der Hand in die Kamera. Der Leiter für die Abteilung "Wissenschaftliche Museumsarbeit « Pëtr Loveckij war zum Zeitpunkt der Aufnahme 27 Jahre alt. Als die Wehrmacht die Republik überfiel, schloss er gerade sein Examen an der historischen Fakultät der Minsker Universität ab. Er floh aus der brennenden Stadt und versteckte sich in einem Dorf, wo er von einer Partisaneneinheit rekrutiert wurde. Als Anführer der Partisanenbrigade »Sturmvogel« hatte er sich über das in seinen Augen unsinnige Telegramm der historischen Kommission mit der Aufforderung, Objekte zu sammeln, beschwert. Spätere muzejščiki bezeichneten Loveckij als »Museumsveteranen«. Ab 1944 arbeitete er 40 Jahre lang im Museum, 14 Jahre davon als Direktor. $^{229}$ Rechts hinter ihm steht auf dem Foto Vera Romanovskaja. Sie war 20 Jahre jung, als der Krieg ausbrach und sie in die Untergrundbewegung eintrat. Später wurde sie Mitglied der Partisanenbrigade »Kalinin«, die Sabotageakte im Minsker Gebiet verübte. Auch sie wird mit über 40 Dienstjahren zu den »Museumsveteranen« gezählt. Sie war eine der ersten Museumsführerinnen und leitete bis 1986 die Abteilung Bildung und Vermittlung. ${ }^{230}$

Neben dem Alter der Fotografierten fällt auf den zweiten Blick auf, dass zwei der Mitarbeiterinnen keine Schuhe tragen (vorne links und hinten rechts). Interessanterweise tut das dem Gesamteindruck des Bildes keinen Abbruch: Hier positionierte sich eine Gruppe stolzer junger Menschen. Sie stellten sich der Größe nach auf; und für die zwei Frauen in der dritten Reihe waren vermutlich extra Stühle oder ähnliche Erhöhungen herbeigeholt worden, damit sie größer erschienen und auf das Gruppenbild passten. Zum Eindruck dieser Inszenierung trägt bei, dass sich die Frauen auf der linken Seite des Bildes zu der Gruppe drehten und

227 Katzer, Nikolaus: Die belagerte Festung, Wiederaufbau, Nachkriegsgesellschaft und innerer Kalter Krieg in der Sowjetunion, 1945 bis 1953, in: Osteuropa 3, 2000, S. 280-299, hier S. 287290.

Bucher, Greta: Struggling to Survive, Soviet Women in the Postwar Years, in: Journal of Women's History, Vol. 12, Nr. 1, 2000, S. 137-159.

229 Voronkova, Irina: Sozdanie i sostavlenie Belorusskogo Cosudarstvennogo Muzeja, S. 14.

230 Ebd. S. 14. 
die Fotografin oder der Fotograf das Bild aus einer leicht erhöhten Position aufnahm. Auch wenn die Kleidung abgewetzt, alt und etwas dreckig wirkt, so scheint es doch, als hätten sich die muzejščiki für dieses Foto ihre besten Blusen, Röcke und Uniformen angezogen.

Die Anstellung als muzejščik war identitätsstiftend und erfüllte sie mit Stolz. Demobilisierte Soldaten und Partisanen trugen ihre Uniformen noch viele Jahre nach dem Krieg - einerseits, weil sie möglicherweise nicht über andere Kleidung verfügten, andererseits, weil die Uniform ihren hohen gesellschaftlichen Status betonte. ${ }^{231}$ Dass nicht jeder oder jede über ein Paar Schuhe verfügte, war im Minsk der Nachkriegszeit nicht weiter bemerkenswert, im Gegenteil: Jemand, der genug Essen, ein Paar Schuhe und Kleidung hatte, galt als reich. ${ }^{232}$

Jedoch konnten und wollten nicht alle ehemaligen Kämpfer als muzejščiki arbeiten. Unter den bereits genannten wissenschaftlichen Museumsmitarbeitenden befand sich beispielsweise auch Vsevolod Sablin, der in seiner Partisaneneinheit für die Niederschrift der täglichen Chronik verantwortlich gewesen war und dessen literarische Tagebücher sich bis heute im Museum befinden. Er verließ das Museum bereits nach einem Jahr, um als Schriftsteller zu arbeiten. Auch der vielfach ausgezeichnete Partisanenführer Pëtr Gončarov wurde von Ponomarenko zur Museumsarbeit eingeteilt - eine Aufgabe, die er zunächst ablehnte, da er weiterhin an den Kämpfen teilnehmen wollte. Er arbeitete zwei Jahre als Kurator der Partisanenabteilung und verließ das Museum 1946, um eine Ausbildung an der Höheren Parteischule zu beginnen.

Diejenigen, die im Museum blieben, konnten aktiv und kreativ an der Eröffnungsausstellung des Museums mitwirken: Der ehemalige Rotarmist Sergej Romanov beispielsweise stellte seine Zeichnungen »Blätter des Kampfes« zur Verfügung, die er in der Partisaneneinheit geschaffen hatte, und fertigte im Auftrag des Direktors weitere Gemälde an. ${ }^{233}$

Der Alltag in Minsk war von einem extremen Mangel an den notwendigsten Alltagsdingen geprägt. Täglich standen die Menschen in endlosen Schlangen an, um überteuerte Grundnahrungsmittel zu erwerben. Die Wirtschaft lag am Boden, und sowohl die Nahrungsmittelversorgung als auch die medizinische Versorgung waren defizitär. Menschen, die eine Arbeit hatten, mussten mit großen Verzöge-

Kashtalian, Iryna: The Repressive Factors, S. 154.

Die meisten Kinder hatten keine Schuhe, da Industrieware nicht mit Rationierungskarten eingetauscht werden konnte. Kashtalian, Iryna: The Repressive Factors, S. 151-155.

Die »Boevye listi« von S. Romanov gelten heute als besonders wertvoller Bestand der Sammlung. Vgl. Voronkova, Irina: Sozdanie i sostavlenie Belorusskogo Gosudarstvennogo Muzeja, S. 13-14. Die anderen drei bislang identifizierten Mitarbeiter und ehemaligen Partisanen sind: Nikolaj. S. Abramov, A. S. Barchatkov, Oleg. V. Lucevič. 
rungen bei der Auszahlung ihrer extrem niedrigen Löhne rechnen und zusätzlich hohe Steuern und Abgaben zahlen. ${ }^{234}$

Die Anstellung im Museum bedeutete für die 28 wissenschaftlichen Mitarbeiterinnen und Mitarbeiter im Jahr 1944 große finanzielle und wirtschaftliche Erleichterungen. ${ }^{235}$ Sie wurden nach einem abgestuften Bonussystem bezahlt. Besonders herausragende Arbeit wurde mit 400 Rubeln, einem Pud Mehl und 80 kg Kartoffeln belohnt. ${ }^{236}$ In Anbetracht des durchschnittlichen (extrem geringen) Monatslohns von 250 bis 300 Rubeln im Jahr 1944 müssen die Honorare und Lebensmittelzugaben für die Museumsangestellten in der allgegenwärtigen Armut und Nahrungsmittelnot eine große Erleichterung dargestellt haben. ${ }^{237}$

Die Aufgaben, vor denen die unerfahrenen muzejščiki im Spätsommer 1944 standen, waren riesig: Woher sollten sie die Exponate nehmen? Woher das Material für den Ausstellungsaufbau, zum Beispiel für den Bau von Vitrinen? Und zuvorderst: Woher sollten sie die Expertise der musealen Praxis nehmen? Qualifizierte Mitarbeiterinnen und Mitarbeiter mit einer museologischen Ausbildung fehlten in den Museen des sowjetischen Belarus noch bis weit in die Nachkriegszeit hinein. ${ }^{238}$

Vor diesem Hintergrund erließ Museumsdirektor Stal'nov einen naheliegenden Befehl: Mit der Unterstützung Ponomarenkos entsandte er vier Mitarbeiter nach Moskau, um die im GIM verbliebenen Exponate der Ausstellung »Belarus

234 Kashtalian, Iryna: The Repressive Factors, S. 151.

235 Karasëva, N. (Hg.): Belaruski Dzjaržaŭny muzej, S. 12-13. Auch in der Verteilung von Rationierungskarten an die muzejščiki zeigte sich ihr privilegierter Status. Diese Karten wurden nur an Arbeiterinnen und Arbeiter der 1. und 2. Kategorie und an Angestellte besonders wichtiger Unternehmen verteilt. Mit den Karten konnten Lebensmittel zu einem wesentlich niedrigeren Preis als auf dem Markt oder in Ceschäften eingetauscht werden. Die Karten wurden mit der Währungsreform am 12. Dezember 1947 abgeschafft. Vgl. Kashtalian, Iryna: The Repressive Factors, S. 173.

236 Pud war ein russisches Gewichtmaß. 1 Pud entsprach 40 Pfund. Die fünf Mitarbeiterinnen und Mitarbeiter in der zweiten Preisklasse erhielten 300 Rubel, ein halbes Pud Mehl und 50 $\mathrm{kg}$ Kartoffeln. Auf der dritten und vierten Stufe wurden die Honorare und Lebensmittelpreise ein weiteres Mal halbiert. NARB, f. 1246, op. 1, d. 3, I. 30; NARB, f. 1246, op. 1, d. 3, I. 20.

237 Kashtalian, Iryna: The Repressive Factors, S. 151. Ein relationaler Vergleich zwischen dem Lohn und den Lebensmittelpreisen ist erst für das Jahr 1947 nach der Währungsreform möglich. Hier führt Irina Kashtalian folgende Preise pro Kilo an: 2,80-3,20 Rubel für Roggenbrot, 5,20 Rubel für Waschseife, 62-66 Rubel für Butter, 288 Rubel für ein Paar Männerschuhe, eine Uhr für 900 Rubel. Vgl. Kashtalian, Iryna: The Repressive Factors, S. 177.

238 Auch wenn entsprechend der Anforderungen des Fünfjahresplans zum Wiederaufbau und zur Entwicklung der Volkswirtschaft der SSSR (1946-1950) 64 Prozent der belarussischen Museen der Vorkriegszeit wiedereröffnet und die entsprechenden Stellen besetzt waren, weist der Bericht des Komitees darauf hin, dass die Angestellten weder Arbeitserfahrung noch eine auf Museen spezialisierte Ausbildung hatten. Vgl. Lesnaja, Olga: Muzejnaja politika BSSR v poslevoennoe pjatiletie, in: VGU imeni P. M. Mašerova (Hg.): Učenye zapiski UO, 202015 , S. $95-99$. 
lebt, Belarus kämpft ...« nach Minsk zu holen. ${ }^{239}$ Stal'nov stellte den jungen und unerfahrenen muzejščiki die Kunsthistorikerin Elena Aladova an die Seite. Sie sollte eine weitere belarussische Ausstellung aus Moskau holen: Die Tret'jakov-Galerie hatte während des Krieges eine Jubiläumsausstellung belarussischer Künstler mit dem Titel »25 Jahre BSSR « gezeigt. Diese Bilder müssen Aladova als geeignete Basis für ihre Gemäldegalerie erschienen sein. Allerdings stellte Stal'nov die Bedingung, dass die besten Gemälde der Ausstellung an das Kriegsmuseum gehen würden. ${ }^{240}$ Aladova verfügte dank ihrer Arbeit im GIM über beste Kontakte zu den Moskauer Museen, die den Minsker muzejščiki von großem Nutzen waren. Museumsdirektor Stal'nov schickte seine kundigsten Mitarbeiterinnen und Mitarbeiter auf eine dreiwöchige Dienstreise, die weit mehr als den Transfer der beiden Ausstellungen beinhaltete. ${ }^{241}$ Sie sollten den wissenschaftlichen Kontakt und die Zusammenarbeit mit den wichtigsten Moskauer Museen etablieren und zur eigenen Orientierung die aktuellen Ausstellungen über den »Großen Vaterländischen Krieg« besuchen, darunter auch die Trophäen-Ausstellungen des Museums der Roten Armee im Gorki-Park. Als Ausdruck der Zusammenarbeit wurden den Moskauer Museen Dubletten (Plakate, Fotos) und andere Exponate (Partisanengewehre), die den Museen in ihrer Sammlung fehlten, übergeben. ${ }^{242}$ Das GIM drückte seine Unterstützung für das junge Museum aus, indem es die Sammlung mit Kunstdrucken und Fotos bereicherte. ${ }^{243}$ Außerdem deckten sich die Minskerinnen und Minsker mit der wichtigsten Literatur zum Krieg ein und erhielten von dem Museumsinstitut methodische Instruktionen zum Aufbau von Ausstellungen. Dieser Kontakt war ausgesprochen wichtig, da die unerfahrenen Minsker muzejščiki bei dieser Gelegenheit methodische Handbücher zur Sammlungsstrategie und Ausstellungsgestaltung konsultieren konnten. Nicht zuletzt gaben sie im besten Atelier für Kriegskunst, dem renommierten Grekov-Studio, fünf prestigeversprechende Kunstwerke in Auftrag. ${ }^{244}$

239 BDMGVAV, op. 5, d. 24, I. 5-6.

240 Ebd. I. 6.

241 Er schickte seinen Stellvertreter und Leiter der Abteilung »Wissenschaftliche Arbeit« Vsevolod Sablin, der während des Krieges als sogenannter Literatur-Arbeiter die Partisanenkämpfe künstlerisch dokumentiert hatte, seinen Sammlungsleiter Stupin, den Leiter der Sammlung »Front« und ehemaligen Spion und Partisan Nikolaj Abramov und den Künstler Oleg Lucevič. VgI. BDMCVAV, op. 5, d. 24, I. 6.

242 Irina Voronkova nennt 36 »künstlerische Plakate«und 83 »Kriegsfotografien«. Vgl. Voronkova, Irina: Sozdanie i sostavlenie Belorusskogo Cosudarstvennogo Muzeja, S. 15. BDMGVAV, op. 5, d. 24, I. 6.

244 Darunter der berühmte Künstler Nikolaj Žukov, der seit seiner Auszeichnung mit dem StalinPreis 1943 mit der künstlerischen Leitung des Crekov-Studios beauftragt war, vgl. BDMCVAV, op. 5 , d. 24 , I. 6. 
In Minsk erhielt unterdessen der stellvertretende Museumsdirektor Sablin den Auftrag, das Personal für die zukünftigen Museumsabteilungen festzulegen. ${ }^{245}$ Seine Aufstellung spiegelt in Anbetracht des großen Mangels an Material und Fachkräften einen idealen Anspruch an eine museale Infrastruktur, die zumindest auf dem Papier eine vorbildliche Museumsführung suggerierte. Sablin hatte an alles gedacht: Neben den inhaltlichen Ausstellungsabteilungen beauftragte er die Einrichtung von Kunst-, Sammlungs- und Redaktionsabteilungen, ein Büro für Ausstellungsführungen, einen Vortragssaal, ein Fotostudio und eine Bibliothek. Auch der hauswirtschaftliche Teil wurde mit der Einrichtung einer Buchhaltung, einer Werkstatt für Restaurationen, einer Tischlerei, einer Schlosserei, einem Heizraum, Wachtmeister, Garderobenfrauen und Putzpersonal bedacht. ${ }^{246}$

Die muzejščiki standen unter großem zeitlichem Druck. Bereits Anfang August 1944 kündigte das Parteiorgan »Stern« die fünf zukünftigen Themen des neuen Kriegsmuseums an: "1. Belarus am Vorabend des Krieges, 2. Die deutsche Besatzung, 3. Belarussische Soldaten an den Fronten des Großen Vaterländischen Krieges, 4. Die Partisanenbewegung in Belarus, 5. Der Wiederaufbau der Landwirtschaft. ${ }^{247}$

Als die Museumsleitung Anfang Oktober 1944 den ersten Ausstellungsplan ihres Museums verfasste, ergänzte sie diese Struktur. ${ }^{248}$ Man plante eine chronologische Dauerausstellung, die mit der Abteilung »Belarus vor dem Krieg« beginnen und mit der Abteilung "Der Wiederaufbau des sowjetischen Belarus« enden sollte. Dazwischen gab es vier Abteilungen, die der Anfangsphase des Krieges, der Besatzungszeit, der Partisanenbewegung und der Befreiung von Belarus gewidmet waren. ${ }^{249}$ Diese sechs Abteilungen sollten bis zum Jahresende 1945 fertiggestellt und das Museum zunächst mit temporären Sonderausstellungen eröffnet werden. Eine Woche später wurden diese Pläne wieder verworfen und die Museumsleitung befahl, das Museum mit zwei Sonderausstellungen über die »Gräueltaten der Deutschen in Belarus « und über "Die Helden des Wiederaufbaus von Minsk « zu eröffnen. ${ }^{250}$ Die sich widersprechenden Anweisungen spiegeln die chaotischen Oktoberwochen vor der Museumseröffnung wider, in denen die inhaltliche Ausrichtung

NARB, f. 1246, op. 1, d. 3, I. 12.

246 Ebd.

247 Zvjazda, 5. August 1944. Diese Ausgabe gilt im NARB als verschollen. Zitiert nach: Voronkova, Irina: Sozdanie i sostavlenie Belorusskogo Gosudarstvennogo Muzeja, S. 18.

248 NARB, f. 1246, op. 1, d. 2, I. 7-9.

249 1. Abteilung: »Belorus' dovoennaja«, 2. Abteilung: »Voenno-frontovoj«, 3. Abteilung: »Belorus' pod igom nemcko-fašistkoj okkupacii«, 4. Abteilung: »Partizanskoe dviženie«, 5. Abteilung »Osvoboždenie Belorussii ot nemeckich zachvatčikov«, 6. Abteilung: »Vosstanovlenie sovetskoj Belorussii«, in: NARB, f. 1246, op. 1, d. 2, I. 7-9. NARB, f. 1246, op. 1, d. 2, I. 22. 
des Museums verhandelt wurde. Mit welchem Thema sollte die museale Kriegserinnerung in Minsk beginnen? Mit einem Fokus auf das Leid und einer Betonung der Opfererfahrung oder mit einer Darstellung, die die Bevölkerung zum Wiederaufbau ihrer Stadt motivierte? Mit einer Präsentation der Untergrundpresse, die das Überleben der kommunistischen Geisteshaltung während der deutschen Besatzung dokumentierte oder mit einer Ausstellung über die selbstgebauten Waffen, die den kreativen Kampfgeist der Partisaninnen und Partisanen bewies? ${ }^{251}$

Diese Diskussionen trafen den Kern der ambivalenten Erinnerungspolitik der sowjetischen Nachkriegszeit unter Stalin, die von unausgesprochenen Grenzen des Sagbaren geprägt war. Die jungen Minsker muzejščiki befanden sich bei ihrer Ausstellungsplanung in erinnerungspolitischen Dilemmata, die spezifisch für ihre agency unter den Bedingungen des Spätstalinismus in Belarus waren. Als Überlebende der deutschen Besatzungszeit standen sie unter dem Generalverdacht der Kollaboration und waren gut beraten, eine Ausstellung über den Widerstand gegen die deutschen Behörden $\mathrm{zu}$ inszenieren. Gleichzeitig konnte Widerstand schwerlich ohne eine Darstellung der Opfer gezeigt werden, und hier tauchten unweigerlich neue Hindernisse auf: Einerseits stand der Fokus auf das (zivile) Leid grundsätzlich im Widerspruch zur allgemein gewünschten Hochstimmung des Wiederaufbaus. Andererseits verwies die Darstellung von deutschen Gräueltaten auf die spezifische Kriegserfahrung der Jüdinnen und Juden - ein Thema, das die sowjetischen Medien zwar nicht gänzlich aussparten, aber tendenziell mieden. ${ }^{252}$

Theoretisch mussten die muzejščiki alle Pläne und Ausstellungskonzeptionen dem ZK zur Kontrolle vorlegen. Für eine weitgehend selbständige Erarbeitung der inhaltlichen Ausrichtung der Ausstellung spricht jedoch, dass Stal'nov und Sablin ihren Ausstellungsplan erst zwei Tage nach der Eröffnung ihres Museums der

251 Für die Eröffnung der Ausstellung der Waffen- und der Untergrundpresse, die für den 3. Oktober1944 geplant war, vgI. NARB, f. 1246, op. 1, d. 2, I. 7-9. Am 9. Oktober erließ der Museumsdirektor zwei Befehle, einen, der die Eröffnung der Waffen- und Untergrundpresseausstellung ankündigte (Befehl 67/71), und einen, der die Eröffnung der Abteilungen über den Vernichtungskrieg und den Wiederaufbau für den 7. November 1944 ankündigte: NARB, f. 1246, op. 1, d. 3, I. 20; NARB, f. 1246, op. 1, d. 3, I. 22.

252 Zur ambivalenten Tendenz der Universalisierung bzw. Homogenisierung der Opfergruppen im »Großen Vaterländischen Krieg« mit dem Ziel, die Spezifik des Holocausts in der nationalsozialistischen Vernichtungspolitik zu verdecken, vgl. Weiner, Amir: Making Sense of War, The Second World War and the Fate of the Bolshevik Revolution, Princeton 2001, S. 209-216; Berkhoff, Karel C.: Total Annihilation of the Jewish Population, The Holocaust in the Soviet Media, in: Kritika: Volume 10, 1 Winter 2009, S. 61-105; Altshuler, Mordechai: The Holocaust in the Soviet Mass Media during the War and in the First Postwar Years Re-examined, in: Yad Vashem Studies, 39, 2011, S. 121-168; Löwe, Heinz-Dietrich: The Holocaust in the Soviet Press, in: Grüner, Frank/Heftrich, Urs/Löwe, Heinz-Dietrich (Hg.): Zerstörer des Schweigens, Formen künstlerischer Erinnerung an die nationalsozialistische Rassen- und Vernichtungspolitik in Osteuropa, Köln/Weimar/Wien 2006, S. 33-55. 
Partei zur Bestätigung vorlegten. ${ }^{253}$ Der große zeitliche Druck, unter dem die $m u$ zejščiki standen, zeigte sich auch in den sich widersprechenden Eröffnungsdaten: Zuerst wurde der Eröffnungstermin des Museums vom 3. Oktober auf den 15. Oktober 1944 verschoben, dann wurde die Eröffnung auf den Feiertag der Oktoberrevolution (7. November) festgelegt, doch schließlich eröffnete das Museum bereits am 22. Oktober 1944. Zwei Jahre zuvor, auf den Tag genau, hatte das Oberkommando der Wehrmacht im selben Gebäude die Propagandaausstellung »Neues Deutschland « eröffnet, die mit der Darstellung der neuen Ordnung des »Tausendjährigen Reiches « um die Gunst der Minsker Bevölkerung warb. ${ }^{254}$ Ob diese terminliche Parallelität in den Überlegungen zum Eröffnungsdatum eine Rolle spielte oder eine Ironie der Geschichte ist, lässt sich nicht abschließend feststellen, da sie in den Quellen nicht kommentiert wird. In Anbetracht der sowjetischen Tradition, die Eröffnung von geschichtspolitisch relevanten Einrichtungen auf staatslegitimierende Feiertage zu legen - und hierbei galt der Tag der Oktoberrevolution als der wichtigste -, überrascht die Vorverlegung der Eröffnung durch die Museumsdirektion. Ein Grund für die Verschiebung könnte in folgender Terminkollision gelegen haben: Die muzejščiki des Kriegsmuseums arbeiteten zeitgleich an einer Ausstellung mit, die von dem Generalmajor der Artillerie der Roten Armee gewünscht wurde. Auf dem Vorplatz des zweiten unzerstörten Gebäudes der Stadt - dem »Haus der Roten Armee« - errichteten Verbände, die an der Befreiung von Minsk teilgenommen hatten, eine riesige Ausstellung, in der sie ihre Kriegstrophäen präsentierten. ${ }^{255}$

Am Sonntag, dem 22. Oktober 1944 um 12 Uhr Mittag war es so weit, das »Staatliche Belarussische Museum zur Geschichte des Großen Vaterländischen Krieges« eröffnete in 15 renovierten Sälen seine zwei ersten Sonderausstellungen zu den »Selbstgebauten Waffen der belarussischen Partisanen« und zu der »Bolschewistischen Presse im belarussischen Untergrund in den Jahren der deutschen Besatzung ${ }^{256}$ Die Museumsleitung hatte sich also für Eröffnungsausstellungen entschieden, die das Narrativ ihres Schirmherren Pantelejmon Ponomarenko über

NARB, f. 1246, op. 1, d. 2, I. 1-6. Hier ist die Ausstellungsstruktur erneut um weitere Unterthemen ergänzt.

254 Ausstellung Neues Deutschland, Artikel in der deutschen Besatzungszeitung »Minsker Zeitung«: Weißruthenen erleben Deutschland im Bilde, Heute Eröffnung der vielseitigen Ausstellung des OKW in Minsk. Zu den Selbst- und Fremdbildern in der nationalsozialistischen Besatzungspresse vgl. Burmistr, Svetlana: Die »Minsker Zeitung«, Selbst- und Fremdbilder in der Nationalsozialistischen Presse, Berlin 2016.

Für die Republiksausstellung der Kriegstrophäen vgl. Voronkova, Irina: Sozdanie i sostavlenie Belorusskogo Cosudarstvennogo Muzeja, S. 24-26, sowie: Ohne Autor: Rèspublikanskaja vystaŭka uzoraŭ trafejnaga uzbraenna, in: Zvjazda, 11. November 1944. 
die kommunistische Parteilichkeit im Untergrund und über den aktiven Partisanenkampf bestärkten. Während die Hintergründe für die Themensetzung auf der Quellengrundlage nicht abschließend geklärt werden können, so lassen sich doch zwei Vermutungen anführen, die die muzejščiki bei dieser Wahl beeinflusst haben könnten. Erstens waren die erinnerungspolitischen Linien in Bezug auf die Kommemoration von Kämpferinnen und Kämpfer eindeutiger als diejenige der zivilen Opfer. Bei Letzteren blieben die Möglichkeiten bis zum sogenannten »Tauwetter « ambivalent und stellten damit ein Risiko für die unerfahrenen Museumslaien dar. ${ }^{257}$ Zweitens bestand laut dem Historiker Arkadi Zeltser unter der Generation der Überlebenden ein gewisser Unwille, an bestimmte Episoden der Besatzungszeit zu erinnern:

»The desire to keep silent was most likely felt by those who had served in the Red Army, or by the partisans, and all the more so by those who had participated in looting, plunder of the civilian population, and violence against women. [...] Among those who had lived in the occupied territories (and not just police personnel and their families, but >ordinary< people), there were probably relatively few who truly remained sbystanders and thus, there was much that they would not wish to remember. ${ }^{258}$

Am Tag der Eröffnung war der Museumseingang mit traditionellen belarussischen Motiven festlich geschmückt und vom Balkon hing ein großes Stalinporträt. ${ }^{259}$ Zehn Säle hatten die muzejščiki für die Sonderausstellung zu den selbstgebauten Partisanenwaffen inszeniert. Der aus Moskau angereiste Korrespondent der »Pravda« schrieb begeistert:

»Hier gibt es nichts, was es nicht gibt! Was für ein spannendes Buch könnte man für die heranwachsende Generation angesichts dieser Maschinengewehre, Pistolen und Granaten schreiben. Aus den von Partisanenhänden gesammelten Schräubchen und Rädchen sind vielfältige und fantasievolle Formen noch nie

257 Als Beleg für diese ambivalente Erinnerungspolitik, die die Kommemoration militärischer Opfer förderte und die der zivilen Opfer vernachlässigte, führt Arkadi Zeltser den Erlass der sowjetischen Behörden für eine Verbesserung und Pflege der Crabstätten der Soldaten und Partisanen vom Februar 1946 an und verweist auf die zwei bekanntesten Grabstätten ziviler Opfer (die Gedenkstätte Babi Yar in Kiew und den Piskarevskoe Friedhof in St. Petersburg), die, obwohl die Finanzierung in beiden Fällen bereits 1945 gesichert war, im Zuge der antisemitischen spätstalinistischen Repressionen 1948 bzw. 1949 verhindert wurden. Vgl. Zeltser, Arkadi: Unwelcome Memory, S. 92-93. Das heikle Thema der Mittäterschaft entlud sich in der Nachkriegszeit häufig in Streitigkeiten um das Eigentum von Verstorbenen oder zurückkehrenden Flüchtlingen. Vgl. Exeler, Franziska: »What did you do during the war?«, S. 805-835. 
gesehener Konstruktionen entstanden. Von den über 70 ausgestellten Maschinengewehren gleicht keines dem anderen. « 260

Besonders große Aufmerksamkeit erfuhr der Waffenmeister Jakov Temjakov, der in der Pinsker Partisaneneinheit 102 Gewehre aus den unterschiedlichsten Materialien gefertigt hatte. Eines seiner einzigartigen Exemplare war ein Gewehr, das er aus dem Rahmen eines erbeuteten deutschen Fahrrads, der eisernen Felge eines Fasses, den Kleinteilen eines abgeschossenen deutschen Flugzeugs und aus einem Kuhhorn gefertigt hatte. Geschwärzt hatte er die Waffe mit einem abgekochten Sud aus Zwiebelschalen und Birkenholz. ${ }^{261}$

Eine Aufnahme (Abb. 21) zeigt die muzejščiki vor dem Kernstück der Sonderausstellung, einer Installation selbstgebauter Partisanengewehre. Ein Exponat in der Hand, erklärt der ehemalige Kommandeur der Partisaneneinheit Pëtr Gončarov der Museumsführerin Vera Romanovskaja die Funktionsweise der Waffe. ${ }^{262}$

Abbildung 21: Pëtr Gončarov und Vera Romanovskaja in der Sonderausstellung »Die selbstgebauten Waffen der Partisanen«, Minsk 20. Juli 1944, Fotografin/Fotograf unbekannt (C) BDMGVAV.

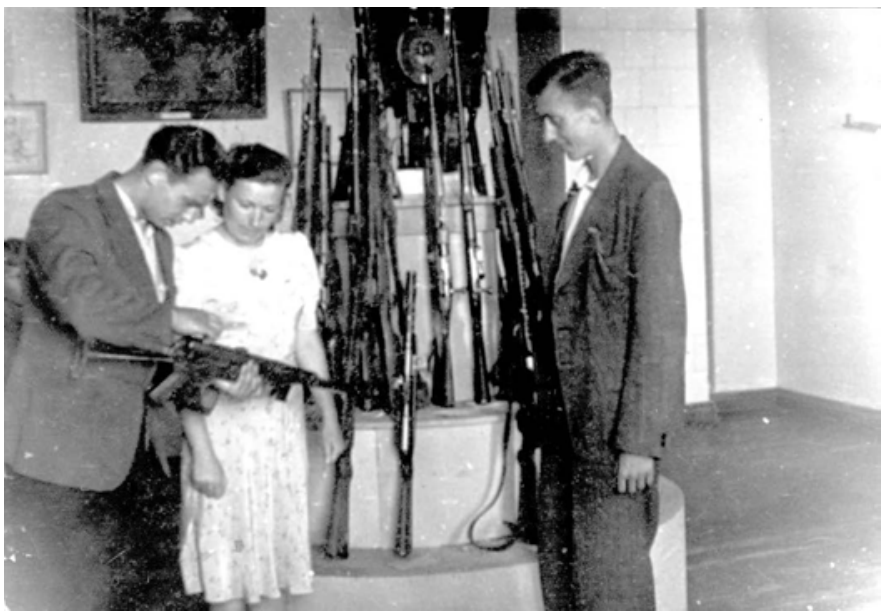

Während die erste und sehr viel größere Eröffnungsausstellung die Waffen bzw. die Kreativität und den Erfindergeist der Partisaninnen und Partisanen ausstellte, widmete sich die zweite der Untergrundpresse im Krieg. Am Eingang der

260 Ebd.

261 Voložinskij, Vladimir: Muzej Velikoj Otečestvennoj vojny (staryj).

262 BDMGVAV, kp. 66403, f. 9857. 
Sonderausstellung »Die bolschewistische Presse in Belarus « lasen die Besucherinnen und Besucher ein Zitat des beliebten belarussischen Dichters Janka Kupala: "Das belarussische Volk lebt in seiner Macht und in seiner Herrlichkeit. ${ }^{263}$ Die vielen ausgestellten Zeitungen, die heimlich und unter Lebensgefahr während der deutschen Besatzung produziert worden waren, waren teilweise auf Tapeten und Geschenkpapier gedruckt, was in den Augen der Betrachterinnen und Betrachter möglicherweise ihren wertvollen Status und die klandestinen Bedingungen ihrer Herstellung unterstrich. Diese Zeitschriften und Almanache eigneten sich besonders für das Thema der Eröffnungsausstellung, da sie als erste Quellen das Geschehen vor Ort dokumentiert und bezeugt hatten. Belegt ist das große Interesse des damaligen Publikums für die von Hand gemalten und geschriebenen bunten Wandzeitungen, Plakate, politischen Karikaturen, Flugblätter, Zeichnungen, Porträts, Gedichte, Tagebücher und Chroniken. ${ }^{264}$ Aufgrund ihres hohen künstlerischen Anspruchs haben diese handgefertigten Quellen bis heute eine ganz eigene ästhetische Wirkung, die in der Sorgfalt und Detailtreue liegt, mit denen die Zeichnungen aus dem Partisanenalltag gestaltet wurden. ${ }^{265}$

Der Eindruck einer wirklichkeitsgetreuen Ausstellung wurde von der Aura der anwesenden muzejščiki verstärkt, die selbst ehemalige Kämpferinnen und Kämpfer waren und die ausgestellten Ereignisse bezeugen konnten. Diese Zuschreibung wurde von oberster Stelle tatkräftig unterstützt. Das kommunistische Oberhaupt der Stadt Iosif Bel'skij würdigte die Ausstellungen in der »Pravda« wie folgt: »Im Museum des Vaterländischen Krieges haben zwei ausgezeichnete Ausstellungen über die Waffen der Partisanen und die bolschewistische Untergrundpresse eröffnet. Diese Ausstellungen wurden von den Händen der ehemaligen Partisanen geschaffen. ${ }^{266}$

263 Voronkova, Irina: Sozdanie i sostavlenie Belorusskogo Cosudarstvennogo Muzeja, S. 22-23.

264 Grigorev'eva, E.: Svedčanni geraičnai barac'by u Belaruskim muzej vjalikau aičinnau vainy, in: Zvjazda, 22. Oktober 1944.

265 Die Kollektion der sogenannten »Partisanen-Almanache« stellt eine Rarität innerhalb der Museumssammlung dar. Vgl. Filippovič, Natal'ja: Partizanskij Al'manach, Minsk 2009. Das Thema »Untergrundpresse« wird bis heute in den belarussischen Ausstellungen gezeigt. Im Unterschied zu den sowjetischen Ausstellungen werden die Redakteure namentlich genannt. Vgl. Keding, Ekaterina: Sieghafter Durchbruch oder vernichtende Niederlage? Deutsche Besatzung, sowjetischer Partisanenwiderstand und Kollaboration in Museen des Vitebsker Cebiets. In: Makhotina, Ekaterina u.a. (Hg.): Krieg im Museum, Präsentationen des Zweiten Weltkriegs in Museen und Gedenkstätten des östlichen Europa. Cöttingen 2015, S. 29-59, hier S. 44. Filippovič, Natal'ja: Partizanskij Al'manach, S. 2 und S. 175. 
Abbildungen 22 und 23: Belarussische Partisanen-Journale, Februar 1942 bis Juni 1944 und »Wie man eine Grippe heilt", Seite aus dem Journal der Rogačevskie Partisanen, Homeler Gebiet Juni 1944 (C) BDMGVAV.
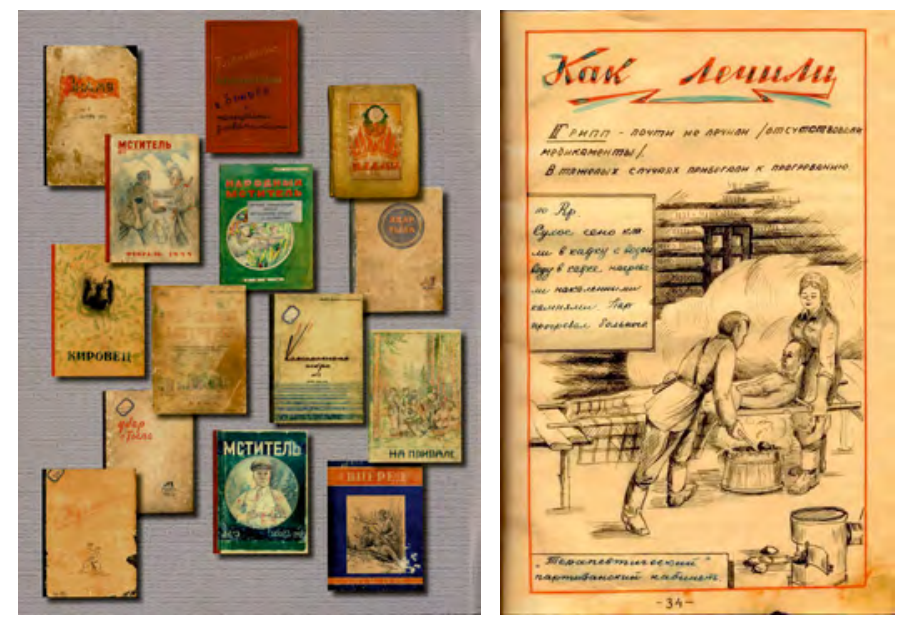

Motiviert von dem Erfolg der zwei Sonderausstellungen versprach Direktor Stal'nov drei Tage nach Museumseröffnung weitere Sonderausstellungen: »Wir, die Arbeiter des Museums Großer Vaterländischer Krieg, verwenden all unsere Kräfte [...], um ausführlich alle Seiten der Geschichte vom Kampf des belarussischen Volkes mit den deutschen Eroberern in den Tagen des Großen Vaterländischen Krieges zu zeigen. ${ }^{267}$

\section{Vernichtungskrieg und Holocaust. Eine Sonderausstellung im November 1944}

Nur einen Monat später, Mitte November 1944, eröffnete das Minsker »Museum zur Geschichte des Großen Vaterländischen Krieges« eine weitere Sonderausstellung, die den Titel »Belarus unter dem Joch der deutschen Besatzer «trug. ${ }^{268}$ Dieser the-

267 Stal'nov, Vasilij: Belaruski dzjaržauny muzej gistoryi vjalikai aičinnaj vainy, in: Zvjazda, 25. Oktober 1944.

268 Die Ausstellungseröffnung wurde in der Parteipresse »Stern « angekündigt: Ohne Autor: U belaruskim dzjaržaǔnym muzej gistoryi aičynnaj vajny, Zvjazda, 17. November 1944. Die Dauerausstellung, die fortlaufend angepasst und erweitert wurde, bestand aus sechs grundlegenden Kapiteln: 1. »Belarus vor dem Krieg«, 2. »Militär und Front«, 3. »Belarus unter dem Joch der deutschen Besatzung «, 4. »Die Partisanenbewegung«, 5. »Die Befreiung Belarus' von den deutschen Eindringlingen«, 6. »Der Wiederaufbau des sowjetischen Belarus«. Die Ausstellung sollte bis zum Jahresende 1945 fertiggestellt sein. Jedes Kapitel wurde zunächst als 
matische Fokus auf das Leid, der Zivilbevölkerung unter der Besatzungsherrschaft widerfahren war, ist für die hier untersuchte museale Kriegskommemoration einmalig und in der Forschung bislang unbekannt. Die Sonderausstellung, für die der ehemalige Partisan Pëtr Loveckij verantwortlich zeichnete, soll daher im Detail rekonstruiert werden. Die muzejščiki inszenierten diverse Aspekte des Leids unter der deutschen Besatzungsherrschaft. Dabei sparten sie den Holocaust nicht aus, sondern benannten ihn explizit. Verschiedene Versionen der sogenannten »Thematischen Ausstellungspläne« ermöglichen die Rekonstruktion des Inhaltes und der Objekte in den neun Sälen, die folgende Titel trugen:

»1. Saal: Die Zerstörung der Städte und der Industrie in der Belarussischen Republik

2. Saal: Die deutsche Agrarpolitik und die Zerstörung der Dörfer in der belarussischen Republik

3. Saal: Die Zerstörung der belarussischen Kultur

4. Saal: Die Gräuel der Deutschen am belarussischen Volk

5. Saal: Die Gräuel der Deutschen am jüdischen Volk (nad evrejskim narodom). Das Chetto

6. Saal: Sowjetische Soldaten in deutscher Kriegsgefangenschaft

7. Saal: Der SD

8. Saal: Die Todeslager

9. Saal: Die Verschleppung in die deutsche Sklaverei. ${ }^{269}$

Innerhalb welcher Diskurse über die Besatzungsherrschaft arbeiteten die muzejšči$k i$, als sie im Herbst 1944 die Ausstellungspläne verfassten? Was wussten sie zu diesem Zeitpunkt über das Ausmaß der Zerstörung des deutschen Vernichtungskrieges und welche Objekte standen ihnen für die Präsentation zur Verfügung? Kurz, in welchem Kontext der historiographischen Aufarbeitung der Besatzungszeit bewegten sich die Kuratorinnen und Kuratoren und welchen Einfluss hatten sie auf denselben? Die Provenienz der Objekte und ihre Inszenierung in den neun Sälen, von denen jeder bis zu 30 Exponate präsentierte, geben Aufschluss über diese Fragen. Der Ausstellungsplan zeigt, dass die Sonderausstellung, wie alle sowjetischen Kriegsausstellungen, in den allgemeinen Diskurs des »Großen Vaterländischen Krieges « eingebettet war. Gleichzeitig enthielt sie jedoch weitreichende neue Themen, die die muzejščiki für den spezifischen Kontext der belarussischen Sowjetrepublik selbst geschaffen hatten. Der Plan legt eine übergreifende Ordnung bei

Sonderausstellung präsentiert und dann in die Dauerausstellung überführt. Vgl.: BDMGVAV, d. 89, I. 2-3 (alte Signatur).

269 Es sind zwei thematische Pläne des dritten Ausstellungskapitels überliefert. Für die Ausstellungsanalyse beziehe ich mich auf den späteren und ausführlicheren Plan (b), der bis auf eine Seite vollständig vorliegt: BDMGVAV, d. 89, I. 20-41 (alte Signatur). 
der Strukturierung der einzelnen Säle offen: Jeder Saal eröffnete und schloss mit einem politischen oder literarischen Zitat. Der erste Saal eröffnete mit einem Zitat aus der ersten Kriegsrede Stalins vom 3. Juli 1941. Die muzejščiki zitierten die zentrale Passage, in der Stalin die tödliche Dimension des Krieges offenbarte und das sowjetische Volk zu einem Kampf für die Freiheit und gegen die deutschen Angreifer aufrief. ${ }^{270}$ Anschließend gingen die Besucherinnen und Besucher an ausgestellten Brandbomben vorbei, die die Nazis bei ihrem ihren Angriffen auf Minsk abgeworfen hatten. ${ }^{271}$ Die Zerstörungskraft dieser Bomben wurde ihnen in einer Vielzahl von Tabellen und Diagrammen demonstriert, die durch großformatige Fotos ausgebombter Städte und Industriebetriebe des Landes ergänzt wurden. ${ }^{272} \mathrm{Als}$ literarischer Epilog des Saals war ein Auszug aus dem bekannten Gedicht »Belarus« von Pjatrus' Broŭka (1905-1980) ausgestellt. ${ }^{273}$ Interessanterweise zählten die ausgewählten zwei Strophen zu den wenigen persönlichen Versen der insgesamt 100 Strophen des Gedichtes. Hier drückte der Dichter seinen eigenen Schmerz über die Zerstörung, die die Deutschen dem Land und den Menschen zugefügt hatten, aus:

»Mein Herz ist von Schmerz und Leid ergriffen, Ich werde es nie vergessen, Belarus,

Wie die Winde heulten, wie die Flüsse weinten,

Wie durch die Felder die blutigen Wellen liefen.

Wie die Wolken am Himmel das Morgenrot verschlossen.

Wie die Arbeit von Jahrhunderten zerstört wurde, Wie die tödliche Finsternis und Gräßlichkeit über der Stadt lagen,

Wie tödliche Explosionen die Straßen zerstörten,

Wie die toten Kinder in Ruinen kalt wurden,

Wie die Sonne hinter den Wolken unsichtbar war. ${ }^{274}$

270 Ebd. I. 29. Beginn und Ende des ausgestellten Zitates: »Vrag šestok i neumolim. [...] ili vpast' v poraboščenie.«Russische Abschrift der Radioansprache unter: www.sovmusic.ru/text.php? fname=st_30741 (Stand: 31.07.2021).

271 Für diese Exponate hatte der stellvertretende Direktor Sablin im Oktober 1944 beim Kommandanten des »Trophäen-Bataillons « angefragt. Auch in diesem Fall kam dem Museum die militärische Ausbildung seiner Angestellten zugute. Sablin erwähnte in dem Schreiben, dass die Bomben ggf. auch von den Museumsmitarbeitenden entschärft werden könnten, falls innerhalb des Bataillons keine verfügbaren Kapazitäten vorhanden seien. Vgl.: NARB, f. 1246, op. 3, d. 5, I. 99.

272 BDMGVAV, d. 89, I. 20; 22, (alte Signatur).

273 Weitere Informationen zu Pëtr Broŭka (Petrus Brovka ist sein literarisches Pseudonym): http s://ru.wikipedia.org/wiki/Бровка,_Пётр_Устинович (Stand: 31.07.2021).

274 Broŭka, P.: Belarus', Strophe 74-75. Dankenswerterweise von Tatjana Pavic Olenina aus dem Belarussischen übersetzt. 
Im Gegensatz zu den anderen Strophen des Gedichts, die die heldenhafte Vergangenheit der sowjetischen Republik, die Waffenbrüderschaft mit den anderen Völkern der Sowjetunion und die Führung Stalins im Kampf beschworen, drückten diese Strophen individuellen Schmerz und Wut aus. Die Menschen fanden nach der Betrachtung der ausgestellten Zerstörung ein Echo ihrer Wahrnehmung in der Lektüre des Gedichtes voller Trauer von einem ihnen vertrauten Dichter. Die Strophen waren, wie weitere Gedichte in den folgenden Sälen, als einzige Texte der Ausstellung auf Belarussisch und nicht auf Russisch verfasst, was die vertraute Wirkung der Zeilen zusätzlich verstärkte, da die Menschen in ihrer eigenen Sprache angesprochen wurden. ${ }^{275}$

Während die vielfach reproduzierten Kriegsreden Stalins vergleichsweise einfach in Ausstellungen zu inszenieren waren, so können die Provenienzen der anderen Ausstellungsstücke Aufschluss über die museale Praxis der Minsker muzejščiki geben. Die Mehrheit der Exponate kreierten bzw. sammelten die muzejščiki selbst. Der Ausstellungsplan vermerkt nüchtern, dass die deutschen Brandbomben in Minsk "gefunden« wurden. Die Fotografien, Tabellen und Diagramme wurden von den wissenschaftlichen Mitarbeitenden selbst erstellt. ${ }^{276}$ Bei der Auswahl der Strophen des Broǔka-Gedichts zeigt sich der Charakter, den die muzejščiki der Ausstellung gaben: Sie inszenierten die Verse, die ihres Erachtens den Inhalt des ersten Saales am besten zusammenfassten. Der Dichter war den muzejščiki aufgrund seiner Texte, die er in den Periodika der Roten Armee und der Partisaneneinheiten während des Krieges veröffentlichte, bekannt. Es ist anzunehmen, dass sie sich bei der Ausstellungsplanung an das erst kurz vor der Ausstellungseröffnung publizierte Gedicht von Broŭka erinnerten. ${ }^{277}$ Mit dieser literarischen Ausrichtung orientierten sich die muzejščiki höchstwahrscheinlich an den Inszenierungen der Sonderausstellung »Belarus lebt, Belarus kämpft ...«. In ihrer Moskauer Sonderausstellung hatte die Historikerkommission der Darstellung der Kultur und insbesondere der belarussischen Dichtung ein Ausstellungskapitel gewidmet.

Im zweiten Saal, der die Agrarpolitik der deutschen Besatzer ausstellte und sie als Zerstörung der belarussischen Landwirtschaft darstellte, lasen die Besucherinnen und Besucher ein Zitat des zweitwichtigsten politischen Führers der Sowjetunion. Es handelte sich um Äußerungen des Außenministers Molotov, in denen er die deutsche Ausbeutung der sowjetischen Städte und Dörfer beschrieb. ${ }^{278}$

BDMGVAV, d 89, I. 22, (alte Signatur). 1945 wurde in Moskau ein Sammelband mit der russischen Übersetzung der Gedichte von Pjatrus Broŭka herausgegeben; die Übersetzung weicht jedoch stark vom Original ab. Vgl. Brovka, P.: Belorus', Stichi, Moskva 1945, S. 24-41. Für die Übersetzung aus dem Belarussischen danke ich herzlich Tanja Pavic Olenina. 
Diese eindeutig negative Schilderung der deutschen Agrarpolitik durch die Autorität Molotovs erschien den muzejščiki erforderlich, da der Gegenstand dieses Saales nicht unumstritten war. Die sogenannte »Neue Agrarordnung«, die die Deutschen im Frühjahr 1942 im »Generalbezirk Weißruthenien« einführten, entsprach praktisch der Auflösung des sowjetischen Kolchos-Systems. ${ }^{279}$ Da die Reform einen wirtschaftlich positiven Effekt hatte und ein »kurzfristiges Stimmungshoch « in der Bevölkerung auslöste und weil die Bäuerinnen und Bauern bei der Auflösung der Kolchosen zum Teil mitwirkten, verschwiegen spätere sowjetische Quellen die deutsche Agrarreform ganz oder behandelten sie als Fiktion. ${ }^{280}$

Interessanterweise stellten die muzejščiki das deutsche Landwirtschaftsreformprojekt aus. Sie präsentierten sogar den entsprechenden deutschen Befehl über die »Neue Agrarordnung «. ${ }^{281}$ Die muzejščiki hatten den Inhalt übersetzt und interpretierten ihn dabei in einer Weise, die keine andere Deutung als die von Molotov bereits angesprochene zerstörerische Absicht der Deutschen zuließ:

»[Die >Neue Agrarordnung war, A.H.] die Etablierung eines umfassenden Systems der >Bodenordnung`, mit dem die Deutschen nicht nur die Führung und die Kontrolle über die Durchführung der Agrarpolitik an sich rissen, sondern auch die Kontrolle über die Gemeinschaften, die zukünftig in Kolchosen umgewandelt werden sollten, übernahmen. ${ }^{282}$

Warum verschwiegen oder leugneten die muzejščiki die deutsche Agrarreform nicht? Hier spielt die zeitliche Nähe der Ausstellung zu den Ereignissen bzw. die Deckungsgleichheit von Erfahrungsgeneration und Kuratorinnen und Kuratoren eine Rolle: Es lässt sich argumentieren, dass die muzejščiki die Ereignisse schlicht nicht unerwähnt lassen konnten, ohne sich in den Augen ihres Publikums unglaubwürdig zu machen. Die Deutschen hatten die Reform in »Ostland « in ihrer Propaganda explizit benannt, viele Familien waren direkt betroffen gewesen, und die deutsche Agrarreform stellte für einen Großteil der Besucherinnen und Besucher einen integralen Teil ihrer Besatzungserfahrung dar. ${ }^{283}$

Die muzejščiki verbanden die Thematik mit historischen Kriegsereignissen, die das Argument der Zerstörung der Dörfer durch die Deutschen stützten. Im Dezember 1941, als der Vorstoß der Heeresgruppe Mitte vor Moskau steckenblieb,

279 Gerlach, Christian: Kalkulierte Morde, S. 362.

280 Ebd.: S. 359-360. Für einen Überblick über die entsprechenden sowjetischen Darstellungen aus den 1960ern und 1970ern Jahren vgl.: Fußnote 810.

281 BDMGVAV, d. 89, I. 24 (alte Signatur).

282 Ebd.

283 Zur Berichterstattung der »Minsker Zeitung« über die Reformierung des sowjetischen Kolchosesystems vgl. Burmistr, Svetlana: Die »Minsker Zeitung«, S. 292-304. 
erließ das Oberkommando im Kontext einzelner Rückzüge an der Front Zerstörungsbefehle, die zum Teil auch den östlichen Teil der sowjetischen Republik Belarus betrafen. Die Minsker muzejščiki zeigten diese Befehle, die die Verbrennung von Vorräten und die vollständige Zerstörung von Wohnhäusern anordneten, um ihrem Publikum die deutsche Intention eines Vernichtungskriegs zweifelsfrei zu beweisen. ${ }^{284}$

Irina Sklokina hat darauf hingewiesen, dass die Präsentation von Dokumenten der Besatzungsmacht eine Besonderheit der frühen sowjetischen Kriegsausstellungen war:

»As these documents were not created by the Soviet side, they informed readers not only about crimes and atrocities against the local population, as they were supposed to do, but also about everyday life, about certain rules regulating the relations between the occupying forces and the locals, about work and food supplies, about locals in lower administrative positions. $^{285}$

Während die lebensweltliche Dimension der Dokumente gewiss eine Wirkung hatte, gingen die muzejščiki jedoch nicht so weit, dass sie die Schlüsselfiguren der deutschen Besatzungsherrschaft (wie zum Beispiel der Generalkommissar von »Weißruthenien« Wilhelm Kube) namentlich nannten oder anhand von Fotografien ausgestellt hätten. Aber auch eine Leerstelle, konnte bei gleichzeitiger Präsentation der sowjetischen militärischen und politischen Führer, eine Wirkung entfalten. So sollte suggeriert werden, dass die handelnden Akteure im Kriegsgeschehen ausschließlich auf sowjetischer Seite waren, während die gegnerische Seite gesichtslos und anonym blieb. ${ }^{286}$

Im dritten Ausstellungssaal zeigte man anhand von Fotografien, Diagrammen, Texten und Gemälden die »Zerstörung der belarussischen Kultur«. Einen Schwerpunkt nahm die Vernichtung des universitären Lebens und der Belarussischen Akademie der Wissenschaften ein. Unter einem großformatigen Foto der zerbombten Akademie hing ein Porträt Nikolaj Nikolskijs (1877-1959), des Direktors der Historischen Fakultät. ${ }^{287}$ Dem 64-jährigen jüdischen Wissenschaftler und seiner Frau war es, wie den meisten Bewohnerinnen und Bewohnern der Stadt im Juli 1941, nicht gelungen, aus dem brennenden Minsk zu fliehen, und sie gerieten unter die deutsche Besatzungsherrschaft. ${ }^{288}$ Bereits im Frühjahr 1942 bauten sie enge Kontakte

284 BDMGVAV, d. 89, I. 23; 24 (alte Signatur).

285 Sklokina, Irina: The Politics of Remembering the Nazi Occupation in Soviet Museums, S. 143.

286 Ebd.

287 BDMGVAV, d. 89, I. 27 (alte Signatur).

288 Minsk wurde bereits am 22. Juni 1941 von deutschen Luftangriffen getroffen. Am 24. Juni wurde das ZK der KP Belarus nach Moskau evakuiert, ohne Maßnahmen zur Evakuation der Bevölkerung zu organisieren. Sechs Tage nach Kriegsausbruch befand sich Minsk unter deutscher Herrschaft. Von den insgesamt 240'000 Einwohnerinnen und Einwohnern blie- 
zu Mitgliedern des kommunistischen Untergrunds auf, die sie im August 1943 aus der Stadt und zu den Partisaneneinheiten brachten. Von dort wurden sie sieben Monate später nach Moskau evakuiert. Vor der Abreise baten die Partisanenführer den Historiker, seine Erlebnisse für einen ihrer Almanache aufzuschreiben. ${ }^{289}$ Die Erinnerungen »Wie wir zu den Partisanen kamen«, die die muzejščiki präsentierten, bestachen durch ihre Unmittelbarkeit und ihre Glaubwürdigkeit, die nicht zuletzt durch die angesehene Position des Verfassers als Mitglied der belarussischen Akademie der Wissenschaften transportiert wurde. ${ }^{290}$ Der jüdische Historiker schilderte die zwei Jahre, die er unter deutscher Besatzung verbracht hatte und verschwieg dabei weder seine Angst und Hoffnungslosigkeit noch die Existenz des nicht-offiziellen Minsker Untergrunds. ${ }^{291}$ Letzteres lässt sich zum Zeitpunkt der Niederschrift erklären: Im Februar 1944, als Nikolskij seine Memoiren verfasste, hatte Staatssekretär Pantelejmon Ponomarenko die erste, autonom gegründete Untergrundbewegung noch nicht als Fiktion diffamiert. Die öffentliche Ausstellung dieser Erinnerungen im Herbst 1944, als Ponomarenko die Mitglieder des Untergrunds bereits verfolgte, überrascht allerdings und lässt sich ansatzweise über die persönliche Kriegserfahrung der Kuratorinnen und Kuratoren erklären.

Eine Fotoreihe schlug den Bogen zurück zum »Großen Vaterländischen Krieg« und verortete die belarussische Kriegserfahrung in der unionsweiten Meistererzählung. Die Fotos zeigten die Zerstörung von Kultureinrichtungen außerhalb der Republik: das Wohnhaus von Lev Tolstoi in Jasnaja Poljana (Tulaer Gebiet), das Tschaikowski-Museum in Klin (Moskauer Gebiet) und das Museum des Schriftstellers Vladimir Korolenko in Poltawa (heutige Ukraine). ${ }^{292}$ Hier zeigt sich erneut die Übernahme von Elementen aus der Gründungsausstellung im Moskauer GIM. Die Kuratorinnen und Kuratoren von »Belarus lebt, Belarus kämpft ...« konnten auf Materialien ihrer Partnerorganisation, der ČGK, die die Zerstörung der Kulturgüter in der ganzen Sowjetunion dokumentierte, zurückgreifen. Bereits während des Krieges wurde Jasnaja Poljana zum unionsweiten Symbol für die Zerstörung russischer Kultur durch die »barbarischen Deutschen «. ${ }^{293}$

ben 200 '000 in der Hauptstadt zurück, die zu 80 Prozent zerstört war. Circa die Hälfte der Minsker Bevölkerung war jüdisch. Vgl. Gartenschläger, Uwe: Surviving in occupied Minsk, in: Bonwetsch, Bernd/Thurston, Robert: The People's War, S. 13-28, hier: S. 14 und 21. Gulenko, V./Šumejko, M.: Kak my prišli k partizanam, Vospominanija N. M. Nikol'skogo, in: dies.: Pracy gistaryčnaga fakul'tèta BDU, navuk. zb. Vyp. 3, Minsk 2008, S. 155-165. BDMGVAV, d. 89, I. 27 (alte Signatur).

291 Zum inoffiziellen, das heißt nicht staatlich gegründeten »Stadt-Komitee«, vgl. Epstein, Barbara: The Minsk Chetto, Jewish Resistance and Soviet Internationalism, Berkeley 2008, S. 112. BDMGVAV, d. 89, I. 28 (alte Signatur).

293 Vgl. Dokumentarfilm »Die Zerschlagung der deutschen Truppen vor Moskau« vom Februar 1942, in dem die Zerstörung von Jasnaja Poljana, dem Gutshaus von L. Tolstoj, und des dazugehörigen Museums detailliert gezeigt wird. 
Die Bezeichnungen der folgenden zwei Säle »Verbrechen am belarussischen Volk « und »Verbrechen am jüdischen Volk. Das Ghetto« suggeriert, dass zwischen zwei Opfergruppen unterschieden wurde. In den neuen Grenzen der sowjetischen Republik Belarus lebten vor Kriegsausbruch rund I Millionen Jüdinnen und Juden, die 10 Prozent der Gesamtbevölkerung ausmachten. Der Holocaust, der hier schätzungsweise 800.000 Opfer forderte, wurde als Teil einer gemeinsamen GenozidErfahrung im deutschen Vernichtungskrieg interpretiert. ${ }^{294}$ Die allgemeine erinnerungspolitische Tendenz verfolgte eine Universalisierung der Opfer, die eine ethnische Unterscheidung von Toten unterließ. Gleichzeitig war der Bezug auf den Holocaust möglich, da er von den Medien weder während des Krieges noch in der Nachkriegszeit vollständig ausgeblendet wurde. ${ }^{295}$ Der erste dieser zwei Säle zeigte Fotos, Gemälde und deutsche Befehle von Erschießungen und Hängungen der belarussischer Zivilbevölkerung. ${ }^{296}$ Im Tafeltext ließen die muzejščiki Stalin den Kriegsplan der Nazis erklären. Stalin zitierte Hitlers Aussage, dass nur eine »vollständige Vernichtung der slawischen Völker zum Ziel der Gründung eines deutschen Großreichs« führen würde. ${ }^{297}$

Die begleitenden Exponate waren emotional stark aufgeladen. So zeigte ein Diagramm die Anzahl der lebendig verbrannten Zivilisten in der BSSR und eine Pietà-Allegorie stellte eine Mutter mit ihrem toten Kind in den Armen dar. ${ }^{298}$ Dieser emotionale Druck fand seine Entsprechung in einem Gedicht von Janka Kupala, dem belarussischen Dichter, der bereits in der Moskauer Vorgängerausstellung gewürdigt worden war. Bevor Kupala im Juni 1942 unerwartet starb, hatte er an einer Ballade geschrieben, die den Titel »Neun Pfähle aus Espenholz«trug. Die muzejščiki wählten folgende Verse aus den 14 Strophen aus:

»Er ist ein Raubritter, ein Wegelagerer auf einer glatten Straße,

Ganz Belarus dient ihm für seinen Raub.

Mein in Eisen gelegtes Volk hält er in einem Cefängnis eingesperrt,

Die ganze Republik hat er in Brand gesteckt. ${ }^{299}$

Die genauen Opferzahlen sind bis heute ungeklärt. Ich beziehe mich bei den genannten Angaben auf: Smilovitsky, Leonid: Jewish Life in Belarus, S. 15.

Arkadi Zeltser verweist an dieser Stelle auf Il'ja Ehrenburg, der die spezifische Dimension des Vernichtungskrieges und die Zahl von sechs Millionen toten Jüdinnen und Juden am 17. Dezember 1944 in einem »Pravda«-Artikel erwähnte. Vgl. Zeltser, Arkadi: Unwelcome Memory, S. 106-107. BDMGVAV, d. 89, I. 29 (alte Signatur).

297 Ebd.

298 BDMGVAV, d. 89, I. 31 (alte Signatur).

299 Ebd. I. 31. Kupala, Janka: Dzevjac' asinavych kolljaŭ, fünfte Strophe. Übersetzt von Tatjana Pavic Olenina. 
Die Zeilen, in der Ausstellung auf Belarussisch zitiert, fassten die in Zahlen und Kunstwerken gezeigten Verbrechen in Worte. Die Verzweiflung des Dichters über die Besatzer und der Schmerz angesichts der Zerstörung der Menschen und des Landes standen stellvertretend für die Gefühle, die die Ausstellung auslösen konnte.

Die Inszenierung dieses Gedichtes überrascht im zeitgenössischen politischen Kontext. In den restlichen Strophen beschrieb Kupala, wie neun deutsche SSSoldaten Zivilisten zwangen, bei der Erschießung von Juden und Jüdinnen des Minsker Ghettos mitzuhelfen. Indem er beide Opfergruppen »meine Belarussen, meine Juden« als »unschuldige, ihm vertraute und liebe Menschen« (Maich belarusaŭ, maich jaŭrëjă, ljudzej nepavinnych, mne rodnych, blizkich) bezeichnete, zeigte er nicht nur große Empathie, sondern verwies auch auf das Selbstverständnis der Jüdinnen und Juden als integrale Volksgruppe der belarussischen Gesellschaft. ${ }^{300}$ Heute wird Kupala als erster belarussischer Dichter, der über den Holocaust schrieb, verehrt. Da dieses Gedicht bis zur Perestroika nicht veröffentlicht werden durfte, überrascht die Inszenierung. ${ }^{301}$ Die Auswahl der Strophe zeigt, dass die muzejščiki das ganze Gedicht gekannt haben müssen und sich für eine politisch ungefährliche Strophe entschieden. Womöglich erinnerten die ausgestellten Verse die Besucherinnen und Besucher an die anderen Strophen und damit an das Schicksal der Minsker Jüdinnen und Juden. So diente diese Strophe zur Überleitung in den nächsten Saal, der das Ghetto von Minsk präsentierte.

Die oben angesprochene Solidarität zwischen der jüdischen und der belarussischen Bevölkerung in der sowjetischen Republik war nicht die Wunschvorstellung eines Dichters, sondern entsprach in Teilen der Realität im besetzen Minsk. Das jüdische Ghetto, das die Deutschen bereits Anfang Juli 1941 errichteten und das zu den größten Ghettos in Europa zählte, unterschied sich in seiner Form des Widerstandes von anderen Ghettos. ${ }^{302}$ In Minsk hatte der Widerstand nicht die bewaffnete Gegenwehr (wie in Warschau oder Vilnius) zum Ziel, sondern die Rettung von Jüdinnen und Juden durch heimliche Evakuationen in die Partisanenwälder. ${ }^{303}$ Das setzte eine Zusammenarbeit mit nichtjüdischen Menschen außerhalb

300 Ebd. Achte Strophe.

301 Zuborev, Leonid: Belorusskie poèty o Cholokoste, in: https://news.tut.by/culture/371291.html (Stand: 30.12.2017).

302 Innerhalb des deutsch besetzten Gebietes der Sowjetunion war das Minsker Ghetto nach Lvov das zweitgrößte. Es bestand aus drei Teilen und umfasste bis zu seiner Auflösung im Juni 1944 bis zu 100.000 Gefangene. Im dritten Teil, dem sogenannten »Sonderghetto«, wurden insgesamt 23.904 Jüdinnen und Juden gefangen gehalten, die in 25 Transporten aus Deutschland, Österreich und der Tschechoslowakei nach Minsk gebracht wurden. Vgl. Smilovitsky, Leonid: Jewish Life in Belarus, Fußnote 13, S. 169.

303 Die genaue Anzahl der aus dem Chetto geretteten und zu den Partisanenverbänden gebrachten Jüdinnen und Juden ist nicht zu beziffern. Die Forschung bezieht sich auf die von Reu- 
des Ghettos, konkret mit der Minsker Untergrundbewegung und den Partisaneneinheiten voraus. ${ }^{304}$ Und genau diese Darstellung des gemeinsamen Widerstandes von jüdischen und nichtjüdischen Menschen bildet den bemerkenswerten Teil des fünften Ausstellungssaales. Neben einer Vitrine, die einerseits das Abzeichen der jüdischen Ghettohäftlinge (gelber Stern) und andererseits die Oberarmbänder des deutschen Sicherheitsdienstes präsentierte, zeigten die muzejščiki zwei "gefälschte Pässe (poddel'nyj pasport). ${ }^{305}$ Diese Pässe gaben Chasja Pruslina und Hersh Smolar, zwei bekannten jüdischen Akteuren der Untergrundbewegung, eine sowjetische Identität, mit der sie sich unerkannt in Minsk bewegen konnten. Der Exponatstext erklärte, dass diese Pässe der Kommunikation mit den Gebieten außerhalb des Ghettos dienten. ${ }^{306}$ Damit waren die Mitglieder der Untergrundbewegung »StadtKomitee (gorodskoj komitet) gemeint, die belarussische Kommunistinnen und Kommunisten nach der Flucht ihrer Parteiführung im Herbst 1941 gegründet hatten. ${ }^{307}$

Die Personen der ausgestellten Pässe waren keine Unbekannten in der Minsker Nachkriegsbevölkerung. Der bei Kriegsausbruch 36-jährige Hersh Smolar (19051993) war ein belarussischer jüdisch-polnischer Kommunist, der vom Westen der sowjetischen Republik nach Minsk geflohen war und im Ghetto die Führung der Widerstandsbewegung übernommen hatte. ${ }^{308}$ Auch Chasja Pruslina (1901-1972) war unter den Kommunistinnen und Kommunisten im sowjetischen Belarus sehr geschätzt und gut vernetzt, was sie zu einer idealen Verbindungsperson zwischen den beiden Untergrundbewegungen in der Stadt und im Ghetto machte. ${ }^{309}$ Neben der Herstellung von gefälschten Pässen initiierte Pruslina die Rettung jüdischer Kinder aus dem Minsker Ghetto. Sie etablierte Kontakte zu Familien und Waisenheimen, die bereit waren, jüdische Kinder unter belarussischem Namen zu

ben Ainsztein genannte Zahl von 10.000 Minsker Jüdinnen und Juden, die jedoch zuletzt von Christian Cerlach als zu gering bezeichnet wurde. Vgl. Gerlach, Kalkulierte Morde, S. 744, insb. Fußnote 1298.

Epstein, Barbara: The Minsk Chetto, S. 14-15. BDMCVAV, d. 89, I. 32 (alte Signatur).

306 Ebd. Die Gebiete außerhalb des Chettos wurden von den Jüdinnen und Juden »russische Cebiete« und von den Belarussinnen und Belarussen »die Stadt« genannt. Vgl. Epstein, Barbara: The Minsk Ghetto, S. 110-111.

307 Epstein, Barbara: The Minsk Chetto, S. 112. Es existiert praktisch keine westeuropäische Forschung zum Minsker Untergrund. Uwe Gartenschläger betont, dass die Kommunisten die Untergrundbewegung von Beginn an dominiert hätten. Vgl. Gartenschläger, Uwe: Surviving, S. 20-21.

308 Ebd. S. 113. Nach seiner Flucht in die Partisanenwälder wurde Smolar Kommissar einer Partisaneneinheit. 1946 publizierte der Emes-Verlag in Moskau seine jiddischen Memoiren: »Fun Minsker geto«.

309 Logvinov, I. (Hg.): Archiv Chasi Pruslinoj, Minskoe getto, antifašistskoe pod'pole, repatriacija detej iz Germanii, Minsk 2010, S. 129. 
verstecken. ${ }^{310}$ Die muzejščiki wussten von dieser gemeinsamen Rettungsaktion und stellten einen Brief aus, in dem sich eine jüdische Frau bei einer belarussischen Frau für die Rettung des Lebens ihres Kindes bedankte. ${ }^{311}$

Die Präsentation spezifisch weiblicher Strategien der Lebensrettung erstaunt im Kontext einer sowjetischen Widerstandsbewegung. Die hier vorherrschende Dominanz von männlichen Soldaten- oder Partisanenbildern vermittelte traditionelle Vorstellungen von heldenhaftem militärischem Widerstand - die Exponate der muzejščiki regten dazu an, über andere, weiblich geprägte Räume des Widerstandes nachzudenken.

Die Ausstellung war nicht nur ungewöhnlich (und) mutig im Kontext zeitgenössischer Genderrollen, sondern auch im Hinblick auf die politischen Diskurse, die die muzejščiki umgaben. Dabei lief nicht primär die Ausstellung über den Holocaust und das Minsker Ghetto Gefahr, den Unwillen der Parteiführung zu erregen, sondern die Präsentation des kommunistischen Untergrundes. Da Ponomarenko vor seiner Evakuation aus Minsk im Juli 1941 keine Untergrundbewegung organisiert hatte und erst im Frühjahr 1942 entsprechende Kommissare aus Moskau sandte, diffamierte er nach seiner Rückkehr die Mitglieder des »Stadt-Komitees" als Kollaborateure der Nazis und ließ bis 1949 mindestens 126 Personen verhaften. Die Existenz dieses grassroot-Widerstandes war eine öffentliche Beschämung für den Ersten Generalsekretär und brachte seine politische Stellung in Gefahr. ${ }^{312}$

Die muzejščiki beteiligten sich nicht am Verrat des »Stadt-Komitees«. Verschiedene, sich ergänzende Motive bieten sich zur Erklärung dieser eigenständigen Position an. Grundlegend ist wieder die zeitliche Nähe des Ausstellungsinhaltes zu den gerade erst vergangenen Ereignissen. Die muzejščiki schrieben den thematischen Ausstellungsplan in wenigen chaotischen Wochen, kurz nach der Befreiung der Stadt Minsk im Herbst 1944, während der Krieg im Westen des Landes und außerhalb der sowjetischen Republik andauerte. Die Deutung der Ereignisse war in der Nachkriegsgesellschaft noch nicht festgeschrieben bzw. die Kuratorinnen und Kuratoren übernahmen selbst die Deutung der Geschichte wie im Fall der »Neuen Agrarordnung«. Die Darstellung des »Stadt-Komitees« könnte also auch ein Resultat von Eigeninitiative in Anbetracht fehlender Absprachen unter großem Zeitdruck gewesen sein. Die zeitliche Nähe zu den gerade erst historisch werdenden Ereignissen hatte noch einen weiteren Effekt auf die Ausstellung. Nach der Befreiung sprachen Nachbarn und Bekannte miteinander über das erlebte Leid.

310 Ebd. S. 126-127, zur Rettung der jüdischen Kinder: S. 171-180.

311 BDMGVAV, d. 89, I. 32 (alte Signatur). Die synonyme Verwendung der Bezeichnungen belarussisch/russisch im Ausstellungsplan spiegelt die Haltung der Zeitgenossinnen und Zeitgenossen, für die diese Unterscheidung keinen Sinn ergab. Vgl. Gartenschläger, Uwe: Surviving, S. 17. 
Während der deutschen Besatzung war es unmöglich gewesen, nicht auf die eine oder andere Weise mit den Deutschen in Kontakt zu kommen. Auch wenn man nicht über die eigene Involvierung in der deutschen Besatzungsherrschaft sprach, so sprach man doch darüber, was andere getan hatten. ${ }^{313}$ Die muzejščiki verstanden sich als Teil dieser Verarbeitungs- und Verstehensprozesse und gestalteten sie mit.

Dieser gesellschaftliche Diskurs wurde durch die Verbrechensaufklärung der ČGK gefördert und schuf ein Klima der Sagbarkeit. ${ }^{314}$ Auch die Anklagen in den Minsker Kriegsverbrecherprozessen, die im Januar 1946 in Minsk stattfanden, bezogen sich auf die Akten der ČGK und inszenierten die Verfahren öffentlichkeitswirksam. ${ }^{315}$ Die Schuldvorwürfe, die den Grad der persönlichen Involvierung der Angeklagten betonten, konzentrierten sich auf die »Tötung von Zivilisten im $\mathrm{Zu}$ ge von Partisanenkampfaktionen, die systematische Tötung von Juden, die unmenschliche Behandlung und gezielte Ermordung von Kriegsgefangenen «. ${ }^{316}$ Die 18 Angeklagten wurden am 30. Januar 1946 öffentlich hingerichtet und die Stenogramme der vierzehntägigen Hauptverhandlung im Folgejahr veröffentlicht. ${ }^{317}$

Anika Walke betont ein Unterscheidungsmerkmal des Holocausts in den sowjetischen Gebieten. Hier wurde die lokale jüdische Bevölkerung nicht in ferne Konzentrationslager deportiert, sondern in ihren Heimatstädten in Ghettos mitten in der Stadt interniert und in nahegelegenen Vernichtungslagern umgebracht: "Killing sites are thus in close proximity to where the victims had lived, and where their neighbours, classmates, clients, friends, or enemies continued to live after

Exeler, Franziska: »What Did You Do During the War?«, S. 814.

314 In der gesamten Sowjetunion teilten mehrere Millionen Menschen ihre Kriegserlebnisse der ČGK mit, was zu über 250.000 Protokollen und Anklagen gegen nationalsozialistische Verbrechen führte. Auf Befehl der KP sollten alle Stadt- und Gebietskomitees Massenversammlungen durchführen, um Aufklärungsvorträge und Cespräche durchzuführen. Vgl. dies., S. 824.

315 Der Minsker Prozess, der zwischen dem 15. und 29. Januar 1946 stattfand, wird zu der ersten Welle öffentlicher Kriegsverbrecherprozesse gezählt, die seit Dezember 1943 (Charkow) in der Sowjetunion stattfanden. Zeitgleich zu dem Minsker Prozess fand ein ähnlicher Prozess in Kiew statt. Parallel begann in Nürnberg die erste Phase der Nürnberger Hauptkriegsverbrecherprozesse. Manfred Zeidler hat auf die strukturellen Gemeinsamkeiten dieses Minsker Prozesses mit den stalinistischen Schauprozessen der 1930er Jahre hingewiesen. Vgl. Zeidler, Manfred: Der Minsker Kriegsverbrecherprozess vom Januar 1946, Kritische Anmerkungen zu einem sowjetischen Schauprozess gegen deutsche Kriegsgefangene, in: Vierteljahrshefte für Zeitgeschichte, Nr. 2, 2004, S. 211-244.

Ebd. S. 225-226.

317 Das 472 Seiten lange Dokument wurde unter dem Titel »Sudebnyj process po delu o zlodejanijach soveršennych nemecko-fašistkimi zachvatčikami v Belorusskoj SSR« 1947 in Minsk veröffentlicht, zitiert nach: Zeidler, Manfred: Der Minsker Kriegsverbrecherprozess vom Januar 1946, S. 215, Fußnote 19. 
the war. « ${ }^{318}$ Die Historikerin schließt daraus, dass die Folgen und die Bedeutung dieser räumlichen Nähe von Forschung und Erinnerung an den Holocaust im sowjetischen Belarus stärker berücksichtigt werden müssen.

Eine weitere entscheidende Motivation für die muzejščiki war die bereits angesprochene Solidarität gegenüber den Opfern des Holocausts. Diese Hilfe konnte verschiedene Formen und Ausmaße annehmen und sich im Teilen von Nahrungsmitteln, im Gewähren von Obdach, im Verstecken von Jüdinnen und Juden oder im Schmuggel zu den Partisanenverbänden im Wald ausdrücken. Dabei gingen die Helferinnen und Helfer ein existentielles Risiko für sich und ihre Familien ein: Bereits der Verdacht auf geleistete Hilfe konnte zur Erschießung durch die deutschen Besatzungsbehörden führen. Franziska Exeler betont, dass Überlebende nicht nur selbstlose Hilfe, sondern auch Zögern, Angst, Gleichgültigkeit und offene Feindschaft von ihren nichtjüdischen Mitmenschen erfuhren. ${ }^{319}$ Sie widerspricht der Forschung, die in der sowjetischen Republik Belarus einen Sonderfall sieht, da hier der Antisemitismus, der in anderen osteuropäischen Ländern zu einer relativen Indifferenz der Nichtjuden und Nichtjüdinnen gegenüber dem Holocaust beigetragen habe, gering ausgeprägt gewesen sei. ${ }^{320}$ »In my reading of [...] accounts of survivors from both eastern and western Belorussia, each case showed a spectrum of human behavior, but each case fundamentally depended on the individuals involved, and the specific circumstances in which these found themselves. ${ }^{321}$ Hier schließt ihre Forschung an den Befund einer unterschiedlichen Prägung der westlichen (erst ab 1939 zur sowjetischen Republik Belarus gehörende Gebiete) und der östlichen Gebiete an, zu denen auch die Minsker muzejščiki zählten. ${ }^{322}$ In Minsk hatte die kommunistische Ideologie des Internationalismus in den 1930er Jahren zu einer tiefen und selbstverständlichen Integration der sowjetischen Jüdinnen und Juden geführt. Überlebende des Holocausts beschrieben diese innerethnische Verbundenheit als gelebte Realität der Vorkriegszeit. ${ }^{323}$ Als die Rassenideologie der Nazis die Minsker in eine Opferhierarchie stellte, wurde aus dem Gefühl gesellschaftlicher Gleichberechtigung eine kämpferische Solidarität. ${ }^{324}$ Die muzejščiki, die diese Ideologie der 1930er Jahre zum großen Teil als Jugendliche und junge Erwachsene erlebt hatten, kämpften im Krieg als Partisaninnen und Partisanen oder

318 Walke, Anika: Split Memory: The Geography of Holocaust, Memory and Amnesia in Belarus, in: The Slavic Review, Nr. 1, 2018, S. 174-197, hier S. 197.

319 Exeler, Franziska: Chosts of War, Nazi Occupation and its Aftermath in Soviet Belorussia, im Erscheinen (voraussichtlich Sommer 2022) bei Cornell University Press, S. 135.

320 Cerlach, Christian: Kalkulierte Morde, S. 747.

321 Exeler, Franziska: Chosts of War, S. 135.

322 Bemporad, Elissa: Becoming Soviet Jews: The Bolshevik Experiment in Minsk, Indiana 2013.

323 Walke, Anika: Pioneers and Partisans, An Oral History of Nazi Cenocide in Belarussia, Oxford 2015, S. 13. 
im Untergrund - sie hatten ein intrinsisches Interesse an der Musealisierung ihrer Geschichte. ${ }^{325}$

Schlussendlich orientierten sich die unerfahrenen Kuratorinnen und Kuratoren an der Ausstellung der Historikerkommission, die sie als Grundlage ihrer Arbeit aus Moskau übernommen hatten. Bereits ihre Vorgänger hatten sich um eine möglichst umfassende Darstellung der Besatzungsherrschaft bemüht, die sogar so weit ging, die Kollaboration mit der deutschen Besatzungsmacht anzusprechen. Auch wenn die Minsker muzejščiki diese Vitrine nicht übernahmen und diese ambivalente Besatzungserfahrung ausklammerten, so übernahmen sie doch den thematischen Fokus auf das individuell erlittene Leid und Unrecht. Hier zeigt sich, dass die Leerstelle, die die stalinistische Erinnerungspolitik in Bezug auf die zivilen Opfer ließ, paradoxerweise zu Freiräumen in der kommemorativen Gestaltung der Kriegserinnerung führen konnte.

Während die wissenschaftlichen Museumsmitarbeitenden die Objekte mit zweidimensionalen Exponaten wie Texttafeln oder Diagrammen ergänzten, waren die im Museum angestellten Künstlerinnen und Künstler für die Gemälde und Zeichnungen zuständig. Auch sie wurden in der Regel aus den Reihen der ehemaligen Partisaneneinheiten rekrutiert. In dem sechsten Ausstellungssaal, der den sowjetischen Kriegsgefangenen gewidmet war, hing ein Gemälde des Künstlers Sergej Romanov. ${ }^{326}$

Der 1914 geborene Romanov studierte an der Moskauer Kunsthochschule Graphik und »Politisches Plakat«. Zu Beginn des Deutsch-Sowjetischen Krieges geriet er in deutsche Gefangenschaft und konnte $1943 \mathrm{zu}$ den Partisaneneinheiten ins Homeler Gebiet fliehen. Hier wurde er für die Gestaltung von Flugblättern bekannt, die bis heute einen berühmten Bestand des Minsker Museums darstellen. ${ }^{327}$ Nach der Minsker Partisanenparade im Juli 1944 wurde er im »Museum des Großen Vaterländischen Krieges « als Künstler angestellt. Seine Gemälde in den Ausstellungen machten ihn in der sowjetischen Republik bekannt, und ein Jahr später wurde er in den Künstlerverband aufgenommen. ${ }^{328}$ Sein großes Gemälde "Auf der Suche nach dem Sohn« (V poiskach syna, 85,0 cm x 125,0 cm, Abb. 25), das bis heute in

Nachdem deutsche Razzien den Untergrund im März und September 1942 praktisch ausgelöscht hatten, waren es insbesondere junge Mitglieder, die den Widerstandskampf neu aufnahmen. Laut Gartenschläger ist deswegen die Betonung der Rolle des Komsomols im Widerstand in der sowjetischen Historiographie gerechtfertigt. Vgl. Gartenschläger, Uwe: Surviving, S. 20-21. 
der Dauerausstellung gezeigt wird, stellte eine Szene am Zaun eines sowjetischen Kriegsgefangenenlagers dar. ${ }^{329}$

Abbildungen 24 und 25: Der Maler Sergej Romanov als Rotarmist im »Großen Vaterländischen Krieg«, Kiev 1941, Fotografin/Fotograf unbekannt. Ölgemälde von Sergej Romanov "Aufder Suche nach dem Sohn«, Minsk 1945 @ BDMGVAV.
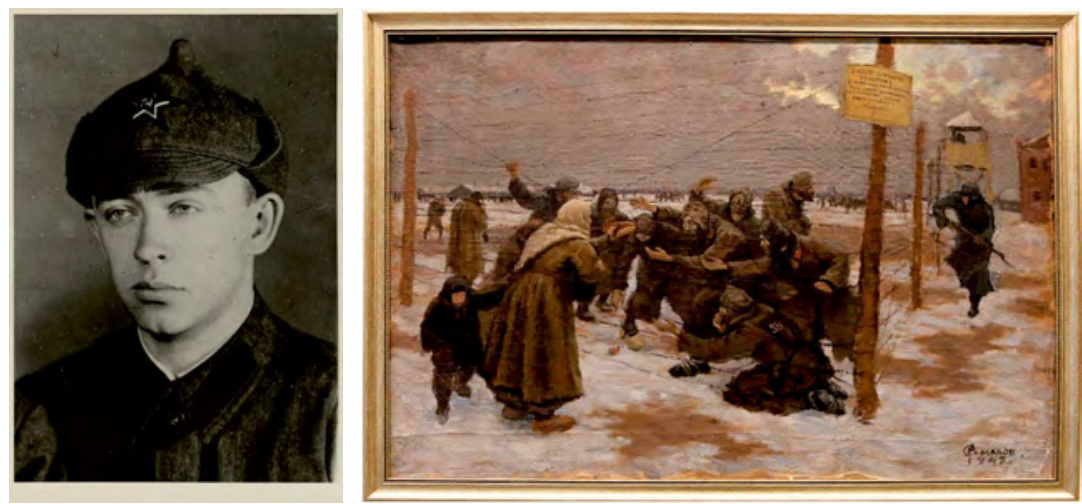

Das Gemälde zeigt die Not der Gefangenen. Der Schnee auf dem Boden vermittelt die winterliche Kälte. Die notdürftig mit Kopftüchern und Mützen bedeckten, frierenden Soldaten drängen sich an den Zaun und bitten die Frau auf der anderen Seite mit ausgestreckten Händen um Essen. Die Frau mit Valenki hat ein kleines Kind bei sich und fragt die Gefangenen nach dem Verbleib ihres Sohnes. Ein deutscher Aufseher in grüner Uniform läuft mit schussbereitem Gewehr auf die Gruppe zu und das Schild, auf dem auf deutsch und russisch »Zutritt zum Lager verboten! Es wird ohne Anruf geschossen!« steht, vermitteln die unmittelbare Lebensgefahr in der die Gefangenen und die Frau mit dem Kind am Zaun schweben.

Die größte Opfergruppe in der besetzten Republik Belarus war die der sowjetischen Kriegsgefangenen. ${ }^{330}$ Die ungeschützten Lager, in denen die Gefangenen Hunger und Kälte, Krankheiten und der Willkür der Aufseher ausgesetzt waren, dienten den Deutschen als Instrumente in ihrem Vernichtungskrieg. Die Forschung hat die Öffentlichkeit dieses Mordens betont, die der Zivilbevölkerung laruski dzjaržaŭny muzej gistoryi vjalikaŭ ajčynnaŭ vajny, Minsk 2015, S. 285. Belarus. Das entspricht 700.000-800.000 toten Kriegsgefangenen. Vgl. Gerlach, Christian: Kalkulierte Morde, S. 855-859. 
bereits in den ersten Kriegswochen die Absichten der deutschen Besatzungsverwaltung vor Augen geführt habe. ${ }^{331}$ Der Rotarmist und Künstler Romanov (Abb. 24), der die deutsche Gefangenschaft selbst erlebt hatte, stellte in seinem Gemälde nicht nur diese Öffentlichkeit, sondern auch eine gewisse Solidarität zwischen Zivilbevölkerung und Kriegsgefangenen dar. ${ }^{332}$ Es ist anzunehmen, dass die Frau auf dem Bild den Gefangenen im Tausch für Informationen Essen an den Lagerzaun bringt. ${ }^{333}$ Auch hier geht die Minsker Ausstellung über die Sagbarkeitsgrenzen des offiziellen Kriegsdiskurses hinaus. Rotarmisten, die in deutsche Gefangenschaft gerieten, galten seit Stalins Befehl im August 1941 als Verräter, da sie nicht bis zu ihrem eigenen Tod gekämpft hatten. Die insgesamt 5,7 Millionen sowjetischen Gefangenen standen nach Kriegsende unter dem Generalverdacht der Kollaboration und wurden bis zu ihrer partiellen Rehabilitierung während des »Tauwetters" diskriminiert und aus der Nachkriegsgesellschaft ausgeschlossen. ${ }^{334}$ Während die Kriegsgefangenen, gemäß dem Diskurs, in der Moskauer Schau nur als tote Soldaten ausgestellt wurden, zeigte sie die Minsker Ausstellung als Opfergruppe der deutschen Besatzungsherrschaft. Laut Ausstellungsplan befand sich das Bild bereits im Herbst 1944 in der Museumssammlung. Es ist also davon auszugehen, dass Romanov, als angestellter Künstler des Museums, in die Ausstellungsplanung miteinbezogen wurde und die Inszenierung seines Werkes mitbestimmen konnte.

Im Herbst 1945, ein Jahr nach der Museumseröffnung, hatte sich die spontane Ausstellungsarbeit bereits bürokratisiert. Nun entschied ein eigener »Künstlerischer Rat« über die Auswahl der künstlerischen Werke und ihren Inhalt. Die Ratsmitglieder des Museums lehnten Werke externer und interner Künstler ab, gaben sie zur Überarbeitung zurück oder nahmen sie gegen Honorar in die Sammlung und Ausstellung auf. 335

Bei ihrer Ausstellungsarbeit waren die muzejščiki abhängig von einer guten $\mathrm{Zu}$ sammenarbeit mit den Kommissariaten. Museumsdirektor Stal'nov verfügte über konkretes Wissen über das Minsker Lager Nr. 168, in dem deutsche und verbündete Kriegsgefangene interniert wurden. Im November 1944 hatte er einen Brief an den NKVD verfasst, in dem er Objekte (in präziser Stückzahl) aufzählte, die er

Dieses Bewusstsein entstand laut Gerlach, weil diese Opfergruppe sichtbarer war als die der Jüdinnen und Juden oder der Zwangsarbeiterinnen und Zwangsarbeiter und sich aus einem Querschnitt der sowjetischen Cesellschaft zusammensetzte. Ebd. S. 858.

Foto von S. Romanov in: BDMCVAV, Fond Dokumentatsija, N/D 25627. Name, Datum und Ort handschriftlich auf der Rückseite des Fotos vermerkt.

Laut V. I. Adamushko versuchten die Frauen in Minsk regelmäßig, den Gefangenen Essen zukommen zu lassen. Vgl. Adamushko, V. I./Biryokova, O. V./Zverev, Ju. V. u.a. (Hg.): Lager sowjetischer Kriegsgefangener in Belarus 1941-1944, Ein Nachschlagewerk, Minsk 2004, S. 10. 
in die Museumssammlung aufnehmen wollte. ${ }^{336}$ Darunter Mäntel und Kopfbedeckungen von deutschen, französischen, rumänischen, polnischen, belgischen und spanischen Kriegsgefangenen, sogenannte »Ersatz-Valenki« aus Stroh und Filz sowie Kochgeschirr. ${ }^{337}$ Es ist keine Antwort überliefert und das Lager wurde nicht Gegenstand der Ausstellung.

Im siebten Ausstellungssaal, der den Titel » $\mathrm{SD}$ «trug, standen die Gaswagen im Mittelpunkt. Die Morde an an der Zivilbevölkerung führte in der Wahrnehmung der Zeitgenossinnen und Zeitgenossen in erster Linie der deutsche Sicherheitsdienst durch. Im Volksmund wurden diese umgebauten Lastkraftwagen "Seelentöter« (dušegubka) genannt. Die muzejščiki zitierten Überlebende, die diese Morde bezeugten:

»Während meiner Zeit im Lager der Širokaja-Straße [...] war ich Zeuge, wie die Deutschen die Menschen in >Seelentötern < umgebracht haben. Mit Gewalt zwängten sie 70-80 Menschen in den sSeelentöter und fuhren sie in eine unbekannte Richtung. Ich habe gesehen, wie die Bürger von Minsk, die Professoren Klymov und Anisimov in den sSeelentöter ' gebracht wurden.

Augenzeugenbericht von Maisevič, L. A. «38 $^{338}$

Die Universitätsärzte Klymov und Anisimov waren nicht nur berühmte Minsker Wissenschaftler, sondern den muzejščiki bekannte Mitglieder des »StadtKomitees«. Man gedachte der Opfer mit zwei großformatigen Fotos, unter denen Augenzeugenberichte hingen. ${ }^{339}$ Das Zitat bot Anknüpfungspunkte für die Nachkriegsgesellschaft. Das Minsker Museumspublikum kannten das Lager an der Širokaja-Straße (heute Kujbyševa-Straße). Es befand sich während der Besatzungszeit mitten in der Stadt, nahe dem großen Markt. Möglicherweise erkannten sie die berühmten Wissenschaftler auf den Fotos auch aus Zeitungsberichten wieder. Sicherlich weckte der Augenzeugenbericht, abgefasst in der Landessprache, ihre Aufmerksamkeit.

336 NARB, f. 1246, op. 3, d. 5, I. 37.

337 Ebd.

338 BDMGVAV, d. 89, I- 37 (alte Signatur). Für die Übersetzung danke ich Aliaksandr Pustavitau. Das Lager an der Širokaja-Straße existierte vom 5. Juli 1941 bis zum 30. Juni 1944. Es diente als Arbeitslager und Konzentrationsstelle, in der die Häftlinge aus den Gefängnissen des SD filtriert wurden. Die Personen, die nicht nach Deutschland oder in andere Lager im besetzten Europa gebracht wurden, wurden in den getarnten Lastern vergast und in die Massengräber im Wald von Blagaǔščyna gebracht. Vgl. Naskevič, Natalja: Die Geschichte des Todeslagers Trostenez, anhand der Materialien der Archive und Museen von Belarus, in: Internationales Bildungs- und Begegnungswerk (Hg.): Ort der Vernichtung in Belarus, Die Geschichte des Vernichtungslagers Trostenez und des Chettos Minsk, Dortmund 2003, S. 35-40. Ebd. 
Im Saal über den SD wurden 21 Objekte gezeigt, die die muzejščiki im Herbst 1944 als »Folterwerkzeuge betitelten. ${ }^{340}$ Der frühe Eintritt dieser Objekte in die Sammlung weist auf die herausragende Stellung hin, die das Museum in der direkten Nachkriegszeit einnahm. Offenbar gelangten die muzejščiki schnell an die entscheidenden Orte des Massenverbrechens und besaßen darüber hinaus die $\mathrm{Au}$ torität, Objekte und Fundstücke von diesen Orten als zukünftige Exponate mitzunehmen. ${ }^{341}$

Die privilegierte Stellung des Museums kam aufgrund der engen Kontakte zwischen dem Museumsdirektor und den staatlichen Untersuchungskommissionen zustande. Als die ČGK am 21. Juli 1944 erstmals das ehemalige Konzentrationslager in der Nähe des Dorfes Maly Trascjanec bei Minsk untersuchte und Befragungen unter der Bevölkerung durchführte, begleiteten die muzejščiki die Kommissionsmitglieder und sammelten Materialien für zukünftige Ausstellungen. ${ }^{342}$

Das zeigt, dass die Minsker muzejščiki nicht nur inhaltlich, sondern auch in ihrer Arbeitspraxis an das Vorbild der Historikerkommission anknüpften. Die Kontakte zu den staatlichen Untersuchungskommissionen verhalfen der Ausstellung auch nach dem Krieg zu historisch bedeutsamen Originalen, die dem Museum ein Alleinstellungsmerkmal verschafften.

So präsentierte der achte Saal unter dem Titel »Todeslager« die meisten dreidimensionalen Objekte der Dauerausstellung. Eine Vitrine mit 19 Objekten gibt Aufschluss über das Verständnis der muzejščiki von den 206.500 Opfern in Maly Trascjanec, unter denen sich Tausende Jüdinnen und Juden der sowjetischen Republik Belarus, Deutschlands, Hollands, Ungarns, Polens, Frankreichs und der Tschechoslowakei befanden. ${ }^{343}$ Die Beschriftung lautete: »Persönliche Gegenstände von Bürgern, die in Trascjanec gefoltert wurden. ${ }^{344}$ Neben einer Brille mit Etui, einem

Ebd. I. 38.

Am 16. Oktober 1944 schrieb Museumsdirektor Stal'nov dem belarussischen Ministerium für Staatssicherheit (Gosbezopastnosti) mit der Bitte, dem Museum »Folterwerkzeuge« der Besatzer zur Verfügung zu stellen. Diese Originale seien nötig, da das Museum die »Besucher mit den Details der faschistischen Folterkammern« vertraut machen müsse. Stal'nov bat die Behörde zusätzlich um Fotografien von den Kriegsverbrechen der Besatzer und um weiterführende Informationen zu ähnlichen Museumsexponaten. Vgl.: NARB, f. 1246, op. 3, d. 5, I. 98. In einem weiteren Brief vom Oktober 1944 nannte Stal'nov konkrete Exponate (Fesseln, Schlagstöcke aus Gummi, Peitschen usw.). Vgl.: NARB, f. 1246, op. 3, d. 5, I. 27.

Die Abteilungsleiterin des heutigen Museums betont, dass das Museum die erste Institution gewesen war, die Maly Trascjanec nach der Befreiung besuchen durfte, und dass die Sammlung deswegen als einzige des Landes Cegenstände des ehemaligen KZ besitze, die bis heute in der Ausstellung gezeigt werden. Vgl. Naskevič, Natalja: Die Geschichte des Todeslagers Trostenez, S. 37. BDMGVAV, d. 89, I. 39 (alte Signatur). 
Kamm für Damen oder einem Pass stellten sie ein jüdisches Gebetsbuch aus. ${ }^{345}$ Wie die Objekttafel bereits suggeriert, wurde hier eine gemeinsame Opfergruppe ausgestellt. Dabei stand das Leid, nicht die Religion der Opfer im Vordergrund. Dieses umfassende Opferverständnis der muzejščiki spiegelte sich auch im Saaltitel »Todeslager « (lager' smerti) wider. Während die westliche Historiographie unter diesem Begriff Vernichtungslager versteht, gebrauchten sowjetische Medien diesen Begriff für Konzentrationslager und Kriegsgefangenenlager, in denen neben jüdischen auch nichtjüdische Häftlinge interniert waren. ${ }^{346}$

Am Ende ihres Rundganges durch die Ausstellung über die deutsche Besatzungsherrschaft gelangten die Besucherinnen und Besucher in einen Saal mit dem Titel »Die Verschleppung in die deutsche Sklaverei«. Die Verschleppung von Zwangsarbeiterinnen und Zwangsarbeiter gehörte zu den Maßnahmen der Deutschen, die in der Bevölkerung den meisten Hass hervorriefen. Nachrichten über die entwürdigenden und grausamen Umstände der Zwangsarbeit im Reich verbreiteten sich wie Lauffeuer in der besetzten sowjetischen Republik Belarus. Die Berichte erinnerten die Menschen an die Verbannung und Zwangsarbeit im Zarenreich. Sie beschrieben den Abtransport nach Deutschland als "Verschickung in die Sklaverei« und als eine "Strafe«, die »schlimmer" sei als »eine Verschickung nach Sibirien «. ${ }^{347}$ Die muzejščiki übernahmen diese Rhetorik im Saaltitel und in der Beschreibung ihrer Exponate. Die Provenienz der ausgestellten Briefe von Zwangsarbeiterinnen und Zwangsarbeitern wurde mit »aus der deutschen Sklaverei« (iz nemeckogo rabstva) angegeben. ${ }^{348}$ Die Abzeichen mit der Beschriftung »Ost« mussten laut Objekttafel von »Belarussen, Russen und Ukrainern« getragen werden, die »sich in der deutschen Katorga [russische Bezeichnung für Verbannung und Zwangsarbeit im Zarenreich, A.H.] befanden « (nachodjaščichsja na katorge $v$ Germanii). ${ }^{349}$ Vielleicht erinnerte der Anblick der Abzeichen an die Vitrine mit den gelben Sternen im Saal über das jüdische Ghetto. Die deutschen Lageberichte über den Abtransport der »Ostarbeiter« berichteten jedenfalls, dass die Bevölkerung die »Ost«-Abzeichen mit den Judensternen verglich. ${ }^{350}$ Diese Parallelität in der Inszenierung ist ein weiterer Hinweis auf die Intention, das Leid der Bevölkerung und ihren Umgang mit der Gewalterfahrung der deutschen

Ebd. I. 39-40.

Berkhoff, Karel: »Total Annihilation of the Jewish Population«, The Holocaust in the Soviet Media, 1941-45, in: Kritika, Vol. 10, Nr. 1, 2009, S. 61-105, hier S. 96.

Gerlach, Christian: Kalkulierte Morde, S. 477-478.

BDMGVAV, d. 89, I. 32 (alte Signatur). Seit August 1942 durften die Ostarbeiterinnen und Ostarbeiter zweimal im Monat Postkarten und Briefe schicken, die, wegen der großen Zahl der Sendungen, nur zu einem kleinen Teil von der deutschen Zensur überprüft wurden. Vgl. Gerlach, Christian: Kalkulierte Morde, S. 478. 
Besatzung als zentralen Bezugspunkt der Ausstellung zu inszenieren. Dadurch reihte sich der Holocaust in eine allgemeine Genozid-Erfahrung im Krieg ein.

Diese Beobachtung wirft ein neues Licht auf die vermeintliche Marginalisierung oder gar Tabuisierung des Holocausts durch die sowjetische Historiographie. ${ }^{351}$ Wie bereits angesprochen geht die neuere Forschung nicht mehr von einem grundsätzlichen Verschweigen des Holocausts in der sowjetischen Erinnerungspolitik aus, sondern betont vielmehr pragmatische Gründe, die die Führung zu einer ambivalenten, ja widersprüchlichen Haltung zu Denkmälern und öffentlichem Gedenken an die spezifische deutsche Vernichtungspolitik gegenüber dem Judentum motivierte. ${ }^{352}$ In Anbetracht der zahlreichen erfolgreiche Initiativen, die Jüdinnen und Juden in der ganzen Sowjetunion während des Krieges und im Spätstalinismus verfolgten, um mit Denkmälern und Anlässen an den Holocaust zu gedenken, erscheint diese Interpretation einer situativen und regionalspezifischen Erinnerungspolitik schlüssig. ${ }^{353}$

351 Ekaterina Makhotina verweist auf den »festen Platz«, den der »vollständige Ausschluss jüdischer Opfer aus der öffentlichen sowjetischen Erinnerungskultur« habe. Für diese These sprechen laut der Autorin die offiziellen sowjetischen Bezeichnungen der jüdischen Opfer als »sowjetische Zivilisten« oder »Häftlinge des Chettos«. Einschränkend bemerkt sie, dass dies keine vorsätzliche Tabuisierung gewesen sei, da der Holocaust in der osteuropäischen Kriegserfahrung ein integraler Teil des Raub- und Vernichtungskrieges gewesen sei, der gegenüber der Zivilbevölkerung Züge eines Cenozides angenommen hätte. Trotz dieser spezifischen osteuropäischen Erfahrung müsse man bei dem sowjetischen Umgang mit dem Holocaust dennoch von einer »Bemäntelung « oder »Marginalisierung «sprechen, da die »genozidale Intention der deutschen Besatzer «verschwiegen worden sei. Vgl. Makhotina, Ekaterina: Erinnerungen an den Krieg, Krieg der Erinnerungen, Litauen und der Zweite Weltkrieg, Cöttingen 2017, S. 193-194.

Arkadi Zeltser betont dass, »[...] the idea of hushing up the ethnic (Jewish) component of the war was most likely never formally or openly prescribed anywhere [...] «. Als Gründe für die dennoch zögerliche Haltung des sowjetischen Regimes, den singulären Vernichtungscharakter des Holocausts zu benennen, führt er neben dem vorherrschenden Antisemitismus in der Führungsriege erstens die Bedenken der sowjetischen Propagandaabteilung an, bei einer Betonung der großen Anzahl jüdischer Opfer der deutschen These des »]udeo-Bolschewismus « in die Hände zu spielen. Zweitens verfolgten die sowjetischen Behörden die Mobilisierung aller Bevölkerungsgruppen für den »Croßen Vaterländischen Krieg « und verzichteten vor dem Hintergrund des auch in der sowjetischen Bevölkerung weitverbreiteten Antisemitismus auf die Überbetonung einer spezifischen Opfergruppe, um ein Konkurrenzdenken in Bezug auf die vollbrachten Taten und Opfer im Krieg zu verhindern. An dieser Stelle zitiert Zeltser Zvi Gitelman mit der treffenden Aussage: »The Great Fatherland War was too valuable a political asset to be awarded to the Jews. «Vgl. Zeltser, Arkadi: Unwelcome Memory, S. 107-109.

Mordechai Altshuler zeigt auf, wie die zahlreichen Erinnerungspraktiken der Jüdinnen und Juden in den diversen Regionen der UdSSR auf unterschiedliche Reaktionen der staatlichen Behörden trafen. Vgl. Altshuler, Mordechai: Jewish Holocaust Commemoration Activity in the USSR under Stalin, in: Yad Vashem Studies XXX, Jerusalem 2002, S. 271-296. 
Die Ausstellungsanalyse zeigt, dass diese Pauschalisierungen nicht überall oder zur jeder Zeit Bestand hatten. Obwohl die Ausstellung zur Präsentation einer gemeinsamen Leiderfahrung tendierte, in der die jüdische Opfergruppe in einer von Vernichtung bedrohten Gesellschaft aufging, so wurde das spezifische Schicksal der Jüdinnen und Juden dabei nicht (wie in anderen Teilen der Sowjetunion) verschwiegen. Damit fiel die Ausstellung jedoch keineswegs aus dem erinnerungspolitischen Rahmen der Zeit. ${ }^{354}$ Einer der wichtigsten Referenzpunkte der Minsker muzejščiki waren die Unterlagen der ČGK. Als die Ausstellungsvorbereitung im Herbst 1944 auf Hochtouren lief, publizierte diese Untersuchungskommission ihre Ergebnisse über die deutschen Kriegsverbrechen im Minsker Ghetto in der »Pravda« und gab der Inszenierung eine staatliche Legitimation. ${ }^{355}$ Mit Betreten des Ghetto-Saales standen die Besucherinnen und Besucher vor einem Zitat Ilja Ėrenburgs, das die rassisch motivierte Intention des Holocausts beschrieb:

»In den eroberten Ländern und Gebieten ermorden die Hitleristen Millionen Juden [...]. Nie zuvor gab es in der Ceschichte ein vergleichbar methodisch ausgeführtes Verbrechen. Es entspringt dem faschistischen Umfeld. [...] Faschismus beginnt bei den Vorurteilen und endet im Verbrechen. «356

Der bekannte jüdische Journalist, der während des ganzen Krieges in der sowjetischen Presse über das Leid berichtet hatte, betonte hier die Singularität des deutschen Verbrechens an den Jüdinnen und Juden und stellte es in den rassenideologischen Kontext des Nationalsozialismus. ${ }^{357}$ Die muzejščiki kannten diese Texte

354 Dieser Befund scheint auch auf die Ausstellungspraxis der deutschen Nachkriegszeit zuzutreffen. Wobei hier, ähnlich wie für die Ausstellungen der Kriegszeit, weitere Forschungen wünschenswert wären. Einen ersten Ansatz bietet die Studie von Christine Beil zu den Kriegsgefangenenausstellungen der Adenauerzeit. Hier stellt sie fest, dass sich die »staatliche Ausstellungspraxis gegenüber den Opfern der nationalsozialistischen Ausgrenzungs- und Vernichtungspolitik durch Ignoranz und Abwehr « auszeichnete, während die Gedenkstätten für zivile (deutsche) Kriegsopfer und Wehrmachtssoldaten »Konjunktur«hatten. Vgl. Beil, Christine: Erfahrungsorte des Krieges, S. 240.

355 »In einem speziellen Lager-Chetto, im südlichen Teil der Stadt Minsk, haben die Deutschen 100.000 Juden festgehalten. Die Augenzeugen haben ausgesagt, dass [...] der Helfer des Lagerkommandanten Cottenbach zur Musik einen Toast auf die Vernichtung der Juden gesprochen hat, er zwang die Todgeweihten ein Lied zu singen und zu tanzen, während er selbst die Gefangenen erschoss. «In: Ohne Autor: O zlodejanijach nemecko-fašistskich zachvatčikov v gorode Minske, in: Pravda, 20. September 1944, S. 3.

356 BDMGVAV, d. 89, I. 32 (alte Signatur).

357 Karel Berkhoff, der die sowjetische Presse während des Krieges auf die Berichterstattung über den Holocaust untersucht hat, betont, dass die Texte Ėrenburgs eine Ausnahme darstellten, da der Schriftsteller die ungeschriebene Erlaubnis von Stalin gehabt habe, zu schreiben wie es ihm passte, vgl. Berkhoff, Karel: »Total Annihilation of the Jewish Population«, S. 69. Für die Berichterstattung I. Ehrenburgs über den Holocaust in der Sowjetunion vgl. Lustiger, 
und integrierten sie in ihr Narrativ. Dieser Befund bestätigt die Forschung, dass es in der sowjetischen Presse keine konsistente Politik der Verheimlichung des Holocausts gab. ${ }^{358}$ Diese Leerstellen schufen Gestaltungsräume für die Akteure in den Museen. Ihre Handlungsräume zeigten sich in der Auswahl der Exponate, die sie präsentierten. Diese Räume waren in erster Linie durch die zeitliche und räumliche Nähe der Sonderausstellung zu den in ihr präsentierten Ereignissen bestimmt. Beim Verfassen des Ausstellungsplans imaginierten die muzejščiki ihr Publikum, das, genau wie sie selbst, die deutsche Besatzung mit all ihren unterschiedlichen Facetten erlebt hatte. Die auszustellende Geschichte war sowohl für sie als auch für die muzejščiki gerade frisch vergangene Gegenwart und ihre Deutung noch nicht festgeschrieben. Die Inszenierung der Ausstellung über die »Gräuel der Deutschen in Belarus« war eine Kombination aus dem Bedürfnis der Kuratorinnen und $\mathrm{Ku}$ ratoren, die gemeinsame Besatzungserfahrung der belarussischen Gesellschaft zu bezeugen und ihrem Auftrag zur Interpretation und Deutung gerecht zu werden.

Die neun Säle eröffneten der Minsker Bevölkerung besondere Resonanzräume. Während die geschilderten Ereignisse in den Sälen mit Hilfe von Stalin- oder Molotov-Zitaten immer wieder an den Referenzrahmen des »Großen Vaterländischen Krieges« zurückgebunden wurden, bot die Ausstellung eine Vielzahl von Identifikationsmomente, die die spezifische Erfahrung der sowjetischen Republik Belarus repräsentierten. Die in belarussischer Sprache ausgestellten Gedichte von Broŭka und Kupala, der Bericht des Historikers Nikolskij oder das Gemälde des Kriegsgefangenen Romanov spiegelten das universelle Leid auf einer sehr persönlichen Ebene. Die Augenzeugenberichte der Überlebenden und die persönlichen Gegenstände der Opfer verstärkten diese Bezüge. Am deutlichsten drückt sich die agency der muzejščiki in der Darstellung des jüdischen und nichtjüdischen Widerstandes aus. Hier scheint die für Minsk spezifische innerethnische Solidarität die Ausstellung vorstrukturiert $\mathrm{zu}$ haben.

Irina Sklokinas Analyse einer Ausstellung im Historischen Museum Charkow in der ukrainischen Sowjetrepublik bietet sich hier als Vergleich an. Auch in diesem Museum wurden die Besatzungserfahrung der Zivilbevölkerung und der Holocaust direkt nach der Befreiung 1943 ausgestellt. Die Ausstellungen weisen inhaltliche Parallelen in den Inszenierungen auf: Beide Häuser stellten die Themen >Sowjetische Kriegsgefangene und `Zwangsarbeiterinnen und Zwangsarbeiter anhand von Fotos und Gemälden aus. Ferner wurden die Kriegsverbrechen der Besatzer anhand ähnlicher und sogar gleicher Exponate präsentiert (so wurden auch in Charkow ein Vergasungswagen und Folterwerkzeuge der SS gezeigt). Jedoch wurde der Holocaust in Charkow laut Sklokina nur indirekt thematisiert. Jüdinnen

Arno (Hg.): Das Schwarzbuch, Der Genozid an den sowjetischen Juden, Reinbeck bei Hamburg 1995; für den Holocaust in Belarus und die Materialien der ČCK insb. S. 226-400. 
und Juden wurden nicht als spezifische Opfergruppe genannt. Dennoch kommt die Historikerin zu dem Schluss, dass diese Ausstellung der direkten Nachkriegszeit eine besondere Qualität aufwies, die in dem Versuch lag, »[...] to overcome the divison between historical reality and museum exhibits by crafting representations of the authentic past «. ${ }^{359}$

Auch das erste und einzige jüdische Museum in der gesamten Sowjetunion der Nachkriegszeit, das »Museum für jüdische Kunst und Kultur«, das am 26. Juli 1944 in Vilnius eröffnete, bietet sich für einen Vergleich an. Nach der Befreiung der Stadt gründeten jüdische Überlebende, ehemalige Ghetto-Kämpferinnen und Kämpfer, sowie aus der Evakuierung zurückgekehrte jüdische Intellektuelle ein Museum mit acht Räumen, in denen sie eine Ausstellung zusammenstellten, die den Titel »Die Vernichtung der Juden in Litauen während der deutschen Okkupation « trug. ${ }^{360}$

Das Vorgehen der muzejščiki macht einen Entscheidungsfindungsprozess deutlich, der charakteristisch war für den Umgang der Kulturschaffenden mit der stalinistischen Erinnerungspolitik. Die hierarchische Kommunikation zwischen den verschiedenen Akteursebenen war selten von klaren, eindeutigen Befehlen, sondern vielmehr von Hinweisen und Andeutungen geprägt, die es zu interpretieren galt. Sheila Fitzpatrick nannte diese indirekten Informationen, die sich durch Reden oder Zeitungsartikel vermittelten, »Stalin's Signals«, und es war an den Ausführenden auf allen Ebenen, diese Zeichen, die häufig für einen politischen Richtungswechsel standen, »richtig « zu deuten. ${ }^{361}$ Die Ambivalenz, die in dieser Kommunikation bewusst als Strategie angelegt war, führte zwangsläufig dazu, dass sowohl in den obersten Etagen als auch auf lokaler Ebene Entscheidungen auf Grundlage der eigenen Interpretation getroffen wurden. Den Minsker muzejščiki war es offenbar gelungen, die Zeichen und Trends, die die Grenzen der Sagbarkeitsräume absteckten, in einem spezifischen Moment der Nachkriegszeit so zu deuten, dass eine Ausstellung entstehen konnte, die die zivile Leiderfahrung und den Holocaust in der sowjetischen Republik Belarus in das Narrativ des »Großen Vaterländischen Krieg« integrierte. Ging diese besondere Fähigkeit des Zeichenlesens jedoch verloren, so konnte das die Kulturschaffenden schnell ihre Karriere kosten - und unter den Repressionen des Stalinismus sogar das eigene Leben.

359 Sklokina, Irina: The Politics of Remembering, S. 142-156.

360 Makhotina, Ekaterina: Krieg der Erinnerungen, S. 231-236.

361 Fitzpatrick führt aus: »What all these signals had in common was that they indicated a shift of policy in a particular area without spelling out exactly what the new policy entailed or how it should be implemented. «Vgl. Fitzpatrick, Sheila: Everyday Stalinism, Ordinary Life in Extraordinary Times, Soviet Russia in the 1930s, Oxford 1999, S. 26. 


\section{Spätstalinistische Repressionen im Minsker Museum}

In den ersten Nachkriegsjahren gewann das Minsker Museum stetig an erinnerungspolitischer Relevanz. 1946 wurde ihm unionsweite Bedeutung zugesprochen und es wurde, wie das Moskauer Armeemuseum, in den »Ersten Rang« der Museen gehoben. Für den neuen Museumsdirektor Nikolaj Grakov (Belarussisch: Mikalaŭ Grakoŭ) waren diese neuen Vorzeichen, die als größere Deutungshoheit und damit verstärkte Kontrolle von oben interpretiert werden konnten, Anlass an das Komitee für Kulturangelegenheiten des Narkompros der RSFSR zu schreiben. Aus Eigeninitiative kündigte er im November eine grundsätzliche Erweiterung der Ausstellung an. ${ }^{362}$ Die existierenden Sonderausstellungen seien »in Eile« inszeniert worden, und er bat um Verständnis, dass die Inszenierungen deshalb von »sehr dürftigem Charakter « (ves'ma ubogij charakter) waren. ${ }^{363}$ Insbesondere zwei neue thematische Schwerpunkte - über die Vorkriegsgeschichte der sowjetischen Republik Belarus und über den Kampf der Roten Armee - sollten laut Grakov zur Grundlage der neuen Dauerausstellung werden. ${ }^{364}$ Diese wurde im Mai 1947 fertiggestellt. Zur Unterstützung bei methodischen Fragen der Ausstellungsinszenierung hatten sich die Minsker muzejščiki an das Museumsinstitut des Narkompros der RSFSR in Moskau gewandt. ${ }^{365}$ Von nun an präsentierte das Museum nicht mehr nur die zwei Abteilungen zur Partisanenbewegung und zur deutschen Besatzungsherrschaft, sondern insgesamt sechs Kapitel der Kriegskommemoration:

»1. Belarus in der Vorkriegszeit,

2. Die heroische Verteidigung des sowjetischen Volkes gegen die deutsch-faschistischen Eroberer,

NARB, f. 1246, d. 12, I. 26-27. N. Grakov, der V. Stal'nov am 2. März 1946 als Museumsdirektor ablöste, war vor dem Krieg Direktor des Belarussischen Museums der Revolution gewesen, das durch die deutsche Bombardierung von Minsk vollständig zerstört und anschließend geplündert wurde. Vgl.: Hužaloŭski, Aljaksandr: Gistorija muzejnaj spravy belarusi, S. 222. Dieses vorsichtige Verhalten war, wie Arkadi Zeltser betont, weit verbreitet und nachvollziehbar, da die Grenzen der Sagbarkeitsräume nur durch ein Austesten auszuloten waren und der Ausgang einer solchen Initiative schwer vorauszusehen war und mögliche negative Konsequenzen nach sich ziehen konnte. Zeltser, Arkadi: Unwelcome Memory, S. 112-113. Ebd. I. 26.

Ebd. Grakov argumentierte, dass es in der Republik kein anderes Museum gäbe, das diese Themen ausstellen könnte. Hier zeigt sich, das Selbstverständnis des Museumsdirektors mit republiksweiten Führungsanspruch in der Deutung des »Crossen Vaterländischen Krieges«.

Am 14. Januar 1946 schickte das Komitee für Kulturangelegenheiten des Narkompros der RSFSR dem belarussischen Komitee ein Schreiben mit Informationen über das Angebot und einer Einladung für Weiterbildungskurse am Institut. Anbei lagen methodische Empfehlungen des Museumsinstitutes. Vgl. Galkina (14. Januar 1946) Upravlenie muzeev, in: NARB, f. 790, op. 1, d. 11, I. 1. 
3. Das Besatzungsregime der deutsch-faschistischen Eroberer in Belarus,

4. Die Partisanenbewegung des ganzen belarussischen Volkes,

5. Die Befreiung der Sowjetunion von den deutsch-faschistischen Eroberern,

6. Die Rote Armee, Befreierin der Völker Europas von der faschistischen Sklaverei. $\ll^{366}$

Eingerahmt in den militärischen und ideologischen Kontext des stalinistischen Machtmonopols, das vor, während und bis über den Krieg hinaus bestand, konnte die Darstellung des (zivilen) Leids im Museum bestehen bleiben. Auch für das Festhalten an der musealen Kommemoration des Holocausts gab es 1946/47 legitimierende Anzeichen. Unter den ersten wissenschaftlichen Studien, die in diesen Jahren sowohl auf Jiddisch als auch auf Russisch über den Mord an den Jüdinnen und Juden erschienen, befand sich auch das Buch des Untergrundkämpfers Hersh Smolars »Fun minsker geto« (Das Minsker Ghetto). Und obwohl diese Texte die grundlegenden Annahmen einer Freundschaft der Völker und des Vernichtungskrieg der Nazis, der sich gegen alle Völker der Sowjetunion richtete, nicht hinterfragten, so enthielten sie doch umfassende Informationen über das spezifische Schicksal der Jüdinnen und Juden. ${ }^{367}$ Ebenfalls ein Zeichen der Sagbarkeitsräume war das Holocaust-Denkmal, das im August 1946 in der sogenannten »Jama« (belarussisch für Grube) im ehemaligen Minsker Ghetto von überlebenden Jüdinnen und Juden initiiert wurde. Dieses Denkmal gilt nicht nur als einer der ersten Erinnerungsorte an den Holocaust in der Sowjetunion, sondern auch als eines der wenigen, die jiddische Inschriften trugen. ${ }^{368}$ Der jüdische Dichter Chaim Mal'tinsky, der als Offizier in der Roten Armee gekämpft hatte, während seine Mutter, Frau und Sohn im Minsker Ghetto umkamen, verfasste die Inschrift, die in Jiddisch und Russisch auf der schwarzen Granitstele eingraviert wurde: »Zum ewig gesegneten Gedenken an die fünftausend Juden, die von den Todfeinden der Menschheit den deutschen faschistischen Übeltätern - ermordet wurden, 2. März $1942{ }^{369}{ }^{369}$ In seiner Studie zur Geschichte der Holocaust-Denkmäler in der Sowjetunion nennt der Historiker Arkadi Zeltser das Minsker Denkmal, weil es die jüdischen Opfer in

366 NARB, f. 1246, op. 1, d. 12, I. 27-27ob.

367 Zur gleichen Zeit erschienen auch die Bücher von Avrom Sutzkever »Fun vilner geto« (Das Chetto in Vilna «) und von Ber Mark »Der ufshtand fun varshever geto (Der Aufstand im Warschauer Chetto). Vgl. Zeltser, Arkadi: Unwelcome Memory, S. 120.

368 Arkadi Zeltser weist auf die parallelen Entwicklungen in Vilnius hin, wo jüdische Kreise an der Erschießungsstelle Ponary ebenfalls ein Denkmal mit jiddischen und sogar hebräischen Inschriften errichteten. Vgl. Zeltser, Arkadi: Unwelcome Memory, S. 123.

369 Smilovitsky, Leonid: Jewish Life in Belarus, S. 168. Zu den Memoiren von Chaim Mal'tinsky und den Aktivitäten und Hintergründen der jüdischen Cemeindemitglieder, die sich für die Errichtung des Denkmals einsetzten, vgl. Cerasimova, Inna: Novaja istoria starogo pamjatnika, in: Mishpoha 22, 2008, S. 90-97. 
beiden Sprachen nannte, einen wichtigen Präzedenzfall, der Signalwirkung nicht nur für die Republik, sondern die ganze Sowjetunion hatte. ${ }^{370}$

Doch diese erste Periode der Nachkriegskommemoration (1943-1947), in der die Behörden dazu neigten, die jüdische Holocaust-Erinnerung zu tolerieren, wurde schleichend von einer Stimmung abgelöst, die kaum mehr Raum für die jüdische oder, allgemeiner gesprochen, die Leiderfahrung der sowjetischen Gesellschaft bot. Der Vorsitzende des Jüdischen Antifaschistischen Komitees (JAK) Solomon Michoels drückte die allgemeine Erwartung an eine vorwärtsgerichtete Geisteshaltung folgendermaßen aus: »It was required that we should not succumb to lamenting the past but rather build a new life. And the less we pick up old wounds, the sooner we would build it. ${ }^{371}$

Im April 1948 wurde die neue Dauerausstellung des Minsker Museums von der obersten Parteiinspektion scharf kritisiert und musste grundlegend umgebaut werden. ${ }^{372}$ Moniert wurde insbesondere der zu starke Fokus auf die spezifische Kriegserfahrung der sowjetischen Republik Belarus. In der Folge musste das Ausstellungskapitel zum Besatzungsregime Exponaten und Inszenierungen über die Heldentaten der Roten Armee weichen. Eine Reihe von Museumsangestellten wurde entlassen. Erste Anzeichen für diese politisch motivierte Säuberung hatte es bereits Ende 1947 gegeben, als die »Trophäenausstellung« (trofejnaja vystavka), an der die muzejščiki intensiv mitgearbeitet hatten, geschlossen wurde. Die Präsentation erbeuteter Waffen, die auch im Zentrum der ersten Sonderausstellung des Moskauer Armeemuseums gestanden hatte, war spätestens seit der monumentalen Trophäenausstellung im Gorki-Park im Sommer 1943 ein populäres Mittel der musealen Kriegspropaganda. ${ }^{373}$ Auch die Ausstellung, die unter der Leitung des Generalmajors der Artillerie I. Novikov am 7. November 1944 in Minsk eröffnet wurde, war sehr beliebt gewesen. Die bekannten Architekten Jakob Lichtenberg und Boris Vilenskij, die mit einer Gruppe von Baumeistern für den Wiederaufbau von der Regierung nach Minsk gerufen worden waren, planten die Trophäenausstellung

Zeltser, Arkadi: Unwelcome Memory, S. 127.

Rolnikaite, Marija: I vse eto - Pravda, St Petersburg 2002, S. 333, zitiert nach Zeltser, Arkadi: Unwelcome Memory, S. 129.

Auch die Inspektoren der Partei wandten sich an das Moskauer Museumsinstitut, um methodische Empfehlungen für die »richtige« museale Darstellung des »Großen Vaterländischen Kriegs « zu erhalten. NARB, f. 790, op. 1, d. 11, I. 4.

Auf den Tag genau zwei Jahre nach dem Überfall der Wehrmacht auf die Sowjetunion eröffnete am 22. Juni 1943 im Moskauer Gor'kij Park eine Trophäenausstellung. Das Staatliche Verteidigungskomitee der UdSSR hatte die vielbesuchte Ausstellung, die in mehreren Abteilungen die verschiedenen Waffengattungen der Wehrmacht und ihrer Verbündeten zeigte, initiiert. Sie war bis zum 1. Oktober 1948 geöffnet. Das Kinostudio »Mosfilm«drehte eine Dokumentation der Ausstellung: »Trofei velikich bitv, Vystavka obrazcov trofejnogo vooruženija, in: https://www.youtube.com/watch?v=mDFPdeASvoA (Stand: 17.12.2018). 
als Teil eines neuen Stadtparks. $17.000 \mathrm{~m}^{2}$ Ruinenlandschaft wurden von Schutt, Trümmern und Müll geräumt, Akazienbüsche und Bäume wurden gepflanzt und 100 Bänke aufgestellt. ${ }^{374}$ Am Haupteingang stand einer der ersten sowjetischen Panzer, die Minsk erreicht hatten. Auf seinem Postament standen die berühmten Worte der Filmrede Aleksandr Nevskijs »Wer mit dem Schwert zu uns kommt, wird durch das Schwert fallen «. ${ }^{375}$ Auf der gegenüberliegenden Seite war eine große Tafel angebracht, die die Zahlen der Gefallenen bei den Kämpfen zur Befreiung der sowjetischen Republik Belarus aufführte. Sie wurde von zwei Obelisken mit den Daten der Kämpfe um Minsk und der Befreiung anderer belarussischer Städte flankiert. ${ }^{376}$ Ein Zaun aus Sperrholzplatten, die mit Kampfszenen bemalt und mit Kriegsrhetorik bestickten roten Tüchern geschmückt waren, rahmte die großzügige Fläche ein. Eine große Stalin-Statue, deren Sockel die Worte »Wir schwören, Genossen, dass wir keine Kräfte schonen werden, um unsere Rote Armee und unsere Rote Flotte zu unterstützen« trug, überragte die Ausstellungsfläche. Vier Ausstellungsbereiche waren den einzelnen Waffengattungen Artillerie, Panzer, Flugwaffe und Ingenieurswesen gewidmet. Aus den Kesselschlachten von Minsk und Babrujsk waren eine Vielzahl eroberter Waffen herbeigeschafft worden. Die Ausstellung zeigte neben der Technik der Wehrmacht französische, holländische, belgische, tschechoslowakische, jugoslawische, polnische und norwegische Fabrikate. ${ }^{377} \mathrm{Zu}$ Anschauungszwecken wurde sogar ein Bunker restauriert, den die Deutschen zur Verteidigung von Minsk gebaut hatten. Ende November 1944 wurden zusätzlich sechs Pavillons aus Holz errichtet. Sie präsentierten die Telekommunikation und andere militärische Ausrüstung sowie die Minen und ihre Zünder, die die Deutschen vor ihrer Flucht in der Stadt vergraben hatten. Besonderes Interesse im Publikum rief das bewegliche Panzernest »Krabbe« hervor, das die Wehrmacht in den Verteidigungslinien eingesetzt hatte. Offiziere, die an den Kämpfen teilgenommen hatten, führten Schulklassen, Sttudierende und Arbeiterkollektive durch

374 Ohne Autor: Respublikanskaja vystauka uzorau trafejnaga uzbraennja, in: Zvjazda, 11. November 1944, S. 3.

375 Dieses Zitat, das als Kurzformel für die politische Botschaft des Filmes »Aleksandr Nevskij« von 1938 gilt, entbehrt jeder historischen Quellengrundlage. Dennoch wurde dieses angeblich aus dem 13. Jahrhundert stammende Zitat während des Deutsch-Sowjetischen Krieges von Stalin als rhetorisches Stilmittel mit neuer Bedeutung versehen. Vgl. Schenk, Frithjof Benjamin: Aleksandr Nevskij, S. 375-364.

376 Voronkova, Irina: Sozdanie i sostavlenie, S. 25.

377 Die Waffen waren in drei Reihen angeordnet. In der Mitte befanden sich die deutschen Geräte, darunter: zwei Jagdflieger (»Messerschmitt 109« und »Fokke-Wulf-190«), Panzer (»Tiger«, »Panter«, »Ferdinand«, »T-VI«), Granatwerfer und Kanonen verschiedener Kaliber (210 mm Kanone), Maschinengewehre, Panzerwagen, Autos, Transportgeräte und Ausrüstung. Vgl. Voronkova, Irina: Sozdanie i sostavlenie Belorusskogo Gosudarstvennogo Muzeja, S. 25. 
die Parkanlage und die Pavillons. ${ }^{378}$ Wie im Kriegsmuseum wurden auch hier keine Mittel gescheut, um eine aufwendig inszenierte Trophäenschau zu präsentieren.

Trophäe stammt von dem griechischen Wort tropaion ab und bezeichnet den Ort, an dem die Sieger den Ort ihres Sieges mit den Waffen der Besiegten markierten. Tropaion wiederum wurde von dem Wort trope abgeleitet, das den Moment der Schlacht und den Raum auf dem Schlachtfeld beschreibt. Der Ort also »[...] an dem die Siegesgewissheit der einen Seite umkippt, ihr Kampfwille (die >Morak) abfällt, die militärische Formation sich auflöst und die gesamte Streitmacht ihr Heil in der Flucht [...] sucht «. ${ }^{379}$ Die Artilleristen der Operation »Bagration« knüpften bei der Minsker Inszenierung, unbewusst oder nicht, an diese Tradition an, indem sie den Ort ihres Sieges mit den Waffen der Besiegten kennzeichneten und, als weiteren territorialen Marker dieses Sieges, den deutsche Bunker bewusst bewahrten.

Die genauen Hintergründe der Ausstellungsschließung in den Nachkriegsjahren 1947/48 sind nicht bekannt. Es lässt sich vermuten, dass es eine politisch motivierte Handlung war, die den Ruhm des Militärs und der einzelnen Waffengattungen im Kontext der stalinistischen Säuberungen einschränken wollte. Vielleicht spielte auch eine veränderte Wahrnehmung der Ausstellungsstücke, der Trophäen, eine Rolle. Denn die zahlreichen ausgestellten Waffen stammten, mit Ausnahme des >Nevskij-Panzers`, alle vom Feind. ${ }^{380}$ Brandon Schechter hat in seiner Untersuchung der materiellen Kultur der Roten Armee gezeigt, dass die Konfrontation der Roten Armee mit den Trophäen des Feindes (der insbesondere in den ersten zwei Kriegsjahren weitaus besser ausgerüstet war), eine »combination of attraction and revulsion « hervorrief. ${ }^{381}$ Diese >widerwillige Faszination deutet Schechter als unbeabsichtigte Folge der sozialistischen Propaganda, die den sowjetischen Menschen von Beginn an eine Ablehnung von (bourgeoisen) Besitztümern anerziehen wollte. Das führte dazu, dass der Staat im Verlauf des Krieges seine Kontrolle über die Trophäen immer weiter ausdehnte. ${ }^{382}$ Während zu Beginn des Krieges, als der Roten Armee die Niederlage drohte, zerstörtes deutsches Kriegsgerät en masse ausgestellt wurde, um die Besiegbarkeit der Wehrmacht zu beweisen, drohten die Trophäen am Ende des Krieges den sowjetischen Herrschaftsanspruch zu unterminieren. Die große Beliebtheit der Ausstellung unter den Minskerinnen und Minskern und ihre offensichtliche Faszination für die ausländische Militärtechnik

Ebd. S. 26.

Das Bedeutungsfeld von trope umfasst die Vorstellung von Wandlung, Umkehr, Flucht, Wechsel, Veränderung. Vgl. Schivelbusch, Wolfgang: Die Kultur der Niederlage, S. 17, sowie Fußnote 14, S. 348.

Kiričenko, Vitalij: Minsk 1944-1952, Istorija poslevoennogo vosstanovlenija, Minsk 2004, S. 49.

Schechter, Brandon: The Stuff of Soldiers, S. 214.

Ebd. S. 192-198. 
mögen, in Kombination mit den selbstbewussten Artilleristen, die sich hier ihr persönliches Tropaion errichtet hatten, zu der Schließung des Parks geführt haben. ${ }^{383}$ Das Schicksal der zahlreichen Exponate ist weitgehend unbekannt. Die Anfrage des Museumsdirektors Grakov vom März 1948 an die belarussische Militärverwaltung, ob sie den T-34-Panzer der »liquidierten Trophäen-Ausstellung« der Sammlung des Kriegsmuseums übergeben könnten, blieb unbeantwortet. ${ }^{384}$

Zur gleichen Zeit kam es innerhalb der obersten Parteiführung der belarussischen Sowjetrepublik zu einem Machtwechsel. Der Parteiinspektor Nikolaj Gusarov übernahm den Posten des Ersten Sekretärs der KP Belarus von Pantelejmon Ponomarenko und schickte Ende April 1948 eine Untersuchungskommission zur Überprüfung der Ausstellung in das Minsker Museum.

Die Historikerin Irina Sklokina betont, das diese staatlichen Kommissionen von den Museen nicht zwangsläufig als »dangerous external force intending on punishing the museum for its ideological mistakes« erachtet wurden, sondern den muzejščiki auch als hilfreiche Orientierung bei der Ausrichtung ihrer Arbeit dienten: "Indeed, inviting a higher official to review the museum was the easiest way to legitimize an exhibition, shifting responsibility onto this official and thereby reducing the fear of any punishment. These commissions were viewed as helpful sources of information about the most recent changes at the ideological frontline. ${ }^{385}$

Im Fall des Minsker Museums bestand die Kommission aus dem Stellvertretenden Leiter der Abteilung für Agitation und Propaganda und dem Direktor des Instituts für Parteigeschichte. In ihrem Bericht dokumentierten sie eine »Reihe von äußerst gravierenden Fehlern" (ves'ma suščestvennych nedostatkov) in der Ausstellung des Kriegsmuseums. ${ }^{386}$ Während der erste Kritikpunkt das unzusammenhängende Narrativ des historischen Ausstellungskapitels zur Geschichte der sowjetischen Republik Belarus vor dem Krieg bemängelte, kritisierten die restlichen vier Punkte die unzureichende Berücksichtigung der Rolle der Roten Armee und der Partei im „Großen Vaterländischen Krieg«. Dabei wurden Vorstellungen der Kommission offenbar, die die muzejščiki kaum umsetzen konnten, da es schlicht keine Materialien dazu gab. So wurde beispielsweise verlangt, dass der »heroische Kampf der sowjetischen Armee und des sowjetischen Volkes« zwischen Juni 1941 und Februar 1942

383 Brandon Schechter hat den Drang des sowjetischen Staates beschrieben, Trophäen zu kontrollieren und auf die spezifische »Aura« der beliebten Trophäen aus dem Ausland hingewiesen: „They were things that had belonged to people now dead or in captivity, that had been used against those who took them, or at the very least, been constructed on foreign territory and came from a foreign world. Foreigness was dangerous in the Soviet Union. « Vgl. Schechter, Brandon: The Stuff of Soldiers, S. 217. NARB, f. 1246, op. 1, d. 20, I. 24. Seit 1952 steht der Panzer auf einem aufsteigenden Podest vor dem Haus der Roten Armee (Heute »Haus der Offiziere«) im Zentrum von Minsk. 
stärker ausgestellt werden sollte. ${ }^{387}$ Die Anfangsphase des Krieges, als die Zivilbevölkerung nach der Evakuation der Partei den schnell vorrückenden Wehrmachtsverbänden hilflos ausgeliefert war und die Widerstands- und Partisanenbewegung sich noch nicht formiert hatte, konnte unmöglich im Sinne der Kommission umgedeutet werden.

Auch die Inszenierung der zweiten Phase des Krieges, die für die sowjetische Republik Belarus unter anderem in der Erfahrung des Partisanenkampfs bestand, wurde scharf kritisiert. Hier warfen die Inspektoren den muzejščiki vor, dass sie den Eindruck einer »zweitrangigen Rolle der Roten Armee« bei der Befreiung vermittelten und den Einfluss der Partei auf die Widerstandsbewegung zu wenig betonten. ${ }^{388}$ Die Inspektoren kritisierten politische Nachlässigkeit in der Ausstellungsarbeit und erkannten gleichzeitig den Fokus, dem die Kuratorinnen und Kuratoren ihre größte Aufmerksamkeit gewidmet hatten: „Die Fehler in der Darstellung der Rolle der Sowjetischen Armee im Großen Vaterländischen Krieg [...] treten vor dem Hintergrund der Ausstellungsinszenierung der Partisanenbewegung und des $\mathrm{Be}-$ satzungsregimes besonders deutlich hervor. ${ }^{389}$ Vorwurfsvoll beanstandeten sie, dass in diesen Abteilungen besonders viele Originale und Kunstwerke ausgestellt seien, während man sich in den Kapiteln zur Roten Armee mit Fotos, Tabellen und Schemata zufriedengegeben habe. Die Kapitel zur Besatzungserfahrung waren den Inspektoren dabei ein besonderer Dorn im Auge. Sie würden »den ganzen Rest der Ausstellung beherrschen « (dovlejut nad vsej ostal'noj ekspozicii muzeja). ${ }^{390}$ Der Bericht schloss mit Maßnahmen, die für eine Beseitigung der »Fehler« in der Ausstellung unumgänglich seien: Das historische Ausstellungskapitel zur Geschichte der sowjetischen Republik Belarus vor dem Deutsch-Sowjetischen Krieg sollte geschlossen werden und der Platz für die Darstellung des Kampfes der Roten Armee in der ersten Kriegsphase genutzt werden. Der »Saal des Sieges« sollte so umgebaut werden, dass Stalins Anteil am Sieg deutlicher werde. Auf Kosten von Exponaten zum Kapitel über das Besatzungsregime sollten Materialien ausgestellt werden, die den großen Einfluss der Partei auf die Partisanenbewegung zeigten. ${ }^{391}$

Noch am gleichen Tag schickte Museumsdirektor Grakov ein Schreiben an den Parteisekretär für Propaganda und Agitation Michail Iovčuk, in dem er seine Pläne zu einem Ausstellungsumbau gemäß den Wünschen der Inspektoren darlegte. ${ }^{392}$ Dieses Schreiben markiert den Eintritt einer homogenen Meistererzählung in das Minsker Museum. Die historische Einführung im ersten Ausstellungssaal wurde

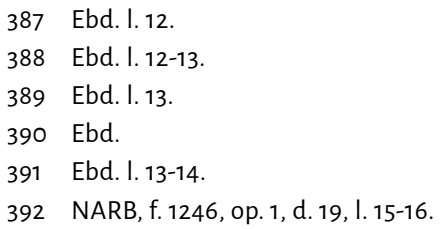


abgeräumt und universelle Themen mit identischem Wortlaut (»Der wortbrüchige Überfall der deutsch-faschistischen Eindringlinge in die Sowjetunion und die heldenhafte Verteidigung des Sowjetischen Volkes«) verdrängten die lokale Erinnerung. Porträts der Mitglieder des Politbüros und Gemälde der Schlacht um Stalingrad wurden in Auftrag gegeben. Die Ausstellung wurde mit 44 neuen Exponaten zur Rolle der Roten Armee ergänzt. ${ }^{393}$

Die spätstalinistischen Säuberungen zwangen die muzejščiki im Minsker Kriegsmuseum zur Wegnahme jener Exponate, die die Massenvernichtung der Jüdinnen und Juden im Minsker Ghetto darstellten. Der Mitarbeiterstab wurde gekürzt und es kam zu Entlassungen insbesondere von Personen, die sich während des Krieges unter deutscher Besatzung befunden hatten. ${ }^{394}$

Diese personellen und inhaltlichen Eingriffe in die Museumsarbeit sind im Kontext der bereits erwähnten Kulturpolitik namens »ždanovščina« und in den stark antisemistisch geprägten Repressionen des Spätstalinismus zu sehen. ${ }^{395}$ Die Kulturpolitik unter Ždanov richtete sich gegen jede Erinnerung, die den Krieg als etwas Lokales, Individuelles, Schmerzhaftes oder Absurdes darstellte, kurz: gegen alles, das den Krieg nicht als gemeinsamen großen Kampf beschrieb. ${ }^{396} 1949$ kulminierte diese »kulturelle Eiszeit« in der sogenannten »Leningrader Affäre«, die zur Auslöschung der spezifischen Blockade-Erinnerung der Stadt führen sollte. ${ }^{397}$ Diese Kampagne, die Steven Maddox als »Stalin's most vicious postwar purge« bezeichnete, repressierte die Leningrader Parteielite und die kulturschaffenden Institutionen, die die Erinnerung an die Blockade am stärksten gefördert hatten. ${ }^{398}$

393 Ebd. I. 15-16.

394 Hužaloŭski, Aljaksandr: Gistorija muzejnaj spravy belarusi, S. 222-223.

395 Zur Lage der jüdischen Bevölkerung im Spannungsfeld zwischen sowjetischem Antisemitismus, jüdischer Selbstbehauptung im »]üdischen Antifaschistischen Komitee« (JAK) und Stalinismus in den Jahren 1941 bis 1953 siehe: Grüner, Frank: Patrioten und Kosmopoliten, Juden im Sowjetstaat 1941-1953, Köln/Weimar/Wien 2008. Zur historischen Entwicklung der anti-jüdischen Kampagnen und Säuberungen im Spätstalinismus (der »Kampagne gegen den wurzellosen Kosmopolitismus« und der sogenannten »Ärzteverschwörung«) siehe: Kostyrchenko, Gennadi: Out of the Red Shadows, Anti-Semitism in Stalin's Russia, Amherst 1995. Die Beiträge in dem von Leonid Luks herausgegeben Sammelband »Der Spätstalinismus und die sjüdische Frageく, Zur antisemitischen Wendung des Kommunismus, Köln/Weimar/Wien 1998« gehen den unterschiedlichen Ausprägungen in verschiedenen Regionen der sowjetischen Einflusssphäre in der Nachkriegszeit nach.

396 Kirschenbaum, Lisa: The Legacy of the Siege, S. 142-143.

397 Zur»Leningrader Affäre«, die vordergründig ein Machtkampf zwischen dem Leningrader und dem Moskauer Parteibüro war, und für eine Einordnung innerhalb der sowjetischen Nachkriegsrepressionen, vgl. Zubkova, Elena: Russia after the War, Hopes, Illusions, and Disappointments, 1945-1957, übersetzt und herausgegeben von Hugh Ragsdale, Armonk 1998, S. $130-138$.

398 Maddox, Steven: Saving Stalin's Imperial City, S. 171. 
Laut Lisa Kirschenbaum war das Museum der Leningrader Verteidigung der prominenteste und in den Augen der Moskauer Parteielite der gefährlichste Träger der Erinnerung an die Belagerung. Als angesehenes und beliebtes Museum präsentierte es eine vermeintlich umfassende und präzise Darstellung der Blockadeerfahrung und provozierte bei dem Publikum durch emotionale Identifizierung Empathie und Verständnis für die zivilen Opfer. ${ }^{399}$ Als das ZK-Mitglied Georgij Malenkov im Februar 1949 das Museum besuchte, ließ er sich den Ausstellungsführer geben und beschuldigte die muzejščiki, anti-sowjetische Exponate auszustellen und Stalins Rolle bei der Verteidigung zu »pervertieren« (izvraščat'). Sie hätten nur das Leid der Leningraderinnen und Leningrader ausgestellt, ohne die Bedeutung der Partei zu berücksichtigen. ${ }^{400}$ Der Vorwurf bestand in der Etablierung eines eigenen, unabhängigen Mythos eines spezifischen Kriegserlebnisses während der Belagerung und führte zur Verhaftung der leitenden muzejščiki. Das Museum wurde geschlossen und am 18. Februar 1953 offiziell aufgelöst. Seine Sammlungen, mehr als 32.000 Objekte, wurden auf diverse Museen verteilt oder zerstört. ${ }^{401}$

Definitiv waren die »Leningrader Affäre« und die Intervention Malenkovs im »Museum der Verteidigung von Leningrad« als politische Warnsignale gegen zu autonome und vor allen Dingen partikulare museale Kriegserinnerung zu interpretieren. Ein weiteres >Museumsopfer $<$ der spätstalinistischen, antisemitischen Säuberungen war das einzige jüdische Museum der sowjetischen Nachkriegszeit, das 1944 von Jüdinnen und Juden in Vilnius eröffnet worden war. Im Juni 1949 wurde das »Museum der jüdischen Kunst und Kultur « vom Ministerrat der litauischen SSR »reorganisiert«, was praktisch einer Liquidierung gleichkam, da alle Objekte auf diverse Archive und Museen im Land verteilt wurden und im ehemaligen Museumsgebäude eine Fachhochschule eingerichtet wurde. ${ }^{402}$ Die Ghetto-Überlebende und Mitgestalterin des Vilniusser Museums Marija Rolnikaite »[...] erinnert sich an die bittere Enttäuschung, als das Museum, das Einzige, was noch in der Stadt an das tragische Schicksal ihrer Angehörigen erinnerte, geschlossen wurde: >... es war gnadenlos - das zu vernichten, was während der deutschen Besatzung unter Lebensgefahr gerettet wurde. « 403

399 Nach der Ermitage war das Museum der Verteidigung von Leningrad das bekannteste und beliebteste Museum der Stadt. Seit seiner Eröffnung im April 1944 hatten bis 1949 über eine Millionen Menschen das Museum besucht. Dies entsprach in etwa der Leningrader Nachkriegsbevölkerung. Vgl. Kirschenbaum, Lisa: The Legacy of the Siege, S. 145-146.

400 Maddox, Steven: Saving Stalin's Imperial City, S. 190.

401 Unter den Objekten erwähnt Lisa Kirschenbaum 123 Dioramen und Modelle, 131 Karten, 6 Flugzeuge und einen Panzer. Vgl. Kirschenbaum, Lisa: The Legacy of the Siege, S. 145.

402 Makhotina, Ekaterina: Krieg der Erinnerungen, S. 235.

403 Rolnikaite, Marija: I vse eto - Pravda, St. Peterburg 2002, S. 392, zitiert nach: Makhotina, Ekaterina: Krieg der Erinnerungen, S. 236. 
Die anti-jüdischen Repressionen spitzten sich bis zur sogenannten »Ärzteverschwörung « und Stalins Tod im März 1953 immer weiter zu. Im Januar 1948 wurde Solomon Michoels in Minsk ermordet, und das Jüdische Antifaschistische Komitee wurde verboten. Die »Kampagne gegen den wurzellosen Kosmopolitismus« führte zu Massenverhaftungen jüdischer Kunstschaffender, unter denen sich auch der Bildhauer Mordukh Sprishen befand, der 1946 das Holocaust-Denkmal in der Jama beschriftet hatte. Unter der Anklage »Jüdisch-bourgeoiser Nationalismus « und mit dem Vorwurf »Juden« anstelle von »sowjetischer Bürger« auf das Denkmal geschrieben zu haben, wurde er zu zehn Jahren Zwangsarbeit in den Kohleminen von Pečora verurteilt. ${ }^{404}$

Vor diesem Hintergrund lesen sich die Repressionen, die Entlassungen und die forcierten Ausstellungsumgestaltungen, zu denen das Minsker Kriegsmuseum gezwungen wurde, vergleichsweise harmlos. Die Solidarität, die die muzejščiki im Herbst 1944 dazu motiviert hatte, das spezifische Leid der Jüdinnen und Juden als Bestandteil der Besatzungserfahrung in der sowjetischen Republik Belarus darzustellen, überdauerte jedoch den Spätstalinismus. Die ehemalige Untergrundkämpferin Chasja Pruslina, die Jüdinnen und Juden aus dem Minsker Ghetto gerettet hatte, kämpfte trotz massiver staatlicher Einschüchterungsversuche in der Nachkriegszeit über 15 Jahre lang für eine offizielle Anerkennung der ersten Widerstandsbewegung. Sie erinnerte sich, dass die Angestellten des Minsker Kriegsmuseum 1954, zum 10. Jahrestag der Befreiung von Minsk, die ehemaligen Mitglieder des »Stadt-Komitees « zu einer Konferenz eingeladen hatten. Alle Beteiligten konnten hier ihren Beitrag zum Widerstand gegen die deutsche Besatzung öffentlich äußern und ihre Diskriminierungserfahrung in der Nachkriegszeit miteinander teilen. Chasja Pruslina betonte, dass das Museum als Veranstaltungsort dieser einwöchigen Konferenz öffentliche Aufmerksamkeit erregte und Legitimität für den politisch diffamierten Untergrund herstellte. ${ }^{405}$

Das Fallbeispiel der Minsker Museumsarbeit in der Nachkriegszeit zeigt, wie eine regionalspezifische Kriegskommemoration, die sogar vermeintliche Tabus der Erfahrungsgeneration (Holocaust, sowjetische Kriegsgefangene, ziviles Leid) ausstellte, möglich wurde. Damit fordern uns die Minsker muzejščiki auf, das Verständnis von der Entstehung der sowjetischen musealen Kriegserinnerung unter Stalin um die Dimension des Einflusses der Überlebensgeneration zu erweitern. 


\section{Steine im Krieg. Eine Ausstellung im Tscheljabinsk der Nachkriegszeit}

Am 16. April 1946, ein knappes Jahr nach Kriegsende, lud der Tscheljabinsker Museumsdirektor Ivan Gorochov zur Vernissage der Sonderausstellung »Die Rolle Tscheljabinsks im Großen Vaterländischen Krieg«. Fast fünf Jahre war das beliebte Museum im Zentrum der Stadt geschlossen gewesen. Das Kommissariat für Inneres (NKVD) hatte die Ausstellungsräume in der ehemaligen Kirche für die evakuierten Bestände seiner Archive beansprucht.

Obwohl oder gerade weil der Museumsdirektor während des Krieges seiner klassischen Ausstellungsarbeit nicht mehr nachgehen konnte, hatte Ivan Gorochov andere Mittel und Wege gefunden, den Menschen das entbehrungsreiche Leben an der Heimatfront zu erleichtern. Mit seinem geschickten Lavieren zwischen Erfüllung, Umdeutung und Nichtbeachtung der Vorgaben, die ihm das zentrale Museumsinstitut in Moskau machte, hatte sich Ivan Gorochov im Schatten des DeutschSowjetischen Krieges berufliche Handlungsfreiräume geschaffen. Seine Überzeugung von kraevedenie, die die Erforschung lokaler Mensch-Natur-Beziehungen verfolgte, hatte ihn veranlasst, nicht nur Heilkräuter und essbare Pflanzen zur Linderung der Hungersnot zu sammeln, sondern auch die geologischen Vorkommen des Süd-Urals als Ressourcen der militärischen Verteidigung zu erforschen. Sein Engagement schien im Einklang mit den Anforderungen der Zeit zu stehen, denn im November 1945 zeichnete das Präsidium des Obersten Sowjets den Museumsdirektor mit dem Orden »Für selbstlose Arbeit im Großen Vaterländischen Krieg 19411945« (Za doblestnij trud v velikoj otečestvennoj vojne 1941-1945 gg.) aus und die Tscheljabinsker Stadtverwaltung gab ihm sein Gebäude zurück, damit er die Museumstätigkeit wieder aufnehmen konnte. ${ }^{406}$

Jedoch verfügte der Museumsdirektor nach dem Krieg weder über das wissenschaftliche und technische Personal noch über die finanziellen und materiellen Mittel, um an die Ausstellungen der Vorkriegszeit anzuknüpfen. Seine Sammlungen hatten während der »Konservierung« im Krieg unter den ungünstigen Lagerbedingungen stark gelitten, und die Ausstellungsräume der Kirche befanden sich in einem schlechten Zustand, da die Witterung durch das kaputte Dach eindrang. Für die dringend nötigen Renovierungsarbeiten fehlte, genauso wie für die Deckung der Personalkosten und aller hauswirtschaftlichen Notwendigkeiten, die Unterstützung durch den staatlichen Museumsfond. Diese Sorgen teilte Ivan Gorochov mit den muzejščiki im ganzen Land. Die fehlenden finanziellen Mittel für die Angestellten behinderten den Wiederaufbau der Museen. Das Budget für die Besetzung von Kaderstellen, das seit den 1920-30er Jahren nicht mehr angepasst worden war, war so gering, dass viele regionalwissenschaftliche Museen zwar Personal für Führungen anstellen konnten, jedoch höchstens zwei wissenschaftliche 
Mitarbeiterinnen und Mitarbeiter beschäftigen durften. ${ }^{407}$ Möglicherweise zeigten sich in der Verteilung der Planstellen die Prioritätensetzung des Museumsinstitutes: Die Hauptaufgabe der Museen sollte die Bildungs- und Vermittlungsarbeit sein; die wissenschaftliche Forschungstätigkeit stand an zweiter Stelle. ${ }^{408}$ Vor dem Hintergrund, dass die meisten regionalen Museen im ersten Nachkriegsjahrzent vor extrem großen Schwierigkeiten standen (nur geringe oder gar keine finanzielle Unterstützung für den Ankauf von Ausstellungsobjekten, großer Personalmangel und unzureichende Lagerbedingungen für den Schutz der Objekte), musste Ivan Gorochov sich glücklich schätzen, dass ihm wenigstens sein Haus zurückgegeben wurde. ${ }^{409}$ Die Wiedereröffnung im April 1946 ist beachtlich und spiegelt die allgemeine Stimmung der direkten Nachkriegszeit, die von Elan und Hoffnungen auf einen Neuanfang nach den schweren Entbehrungen des Krieges geprägt war.

In der Industrie- und Forschungsstadt Tscheljabinsk wurde die wissenschaftliche Expertise des Museumsdirektors sehr geschätzt. Seit 1942 war er Mitglied im »Haus der Wissenschaftler«, und im Frühjahr 1944 wurde er zum Gründungsmitglied der »Tscheljabinsker Geografischen Gesellschaft « ernannt. ${ }^{410}$ Gorochov hatte sich bei den entscheidenden (natur-)wissenschaftlichen Institutionen der Stadt unentbehrlich gemacht. Als die Stadt dem Museumsdirektor im August 1944 das zu Beginn des Krieges beschlagnahmte Gebäude zurückgab, war Gorochov das scheinbar Unmögliche gelungen: Er hatte ohne Geld, Personal und Gebäude die verschiedenen Museumssammlungen durch die Kriegsjahre gerettet, während andere Kulturinstitutionen der Stadt ihre Sammlungen verloren hatten und nach dem Krieg nicht wieder eröffnet werden konnten. ${ }^{411}$

407 V. Zlatoustova macht Angaben über die Verteilung der Gelder des Ministeriums für Finanzen in den verschiedenen Museumskategorien der Sowjetunion (Stellen, Löhne, Budget). Sie weist jedoch daraufhin, dass diese Zahlen wenig aussagekräftig seien, da sie unvollständig vorlägen und keinen Eindruck von den tatsächlichen Bedürfnissen der Museen vermittelten. Vgl. Zlatoustova, Valentina: Cosudarstvennaja politika v oblasti muzejnogo dela, in: NII kul'tury (Hg.): Muzej i vlast', Cosudarstvennaja politika v oblasti muzejnogo dela (XVIII-XX vv.), Moskva 1991, S. 235-237, hier S. 242-243.

408 Diese Politik führte dazu, dass die Angestellten der regionalwissenschaftlichen Museen über ein geringes Bildungsniveau verfügten (1946 hatten 40 Prozent der Direktoren und 45 Prozent der wissenschaftlichen MitarbeiterInnen der Gebietsmuseen keine universitäre Ausbildung). Ebd. S. 236-238.

409 Zlatoustova, Valentina: Cosudarstvennaja politika v oblasti muzejnogo dela, S. 232-237.

410 Ivan Gorochov zählt seine (Ehren-)Mitgliedschaften und Auszeichnung im Anhang seiner Autobiografie auf: GIM]UU [Staatliches Historisches Museum des Süd-Urals], alte Signatur: ČOKM [regionalwissenschaftliches Museum des Tscheljabinsker Cebietes], A-1794-a. Pr$131 / 32$.

411 Das Cebäude der Tscheljabinsker Cemäldegalerie wurde, ebenso wie das Museum, zu Kriegsbeginn von der evakuierten Verwaltung des NKVD beschlagnahmt. Bei der Rückgabe des Gebäudes 1944 wurde festgestellt, dass ein wertvoller Teil der Cemäldesammlung gestohlen worden war. Deshalb konnte die Galerie erst 1952 wieder eröffnen. I. Gorochov war sich der 
Die Kulturbehörde des Tscheljabinsker Gebietes (Oblkul'tpros) sah in dem Museum ein Gefäß für ihre propagandistisch-ideologischen Kampagnen und griff dem mittellosen Museumsdirektor unter die Arme. Sie stellte ihm eine Kommission an die Seite, die die Sonderausstellung unterstützte und das Museum mit Exponaten über die Rüstungsindustrie ausstattete. ${ }^{412}$ Das Zugeständnis der Stadt ist im Kontext einer allgemeinen Aufbruchsstimmung in der Bevölkerung und der Mobilisierungspolitik des Fünfjahresplans zu sehen, den Stalin im März 1946 verkündet hatte. Genauso wie die volkswirtschaftlichen Betriebe sollten auch die Kultur- und Bildungseinrichtungen ihr Vorkriegsniveau erreichen und übertreffen. ${ }^{413}$

Gorochov, der die Ausstellung in seinem Bericht distanziert »städtische Ausstellung (gorodskaja vystavka) nannte, nahm das Angebot der Stadt an, um seinem Museum nach den Jahren der Schließung einen erfolgreichen Start zu ermöglichen. Auf den ersten Blick schien die Sonderausstellung »Die Rolle Tscheljabinsks im Großen Vaterländischen Krieg« den wiederholten Forderungen des Moskauer Museumsinstituts nach einer Ausstellung über den Krieg gerecht zu werden. Der Kurator Gorochov und sein Team präsentierten Panzermodelle und Statistiken der mächtigen Rüstungsindustrie der >Panzerstadt< (Tankograd). Jedoch war die Rahmung dieser Geschichte von der Rolle Tscheljabinsks im Krieg eine besondere, da sie eine kraevedische Militärgeschichte präsentierte. Dabei spielten die unbelebten Steine und nicht die Fabrikarbeiter die Hauptrolle bei Tscheljabinsk Beitrag zum Sieg. ${ }^{414}$

\section{Ausstellungsrundgang im April 1946}

Die städtische Kulturbehörde kündigte mit in der Stadt aufgehängten Plakaten die Ausstellung im regionalwissenschaftlichen Museum folgendermaßen an:

»Die Ausstellung zum Thema >Die Rolle Tscheljabinsks im Großen Vaterländischen Krieg 1941-1945< präsentiert anhand der strategischen fossilen Rohstoffe

Gefahr des Verlustes sowohl seiner Sammlung als auch seines Hauses bewusst, da er 1946 als Zeuge in den Gerichtsprozess involviert war. Vgl. Trifonova, Galina: Neizvestnye stranizy istorii Čeljabinskoj oblastnoj kartinoj Galerej, in: Boše, Vladimir (Hg.): Čeljabinsk neizvestnyj, Čeljabinsk 2002, S. 508-525. OCAČO, f. R-627, op. 3, d. 398, I. 6 .

Dieses Ziel wurde 1951 erreicht, als die staatliche Museumsabteilung 617 Museen zählte (1940: 614). Vgl. Ebd. S. 232.

Die folgende Ausstellungsanalyse stützt sich auf die Arbeitsberichte des Museumsdirektors, in denen er detailliert Auskunft über die Inszenierung der Ausstellungsobjekte gibt. Fotos der Ausstellung von 1946 ergänzen und erleichtern die Analyse und Rekonstruktion. Es ist ein Clücksfall, dass dem Arbeitsbericht von 194640 Fotos dieser Ausstellung (Saalansichten, Nahaufnahmen von Vitrinen und Schautafeln) hinzugefügt wurden. Vgl. OCAČO, f. R-627, op. 3, d. 401. 
des Tscheljabinsker Cebietes die Geologie des Süd-Urals, [sowie A.H.] Fabriken und Betriebe der Stadt Tscheljabinsk: Schwer- und Leichtmetallverarbeitung, Panzerproduktion und Maschinenbau, Chemie- und Elektrizitätswerke. «15

Das Erste, was die Besucherinnen und Besucher in der Ausstellung sahen, war die großen Stellwand »Die Entstehung der Welt und die Geologie des Süd-Urals«. Die Ausstellungsführerinnen und Ausstellungsführer erklärten die Schautafel und zeigten archäologische Funde aus dem Tscheljabinsker Gebiet, die verschiedene geologische Epochen der Weltgeschichte symbolisierten. ${ }^{416}$ Mit diesem Einstieg griff Gorochov auf ein klassisches Stilmittel der kraevedenie zurück: über lokale Artefakte die Region an die globale Naturgeschichte zu binden. Dieser Einstieg über die Archäologie, der die Bedeutung der lokalen Ressourcen betonte, hatte sich schon in den Dauerausstellungen der Vorkriegszeit bewährt und sollte ein neues Verständnis der Naturgeschichte ihrer Region eröffnen, wie der Kurator in seinem Arbeitsbericht erläuterte. ${ }^{417}$ Dem vorgegebenen Rundgang folgend, ging es zu einer weiteren vertrauten Karte, die das heimatliche Tscheljabinsker Gebiet zeigte. ${ }^{418}$ Die vielen Punkte auf der Karte markierten die zahlreichen Bodenschätze der Region am Fuße des Uralgebirges. In der Vitrine unter der Karte wurden Proben dieser Bodenschätze ausgestellt (Abb. 26). ${ }^{419}$

415 OCAČO, f. R-627, op. 3, d. 398, I. 48.

416 Die 2,5 m hohe Stellwand »Ceschichte der Welt« war ein bewährtes Ausstellungselement, das bereits seit 1930 fester Bestandteil der Dauerausstellung war. Vgl. Antipin, Nikolaj: Čeljabinskij kraevedčeskij muzej, S. 120.

417 OGAČO, f. R-627, op. 3, d. 398, I. 6.

418 Antipin, Nikolaj: Čeljabinskij kraevedčeskij muzej, S. 142.

419 Ebd. 
Abbildung 26: Karte der Bodenschätze im Tscheljabinsker Gebiet in der Sonderausstellung »Die Rolle Tscheljabinsks im Großen Vaterländischen Krieg", Tscheljabinsk April 1946 bis September 1949, Fotografin/Fotograf unbekannt (c) OGAČO.

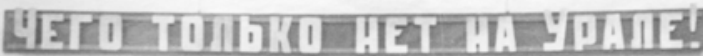

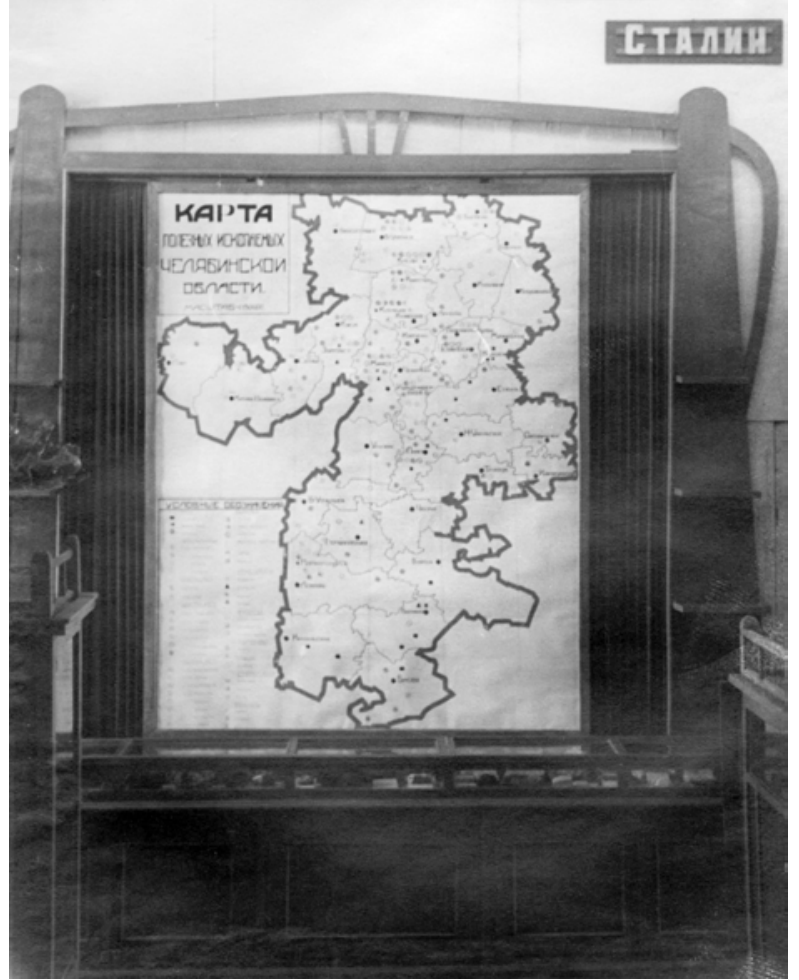

Es folgten weitere Vitrinen mit Mineralien und Steinen, die die kraevedy des Tscheljabinsker Gebietes gesammelt hatten. Hier wurde erklärt, dass dies die "strategischen Rohstoffe des Süd-Urals« seien: schwarzes Eisen, bunte und seltene Metalle, petrogenetische Mineralien, Gebirgssteine und Edelsteine wie Jaspis und Marmor. ${ }^{420}$ Ein Punkt auf der Karte des Tscheljabinsker Gebietes war den Besucherinnen und Besuchern besonders vertraut. Das "Staatliche Naturschutzgebiet Il'men für Mineralien benannt nach V. I. Lenin« (Il'menskij Gosudarstvennij 
mineralogičeskij zapovednik imeni V. I. Lenina). Eine dreiteilige Vitrine repräsentierte den Nationalpark mit seinen mineralogischen Schätzen und Fossilien, der sich noch heute 75 Kilometer westlich von Tscheljabinsk befindet (Abb. 27). ${ }^{421}$

Abbildung 27: Das staatliche Naturschutzgebietes Il'men, Vitrine in der Sonderausstellung »Die Rolle Tscheljabinsks im Großen Vaterländischen Krieg", Tscheljabinsk April 1946 bis September 1949, Fotografin/Fotograf unbekannt (c) OGAČO.

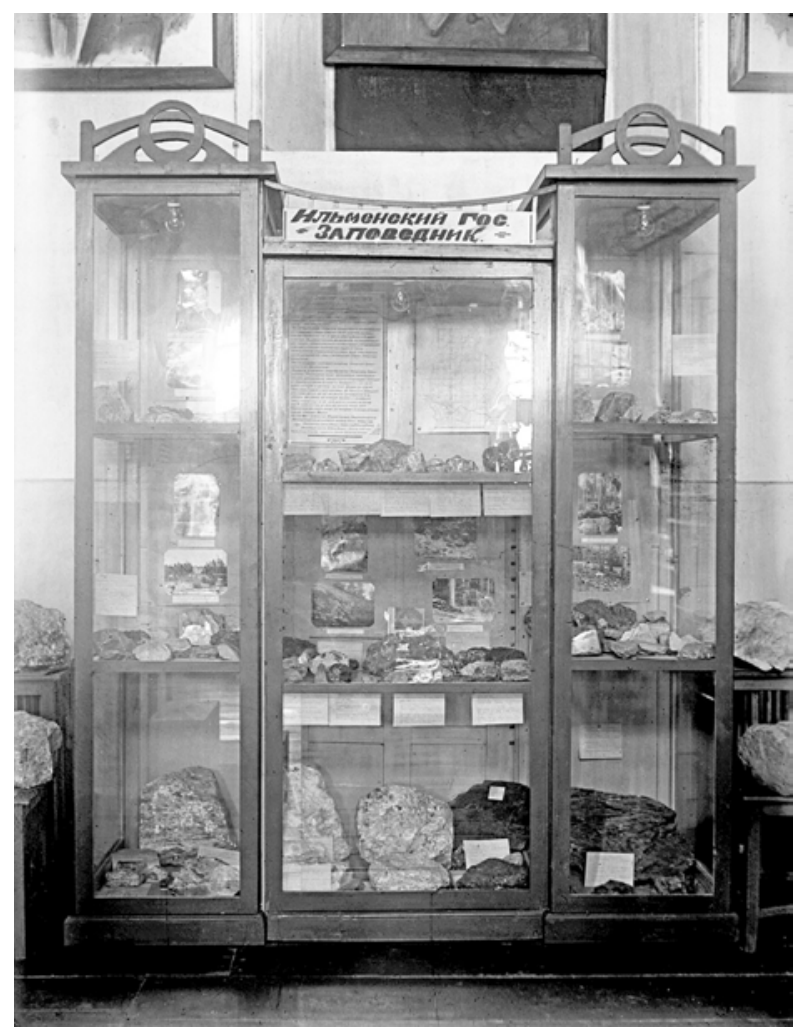

Nachdem im 19. Jahrhundert international bekannte Mineralogen im Ilmengebirge in einem >Halbedelstein-Rausch < eine Vielzahl unbekannter Mineralien entdeckt hatten, weihte Vladimir Lenin auf Initiative des Geologen Aleksandr Fersman 1920 hier das erste Naturschutzgebiet der Sowjetunion ein. ${ }^{422}$ Die »Gesellschaft für

421 Ebd.

422 Aleksandr Fersman (1883-1945) war ein Student des berühmten Ceologen Vladimir Vernadskij (1863-1945). Ihre akademische Forschung über die Prospektion von Bodenschätzen 
das Studium der örtlichen Region", die auch das Tscheljabinsker Museum gegründet hatte, eröffnete in der nahegelegenen Stadt Miass ein regionalwissenschaftliches Museum, das seither eng mit dem Tscheljabinsker Haus zusammenarbeitete. ${ }^{423}$

Bei einem Museumsbesuch zählt der erste Eindruck. Im Fall der Tscheljabinsker Kriegsausstellung war das die besondere geologische Diversität der Region. Geschickt wurde hier der Zusammenhang zwischen der unbelebten Welt der Mineralien und dem »Großen Vaterländischen Krieg« hergestellt:

»Diese Materialien, die dem Wesen nach Materialien der kraevedenie sind, machen uns die Worte des Cenossen Stalin >Was es [sonst A.H,] nicht gibt, im Ural findet es sich! verständlich.

Die Verbreitung der unterschiedlichsten Industriebetriebe gerade im Ural spielte eine große Rolle bei der Verteidigung im Großen Vaterländischen Krieg 1941-1945 $[\ldots] . \ll^{424}$

Dieses Stalinzitat war in Großbuchstaben über der Karte mit den Bodenschätzen des Tscheljabinsker Gebietes angebracht (Abb. 26). Damit wurde die naturgegebene Geologie zum Hauptakteur des Sozialistischen Aufbaus und der sowjetischen Rüstungsindustrie. Die Aussage Stalins, dass es im Ural alles gäbe, wurde durch die Inszenierung noch einmal unterstützt: Die Karte war in einen kunstvoll geschnitzten Holzrahmen eingefasst, in dem, wie im Theater, zwei seitliche Vorhänge aufgezogen waren.

Während das Zitat Stalins als Überleitung zum zweiten Ausstellungsthema der Tscheljabinsker Rüstungsindustrie im Krieg - diente, knüpfte es zugleich an die Lebenswelt des Publikums an. Ganz im Sinne der kraevedenie, die nach regionaler Identität strebte, konnten sich die Tscheljabinskerinnen und Tscheljabinsker bei der Betrachtung des reichen Mineralvorkommens mit ihrer Region identifizieren. Darüber hinaus standen die Bodenschätze für eine spezifische Lebenserfahrung des Urals. Die Mehrheit der Besucherinnen und Besucher wurde in den 1920er Jahren und in der Zeit der ersten beiden Fünfjahrespläne gerade wegen der

im Tscheljabinsker Cebiet beeinflusste den Ceologen I. Gorochov, der in der Zwischenkriegszeit in engem Kontakt mit ihnen stand. In ihren Schriften betonten sie die Dominanz des Menschen über die Natur und sinnierten gleichzeitig über die wechselseitige Abhängigkeit, die sich zwischen der belebten und der unbelebten Natur ergab. Vgl. Frey, Felix/Hasselmann, Anne: Stones at War, S. 534.

Fersmann, Aleksandr: Erinnerungen an Steine, Berlin 1948. Zur Ceschichte des Miassker Museums vgl. Miasskij kraevedčeskij muzej (Hg.): O muzee, in: http://miassmuzey.ru/история/ (Stand: 30.01.2017). 
Ausbeutung dieser Rohstoffvorkommen in den Minen des Süd-Urals zur Arbeit mobilisiert. ${ }^{425}$

Der Rundgang führte in den hinteren Teil der Kirche. Eine der drei Kapellen präsentierte eine große Stellwand mit Porträts von Personen, die für ihre Dienste an der Front und im Hinterland den Stalinpreis erhalten hatten. Ein halbrundes Wandgemälde zeigte das »Tscheljabinsker Traktorenwerk (Čeljabinskij traktornyj zavod, kurz: ČTZ), das als »Kirov-Werk« während des Krieges für seine enorme Panzer- und Waffenproduktion berühmt wurde. ${ }^{426}$ Die Aufmerksamkeit wurde auf die staatlichen Auszeichnungen gelenkt, die das Werk für seine Rüstungsproduktion erhalten hatte. Unter dem Wandgemälde hingen gut sichtbar die fünf Orden, mit denen das Werk ausgezeichnet wurde. An den Wänden waren, einem Panel gleich, Vitrinen aus Holz angebracht, die Produktionsziffern, Ingenieure und Stoßarbeiter nannten. In der Mitte stand ein runder Tisch, der den Motor eines Panzers präsentierte. ${ }^{427}$ Um ihn herum waren kleine Panzermodelle aufgestellt, die ihre Geschützrohre auf die Betrachterinnen und Betrachter richteten (Abb. 28).

425 Dmytro Myeshkov weist daraufhin, dass die sowjetischen Arbeitsmobilisierungen im Kontext der Kolonisierungen in den 1920er Jahren, die Zwangsumsiedlungen der » Kulaken «während der Industrialisierung in den 1930ern und die Deportationen von ethnischen Gruppen im Kontext des Zweiten Weltkrieges im Cebiet des Urals das größte Ausmaß angenommen hatten. Der Ural wurde zu einer der wichtigsten Verbannungsregionen des Landes und die Erfahrung der Zwangsarbeit in Industriebetrieben zu einer mehrere Generationen übergreifenden Lebenserfahrung der Menschen im Ural. Vgl. Myeshkov, Dmytro: Arbeit und Terror im Ural, Deportationen und Arbeitsmobilisierungen im Kontext der sowjetischen Arbeitskräftepolitik, 1930er und 1940er Jahre, in: Luchterhand, Otto/Bergner, Christoph (Hg.): Deportationen in Stalins Sowjetunion, Das Schicksal der Russlanddeutschen und anderer Nationalitäten, Lüneburg 213, S. 79-103.

Zur Umstrukturierung der Traktorfabrik mit Hilfe der evakuierten Leningrader »KirovWerke«, den produzierten Rüstungsgütern, der Massenmobilisierung der Arbeiterinnen und Arbeiter und ihren Arbeitsbedingungen. Vgl. Samuelson, Lennart: Tankograd, S. 91-215.

Antipin, Nikolaj: Čeljabinskij kraevedčeskij muzej, S. 139. 
Abbildung 28: Inszenierung der Rüstungsindustrie in der Sonderausstellung "Die Rolle Tscheljabinsks im Großen Vaterländischen Krieg«, Tscheljabinsk April 1946 bis September 1949, Fotografin/Fotograf unbekannt (c) OGAČO.

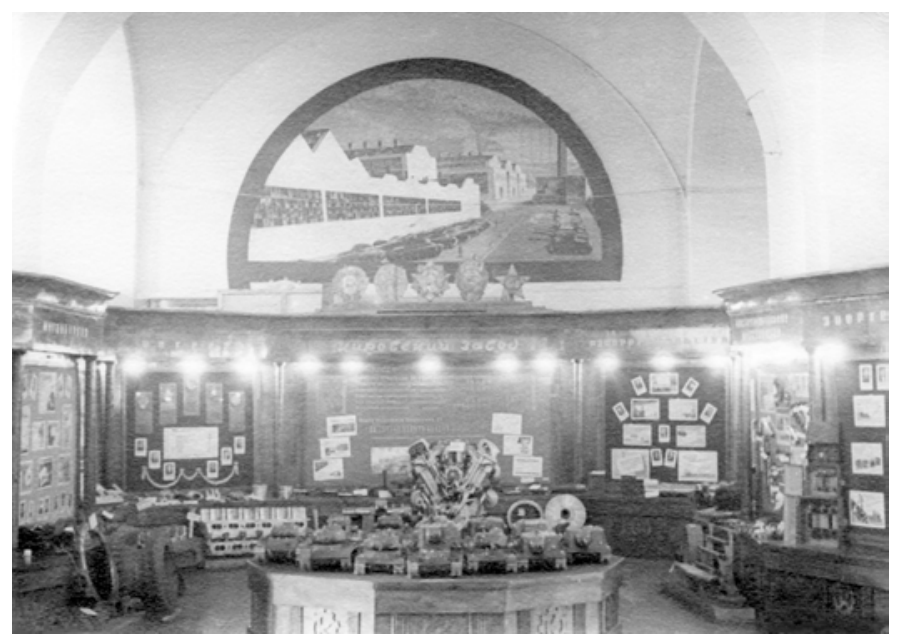

Anschließen sollten 14 weiteren, aufwendig inszenierten Stellwänden und Vitrinen besichtigt werden. Diese präsentierten die Rüstungsfabriken und Zulieferbetriebe der Stadt. ${ }^{428}$ Eine breite Stellwand stellte beispielsweise unter der Überschrift »Unser Beitrag zum Sieg« das Schmiedepresswerk »Stalin« (Kuznečno-pressovyj zavod imeni Stalina, KPZIS) vor. Diese ehemalige Autofabrik wurde im Oktober 1941 mitsamt ihren 850 Angestellten aus Moskau nach Tscheljabinsk evakuiert, und die eingerahmten Schautafeln präsentierten stolz die Anzahl der produzierten Reifen und Schmiedestücke. Unterhalb der Stellwand waren Beispiele und Modelle der einzelnen Werkhöfe ausgestellt. ${ }^{429}$ Eine weitere Wand stellte in einer ähnlichen Inszenierung die Fabrik »Kalibr« aus. Die Fabrik für Präzisionsmessgeräte wurde ebenfalls im Oktober 1941 aus dem Moskauer Gebiet nach Tscheljabinsk evakuiert und dort in dem sich noch im Bau befindlichen Theater- und Opernhaus untergebracht. Unter der Überschrift »Präzision ist die Grundlage der modernen Waffen« waren die Steuer- und Messgeräte ausgestellt, die in Tankograds Panzer eingebaut

428 OGAČO, f. R-627, op. 3, d. 398, I. 6-7.

429 OGAČO, f. R-627, op. 3, d. 401, I. 41. Für die Geschichte der KPZIS vgl.: https://2045-ru.all.biz/i nfo-history (Stand: 31.07.2021). 
wurden. ${ }^{430}$ Gezeigt wurden auch großformatige Bilder des gigantischen Tscheljabinsker Eisenhüttenwerk (Čeljabinskij metallurgičeskij kombinat, ČMK). ${ }^{431}$ Sie erinnerten an die großen Verbände der »Fünften Pionier-Armee« (5-ja sapërnaja armija) und an die deutsche »Arbeitsarmee«, die aus von der Wolga deportierten Russlanddeutschen bestand und die 1942 in der Rekordzeit von neun Monaten das Werk am Stadtrand baute, das am Ende des Krieges jeden dritten Panzer und jedes dritte Flugzeug mit Tscheljabinsker Stahl ausrüstete. ${ }^{432}$ Im gleichen Stil präsentierten neun weitere Stellwände Fabriken und Industriebetriebe, die entweder bereits in der Stadt Tscheljabinsk ansässig waren, während des Krieges erbaut oder aus dem Westen der Sowjetunion in den Süd-Ural evakuiert worden waren. ${ }^{433}$ Die szenografische Gestaltung dieser Wände war in einem eigenen Stil gehalten. Anhand von Tabellen mit aufsteigenden Graphen wurde die beachtliche Produktivität erklärt, Auszeichnungen und Orden, die den Unternehmen während und nach dem Krieg verliehen worden waren, bezeugten ihre Relevanz. Diese zweidimensionale Präsentation von Zahlen und Statistiken wurde mit Fotos und Namen ausgezeichneter "Stoßarbeiter (stachanovcy) sowie mit Mustern und Modellen von Patronen, Bomben oder Miniaturfabriken ergänzt, die den Tabellen größere Anschaulichkeit verleihen sollten. ${ }^{434}$ Ein typisches Element der sogenannten »sprechenden « Ausstellungen der 1930er und 1940er Jahre waren markante Zitate, die die Lesart der Objekte und Inszenierungen vorgaben, im Kontext des »Großen Vaterländischen Krieges« vorzugsweise Auszüge aus Stalins Reden. Der berühmte Ausspruch Stalins »Die Artillerie ist der Gott des Krieges« beispielsweise hing über der Vitrine mit Artilleriegeschossen in der ehemaligen Kirche. ${ }^{435}$

Die letzte Fabrik, die dem Publikum vorgestellt wurde, war die sogenannte »Vitamin-Fabrik«(Vitaminnyj zavod), die zwar rhetorisch nicht aus dem Muster fiel, jedoch ganz andere Produkte präsentierte. Anhand einer Vitrine mit Moulagen von

430 OGAČO, f. R-627, op. 3, d. 401, I. 34. Für die Geschichte der heutigen Instrumenten-Fabrik: ht tp://chiz.ru/o-zavode/istorija-zavoda/ (Stand: 31.07.2021).

431 OGAČO, f. R-627, op. 3, d. 401, I. 31.

432 Kazancevij, Igor/Gejl', Vera: Južnij Ural - frontu, S. 1-2. Sowie Samuelson, Lennart: Tankograd, S. 237-241.

433 Die neun Stellwände repräsentierten die aus Tula nach Tscheljabinsk evakuierten zwei Munitionsfabriken, die aus Moskau, Leningrad und Charkow evakuierten Lack-Werke, das aus Leningrad evakuierte Plexiglas-Werk, das 1942 in Tscheljabinsk errichtete Walzenwerk, das seit 1939 in Tscheljabinsk arbeitende Werk für Eisenlegierungen, das seit 1935 bestehende Zink-Werk und das seit 1933 existierende Schleif-Werk sowie das im Krieg ausgebaute Elektrizitätswerk. OCAČO, f. R-627, op. 3, d. 398, I. 7. Für weitere Informationen zu diesen Betrieben vgl. Kazancevij, Igor/Gejl', Vera: Južnij Ural - frontu, S. 1-3.

434 OGAČO, f. R-627, op. 3, d. 401, I. 20-49.

435 Ebd. I. 43. Iosif Stalin favorisierte die Artillerie als Waffengattung innerhalb der Roten Armee. Das Zitat stammt aus seiner Rede an die Militärakademie am 1. Mai 1941. 
Früchten, Beeren und Gemüse (Abb. 29) und eines Herbariums, das den Titel »Wildwachsende vitaminhaltige Rohstoffe« trug, wurde die Natur als Produzentin von natürlichen, essbaren Rohstoffen der Region präsentiert. ${ }^{436}$

Abbildung 29: »Vitamin-Fabrik, Frucht-Plantagen - Vitaminreiche Rohstoffe", Vitrine in der Sonderausstellung "Die Rolle Tscheljabinsks im Großen Vaterländischen Krieg«, Tscheljabinsk April 1946 bis September 1949, Fotografin/Fotograf unbekannt () OGAČO.

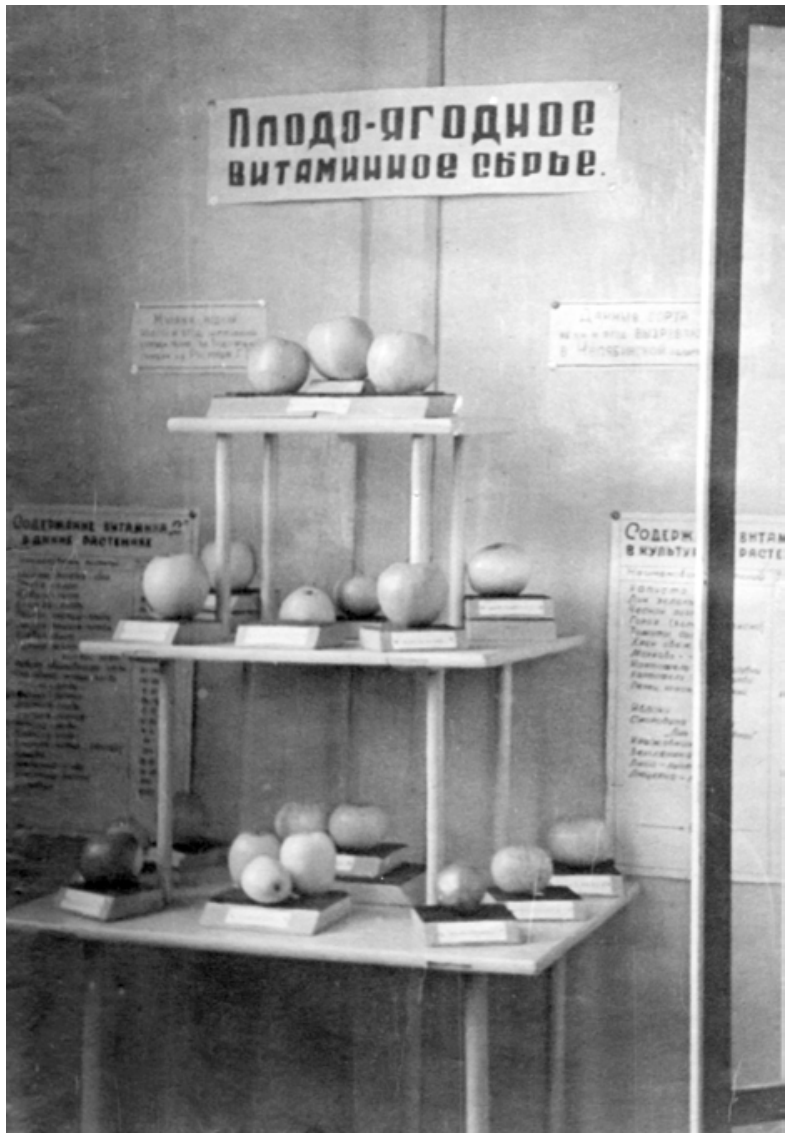

Diese Inszenierung erinnerte die Tscheljabinskerinnen und Tscheljabinsker womöglich an das Engagement der kraevedy während des Krieges. Das Museums- 
kollektiv hatte der hungerleidenden Bevölkerung in zahlreichen Beratungsgesprächen und kleineren Sonderausstellungen die Anlage von Gemüsegärten, Rezepte für essbare Pflanzen und Anleitungen für medizinische Heilkräuter im Hausgebrauch erklärt. Die »Vitamin-Fabrik« fügte sich ideal in die Inszenierung des Krieges ein, die sich an der Vorstellung einer interdependenten Natur-MenschBeziehung ihres Kurators. orientierte. Während die industriellen Ressourcen für die militärische Verteidigung genutzt wurden, produzierte die Natur vitaminreiche Ressourcen für das Überleben an der »Heimatfront«. Den Abschluss der Ausstellung bildeten Stellwände, die die Arbeit der städtischen Betriebe und Organisationen während des Krieges präsentierten. Eine große Stellwand, die den Titel »Der Komsomol in Tscheljabinsk während des Großen Vaterländischen Krieges« trug, zeigte ein Porträt Stalins und Fotos der Mitglieder und Versammlungen des kommunistischen Jugendverbandes, eine andere stellte die »Städtische Union der Invaliden-Genossenschaft « aus. ${ }^{437}$

Am Ende ihrer Führung hatte das Publikum, in erster Linie Schulklassen, Arbeitergruppen und Verbände der Roten Armee, viele verschiedene Informationen über ihre Region erhalten. Sie verließen das Museum mit einem neuen Bewusstsein von der besonderen, vielleicht sogar einzigartigen geologischen Beschaffenheit ihrer Umgebung. Die außergewöhnlichen Steine und Mineralien des Süd-Urals führten, so die Ausstellung, zu einer Konzentration von metallverarbeitenden Industriebetrieben in der Region, die während des »Großen Vaterländischen Krieges« einen wichtigen Beitrag zur Verteidigung des Landes und zum Sieg über Hitler geleistet hatten, auf den man stolz sein durfte. Gleichzeitig wurde anhand von Produktionszahlen und den außergewöhnlichen Leistungen der Angestellten in den Rüstungsfabriken an die körperlich harte Arbeit und die anspruchsvollen und strikten Planvorgaben erinnert, die kaum zu erfüllen gewesen waren. Die Fabrik »Kalibr«, die im Opernhaus der Stadt produzierte, stand stellvertretend für den Stillstand des (kulturellen) Lebens, das während des Krieges an der »Heimatfront « gänzlich der Rüstungsproduktion »Tankograds« untergeordnet war. Das Herbarium und das Obst in der Vitrine erinnerten an die Entbehrungen und die große Not, die die Tscheljabinsker Bevölkerung während des Krieges aufgrund von extremer Rationierung von Lebensmitteln, Brennholz und Wohnraum erlitten hatte.

437 OGAČO, f. R-627, op. 3, d. 401, I. 22. Die anderen acht Stellwände stellten das Institut für mechanische Landwirtschaft sowie das Institut für mechanischen Maschinenbau, die Abteilung für Bauwesen, die Kooperative der Industrieverbände, die Kooperative der Lebensmittelproduzenten und die Kooperative der Handelsunternehmen vor. OCAČO, f. R-627, op. 1, d. 398, I. 7. 


\section{Ausstellungskonzepte der Kuratorinnen und Kuratoren}

Der Einstieg der Ausstellung mit der prähistorischen Geschichte des Süd-Urals ist überraschend. Das Publikum hätte vielleicht eher das Narrativ einer chronologisch geordneten Geschichte der gewonnenen Kriege Russlands erwartet, jenen klassischen Einstieg der Ausstellungen zum »Großen Vaterländischen Krieg«, den auch das Zentralmuseum der Roten Armee in Moskau gewählt hatte. Für ein Museum der stalinistischen kraevedenie wäre auch ein Einstieg mit dem ersten Fünf-JahresPlan (1928-1932) denkbar gewesen - die Jahre, in denen der Süd-Ural neben dem Donbas in der Ukrainischen SSR zum zweiten metallurgischen Zentrum wurde. Diese wirtschaftspolitische Entscheidung Stalins war die Grundlage für die spätere Rüstungsproduktion im Süd-Ural, die als Schlüsselindustrie einen relevanten Beitrag zum Sieg im »Großen Vaterländischen Krieg« leistete. ${ }^{438}$ Dieser Rahmen hätte es den Ausstellungsmacherinnen und Ausstellungsmachern ermöglicht, ausschließlich auf sozialistische und patriotische Proletarier zu fokussieren, die die Waffen für die Verteidigung ihre Heimat produzierten. Die Tscheljabinsker $m u-$ zejščiki lehnten jedoch einen Fokus auf die alles entscheidende Handlungsmacht des Neuen Menschen ab und begannen mit der >Geschichte der Geologie des SüdUrals $\ltimes$. Sie präsentierten Mineralien und Metalle der Region als bestimmende Faktoren der Entwicklung ihres Gebietes und ihrer maßgeblichen Rolle im »Großen Vaterländischen Krieg«. Die Bodenschätze des Süd-Urals wurden als Protagonisten des Kriegstheaters von 1941-1945 präsentiert. Diese Interpretation wurde von der theatralen Inszenierung der Gebietskarte, die mit Stalins Zitat über den unendlichen Reichtum des Urals überschrieben war, unterstützt. Die Lesart von der außergewöhnlichen Vielfalt der Region fand breiten Widerhall in der Gesellschaft. Einer Anekdote zufolge sagten die sowjetischen Schulklassen, wenn sie die Antwort auf die Frage, wo Eisen, Kupfer, Gold, Platin, Nickel, Asbest, Blei, Zink, Kobalt etc. zu finden seien, nicht wussten, immer selbstbewusst: »Im Ural! « ${ }^{439}$

Die Inszenierung fokussierte auf die Spezifika der Mineralien der Region, um das Publikum über die wissenschaftliche Bedeutung und den Nutzen der sie umgebenden Natur aufzuklären. Im Arbeitsbericht bekannte der Museumsdirektor Gorochov offen, dass die Objekte der kraevedenie den Süd-Ural und seine Rolle im

438 Zur wirtschaftlichen Entwicklung des Süd-Urals vgl. Harris, James: The Growth of the Gulag, Forced Labor in the Urals Region, 1921-31, in: The Russian Review, 2, 1997, S. 265-280.

439 Der amerikanische Historiker und Journalist Henry Chamberlin (1897-1969), der über ein Jahrzehnt in der Sowjetunion lebte und diese Anekdote erwähnte, stellte in seinem Buch »The Russian Enigma« (1944) den Mineralreichtum des Süd-Urals als kriegsentscheidende Voraussetzung für die militärische und ökonomische Überlegenheit der Sowjetunion dar, vgl. Chamberlin, Henry: The Russian Enigma, An Interpretation, New York 1944, S. 64. 
»Großen Vaterländischen Krieg« seiner Meinung nach am besten charakterisierten. Geschickt bettete er sie in den Kontext der stalinistischen Wirtschaftsgeografie ein. Die besondere geologische Beschaffenheit des Süd-Urals hatte demgemäß den Standort der Industriekomplexe vorbestimmt. Die Industriezentren entstanden dort, wo das Rohstoffvorkommen lag. Die Politik der industriellen Streuung, die zu einer Allokation der Schwerindustrie im Süd-Ural führte, basierte auf der strategischen Entscheidung, im Kernland der UdSSR einen Kohle-Stahl-Komplex aufzubauen. ${ }^{440}$

Während dieses Verständnis im Hintergrund der Ausstellung wirkte, stellte das Zitat Stalins »Was es [sonst] nicht gibt, im Ural findet es sich!« die Besonderheit des Süd-Urals auf einer offensichtlicheren Ebene aus. Mit diesem Zitat machte Gorochov Stalin zum Gewährsmann seiner Inszenierungsstrategie. Seiner Ausbildung als Geologe und seiner Überzeugung als kraeved folgend, präsentierte er die geologischen Gegebenheiten als Voraussetzungen für den Beitrag des Tscheljabinsker Gebietes zum »Großen Vaterländischen Krieg«. Hier folgte der Museumsdirektor seinem wissenschaftlichen Interesse und seinen beruflichen Vorlieben. Er inszenierte eine Interpretation, die das Vorkommen von Mineralien und Steinen, nicht ihre Verarbeitung zu Stahl und Kohle bzw. Waffen durch den Menschen betonte.

Diese Beobachtungen lassen vermuten, dass es eine grundsätzliche Aufteilung in zwei Ausstellungskapitel gegeben haben muss, an der unterschiedliche Kuratorengruppen beteiligt waren. Der Museumsdirektor und gelernte Geologe hatte das erste Kapitel über die Geologie des Süd-Urals übernommen, die Kommission der Kulturbehörde den Teil über die Rüstungsindustrie und den Abschnitt über die Arbeit der städtischen Organisationen während des Krieges. Diese Aufteilung wird auch in einem Arbeitsbericht deutlich, in dem der Museumsdirektor den naturhistorischen Teil der Ausstellung detailliert beschreibt und seine Zielsetzung kommentiert. Die Stellwände und Vitrinen zu den Rüstungsindustriebetrieben im zweiten Teil der Ausstellung zählte er hingegen nüchtern auf, ohne sie in irgendeiner Form zu kommentieren. Die Markenzeichen und Symbole der Fabriken, die ins Holz der Stellwände und Vitrinen eingraviert wurden, weisen darauf hin, dass diese Ausstellungselemente nicht aus dem Museum selbst stammten. ${ }^{441}$ Es ist anzunehmen, dass die städtische Kommission diverse Vitrinen und Stellwände bei den entsprechenden Betrieben in Auftrag gegeben hatte, damit diese ihre Arbeit für den Krieg dokumentierten. Im Auftrag der städtischen Kulturbehörde fertigten diese dann aufwendige Stellwände und Vitrinen an, die sie dem Museum zur

440 Frey, Felix: Arktischer Heizraum, Das Energiesystem Kola zwischen regionaler Autarkie und gesamtstaatlicher Verflechtung 1928-1974, Köln 2019.

441 An der Stellwand der Fabrik »Kalibr« ist im unteren Teil eine Vitrine angebracht, deren drei Außenwände mit dem Firmenlogo versehen sind: der Buchstabe K, umrahmt von einem Messgerät. Vgl.: OGAČO, f. R-627, op. 3, d. 401, I. 46. 
Verfügung stellten. Ob sie sich bei der Inszenierung und dem Inhalt ihrer Schaukästen von der städtischen Kommission oder den muzejščiki beraten ließen, lässt sich nicht abschließend feststellen. Der ähnliche Aufbau der 13 Stellwände und der Gebrauch von typischen sowjetischen Ausstellungselementen (das plakative Zitat Stalins als Titel der Vitrine) lassen auf die Unterstützung durch einen Museumsexperten schließen.

Der letzte Produzent in der Reihe der Rüstungsbetriebe war jedoch die Natur selbst. Die Inszenierung der »Vitamin-Fabrik« und des Herbariums mit »Pflanzlichen Rohstoffen« war eindeutig die Arbeit der muzejščiki. Diese Vitrine ist ein Ergebnis ihrer Sammlungsarbeit im Krieg. Bei Expeditionen in die Umgebung hatten der Museumsdirektor und die Biologin Vera Sur'janinova gemeinsam mit der Apothekenvereinigung Heilkräuter und essbare Pflanzen gesammelt. Mit der Inszenierung seiner >Natur-Fabrik« erweiterte der Direktor die Präsentation von kriegsrelevanten Betrieben. Er brachte eine persönliche Note in das Ausstellungskapitel Rüstungsindustrie ein und vermittelte unter dem Kriegsbezug der Vitamine regionale Kräuterkenntnisse im Sinne seines Verständnisses von kraevedenie, das den Zusammenhang von belebter und unbelebter Natur, zwischen dem Menschen und seiner Umwelt betonte.

\section{Museumspolitik und kraevedenie}

n der Sonderausstellung »Die Rolle Tscheljabinsks im Großen Vaterländischen Krieg« war es dem Kurator und Geologen Ivan Gorochov gelungen, sein spezifisches Mensch-Umwelt-Verständnis vom Süd-Ural mit der überregionalen Geschichte vom »Großen Vaterländischen Krieg« zu verbinden. Dabei orientierte er sich sowohl an seiner Überzeugung von der Disziplin der kraevedenie als auch an den Publikationen der sowjetischen Museologie. Die Expertinnen und Experten am Moskauer Museumsinstitut hatten konkrete Vorstellungen von den Dauerausstellungen zum »Großen Vaterländischen Krieg« in den regionalwissenschaftlichen Museen. ${ }^{442}$ Die erfahrene Kuratorin des Moskauer GIM Anna Zaks hatte 1943 ein »Handbuch für die Ausstellungsarbeit in den regionalwissenschaftlichen Museen [im Krieg A.H.]« veröffentlicht, das dank ihrer konkreten Angaben und Beispielen eine große Hilfe für die muzejščiki darstellte. ${ }^{443}$ Laut der erfahrenen Museologin sollten die regionalwissenschaftlichen Museen danach streben, »das

442 Manevskij, Aleksej: Osnovnye voprosi muzejno-kraevedčeskogo delo, S. 12.

443 Zaks, Anna: Metodika èkspozicionnoj raboty v kraevedčeskom muzee, in: NIIKMR (Hg.): A.B. Zaks, Metodika èkspozicionnoj raboty v kraevedčeskom muzee, Posobie dlja muzejnich rabotnikov, Moskva 1943, S. 1-20. Einschätzung der Rezeption des Handbuches durch die Kuratorlnnen der regionalwissenschaftlichen Museen, in: Šulepova, E். A. (Hg.) Muzeevedčeskaja mysl'v rossii, S. 743. 
Leben ihrer Region so eindrucksvoll wie irgend möglich« (naibolee jarkij pokaz žizni svoego kraja) darzustellen. ${ }^{444}$ Der gegenwärtige Krieg verlangte gemäß Zaks neue thematische Ausstellungsschwerpunkte, die den akuten gesellschaftlichen Bedürfnissen Recht tragen sollten. In dem klassischen Ausstellungskapitel zu Natur und Umwelt sollten die für die Rüstungsindustrie relevanten Ressourcen der Region im Mittelpunkt stehen, und die Menschen sollten zum gemeinschaftlichen Sammeln von Heilkräutern aufgerufen werden. Gleichzeitig betonte Zaks, dass dem historischen Ausstellungskapitel "große Bedeutung« zukommen sollte: »Jeder Bürger der Sowjetunion soll die Geschichte seiner Heimat, seines Gebietes, seiner Region, seiner Stadt kennen [...].« Die »besonders wichtige Aufgabe der Museen« lag dabei in dem Ausstellungskapitel zum »Großen Vaterländischen Krieg «. ${ }^{445}$

Hier schlugen sich die Arbeitserfahrungen der >kommemorativen Ausstellungen nieder, die die muzejščiki des GIM während des Krieges gesammelt hatten. Die Gegenwart, die in die Museumssäle eingedrungen war, verlangte neue Ausstellungsformen, und Zaks verwies auf das Format der Sonderausstellung, das es ermögliche, »die alleraktuellsten Fragen im Detail zu beleuchten«. ${ }^{446}$ Dabei teilte Zaks ihre während des Krieges erworbenen Erfahrungen mit den muzejščiki der regionalwissenschaftlichen Museen. Sie betonte die "große Bedeutung von dreidimensionalen Objekten«, die gesammelt und studiert werden müssten, damit sie nicht »totes Kapital« blieben, sondern $\mathrm{zu}$ »sprechenden Museumsexponaten« werden könnten. ${ }^{447}$ Dieses Verständnis von die Gegenwart dokumentierenden und ssprechenden` Originalen als Grundlage jeder Ausstellung drückte sich in der Bezeichnung der Exponate als »Zeitgenossen« (sovremenikami) aus. Für die Kapitel der Naturgeschichte empfahl sie Objekte, die dem »lebendigen Leben « entnommen seien und beispielsweise für Ausstellungen mit dem Titel »Bodenschätze« genutzt werden konnten. ${ }^{448}$ Gleichzeitig warnte die erfahrene Kuratorin vor einer zu starken thematischen Ausrichtung der Museen auf ihre Region:

»In den Natur-Abteilungen sollte die Region nicht als eine sich selbst genügende territoriale Einheit, sondern als Teil der UdSSR dargestellt werden. [...] In den historischen Abteilungen (hierzu gehört auch das Thema des Croßen Vaterländischen Krieges) muss die Frage des direkten thematischen Bezugs der Lokalgeschichte zur allgemeinen Geschichte der UdSSR geklärt werden. Eine >Lokalgeschichte isoliert von der allgemeinen historischen Entwicklung gibt es nicht [...].

444 Zaks, Anna: Metodika èkspozicionnoj raboty v kraevedčeskom muzee, Moskva 1943, S. 1.

445 Ebd.

446 Ebd.

447 Ebd. S. 3.

448 Ebd. S. 9. 
Begebenheiten und Ereignisse, die nur eine lokale Bedeutung zu haben scheinen, sind in Wirklichkeit kleine Glieder im allgemeinen Verlauf der Ceschichte. ${ }^{449}$

Gorochovs Ausstellung über den Beitrag der Steine des Süd-Urals für den Sieg im »Großen Vaterländischen Krieg« entsprach den strukturellen und inhaltliche Empfehlungen der Museologin.

Im April 1946, als die Ausstellung in Tscheljabinsk eröffnete, hatte sich jedoch der museumspolitische Wind bereits gedreht. Die regionalwissenschaftlichen $\mathrm{Mu}$ seen, die seit 1918 unter der ideellen Führung des Narkompros standen, wurden im Februar 1945 gemeinsam mit den anderen Museen dem neugegründeten »Komitee für die Angelegenheiten der Kultur- und Bildungseinrichtungen « (Komiteta po delam kul'turno-prosvetitel'nych učreždenij) untergeordnet, das wiederum dem Rat der Volkskommissare (Sovnarkom) unterstellt war. Diese institutionelle Neuorganisation der Museen, die in ihren grundsätzlichen Zügen bis in die 1980er Jahre bestehen blieb, kann als Hinweis auf die museumspolitischen Prioritäten gelesen werden: In der Wahrnehmung der Behörde war die politische Bildung die primäre Aufgabe der Museen. Diese Prämisse führte z.T. zu einer weiteren (finanziellen) Degradierung der naturwissenschaftlichen Forschung im Museum, da die Behörde hier von einem Expertendiskurs ausging, der didaktische Vermittlungsarbeit nicht zu fördern schien. ${ }^{450}$

Ein Jahr später wurde den Museen eine Vorgabe verordnet, die auf eine Vereinheitlichung der musealen Präsentationen abzielte: Die »[e]xemplarische thematische Struktur für den Aufbau von Ausstellungen in den regionalwissenschaftlichen Museen« schränkte den Gestaltungsfreiraum der Kuratorinnen und Kuratoren stark ein. ${ }^{451}$ Gleichzeitig konnte diese Struktur aber auch Orientierung und Unterstützung für die vielen schlecht ausgebildeten Museumsangestellten bieten, wie Marija Kaulen hinzufügt. ${ }^{452}$ Die thematische Struktur der Vorgabe reproduzierte die Ideologie von Stalins »Kurzem Lehrgang« der Vorkriegszeit (1938) und schrieb den Museen vor, ihre Ausstellungen in drei Kapitel zu gliedern: Die Natur

449 Ebd. S. 3.

450 Kaulen, Marija: Muzejnoe delo Rossii, S. 158.

451 NIIKMR (Hg.): Primernaja tematičeskaja struktura postroenija èkspozicij kraevedčeskich muzeev, Moskva 1946, zitiert nach: Zlatoustova, Valentina: Gosudarstvennaja politika v oblasti muzejnogo dela, S. 246. Zlatoustova spricht von einer »Reduzierung der Ausstellungsarbeit auf eine einheitliche, schablonenhafte thematische Struktur«. Galina Fajzullina spricht von der Verordnung als Höhepunkt der Museumspolitik zur thematischen Vereinheitlichung aller regionalwissenschaftlichen Museen des Landes. Vgl. Fajzullina, Galina: Chranenie, sostav i struktura muzejnych fondov Kasachstana v sovetskij period skvoz' prizmu terminologičeskich problem, in: Issik, Gosudarstvennyj istoriko-kul'turnyj zapovednikmuzej, 5. Oktober 2013: http://issykrm.kz/rus/?p=135 (Stand: 20.09.2018). 
der Region, die vorrevolutionäre Geschichte der Region und die sowjetische Periode. ${ }^{453}$ Innerhalb des Museumsinstitutes herrschte jedoch keine Einigkeit über das Ausmaß der Reduzierung des Museums auf seine ideologische Bildungsarbeit. Andere Museologinnen und Museologen des Museumsinstitutes verfochten standhaft ihre Position in Bezug auf die wissenschaftliche Aufgabe des Museums. Ein Gesetz vom Oktober 1948 über den staatlichen Denkmalschutz, der ebenfalls nach Erforschung und Bewahrung von Kulturgütern strebte, unterstützte das Anliegen der Museen. In der Forschung wird die Verordnung »Über die Maßnahmen zur Verbesserung der Kulturdenkmäler« als Resultat des im Krieg gewachsenen historischen Bewusstseins gedeutet. Die Erfahrung des (z.T. unwiederbringlichen) Verlustes hatte innerhalb der Bevölkerung ein Interesse an kulturellem Erbe geweckt und das Bedürfnis nach seiner Bewahrung provoziert. ${ }^{454}$ Ein Paragraf regelte auch den Schutz der Museumssammlungen und legte fest: »Die staatlichen Museen sind die elementaren Speicher der Sammlungen der Kulturdenkmäler. ${ }^{455}$ Dieser Paragraf war von existentiellem Wert für die Museumsarbeit, da er die dokumentierende und bewahrende Funktion der Museen festschrieb. Die Anerkennung, dass das Museum sich um die Erfassung von historischen Exponaten kümmerte, weckte unter den muzejščiki die Hoffnung, dass das Original als Museumsexponat, das in den 1930er Jahren aus den Ausstellungen verbannt worden war, während des Krieges seine Bedeutung wiedererlangte und in der Nachkriegszeit erneut verdrängt zu werden drohte, nun endlich zum Leitmotiv der Ausstellungen werden würde. ${ }^{456}$

Im November 1948 organisierte das Museumsinstitut eine Tagung, zu der sie über 300 muzejščiki aus lokalen und zentralen Museen einluden. Die Ergebnisse waren ambivalent. Einerseits wurde in dem Abschlussdokument die Gleichschaltung der Ausstellungen bestätigt und konkretisiert: Die Kapitel zur Umwelt sollten »die Entfaltung der regionalen Umwelt auf der Grundlage der marxistisch-leninistischen Anschauung und den Prozess der Umgestaltung der Natur gemäß dem schöpferischen sowjetischen Darwinismus nach Mičurin und Lysenko« zeigen. ${ }^{457}$

453 Laut Valentina Zlatoustova reproduzierte die Vorgabe alle»Mängel«, die in den Vorgaben der thematischen Ausstellungsstruktur am Ersten Museumskongress 1930 beschlossen wurden. Vgl. Zlatoustova, Valentina: Gosudarstvennaja politika v oblasti muzejnogo dela, S. 246.

Gesetz vom 14. Oktober 1948 »O merach ulučšenija ochrany pamjatnikov kultury«, zitiert nach: Zlatoustova, Valentina: Gosudarstvennaja politika v oblasti muzejnogo dela, S. 244. Für den Zusammenhang zwischen dem Cesetz und dem im Krieg gewachsenen historischen Bewusstsein vgl. Kaulen, Marija: Muzejnoe delo Rossii, S. 195, sowie Zlatoustova, Valentina: Cosudarstvennaja politika v oblasti muzejnogo dela, S. 245.

455 Ochrana istoričeskich i archeologičeskich pamjatnikov, Moskva 1949, S. 74-75, zitiert nach: Zlatoustova, Valentina: Gosudarstvennaja politika v oblasti muzejnogo dela, S. 245.

456 Ebd., S. 245.

457 Zu den sowjetischen Genetikern Ivan Mičurin und Trofim Lysenko vgl. Segal, Jakob: Mitchourine, Lyssenko et le problème de l'hérédité, Paris 1951. 
Das Kapitel zur sowjetischen Periode sollte diesem Dokument zufolge den zentralen Platz in den Ausstellungen einnehmen und die ideelle Erziehung der Massen gewährleisten. ${ }^{458}$ Andererseits verschaffte das zweite Abschlussdokument den Museen größere Freiheiten. Neben der Bildungsarbeit wurde die wissenschaftliche Forschungsarbeit als zentrale Aufgabe der Museen festgeschrieben. Das führte dazu, dass von nun an im Budget der regionalwissenschaftlichen Museen Speicherräume für die Sammlungen, eine Bibliothek, ein wissenschaftliches Archiv und ein Büro für Ausstellungsbegleitmaterialien vorgesehen und budgetiert werden konnten. Auch wurde den Museen zugestanden, selbständig Literatur- und Kunstausstellungen $\mathrm{zu}$ konzipieren. ${ }^{459}$

\section{Die Vermittlung von kraevedenie}

Die Museumspädagogik war ein Arbeitsbereich des Museums, in dem sich die museumsinternen Ansprüche an wissenschaftliche Forschung mit dem bildungspolitischen Auftrag der Behörden verbinden ließen. Ein zentraler Anspruch der musealen kraevedenie war der Einbezug von interessierten Laien. Gleichzeitig waren die Besucherzahlen für die staatlichen Behörden der wichtigste Kennwert für den Erfolg jedes Museums. Die enge Zusammenarbeit des Museums mit den Schulen, Universitäten und anderen Bildungseinrichtungen war ebenso fester Bestandteil der Museumsarbeit wie das fachliche Beratungsangebot für Fabriken und industrielle Betriebe in der hauseigenen Bibliothek. ${ }^{460}$ Stolz präsentierte der Tscheljabinsker Museumsdirektor Ivan Gorochov seine Zahlen: Die Ausstellung »Die Rolle Tscheljabinsks im Großen Vaterländischen Krieg« erfreute sich großer Beliebtheit - bis zum Jahresende 1946 konnte das Museum bereits über 14.000 Besuche verzeichnen. $^{461}$

458 Zitat aus dem Abschlussdokument »Osnovnye položenija o postroenii èkspozicij oblastnych, kraevych, respublikanskich (ASSR) i krupnych rajonnych kraevedčeskich muzeev«, zitiert nach: Zlatoustova, Valentina: Cosudarstvennaja politika v oblasti muzejnogo dela, S. 247.

Marija Kaulen bezeichnete die »Položenie ob oblastnom, kraevom, respublikanskom (ASSR) kraevedčeskom muzee« als großen Fortschritt in der sowjetischen Museumspolitik, vgl. Kaulen, Marija: Muzejnoe delo Rossii, S. 160.

460 Unter dem Stichwort»Beratungen«(konsul'tacionnaja rabota) führte I. Corochov beispielhafte Anfragen von diversen Einrichtungen an. Ein Ingenieur der Kirov-Werke fragte beispielsweise nach dem Vorkommen und den Fundstellen von Talk-Chloriden und ihrer Zusammensetzung. Vgl.: OCAČO, f. R-627, op. 3, d. 398, I. 4.

461 Die Ausstellung war während der 8,5 Monate Laufzeit im Jahr 1946 an 211 Tagen geöffnet. Im Durchschnitt besuchten 66 Menschen pro Tag das Museum. Aufgrund des Mangels an Führungspersonal konnte nur eine Minderheit der Besucher (1339) das (günstigere) Angebot einer Führung in Anspruch nehmen. Die Mehrheit der Besucher zahlte den doppelten Eintrittspreis (2 Rubel) für eine individuelle Besichtigung. In: OCAČO, f. R-627, op. 3, d. 398, I. 8. 
Das Führungsangebot des Tscheljabinsker Museums bestätigt den in der Ausstellungsanalyse beobachteten Fokus des Museumsdirektors auf die lokalen geologischen Ressourcen. Dem Publikum wurden acht verschiedene thematische Führungen angeboten. Interessanterweise trug nur eine dieser Führungen den Titel der aktuellen Ausstellung, die anderen sieben informierten die Besucherinnen und Besucher über regionalspezifische Themen, die zum Beispiel den Titel »Der Reichtum der Berge des Süd-Urals« trugen. ${ }^{462}$ Die klassischen Führungen (ékskursii) wurden von sogenannten »Schulführungen« (lekcii-ékskursii) ergänzt, die die muzejščiki für die Schulklassen der Stadt anboten. Bei diesen praxisorientierten Führungen wurden zu Beginn archäologische Funde oder der Aufbau eines Herbariums gezeigt. Anschließend wurden die Kinder animiert, selbst die Rolle des Museumsführers einzunehmen und die Gruppe durch die Ausstellung zu führen. ${ }^{463}$ Bei der Bildungs- und Vermittlungsarbeit, die Museumsdirektor Gorochov den Behörden als den »wichtigsten Teil der Arbeit im Jahr 1946« präsentierte, wird eine spezifische Auffassung von kraevedenie im Museum deutlich, die an die Ursprünge der Disziplin anknüpfte: Der thematische Schwerpunkt der Vermittlungsarbeit und ihr hoher pädagogische Anspruch drücken das Streben nach Inklusion der lokalen Bevölkerung aus, ein Anspruch der kraevedenie als pädagogische Reformbewegung des ausgehenden 19. Jahrhunderts. Die junge Generation des Tscheljabinsker Gebietes sollte mit den regionalen Besonderheiten vertraut gemacht werden und dabei das Museum wieder als regionales Expertenzentrum der kraevedenie wahrnehmen.

Das Streben nach naturwissenschaftlicher Grundlagenforschung zeigte sich auch in der Sammlungsarbeit des Museums, die in der Regel parallel zur Ausstellungsarbeit lief. Im Rahmen ihrer wissenschaftlichen Prospektionen für Ressourcen der Rüstungsindustrie waren die kraevedy des Tscheljabinsker Museums im Krieg auf radioaktive Elemente gestoßen. Gorochov war begeistert. Diese Vorkommen im Granitmassiv direkt vor der Stadt seien von »sehr großem Interesse« (ogromnyj interes) und verlangten eine umfassende Erforschung. Deshalb habe das Museum in Eigeninitiative und in Zusammenarbeit mit der Geografischen Gesellschaft die Exploration dieser radioaktiven Quellen übernommen. ${ }^{464}$ Die bereits im Sommer 1946 gesicherten Ergebnisse würden die »Notwendigkeit diktieren« (diktujut neobchodimost'), mit der das Museum auch in den kommenden Jahren mit allen Kräften über die Vorkommen der radioaktiven Elemente forschen müsse. ${ }^{465}$ Die >agency der Steineく, die sich in der Wortwahl des Museumsdirektors ausdrückt, weist wieder auf sein Verständnis von einer unmittelbaren Verknüpfung von unbelebter und belebter Umwelt hin. Dabei passte sich die Erforschung der neuen

\footnotetext{
462 Ebd. I. 9.

463 Ebd.

464 OCAČO, f. R-627, op. 3, d. 398, I. 4.

465 Ebd. I. 5.
} 
radioaktiven Rohstoffe ideal in den wirtschaftspolitischen Kontext der Zeit ein: Sowjetische Kernphysiker arbeiteten Mitte der 1940er Jahre intensiv an der Entwicklung der Atombombe, und Uran war daher ein überaus begehrter Rohstoff. ${ }^{466}$

Ein wichtiger Bestandteil der Sammlungsarbeit waren neben der wissenschaftlichen Forschung auch Ankäufe und Neuzugänge. Gorochov bewies ein erstaunliches Gespür für Objekte, die sich in den folgenden Jahren zu aufsehenerregenden Exponaten und Leitobjekten des Museums entwickeln sollten. Stolz berichtete er über die wertvolle Sammlung von regionalem Kunsthandwerk, die dem Museum geschenkt wurde. ${ }^{467}$ Die in ganz Russland berühmten, kunstvoll gefertigten Eisengussarbeiten aus der Stadt Kasli und die Gravuren aus Zlatoust zählen bis heute zu den prestigeträchtigsten Sammlungsbeständen des Tscheljabinsker Museums. Das Gleiche gilt für den rechten Oberschenkelknochen eines auffallend großen Mammuts, für den der Direktor dem Finder einen hohen Lohn gezahlt hatte. ${ }^{468}$

Unter diesen Neuzugängen befand sich nur ein Objekt, das einen direkten Bezug zur Ausstellung »Die Rolle Tscheljabinsks im Großen Vaterländischen Krieg" hatte: Ein kostenaufwendig und kunstvoll gestaltetes Fotoalbum mit dem Titel »Rapport der Tscheljabinsker Bolschewiki an den Genossen Stalin«. Das Buch, das die Arbeit der 41 Fabriken des Tscheljabinsker Gebietes für die Verteidigung dokumentierte, gilt als das wertvollste Stück der Sammlung der »Gebiets-Kommission zur Suche von Dokumenten und Materialien im Großen Vaterländischen Krieg«. 469 Seit der Schenkung wird es bis heute in den Sonderausstellungen zum »Großen Vaterländischen Krieg« im Museum gezeigt. ${ }^{470}$ Auch im Bereich der Bildenden Kunst verfügte der Museumsdirektor über ein Gespür für Erfolg versprechende Exponate. Gorochov hatte bereits die nächste Sonderausstellung über die Geschichte seiner Stadt im Kopf und bestellte bei einem Tscheljabinsker Maler eine Reihe von Bildern über das vorrevolutionäre Tscheljabinsk. ${ }^{411}$ Die Bilder der Reihe »Das alte

466 Zur sowjetischen Nuklearforschung vgl. Josephson, Paul: Red Atom, Russia's Nuclear Power Program from Stalin to Today, New York 2000; sowie: Holloway, David: Stalin and the Bomb, The Soviet Union and Atomic Energy 1939-1956, New Haven 1994. OCAČO, f. R-627, op. 3, d. 398, I. 10. Ebd. I. 11.

Kalinkina, Elena: Čeljabinskaja oblast', O rabote komissij po sboru dokumentov i materialov po istorii velikoj Otečestvennoj vojny, 20. Februar 2015, in: https://zs74.ru/news/chelyabins kaya-oblast-o-rabote-komissiy-po-sboru-dokumentov-i-materialov-po-istorii-velikoy (Stand: 31.07.2021).

OCAČO, f. R-627, op. 3, d. 398, I. 11. Das Buch wurde zu einem Leitobjekt der Sammlung »Croßer Vaterländischer Krieg«. Zuletzt wurde es in der Sonderausstellung des Museums zum 70. Jahrestag des Krieges (2015) ausgestellt. Vgl. Sonderausstellung »Muzy Pobedy« (Die Musen des Sieges), Laufzeit: 9. April-25. Juni 2015: www.chelmuseum.ru/vystavki-i-ekskursii/vystavk i/muzy-pobedy/ (Stand: 31.07.2021). OGAČO, f. R-627, op. 3, d. 398, I. 11. 
Tscheljabinsk«, die der Maler Ignatij Vandyšev zwischen 1940 und 1950 schuf, zählen heute zu den berühmtesten Darstellungen der Stadt. Mit seinem Auftrag an den mittellosen und unabhängigen Maler Vandyšev (1891-1964) unterstützte Gorochov demonstrativ einen lokalen Künstler, der kein Mitglied einer staatlichen Vereinigung war. ${ }^{472}$

Den auf den ersten Blick sehr unterschiedlichen Neuzugängen der Museumssammlung im Jahr 1946 ist gemeinsam, dass sie alle aus dem Tscheljabinsker Gebiet stammen. Die Schenkungen zeigen, dass das Museum als regionales Sammlungszentrum verstanden wurde. Wenn eine Institution oder eine Privatperson über ein erinnerungswürdiges Objekt verfügte, wandte sie oder er sich an das Museum. Gleichzeitig förderte der Museumsdirektor diese Abläufe, indem er Finderlöhne oder Auftragsarbeiten an die lokale Bevölkerung vergab. ${ }^{473}$

In der Zusammenfassung seiner Arbeitsergebnisse an den Bericht für die Behörden präsentierte Gorochov die Ausstellung über den Krieg als Beginn und Auslöser der »Propagandaarbeit mit den Massen«. Hier zeigt sich erneut sein Verständnis von den lokalen Ressourcen als Voraussetzung für den Sieg im »Großen Vaterländischen Krieg«:

»Die wichtigste Arbeit [...] war der Aufbau der Ausstellung >Die Rolle Tscheljabinsks im Großen Vaterländischen Krieg 1941-1945<. Diese hat es [uns A.H.] erlaubt, die kulturelle Aufklärungsarbeit mit den Besuchern zu beginnen und durchzuführen. Dabei entfalteten sich vor ihnen [den Besuchern A.H.] die einzigartigen [isključitel'nye] natürlichen Ressourcen des Süd-Urals und die riesige Rolle seiner Militärtechnik und die seiner Menschen bei der Zerschlagung des deutschen Faschismus. $\ll^{474}$

Als das Moskauer Museumsinstitut den Arbeitsbericht im Frühjahr 1947 erhielt, reagierte man dort wie bereits im Jahr zuvor mit generellen und eher vagen Empfehlungen für die Museumsarbeit, ohne eindeutige Kritik oder Handlungsanweisungen. ${ }^{475}$ In ihrem jährlichen Brief an die Museumsdirektoren beschränkte sich die stellvertretende Leiterin der Moskauer Museumsabteilung P. Galkina auf den unspezifischen Hinweis, dass die Inhalte der Ausstellungen in den Arbeitsberichten nicht ausreichend beschrieben seien. Sie empfahl, zukünftig nicht nur eine Auflistung der Ausstellungsthemen in dem Arbeitsbericht anzuführen, sondern

472 Bože, Vladimir: Letopiscy zemli ural'skoj, Materialy k istorii čeljabinskogo kraevedenija, Čeljabinsk 1997, S. 44.

473 Die Museumsmitarbeitenden wiesen ihre Besucherinnen und Besucher nach den Führungen auf die Sammelarbeit des Museums hin. Zusätzlich informierte I. Gorochov über die lokalen Zeitungen und den Rundfunk über die Aktivitäten des Museums und verteilte »Anleitungen zum Sammeln « in den Kindergärten, Schulen und Pionier- bzw. Komsomolgruppen.

474 Gorochov, Ivan: Otčet o rabote, 5. März 1947, in: OCAČO, f. R-627, o. 3, d. 398, I. 12.

475 OCAČO, f. R-627, op. 3, d. 401, I. 1-10b. 
anhand einer Beschreibung der Exponate die Bedeutung der Ausstellung zu beschreiben. ${ }^{476}$

\section{Das regionalwissenschaftliche Museum im Spätstalinismus}

Die 3,5-jährige Laufzeit der Sonderausstellung (April 1946 bis zum September 1949) rückt das Tscheljabinsker Gebiet im Spätstalinismus in den Blick, eine Zeit, als der Süd-Ural von der Umstellung der Rüstungsindustrie auf zivile Produktion und den Auswirkungen der landesweiten Hungersnot von 1946-1947 existentiell betroffen war. ${ }^{477}$ Bis zum Ende ihrer Laufzeit wurde die erfolgreiche Ausstellung ständig ergänzt, verändert und vergrößert, bis sie sechs Kapitel vorwies.

Im November 1948 hatte das Moskauer Museumsinstitut eine dreitägige wissenschaftliche Tagung veranstaltet, an der über 300 muzejščiki über die inhaltlichen Konsequenzen von Stalins Fünfahresplan für ihre Arbeitspraxis diskutierten. ${ }^{478}$ Führende Museologinnen und Museologen hatten »schwerwiegende ideelle Mängel« in den Ausstellungen der Museen konstatiert und verfassten ein Abschlussdokument über die »Grundsätze des Ausstellungsaufbaus in den regionalwissenschaftlichen Museen «. ${ }^{479}$ Dieses Papier konkretisierte die festgestellten Mängel und schrieb den muzejščiki eindeutige inhaltliche Schwerpunktsetzungen vor:

»Der Ausstellungsinhalt vieler Museen ist aber nicht regionalwissenschaftlich [kraevedčeskij], da er weder eine Vorstellung vom Umbau der Natur in den Jahren

476 OCAČO, f. R-627, op. 3, d. 402, I. 19-21.

477 Zur Hungersnot 1946-1947, die in der Sowjetunion bis zu 2 Millionen Menschenleben kostete, vgl. Zima, Veniamin F.: Golod v SSR 1946-1947 godov, Proischoždenie i posledstvija, Moskva 1996. Der Autor beschreibt die Hungersnot (und den Umgang damit) als politische Strategie des Spätstalinismus, Kontrolle über die gesellschaftlichen Unruhen der Nachkriegszeit zu erlangen. Nicolas Ganson hingegen betont die externen Faktoren (Zerstörungen des Krieges, Dürre und Missernte), die den staatlichen Umgang mit der Hungersnot bestimmten. Die hier relevante Berücksichtigung der ideologischen Dimension des beginnenden Kalten Krieges erweitert die Forschung um eine internationale Perspektive, die die Konkurrenz mit den USA um politisches Prestige im Umgang der sowjetischen Behörden mit der Hungersnot betont. Vgl. Ganson, Nicolas: The Soviet Famine of 1946-47 in Clobal and Historical Perspective, New York 2009.

Die »Erweiterte Tagung des Wissenschaftsrates des NIIKMR« (Rasširennaja sessija Učenogo soveta NIIKMR) fand vom 25.-27. November 1948 in Moskau statt. Eingeladen waren u.a. Vertreterinnen und Vertreter der ukrainischen, belarussischen, georgischen und lettischen Republiken, die gemeinsam mit russischen Kuratorlnnen an den Sitzungen teilnahmen. Vgl. NIIKMR (Hg.): Očerednye zadači raboty kraevedčeskich muzeev, Moskva 1950, S. 3.

479 Osnovye položenija o postroenii ekspozicii oblastnych, kraevych, respublikanskich (ASSR) i krupnych rajonnych kraevedčeskich muzeev, in: NIIKMR (Hg.): Očerednye zadači raboty kraevedčeskich muzeev, Moskva 1950, S. 197-214. 
der sowjetischen Macht noch über ihren [regionalen A.H.] Platz im Sozialistischen Aufbau gibt. [...]

Die Ausstellungsabteilungen des Sozialistischen Aufbaus nehmen in der Regel keine zentrale und führende Stelle im Museum ein und erfüllen ihre ideelleerzieherische Rolle nicht. [...] Selten sind in den Ausstellungen Modelle von Kolchosen oder die Technologien einzelner Produktionen, die besten Menschen der Industrie und Landwirtschaft, die Helden der Sozialistischen Arbeit zu sehen - das zieht die Qualität des Ausstellungsmaterials herunter, macht es arm [obednjaet ego], langweilig und uninteressant. [...]

Die Ausstellungen der Natur geben keine klare Vorstellung über den natürlichen Reichtum der Region. [...] sie zeigen nicht die Rolle des Menschen bei der Umwandlung der Umwelt und auch nicht die Erfolge des schöpferischen sowjetischen Darwinismus, die Lehre Mičurins und Lysenkos, in der Folge fördern diese Ausstellungen nicht die Bildung einer dialektisch-materialistischen Weltanschauung. $\ll^{480}$

Diese Kritik zeigt, dass Tscheljabinsk kein Einzelfall war und die Mehrheit der regionalwissenschaftlichen Museen aus Sicht der zentralen Behörde eine Überarbeitung ihrer Ausstellungen benötigte. ${ }^{481}$ Um offizieller Kritik zuvorzukommen, betonte Gorochov im Arbeitsbericht die völlig unzureichende finanzielle Ausstattung seines Museums, die es ihm unmöglich machte, entsprechende Ausstellungen zu kuratieren. ${ }^{482}$ Dem Profil entsprechend musste ein regionalwissenschaftliches Museum seine drei Abteilungen (Natur, Geschichte, Wirtschaft) mit Kuratorinnen oder Kuratoren besetzen. 1946 hatte der Direktor lediglich seine langjährige Mitarbeiterin, die Biologin Vera Sur'janinova, für die Leitung der Abteilung "Natur« gewinnen können. ${ }^{483}$ Die Vakanzen waren in erster Linie durch die niedrigen Löhne entstanden, die eine Stelle im Museum sehr unattraktiv machten.

Die Museumsarbeit wurde zusätzlich durch eine weitere schwere Hungersnot erschwert, die das Tscheljabinsker Gebiet im zweiten Jahr nach dem Sieg im »Großen Vaterländischen Krieg« heimsuchte. Die Dürre und die Missernten im Sommer und Herbst 1946 trafen bekanntlich die Gebiete der Ukraine und Moldawiens am

480 Ebd. S. 197-198.

481 Dieser Befund stärkt die Übertragbarkeit der Tscheljabinsker Einzelstudie auf andere regionalwissenschaftliche Museen, die die Mehrheit aller Museen im Netz des Narkompros darstellten.

482 OGAČO, f. R-627, op. 1, d. 398, I. 2.

483 Da V. Sur'janinova nicht über eine abgeschlossene Hochschulbildung verfügte, konnte I. Gorochov sie für ein geringeres Gehalt einstellen. Genau wie I. Gorochov wurde auch sie nach dem Krieg mit dem Orden für »Ehrenvolle und selbstlose Arbeit im Großen Vaterländischen Krieg« ausgezeichnet. Für weitere biografische Informationen zu der Kuratorin vgl. Antipin, Nikolaj: Čeljabinskij kraevedčeskij muzej, S. 194. 
stärksten. Sie führten zu einer Nahrungsknappheit, unter der die ganze Bevölkerung der Sowjetunion schwer litt. Die Katastrophe traf die Bevölkerung zu einem Zeitpunkt, als sie noch von der Mangelernährung der Kriegsjahre geschwächt war. Die Lebensmittelkrise wurde zusätzlich von Faktoren wie den oft schlechten und unhygienischen Lebensbedingungen in ärmlichen Holzhäusern ohne Kanalisation oder Zugang zu sauberem Trinkwasser und den unzureichenden Heizmöglichkeiten verschärft. ${ }^{484}$ Die Umstellung der Rüstungsindustrie auf zivile Produktion hatte gravierende Folgen für die Bevölkerung in Tscheljabinsk, die Lohnkürzungen von 35-50 Prozent hinnehmen musste. Die Abschaffung der Rationierungen führte in den Städten dazu, dass drei von vier erwachsenen Arbeiterinnen und Arbeitern die Lebensmittelkarten und die Versorgung mit rationiertem Brot entzogen wurden. Die Tscheljabinsker Historikerin Olga Nikonova beschreibt die »Panikstimmung « und die erbosten Reaktionen, die Lebensmittelmangel und Lohnkürzungen auch in dem an Weizen reichen Tscheljabinsker Gebiet ausgelöst hatten: Trotz der Hungersnot exportierte die Sowjetunion mehrere Millionen Tonnen Getreide ins Ausland. ${ }^{485}$ Die Statistiken zur Ernährungssituation und Sterblichkeit in der Sowjetunion um 1947 zeigen zwei für den Tscheljabinsker Fall relevante Auswirkungen der Krise: Erstens waren im Gegensatz zu vorherigen Hungersnöten die Städter stärker betroffen als die Bauern auf dem Land, die das fehlende Brot durch eigenen Kartoffelanbau ersetzen konnten. Zweitens traf die Lebensmittelkrise, im Vergleich mit anderen Regionen der Sowjetunion, das Tscheljabinsker Gebiet besonders stark, und die schlechten Lebensbedingungen und der Hunger führten zu einer besonders hohen Sterblichkeit in der Bevölkerung. ${ }^{486}$

Vor diesem Hintergrund ist es nicht überraschend, dass die muzejščiki auch im Jahr 1947 die bereits während des Krieges bei der Bevölkerung sehr gefragten Ausstellungen über die Anlage und Pflege eines eigenen Gemüsegartens erneut präsentierten und Tipps für die Schädlingsbekämpfung in Gemüsekulturen sowie Auskünfte über das Vorkommen von essbaren Pflanzen erteilten. Wie zu Kriegszeiten

484 Filtzer betont, dass die große Mehrheit der Bevölkerung in den meisten Städten (einschließlich Moskaus) unter diesen Umständen lebte. Filtzer, Donald: The 1947 Food Crisis and its Aftermath: Worker and Peasant Consumption in Non-Famine Regions of the RSFSR, in: Filtzer, Donald/Goldman, Wendy Z./Kessler, Gijs u.a. (Hg.): A Dream Deferred, New Studies in Russian and Soviet Labour History, Bern/Berlin/Bruxelles 2008, S. 343-383, hier S. 345-346.

Nikonova, Olga: 1947, Gesichter des Nachkriegssozialismus, in: Behrends, Jan/Katzer, Nikolaus/Lindenberger, Thomas (Hg.): 100 Jahre Roter Oktober, Zur Weltgeschichte der Russischen Revolution, Berlin 2017, S. 126-127.

486 Die Gründe für die im landesweiten Vergleich drastischen Folgen der Hungersnot im Tscheljabinsker Cebiet sind laut D. Filtzer noch ungeklärt. Vgl. Filtzer, Donald: The 1947 Food Crisis, S. 376. Zur Statistik der (Kinder-)Sterblichkeit vgl. ders. S. 349-350, und zu den Unterschieden zwischen der Ernährung der Stadt- und Landbevölkerung vgl. ders. S. 356-357. 
war es die Biologin Vera Sur'janinova ("1882), die diese Ausstellungen konzipierte (Abb. 30). ${ }^{487}$

\section{Abbildung 30: Vera Surjaninova, Bio- login und Kuratorin im Tscheljabinsker regionalwissenschaftlichen Museum, Tscheljabinsk 1937 @ OGAČO.}

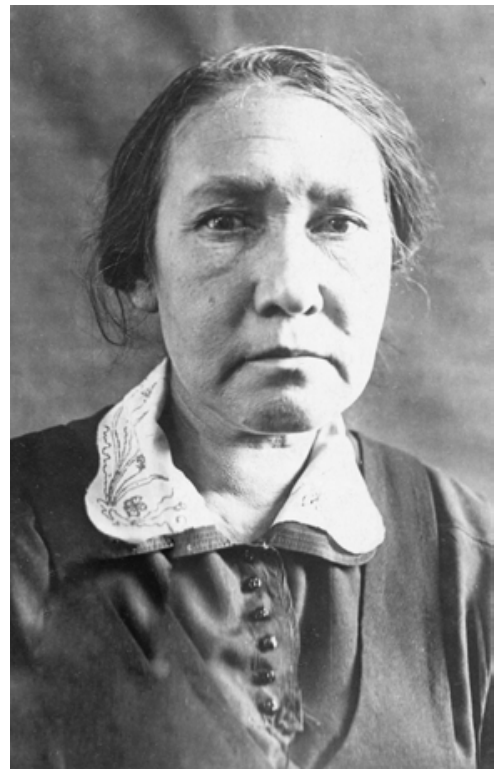

Sie nutzte das Format der Wanderausstellung, um in verschiedenen Einrichtungen der Stadt spezifische Ausstellungen zu zeigen. Die Schautafeln zum eigenen Gemüseanbau wurden beispielsweise in den Bibliotheken der Stadt aufgestellt, wo die Kuratorin mit einem grossen Publikum rechnen konnte. ${ }^{488}$

Während des Krieges hatte der Einbruch in der Lebensmittelversorgung die Regierung gezwungen, ihre Agrarpolitik zu liberalisieren und Subsistenzwirtschaft zuzulassen. Der Wirtschaftshistoriker Andrej Markevič stellte fest, dass diese Überlebensstrategien der Bevölkerung den Krieg überdauerten. Besonders in der zweiten Hälfte der 1940er Jahre kultivierten, in Anbetracht der landesweiten

487 Antipin, Nikolaj: Čeljabinskij kraevedčeskij muzej, S. 169.

488 »Organizacija individual'nogo ogoroda«, »Uchod za ovoščnymi kul'turami«, »Bor'ba s vrediteljami ovoščnych kultur'«, »Dikorastuščie piščevye rastenija Čeljabinskaja oblasti«, in: OGAČO, f. R-627, op. 3, d. 402, I. 10. 
Hungersnot, immer mehr Städter einen eigenen Obst- oder Gemüsegarten auf ihrem Grundstück. ${ }^{489}$ Städtische Institutionen wurden angehalten, die Bevölkerung mit Parzellen, Samen, Dünger und landwirtschaftlichem Gerät zu unterstützen, während Zeitschriften Anleitungen für die Pflege von Gemüse- und Obstgärten publizierten. Die Wanderausstellungen des Tscheljabinsker regionalwissenschaftlichen Museums boten in diesem Kontext eine weitere Möglichkeit, Wissen und Ratschläge für die Selbstversorgung in der Stadt zu erhalten. Diese Aufklärungsarbeit fiel im wörtlichen Sinne auf fruchtbaren Boden. 1955 führten 70 Prozent der Fabrikarbeiterfamilien im Ural einen städtischen Haushalt mit Gemüsegarten, damit standen sie an zweiter Stelle nach den Gebieten des Fernen Ostens, in denen 74 Prozent der Menschen die urbane Subsistenzwirtschaft zum Überleben nutzten. ${ }^{490}$

Während die städtische Kulturbehörde diesen Raum für private Eigeninitiative und regionale Autonomie in Krisenzeiten offenließ und die Ausstellungen der muzejščiki zur Unterstützung der individuellen Selbstversorgung duldete, forderte sie parallel Sonderausstellungen mit anderen thematischen Schwerpunkten. ${ }^{491}$ Mit Schenkungen nahm die Tscheljabinsker Kulturbehörde erfolgreich Einfluss auf die gewünschte Ausstellungsarbeit. Während sie dem Museum im Jahr zuvor das wertvoll gestaltete Buch über die Arbeit der Fabriken im Krieg vermacht hatte, schenkte die Behörde in diesem Jahr Materialien über ein Panzerkorps, das vom Tscheljabinsker Hinterland bis zur Kriegsfront gelangt war. Gorochov reagierte wunschgemäß und begann die entsprechende Ausstellung zu planen. Bald präsentierte er als Ergänzung zu den oben genannten Ausstellungen im Stadtpark eine Wanderausstellung mit dem Titel »Von Tscheljabinsk zur Front«. ${ }^{492}$

Doch auch die Museumsarbeit blieb von der Lebensmittelkrise nicht verschont. Voller Bedauern schrieb der Museumsdirektor im Arbeitsbericht, dass die für 1947 geplanten archäologischen Ausgrabungen und die Erforschung der radioaktiven

489 Markevič, Andrej: Finding Additional Income: Subsidiary Agriculture in Soviet Urban Households, 1941-1964, in: Filtzer, Donald/Goldman, Wendy/Kessler, Gijs u.a. (Hg.): A Dream Deferred, New Studies in Russian and Soviet Labour History, Bern/Berlin/Bruxelles 2008, S. 343383, hier S. 385-415, hier S. 396.

490 Zur Statistik der regionalen Verteilung von Cemüsegärten vgl.: ders. S. 409. A. Markevič betont, dass die städtische Subsistenzwirtschaft nicht auf monetären Cewinn ausgerichtet war. In der Mangelwirtschaft der UdSSR, ermöglichte sie den Bewohnerinnen und Bewohnern, die Nahrungsengpässe auszugleichen und Geld für andere lebenswichtige Cebrauchsgüter zu sparen. Vgl. S. 413.

In der Beurteilung der Arbeit des Tscheljabinsker Museums werden die Wanderausstellungen über die Anlage eines individuellen Cemüsegartens, über die Pflege von Cemüsekulturen und über wildwachsende essbare Pflanzen lobend erwähnt. In: OCAČO, f. R-627, op. 3, d. 402, I. 58. 
Quellen im Granitmassiv nicht durchgeführt werden konnten, da die Stadt die üblichen Brotrationen für Angestellte nicht ausgegeben habe und die Leiterin der Forschungsgruppe nach schwerer Krankheit verstorben sei. ${ }^{493} \mathrm{Da}$ die Forschung im Feld unmöglich war, nutzten die muzejščiki die Zeit für Inventarisierungs- und Archivierungsarbeiten. Sie legten eine Kartei an, in der alle Berge, Flüsse, Seen und natürliche Vorkommen von Mineralien und Pflanzen verzeichnet waren. Diese Wissenskonzentration machte das Museum zum wichtigsten Ansprechspartner im Tscheljabinsker Gebiet. ${ }^{494}$

Doch genau für diese isolierte Stellung wurde das Museum an der Sitzung der Kulturbehörde im August des Jahres 1947 kritisiert. Die muzejščiki würden »sich in ihrer Arbeit einschließen « (zamknulis'v svoej rabote) und ihre Erfahrungen nicht mit anderen Museen teilen. Dies entspräche nicht den Bedürfnissen der »Massen«, und das Museum müsse sich durch Vorträge, Veranstaltungen und die Zusammenarbeit mit Schulen bekannter machen. Dem Museumsdirektor wurde der Auftrag erteilt, die Schulen, Arbeiterklubs, Bibliotheken und andere Institutionen des Gebietes in die museale Vermittlungsarbeit zu integrieren. ${ }^{495}$

Gorochov reagierte und präsentierte die geleistete Bildungs- und Vermittlungsarbeit im Bericht als das relevanteste Erfolgskriterium seines Museums. Während die Besucherzahlen für 1947 im Vergleich zum Vorjahr nur leicht gestiegen waren (19.000 Personen), hatten Gorochov und sein Team viel Zeit und Kraft aufgewendet, um das Museum im Tscheljabinsker Gebiet als Bildungszentrum zu etablieren. ${ }^{496}$ Die Zielgruppe dieser Vermittlungsarbeit waren die Lernenden und Auszubildenden der Region. Der Museumsdirektor sicherte sich diese Klientel und die moralische Unterstützung seiner Arbeit durch die Bildungsinstitutionen der Stadt, indem er sein Ausstellungsprogramm mit den Lehrplänen der Schulen koordinierte. Für die unterschiedlichen Klassen konzipierte das Museum spezielle Führungen, die an die jeweilige Unterrichtseinheit angepasst waren. Das Lehrpersonal konnte das Weiterbildungsangebot der Abteilung Bildung und Vermittlung im Museum in Anspruch nehmen. 497

Ebd. I. 5.

Ingenieure von Wasserwerken erkundigten sich über die Beschaffenheit eines Flussbeckens, und Studierende ließen ihre im Ilmengebirge gesammelten Mineralien von den Museumsangestellten bestimmen. Vgl.: Ebd. I. 6.

5 OCAČO, f. R-627, op. 3, d. 402, I. 58. Neben dem oben genannten Auszug aus dem Protokoll ist für das Jahr 1947 keine Beurteilung der Museumsarbeit seitens der Behörden überliefert. 1947 war das Museum an 302 Tagen geöffnet. Von den 19.000 Besucherinnen und Besucher besichtigten 5.941 Personen (darunter 4.576 Schülerinnen und Schüler) die Ausstellung im Rahmen der insgesamt 244 Führungen. OGAČO, f. R-627, op. 3, d. 402, I. 11.

Zum Beispiel konnte eine 4. Schulklasse im Rahmen einer Unterrichtseinheit zur »Unbelebten Natur « das Museum besuchen, um eine Führung zu Mineralien und Gebirgssteinen zu erhalten. OGAČO, f. R-627, op. 3, d. 402, I. 11. 
Während das Museum so praxisbezogenes und anschauliches Lernen im Museum förderte, bestand das primäre Ziel des Museumsdirektors in der Verbreitung und institutionellen Verankerung seiner Vorstellung von kraevedenie. So erhielten beispielsweise die Kirov-Werke Themenhefte, wie sie in ihrem Pionier-Sommerlager naturhistorische Forschungen durchführen konnten, und die Kindergärten in den Dörfern des Tscheljabinsker Gebietes bekamen bebilderte Anleitungen für das Sammeln von Exponaten der kraevedenie. ${ }^{498}$ Diese Werbekampagne zahlte sich auch auf einer weiteren Ebene aus. Das geweckte Bewusstsein für die Naturgeschichte führte dazu, dass immer mehr Menschen des Tscheljabinsker Gebietes dem Museum ihre privaten Funde vermachten. Der Kindergarten des südlich von Tscheljabinsk gelegenen Dorfes Brodokalamsk wandte sich mit dem außergewöhnlichen Fund eines Nashornzahns an das Museum. Ein Artikel im »Tscheljabinsker Arbeiter « (Čeljabinskij rabočij) griff diesen Fund auf und lobte die kraevedenie-Arbeit des Museums. ${ }^{499}$

Neben dieser thematischen Schwerpunktsetzung strebte der Museumsdirektor nach größerer materieller Unabhängigkeit seines Hauses. Seine jährlich dringlicher werdenden Forderungen nach einem eigenen Gebäude, nach mehr Planstellen mit höheren Gehältern und der bevorzugten Zuteilung von Arbeitsmaterialien zeigen, wie Gorochov sein zweites Ziel, eine größere institutionelle Eigenständigkeit, verfolgte und dabei zunehmend an Selbstbewusstsein gewann. Im Frühjahr 1948, als sich die Ernährungssituation im Tscheljabinsker Gebiet allmählich entspannte, konnte das Museum ein rundes Jubiläum feiern. Vor 30 Jahren hatte im April 1918 ein Kreis von kraevedy das Museum gegründet und Gorochov zu seinem Direktor bestimmt. So war dieses Jahr zugleich das 30-jährige Dienstjubiläum des Direktors. Die Stadt würdigte diese Leistung mit einer Ehrenurkunde für seine »langjährige Tätigkeit auf dem Gebiet der kulturellen Aufklärungsarbeit «. ${ }^{500}$ Scheinbar hatten dieses private Jubiläum sowie die Würdigung durch die Behörden einen Selbstermächtigungseffekt auf den Direktor. Er nahm den Jahrestag zum Anlass, ein Buch über die Geschichte des Museums zu schreiben und damit an die traditionelle, aber brachliegende Publikationstätigkeit des Museums wieder anzuknüpfen. ${ }^{501}$

498 Ebd. I. 13.

499 Zu den Neuzugängen der Museumssammlung im Jahr 1948, vgl.: Ebd. I. 14. Ohne Autor: »O nachoždenii zuba nosogore vospitannikami detdoma v s. Brodokalamsk«, in: Čeljabinskij rabočij, 9. Dezember 1949.

500 GIMJUU, A-1794-a. Pr-131.

501 OGAČO, f. R-627, op. 3, d. 405, I. 15. Zusätzlich plante I. Corochov anlässlich des runden Ceburtstages seines Museums Postkarten von den Bildern I. Vandiščevs zu drucken, die im Museum verkauft werden sollten. Laut dem Tscheljabinsker Historiker Vladimir Bože seien weder das Buch noch die Postkarten produziert worden. Vgl. Bože, Vladimir: Letopiscy zemli ural'skoj, S. 45. 
Dieses Bewusstsein von der Geschichte seines Hauses spornte ihn zu einer noch dezidierteren Durchsetzung seiner beruflichen Ziele an. Der Arbeitsbericht des Jahres 1948 strotzt von einer Vielzahl von Forderungen, Vorwürfen und Handlungsanweisungen an das Gebietskomitee. Die energisch formulierten Forderungen nach mehr Geld, einem eigenen Gebäude und materieller Unterstützung wurden in diesem Jahr durch ein unschlagbares Argument legitimiert: Innerhalb eines Jahres war es dem Museumskollektiv gelungen, die Besucherzahlen der Ausstellung »Die Rolle Tscheljabinsks im Großen Vaterländischen Krieg« zu verdreifachen und damit den Plan um ein Doppeltes zu erfüllen. ${ }^{502}$ Diese Zahlen waren ein schlagendes Argument für die Tscheljabinsker Museumsarbeit, da der Brief des Moskauer Museumsinstitutes die niedrige Besucherzahl als grundsätzliches Defizit (obščij nedostatok) der Museen kritisiert hatte. ${ }^{503}$ Allerdings hatten von den rund 60.000 Besucherinnen und Besucher über 50.000 das Museum als individuell und nicht im Rahmen einer Führung besichtigt. ${ }^{504}$ Das war weder im Sinne der $m u$ zejščiki noch des Museumsinstitutes. Sowjetische Ausstellungen wurden prinzipiell für die Besichtigung im Rahmen einer Führung konzipiert (s. Kapitel 3). An den Wänden der Ausstellungssäle waren in der Regel keine Tafeltexte angebracht und dem Publikum wurde auch kein begleitender Ausstellungsführer ausgehändigt. Eine fachmännische Führung sollte die richtigen Schwerpunkte setzen und für die gewünschte Erkenntnis und Wirkung im Publikum sorgen.

Gorochov war der negative Beigeschmack dieser eigentlich erfreulichen Zahlen bewusst. Geschickt verwandelte er den Makel in ein Argument für seine Forderung nach mehr Unabhängigkeit: ein eigenes Gebäude und mehr Geld. Es sei der Platzmangel in der ehemaligen Kirche, der einen individuellen, aber vorbestimmten Ausstellungsrundgang unmöglich mache. ${ }^{505}$ Zweitens müsse der Personalstand angepasst werden. Da dieser kein Führungspersonal vorsehe, müssten momentan die bereits maximal ausgelasteten wissenschaftlichen Mitarbeiterinnen und Mitarbeiter die Führungen übernehmen. Außerdem sei das Gehaltsniveau der Planstellen immer noch auf dem Stand von 1934 und hätte sich seitdem nur um ei-

502 Im Plan für das Jahr 1948 war vorgesehen, die Besucherzahl auf 30.000 Personen zu steigern. I. Gorochov führte die doppelte Planerfüllung als wichtigsten Punkt seiner Arbeitsergebnisse im Bericht an. OGAČO, f. R-627, op. 3, d. 405, I. 17-18, und I. 28.

503 Zur Orientierung führte der stellvertretende Abteilungsleiter Klabunovskij Negativbeispiele diverser regionalwissenschaftlicher Museen in anderen Gebieten und Regionen an: Orjeler Cebiet: 13.000, Petrovsk: 3.300. OCAČO, f. R-627, op. 3, d. 408, I. 7.

504 Die Tabelle zur Besucherzusammensetzung im Jahr 1948 ist in Monate und Besuchergruppen aufgeteilt. Dabei wurde zwischen Individualbesuch, Gruppenbesuch im Rahmen einer Führung sowie zwischen Erwachsenen/Kindern und Personen, die das Museum gratis besuchten, unterschieden. OGAČO, f. R-627, op. 3, d. 405, I. 18. 
ne zusätzliche Brotration erhöht. Er forderte die Angleichung der Lohnklasse von Museumsmitarbeitenden an die der Bibliothekare und Lehrer des Gebietes. ${ }^{506}$

Diese Forderungen zeigen anschaulich, wie der Museumsdirektor seinen im Krieg gewährten Freiraum nicht nur erhalten, sondern ausweiten wollte. Er flankierte seine zentralen Forderungen mit Ansprüchen auf eine Verbesserung des Arbeitsalltags. Gorochov führte mehrere konkrete Beispiele an, die die materielle und bürokratische Begrenztheit seiner Arbeitsmöglichkeiten zeigten: Um den Schulklassen im Museum zu demonstrieren, dass praktisch alle Mineralien quasi Edelsteine seien, brauchten seine Angestellten Lupen. Eine nahegelegene Fabrik wollte die Bestellung aber nicht aushändigen, da sie keine Erlaubnis des Moskauer Verteidigungsministeriums vorweisen konnten. ${ }^{507}$ Es ist anzunehmen, dass der $\mathrm{Mu}$ seumsdirektor nicht darauf hoffte, dass das Tscheljabinsker Gebietskomitee derlei unsinnige bürokratische Hürden bald abschaffen würde - seine Beschwerde zielte in erster Linie darauf, Präsenz zu zeigen. Er nutzte den Arbeitsbericht, um auf Missstände hinzuweisen und sich gleichzeitig als engagierten und vorausdenkenden Bürger zu präsentieren. Der Arbeitsbericht erscheint hier als Medium der Selbstrepräsentation, in dem sich emanzipierte Akteure ihren übergeordneten Behörden entgegenstellen.

Im Sommer 1948 konnten endlich die von Gorochov lang geplanten archäologischen Forschungen im Tscheljabinsker Gebiet durchgeführt werden. Als Leiter der wissenschaftlichen Expedition hatte der Museumsdirektor seinen langjährigen Freund und Arbeitskollegen Konstantin Vladimirovič Sal'nikov (1900-1966), einen anerkannten Professor für Ur- und Frühgeschichte, gewinnen können. ${ }^{508}$ Die Ergebnisse, die der Archäologe im Rahmen der einmonatigen Ausgrabungen gemeinsam mit seinen Studenten erarbeitet hatte, waren in den Augen des $\mathrm{Mu}$ -

In der Mitarbeiterliste des Museums waren zwölf Planstellen vorgesehen: Direktor, Stellvertreter, zwei wissenschaftliche Mitarbeiter/Mitarbeiterinnen, ein Bibliothekar und ein Buchhalter sowie sechs Angestellte für hauswirtschaftliche Aufgaben. Den höchsten Monatslohn (640 Rubel) bezog die Bibliothekarin, der Museumsdirektor erhielt 602 Rubel, während die drei Putzfrauen den niedrigsten Lohn von 230 Rubel erhielten. Bei dieser Gelegenheit beschwerte sich der Museumsdirektor über die Finanzabteilung des Tscheljabinsker Cebietes. Die bewilligten Zahlungen würden beinahe jedes Jahr erst im dritten Quartal eintreffen und dann entsprechend für die Bedürfnisse des verbleibenden Jahres angepasst werden, so dass von der erwarteten Summe meist nur die Hälfte beim Museum ankäme: OCAČO, f. R-627, op. 3, d. 405, I. 4-5 und I. 29.

507 In den anderen zwei Beispielen beklagte I. Gorochov, dass unerlässliche Arbeitsutensilien wie ein starker Spezialklebstoff und ein Präparat zur Entrostung von Metallen nicht im Tscheljabinsker Gebiet zu erhalten seien. OGAČO, f. R-627, op. 3, d. 405, I. 6-7.

508 Für eine kurze Biografie von K. Sal'nikov und eine Beschreibung seiner Mitarbeit im regionalwissenschaftlichen Museum vgl. Antipin, Nikolaj: Čeljabinskij kraevedčeskij muzej, S. 188189. 
seumsdirektors von so großer wissenschaftlicher Relevanz, dass er den Professor einen Expertenbericht verfassen ließ, den er dem Bericht als Anhang beifügte. ${ }^{509}$

Auch die Beschreibung der Ausstellung im Bericht von 1948 bestätigt den Eindruck einer Bestandsaufnahme der Arbeit der vergangenen drei Jahre. Gorochov sicherte seine Ergebnisse, indem er die von ihm entwickelten sechs Abteilungen des regionalwissenschaftlichen Museums als Dauerausstellung festschrieb:

»a) Die Entstehung der Welt und die geologische Vergangenheit des Süd-Urals,

b) Mineralien und Gebirgssteine des Süd-Urals,

c) Die Bodenschätze des Tscheljabinsker Gebietes,

d) Die Tierwelt des Tscheljabinsker Gebietes,

e) Die Geschichte der Stadt Tscheljabinsk,

f) Die Rolle Tscheljabinsks im Großen Vaterländischen Krieg 1941-1945. \$10 $^{510}$

Am Ende des Jahres 1948, zweieinhalb Jahre nach ihrer Eröffnung, war die Eröffnungsausstellung, die der Museumsdirektor gemeinsam mit der städtischen Kommission und den Rüstungsbetrieben konzipiert hatte und die mit ihren Exponaten den ganzen Ausstellungsraum der ehemaligen Kirche ausgefüllt hatte, zu einem Kapitel neben fünf anderen geschrumpft. Die Prävalenz naturhistorischer Abteilungen der Ausstellungsstruktur deckt sich mit den Angaben zu den Sammlungsbeständen im Museum. Die zahlenmäßig größte Sammlung bestand mit insgesamt bis zu 25.000 Exponaten aus Mineralien und Gebirgssteinen. ${ }^{511}$ Darauf folgte die Sammlung, die laut dem Museumsdirektor am besten erhalten war und von der beinahe alle Exponate ausgestellt waren, nämlich die zoologische Sammlung der ausgestopften Tiere. Der älteste Sammlungsbestand des Museums, den der bereits in vorrevolutionärer Zeit berühmte Botaniker und Initiator des Museums Ippolit Krašennikov (1884-1947) angelegt hatte, bestand aus einem Grundstock von Herbarien. An vierter Stelle stand die Historische Sammlung, die sich aus archäologischen, historischen, ethnographischen und numismatischen Beständen zusammensetzte. An letzter Stelle stand die Sammlung der geplanten Abteilung "Sozialistischer Aufbau«, die Exponate zur Landwirtschaft und zur Industrie beinhaltete

509 Das Fachgebiet des Ur- und Frühgeschichtlers K. Sal'nikov war die Andronovo-Kultur, eine Epoche der Bronzezeit in Südwestsibirien und Mittelasien. In der Expedition im Sommer 1948 entdeckte seine Forschungsgruppe unbekannte Grabhügel und Siedlungen der AndronovoKultur im Tscheljabinsker Cebiet. OCAČO, f. R-627, op. 3, d. 405, I. 1-2.

510 Ebd. I. 8.

511 Ebd. I. 23-24. Von diesem Sammlungsbestand befand sich nur ein Bruchteil (2.000 Objekte) als Exponate in der Ausstellung. Während Museumssammlungen in der Regel immer um ein Vielfaches größer sind als die Zahl der ausgestellten Objekte, so bestätigt das Verhältnis im Tscheljabinsker Fall dennoch die Beschwerden des Museumsdirektors über die unzureichende Ausstellungsfläche in der ehemaligen Kirche. 
- diese seien jedoch bislang weder beschrieben noch inventarisiert und deswegen nicht ausgestellt.

Während diese Themenverteilung ideal zu Gorochovs Vorstellungen eines regionalgeschichtlichen Museums passte, erfüllte sie nicht die Vorstellungen des zentralen Museumsinstitutes. Dabei war nicht so sehr die Verkleinerung der Kriegsausstellung der Anlass zur Kritik, sondern vielmehr das dadurch entstandene Missverhältnis zwischen den drei erwünschten Ausstellungsbereichen. Selbstverständlich war dem Museumsdirektor die thematische Abweichung bzw. die Auslassung der ökonomischen Dimension in seiner Ausstellung bewusst. Um einem entsprechenden Vorwurf zuvorzukommen, kündigte er einen Umbau der Ausstellung im nächsten Jahr an: 1949 würde die Abteilung »Die Rolle Tscheljabinsks im Großen Vaterländischen Krieg« komprimiert werden, um Platz für den »Sozialistischen Aufbau« zu schaffen. ${ }^{512}$ Der Museumsdirektor hatte die Behörden richtig eingeschätzt: Einige Wochen nach der Abgabe seines Arbeitsberichtes erhielt er die Antwort des Leiters des Moskauer Museumsinstitutes. ${ }^{513}$ Die Kritik, die an alle regionalwissenschaftlichen Museen des Landes gerichtet war, war unmissverständlich:

»Die Analyse der Jahresberichte der regionalwissenschaftlichen Museen für das Jahr 1948 zeigt, dass eine große Zahl von Museen die Bedeutung der Ausstellung zum Sozialistischen Aufbau immer noch nicht zu würdigen weiß [ešče ne doocenivaet]. Sie richten das Hauptaugenmerk ihrer Ausstellungs- und Sammelarbeit auf die Ceschichte [...] und begeistern sich [uvlekajas'] für archäologische Forschungen.«

Gorochov musste sich angesprochen fühlen. Zwar streiften seine Ausstellungsabteilungen zur Geschichte der Stadt Tscheljabinsk und zum Krieg die gewünschte Thematik, doch hatte er keine separate Abteilung zu den geforderten »sozialistischen Errungenschaften«. Darüber hinaus gehörte sein Museum definitiv zu den angesprochenen Häusern, die sich in erster Linie für die archäologische Beschaffenheit der Region interessierten.

Dem Leiter des Museumsinstitutes Ivan Krjažin, selbst Direktor eines biologischen Museums, war es ernst - er forderte die Direktoren auf, ihm innerhalb der nächsten zehn Tage einen Plan zuzustellen, in dem sie erstens Maßnahmen zur Ergänzung ihrer Sammlungen mit Exponaten für die Abteilung »Sozialistischer Aufbau« anführten, und zweitens detailliert Auskunft über die bereits vorhandenen Exponate in dieser Abteilung gaben. ${ }^{514}$ Auch wenn die geforderte Liste bzw.

512 OGČAO, f. R-627, op. 3, d. 405, I. 9.

513 OGČAO, f. R-627, op. 3, d. 408, I. 1. Zur Biografie von Ivan Krjažin vgl. Kudrjaceva, Elena: Obrazovanie i pervye gody suščestvovanija Instituta.

514 Der große Druck, den Ivan Krjažin mit der kurzen Frist auf die Museumsdirektoren ausübte, wurde zusätzlich von dem sehr konkreten Sammlungsauftrag verstärkt. Die zu erstellen- 
der Maßnahmenplan nicht überliefert ist, gibt der Arbeitsbericht vom Folgejahr 1949 Auskunft über den Umgang Gorochovs mit dieser Kritik. ${ }^{515}$ Mit dem Vorwurf an die Planungsbehörde des Gebietskomitees, dem Museum nicht genügend Planstellen und Gehälter zu bewilligen, warf er den Ball zurück und nahm gleichzeitig seine Mitarbeitenden in Schutz. ${ }^{516}$ Wohl wissend, dass mit diesem Hinweis im günstigsten Fall Zeit gewonnen war, kooperierte Gorochov und kündigte pünktlich zum 1. Mai 1950 Ausstellungsabteilungen zum »Sozialistischen Aufbau« und zur Geschichte der Region an. ${ }^{517}$

Die inhaltliche Realisierung dieser zwei Abteilungen entsprach wiederum nur zum Teil den Wünschen der Behörden. Den Forderungen nach der Präsentation der "sozialistischen Errungenschaften « kam der Direktor nach, indem er der Kuratorin Vera Sur'janinova den Auftrag gab, eine Ausstellung zur »Landwirtschaft im Tscheljabinsker Gebiet « zu inszenieren. Während diese Abteilung zumindest sozialistischen Interpretationsspielraum ließ, präsentierte die neue Abteilung »Geschichte« keineswegs Errungenschaften der Sowjetunion, sondern die vor dem Krieg entdeckten paläolithischen Siedlungsspuren im Tscheljabinsker Gebiet. ${ }^{518}$ Hier hatte der Direktor scheinbar selbst als Kurator agiert: Während er Galina Orlova, seine noch unerfahrene Kuratorin für die Abteilung »Geschichte«, auf eine Bildungsreise nach Sverdlovsk (heute Jekaterinburg) und Moskau schickte, damit sie sich ein Bild von den dortigen historischen Ausstellungen machen konnte, engagierte er einen Künstler, der die im Vorjahr entdeckten prähistorischen Höhlen für ihn zeichnete..$^{519}$

Die archäologisch ausgerichtete Geschichtsabteilung wurde um die Präsentation über den aus dem Süd-Ural stammenden weltberühmten Metallurgen Pavel Anosov (1796-1851) ergänzt. Hier scheinen Kulturbehörden und muzejščiki einen Kompromiss gefunden zu haben. Gorochov nahm den Beschluss des Ministerrates der UdSSR, dem Wissenschaftler in der Stadt Zlatoust (Tscheljabinsker Gebiet) ein Denkmal zu errichten, zum Anlass, eine Sonderausstellung zu der »Verewigung des

de Sammlung sollte Objekte aus verschiedenen Jahren bzw. Epochen der sowjetischen Ceschichte vorweisen können: 1917, 1918, 1920, 1921-1925, 1926-1934, 1935-1941, 1941-1945, 19451948. OCČAO, f. R-627, op. 3, d. 408, I. 1.

OCČAO, f. R-627, op. 3, d. 408, I. 11-26 (zusätzlich: nicht numerierte Rückseiten). Unter dem Punkt »Sammlungen« (I. 21) erwähnt I. Gorochov, dass er dem Moskauer Komitee einen Bericht über die Sammlungen zugestellt habe. 
Gedenkens an den herausragenden Metallurgen des Süd-Urals « zu erarbeiten. ${ }^{520}$ Diese Ausstellungsabteilung, die ein Thema von lokaler wie auch unionsweiter Bedeutung präsentierte, war nicht nur ein inhaltlicher Kompromiss, sondern auch ein methodischer. Für die Ausstellungsrecherche entsandte Gorochov vier Studierende der historischen Fakultät der Tscheljabinsker Universität in das Zlatouster Archiv. ${ }^{521}$ Dieser Einbezug von regionalen Auszubildenden war sowohl im Sinne der musealen Forschung als auch der vom Museum nachdrücklich geforderten »Propaganda für die Massen«.

Ein deutliches Signal der thematischen Anbindung der Tscheljabinsker kraevedenie an die unionsweiten Narrative waren die großflächigen Plakate an den Außenwänden des Museums. Auf über 14 Quadratmetern präsentierte das Museum »Den großen Plan zur Umwandlung der Natur« und eine Ausstellung zum 70. Geburtstag des Genossen Stalin. ${ }^{522}$

Auch im Museum selbst hatte der Museumsdirektor bereits Platz für die neuen Ausstellungen geschaffen: Seit Ende September 1949 war die Ausstellung »Die Rolle Tscheljabinsks im Großen Vaterländischen Krieg« abgebaut. Die Frage nach dem weiteren Verbleib der Objekte gibt Aufschluss über den Status des Museums. Im Frühjahr 1946 hatte die Stadt dem Museum aus Mangel an eigenen Objekten Ausstellungsexponate als Leihgabe organisiert. Nun sollten diese den Leihgebern (den Fabriken) zurückgegeben werden. Gorochov konnte jedoch durchsetzen, dass die »wertvollsten und interessantesten Exponate« im Sammlungsbesitz des Museums blieben und nur die Objekte mit »reiner militärischer Bedeutung« (z.B. Projektile) den Fabriken zurückgegeben wurden. ${ }^{523}$ Je umfassender und vielfältiger die Sammlungen des Museums waren, desto größer wurden die Möglichkeiten des Museumskollektivs, Ausstellungen innerhalb und außerhalb des eigenen Hauses zu erstellen. Deshalb betonte Gorochov zur Bekräftigung seines Anspruchs auf die begehrten Objekte die Verantwortung, die sein Haus als Museum der Gebietshauptstadt trage: Neben der Beratungstätigkeit, mit der sein Kollektiv den regionalwissenschaftlichen Museen des Tscheljabinsker Gebietes zur Seite stünde, habe das Museum eine Reihe von »Patenschaften« (̌̌efstva) für kleinere Häuser übernommen und organisiere Ausstellungen für sie. ${ }^{524}$

Ebd. Am 15. November 1948 hatte der Ministerrat der Sowjetunion die Errichtung des Denkmals im historischen Zentrum der Stadt Zlatoust beschlossen. Eingeweiht wurde das Denkmal, das einen Metallurgen beim Biegen von Stahl zeigt, am 19. Dezember 1954.

OGČAO, f. R-627, op. 3, d. 408, I. 17.

I. Gorochov erwähnt an dieser Stelle den Auftrag der Stadt, die Patenschaft für das Dorf Miasskoe zu übernehmen und dort eine Wanderausstellung und eine kleine Bibliothek einzurichten sowie einen Vorlesungszyklus zu starten und Anschauungsmaterial für Schulen zur Verfügung zu stellen. Diese Betreuung wurde wahrscheinlich bei der Museumskonferenz des 
In der abschließenden Zusammenfassung der Arbeitsergebnisse konzentrierte Gorochov seine Forderungen erneut. Die Beschwerde über die fehlende Unterstützung durch die Kulturbehörden drückte er in seinem Anspruch nach einem Neubau aus. Die Formulierung dieser Forderung ist ein Gradmesser des gewachsenen Selbstbewusstseins des Museumsdirektors. Während er 1946 das ehemalige Kirchengebäude noch als "wenig geeignet « (malo prisposobeno) beschrieb, beklagte er drei Jahre später die unzureichende Ausstellungsfläche als »sehr schlecht « (očen' plocho) für die Museumsarbeit. Während die Berichte auf den ersten Blick wie ein Ventil für seinen Ärger wirken, nutzte er sie zugleich zur Artikulation seiner Vision. Die besondere Raffinesse war dabei die rhetorische Subtilität in Gorochovs Vorgehen, mit der er sich selten als Akteur mit eigener Agenda, sondern meist als Erfüller der gesellschaftlichen Bedürfnisse unter schwierigen Bedingungen darstellte. Gorochov beherrschte das Spiel von >Geben und Fordern`. Moralische Unterstützung erhielt er bei diesem Balanceakt von seinen Angestellten, die seine museumspolitischen Ansichten zu teilen schienen. Mit einem Lob am Ende des Berichts von 1949 stellte er sich hinter sein Kollektiv und übernahm die alleinige Verantwortung für die auf seine Vorstellungen von kraevedenie ausgerichtete Museumsarbeit:

»Trotz dieser schwierigen Arbeitsbedingungen muss ich sagen, dass den lebensmutigen Mitarbeitern die Liebe zur Sache hilft, die Schwierigkeiten zu überwinden und dass sie sinnvolle und notwendige Arbeit leisten; beim Studium ihrer Region und bei der kulturellen Vermittlungsarbeit in der örtlichen Bevölkerung. « ${ }^{525}$

Ende der 1940er Jahre war die Stimmung unter den muzejščiki angespannt. Die aufsehenerregenden Schließungen der beliebten und bekannten Museen in Moskau und Leningrad setzten die Museen in der ganzen Sowjetunion unter Druck und schürten die Angst vor einem ähnlichen Schicksal. Die »Leningrader Affäre« und die Prozesse gegen die sogenannten »Kosmopoliten « bestimmten die staatliche Kulturpolitik, die sich unter der Flagge des Kampfes gegen die »Kriecherei vor dem Westen« und für die "Verteidigung der sozialistischen Werte« gegen alles richtete, was nicht der ideologischen Normvorgabe entsprach. Für die Museen bedeutete das laut Valentina Zlatoustova, dass sie den Kurs wiederaufnehmen mussten, den sie in den 1930er Jahren begonnen hatten und der im Wesentlichen in der »Lobpreisung« der Wirklichkeit, der »Verdrehung« der historischen Wahrheit und der Verbreitung des stalinistischen Personenkults bestand. ${ }^{526}$

Auf Befehl des Ministerrates führte das Komitee 1950 eine Erfassung aller $\mathrm{Mu}$ seen durch. Teil dieser staatlichen Kontrolle war eine Zertifizierung (pasportizacija)

Tscheljabinsker Gebietes festgelegt, an der im Mai 1949 alle Museen des Gebietes teilnahmen. Vgl.: OGČAO, f. R-627, op. 3, d. 408, I. 120 b und I. 18. 
der Museen, die zu mehr Ordnung und Homogenität führen sollte. Die Ergebnisse waren wenig erfreulich: Die völlig unzureichende staatliche Finanzierung hatte eine große Zahl der regionalwissenschaftlichen Museen an den Rand ihrer Existenz gebracht. Die Lösung konnte für das Komitee nicht in einer grundsätzlichen Aufstockung des Budgets bestehen, da das Finanzministerium drängte, eine bedeutende Zahl von Museen zu schließen, um andere besser fördern zu können. ${ }^{527}$ Die Schließung der regionalwissenschaftlichen Museen Anfang der 1950er Jahre war kein reiner Akt staatlicher Willkür, sondern berief sich auf die unzureichende Entsprechung der Häuser gemäß der Vorgaben von 1948. Dabei stand die Bewertung der Sammlungen im Zentrum. Der Beurteilung nach litten die Sammlungen unter einer starken Einseitigkeit. In den Augen der Prüferinnen und Prüfer »verstopften « die Objekte der Gegenwart, die die Kultur und den Alltag der Bevölkerung spiegelten, die Sammlungen und zeugten von unzureichender Museumsarbeit. Am 11. Januar 1954 erließ der Ministerrat die Verordnung Nummer 84 über die »ernstzunehmenden Mängel in der Arbeit der regionalwissenschaftlichen und Memorialmuseen (memorial'nych muzeev) des Kulturministeriums der RSFSR und Maßnahmen über die Verbesserung ihrer Tätigkeit «. ${ }^{528}$ Neben einer partiellen Unterstützung der Museumsarbeit einzelner Häuser wurden 33 regionalwissenschaftliche Museen geschlossen und sieben kleine Memorialmuseen in Bibliotheken transformiert. ${ }^{529}$ Laut der Forschung waren diese Museen »effektiv schwache Museen «, die zum größten Teil sehr jung waren und weder über wissenschaftliche Mitarbeiterinnen und Mitarbeiter noch eine ausreichende Ausstellungsfläche oder große Sammlungen verfügten. ${ }^{530}$ Gleichzeitig lagen der Schließung jedoch keine klaren Kriterien oder perspektivischen Analysen der Entwicklungsmöglichkeiten der $\mathrm{Mu}$ seen zugrunde.

Im Tscheljabinsker Museum wurde die wissenschaftliche Arbeit fortgeführt. Forschungsexpeditionen mit archäologischer, historischer und ethnographischer

\section{Ebd. S. 239.}

»O ser'eznych nedostatkach v rabote kraevedčeskich i memorial'nych muzeev Ministerstva kul'tury RSFSR i merach ulučšenija ich dejatel'nosti«, zitiert nach: Zlatoustova, Valentina: Gosudarstvennaja politika v oblasti muzejnogo dela, S. 241.

Valentina Zlatoustova nennt das Erinnerungsmuseum F. Dzeržinskij in dem Dorf Kaj (Kirovsker Cebiet), das Haus-Museum S. Ordžonikidze im Dorf Potoskuj (Krasnodarsker Region), das Museum P. Morozov im Dorf Gerasimovka (Sverdlovsker Gebiet) und das Haus-Museum G. Plechanov in der Stadt Lipeck, vgl. Zlatoustova, Valentina: Gosudarstvennaja politika v oblasti muzejnogo dela, S. 241.

Außer dem regionalwissenschaftlichen Museum der Stadt Ruza (Moskauer Gebiet) und dem in Nikolsk (Wolodger Gebiet) waren 20 der 33 Museen in den 1920-30er Jahren gegründet worden, die restlichen nach dem Deutsch-Sowjetischen Krieg. 16 Museen der Liste hatten keine wissenschaftlichen Mitarbeiterinnen/Mitarbeiter, und die Ausstellungsfläche war im Durchschnitt nicht größer als $100 \mathrm{~m}^{2}$. In den Sammlungen befanden sich zwischen 200 bis 4.000 Objekte, wobei die Mehrheit archäologische Fundstücke waren. 
Ausrichtung bestimmten das erste Nachkriegsjahrzehnt. ${ }^{531}$ Insbesondere die Prospektionen und Ausgrabungen unter der Leitung des bekannten sowjetischen Archäologen Konstantin Sal'nikov führten 1953 zu der Entdeckung von Siedlungen aus der Bronzezeit, die bislang für das Tscheljabinsker Gebiet völlig unbekannt gewesen waren. ${ }^{532}$ Im April 1956 durfte Nina Kiparisova, die Archäologin des Museums, am »Institut für die Geschichte der Materiellen Kultur« der Moskauer Akademie der Wissenschaften die Ergebnisse des Tscheljabinsker Museums vortragen. Die Zuhörerinnen und Zuhörer waren begeistert. Im Abschlussdokument der Sitzung fand sich folgende Würdigung:

»Die archäologischen Forschungen, die das Tscheljabinsker Cebietsmuseum durchführt, haben eine große wissenschaftliche Bedeutung für die Erforschung der Siedlungen aus der neolithischen Epoche und der Bronzezeit im Süd-Ural; dabei lösen sie nicht nur eine Reihe von historischen Fragen zur Ur- und Frühgeschichte des Süd-Urals, sondern auch im riesigen Cebiet unseres Landes. [...] Diese sinnvollen Forschungen sollten unbedingt weiterverfolgt werden. « ${ }^{53}$

Diese Wertschätzung der regionalen archäologischen Forschung schien - drei Jahre nach Stalins Tod und wenige Monate nach dem 20. Parteitag der KPdSU, der zum sogenannten »Tauwetter« geführt hatte - den zentralen Kulturbehörden zu weit $\mathrm{zu}$ gehen. In einem Leitartikel ihrer zentralen Zeitschrift »Sowjetische Kultur« (Sovetskaja kul'tura) diskreditierten sie zwei Monate später die Arbeitsweise des Tscheljabinsker regionalwissenschaftlichen Museums und führten es gegenüber allen anderen Museen als Negativbeispiel vor:

»Eine Reihe von Museen macht allerdings keinen guten Gebrauch von ihren Sammlungen, indem sie die Anforderungen des Lebens vergessen, reduzieren sie ihre Tätigkeit manchmal auf eine abstrakte Vermittlung. Die Arbeiter des Tscheljabinsker Cebietsmuseums sehen ihr Museum als Schatzkammer von Raritäten, unter denen sich, wie sie betonen, der heilige Stein des Ostens befindet: Jade. Ihren Ausstellungen liegt nicht das gegenwärtige Leben zu Grunde, das kreative

531 Antipin, Nikolaj: Čeljabinskij kraevedčeskij muzej, S. 71.

5321954 verfasste Ivan Gorochov einen Aufsatz über die »Expeditionen des Tscheljabinsker regionalwissenschaftlichen Museums «. Er beschrieb ausführlich zehn verschiedenene Expeditionen (vier archäologische, zwei botanische zwei ethnographische und eine geografische), die das Museum 1953 durchgeführt hatte. Vgl.: OGAČO, f. R-627, op. 3, d. 441, I. 55-56ob. Der Archäologe Konstantin Sal'nikov, der für weitreichende Entdeckungen in der Andronovo-Kultur berühmt wurde, war bereits vor dem Krieg eng mit dem Museum verbunden gewesen, als er ab 1937 im Museum arbeitete. Für eine Kurzbiografie vgl. Antipin, Nikolaj: Čeljabinskij kraevedčeskij muzej, S. 188-189.

533 Der Vortrag der Tscheljabinsker Museumsmitarbeiterin Nina Kiparizova (1900-1958) fand am 10. April 1956 statt. Eine Abschrift des Schlussplädoyers der Konferenz am Institut für Materielle Kultur findet sich in: OGAČO, f. R-627, op. 3, d. 454, I. 46. 
und schöpferische Werk der Arbeiter, der Kolchosebauern, der Intelligenz. Solche Museen findet man leider viel zu oft. «534

Die naturwissenschaftliche Sammlungsarbeit der Tscheljabinsker muzejščiki wurde kritisiert. In ihrer Einseitigkeit ließen sie in den Augen der Behörden die relevanteren Bereiche, wie den wirtschaftlichen Aufschwung des Landes, außer Acht. In der Tat, die an den lokalen Beziehungen zwischen Mensch und Umwelt ausgerichtete Sammlungsarbeit hatte zu Ausstellungen geführt, die die Natur der Region, die ur- und frühgeschichtlichen Siedlungen und die vorrevolutionäre Geschichte präsentierten. Nach dem Abbau der Sonderausstellung zum »Großen Vaterländischen Krieg« war die sowjetische Periode lediglich über ein Ausstellungskapitel zum Bürgerkrieg präsent. ${ }^{535}$ Schuldig an diesem Missstand waren gemäß dem Kulturministerium nicht nur die muzejščiki selbst, sondern auch die Kulturbehörden vor Ort und das Wissenschaftliche Forschungsinstitut, die bei der gewünschten Betreuung und Leitung der Museen versagten:

»In die schwache Museumsarbeit sind in der Regel nicht nur die Museen selbst verstrickt, sondern auch die Organe des Kulturministeriums, dessen Arbeiter die grundlegenden Fragen der Museumsarbeit nicht geklärt haben. [...] Auch das Wissenschaftliche Forschungsinstitut hilft den Museen zu wenig, manchmal ebnen sie sogar mit ihren unüberlegten Verordnungen den Irrweg der Museumsarbeiter. In ihren Publikationen orientieren sie sich im großen Stil an der Erforschung von seltenen und ausgefallenen Objekten. In den Augen des Institutes liegt der Sinn des Museums, die Besonderheit seiner Tätigkeit, im Sammeln, Bewahren und Ausstellen. Ohne Zweifel, seltene Exponate muss man sammeln, aber man darf bestimmt nicht die wichtigen wirtschaftlichen Aufgaben umgehen, die die Arbeiterschaft der Republiken, der Regionen und der Gebiete bewältigen. ${ }^{536}$

Diese Kritik am Wissenschaftlichen Forschungsinstitut zeigt, dass Empfehlungen, wie sie die Museologin Anna Zaks während des Krieges gegeben hatte, als sie die regionale Forschung und ihre Bezüge zur unionsweiten Geschichte empfahl, überholt waren. Auch wenn es den Tscheljabinsker kraevedy offenbar gelungen war, die Erkenntnisse über die Besonderheiten ihrer Region im Kontext der sowjetischen Umweltgeschichte zu präsentieren, waren den Moskauer Behörden diese Ansätze suspekt. Im Zentrum der Arbeit des Museums sollten die Errungenschaften der Gegenwart stehen. Im sich zuspitzenden Kalten Krieg, in dem zwei Gesellschaftssysteme gegeneinander ausgespielt wurden, sollten die Ausstellungen der regionalwissenschaftlichen Museen keine Kenntnisse über das regionalspezifische (archäo- 
logische) Erbe der vorsowjetischen Zeit, sondern die wirtschaftliche Überlegenheit der gegenwärtigen Sowjetunion vermitteln. Diese Beobachtung konkretisiert den allgemeinen Befund Marija Kaulens, dass die Freiheiten des »Tauwetters « nur dann gewährt wurden, wenn sie eine Stärkung des Sozialismus beinhalteten. ${ }^{537}$

Ein halbes Jahr später, im Februar 1957, bat der 73-jährige Museumsdirektor Gorochov um Versetzung. Als Sammlungsleiter des Museums arbeitete er noch anderthalb Jahre im Museum, bis er aus gesundheitlichen Gründen auch diese Tätigkeit aufgab. 1963, sieben Jahre vor seinem Tod, verfasste er eine kurze Autobiografie, die er mit folgendem Satz abschloss:

»Wenn ich die Ergebnisse eines fast vollendeten Lebens zusammenfasse, bin ich zufrieden, dass es mir gelungen ist, meinen jugendlichen Traum zu verwirklichen: Eine naturwissenschaftliche Ausbildung zu erhalten, mein Wissen und meine Erfahrungen für die Erforschung unseres Cebietes - den Süd-Ural - anzuwenden und ein regionalwissenschaftliches Museum zu gründen und es meinem heimatlichen Tscheljabinsk zu hinterlassen. ${ }^{538}$

Gorochov, der das Musem rund 40 Jahre geleitet hatte, blickte trotz aller beruflichen, materiellen und finanziellen Schwierigkeiten wohlwollend auf sein Arbeitsleben zurück. ${ }^{539}$ Die wissenschaftliche Forschungstätigkeit, die unter den begeisterten kraevedy zu Beginn der 1920er Jahre zur Gründung des Museums geführt hatte, war unter seiner Leitung immer die Grundlage für die Sammlungs,- Ausstellungsund Vermittlungsarbeit gewesen. Seinem Nachfolger Pëtr Vasil'evič Meščerjakov (1904-1960), der bereits in den 1930er Jahren als wissenschaftlicher Mitarbeiter im

537 Kaulen, Marija: Muzejnoe delo Rossii, S. 160.

538 Gorochov, Ivan: Kratkaja avtobiografija osnovatelja i pervogo direktora Čeljabinskogo oblastnogo kraevedčeskogo muzeja I. G. Gorochova, S. 10.

539 Ein äußerer Anlass für das Verfassen der Autobiografie oder ein Hinweis auf den intendierten Adressatenkreis ist der Verfasserin nicht bekannt. Alexey Tikhomirov sieht diese autobiografische Praxis als Teil der Arbeit an dem sowjetischen Selbst. Er schrieb: »Ein sowjetischer Mensch arbeitet sein ganzes Leben lang an der Vervollkommnung seiner Subjektivität: Er gestaltet fortwährend den eigenen Lebenslauf, füllt Fragebögen aus, wendet sich mit Bittgesuchen an das Regime, durchläuft Phasen der Selbstkritik und Parteisäuberungen«. Vgl. ders.: Das »Vertrauen der Partei« verdienen, rechtfertigen und wiederherstellen, Das sowjetische »Ich« in Briefen an das Regime im frühen Sowjetrussland, in: Ceschichte in Wissenschaft und Unterricht, 69 2018, Heft 5/6, S. 271-293, hier S. 292. Die 13 Jahre zuvor (am 9. Februar 1950) verfasste »Ergänzung zu der Autobiografie von I. G. Gorochov« (Dopolnenija k avtobiografii I. G. Gorochova), die eine Kurzbiografie in Stichpunkten mit den wichtigsten beruflichen Stationen und Auszeichnungen enthalten, verweist auf seine langjährige Absicht, eine Autobiografie zu verfassen. Dieser Befund steht in Übereinstimmung mit den Forschungen zu den sowjetischen Briefeschreibern und Briefeschreiberinnen. Vgl. Tikhomirov, Aleksey: The Regime of Forced Trust, Making and Breaking Emotional Bonds between People and State in Soviet Russia, 1917-1941, in: Slavonic and East European Review, 91, 1 2013, S. 78-118, hier S. 97. 
Museum gearbeitet hatte, gelang es, den langersehnten Umbau und die Renovierung des Museums durchzusetzen, und als das Haus Ende der 1950er Jahre neueröffnete, waren alle Abteilungen stark überarbeitet und nach den politisch-ideellen Gesichtspunkten der Entstalinisierung unter Chruschtschow ausgerichtet. ${ }^{540}$

540 Antipin, Nikolaj: Čeljabinskij oblastnoj kraevedčeskij muzej, Na puti k stoletnemu jubileju, Tscheljabink 2013, S. 7. Die frühen 1960er Jahre waren von einer Kulturpolitik geprägt, die die gemeinsame Vergangenheit betonte, damit sich die Menschen in der Sowjetunion ihrer Rolle in der sowjetischen Geschichte bewusst werden und die letzte Phase des Aufbaus des Kommunismus unterstützten. Victoria Donovan argumentiert, dass die kraevedenie im Zuge dieser Kulturpolitik ein »revival« erlebte, da lokales historisches Wissen bewusst gefördert wurde, um Unterstützung unter der Bevölkerung für die Regierung zu generieren. Vgl. Donovan, Victoria: »How Well Do You Know Your Krai?« The Kraevedenie Revival and Patriotic Politics in Late Krushchev-Era Russia, in: Slavic Review, vol. 74, Nr. 3, 464-483. 


\section{Kapitelfazit}

Im Winter 1941/42, als die Hauptstadt evakuiert worden war, blieben im Moskauer Armeemuseum wenige Frauen und Männer zurück. Sie schufen unter widrigsten Umständen eine Ausstellung über die Ereignisse der vergangenen drei Monate. Die Sonderausstellung über die Verteidigung von Moskau orientierte sich dabei an dem in der Stadt verfügbaren Wissen. Die muzejščiki griffen auf die Topoi des ersten Dokumentarfilms über die Verteidigung von Moskau und auf innovative Inszenierungen der >Gegenwartsausstellungen ‘ des GIM zurück und entwickelten langlebige Sujets und Ausstellungselemente. Die Fallstudie zeigt, dass es keine übergeordnete Parteiinstanz, sondern die muzejščiki selbst waren, die die bis heute wirksamen Topoi auswählten und zu ihrer Verbreitung und Verstetigung beitrugen.

Die Sonderausstellung des Armeemuseums, obwohl sie nach den eigenen Maßstäben des Museums dilettantisch und defizitär war, entwickelte eine beeindruckende Anziehungskraft. Sie hatte zu Beginn des Kriegsjahres 1942 eröffnet, zu einer Zeit die zugleich von dem ersten großen Sieg und der größten Angst geprägt war. Die Ausstellung über die `Zerschlagung der deutschen Truppen vor Moskau< hatte die Macht, die Menschen davon zu überzeugen, dass die drohende Gefahr einer Vernichtung durch die deutsche Wehrmacht abgewendet werden könne. Die metallene Materialität des zerstörten deutschen Kriegsgeräts war ein untrüglicher Beweis für die Besiegbarkeit des Feindes, der durch die Präsentation der fremden (und oft überlegenen Technik) noch überzeugender wirkte. Die Trophäen dienten als materielle Beweise für die Niederlage des Feindes. Die Soldaten gingen vor der Abreise an die Front ins Museum, um Informationen über den Feind zu erhalten. Die unbrauchbar und unschädlich gemachte deutsche Militärtechnik nahm ihnen möglicherweise ein Stück ihrer Angst und konnte ihnen Mut machen. Die muzejščiki verstärkten diese Wirkung durch eine Sakralisierung der Objekte als »Reliquien« des Krieges. Die Kuratorinnen und Kuratoren schufen mit ihrer Ausstellung einen Raum, in dem die gerade vergangenen Ereignisse noch einmal durchlebt werden sollten. Die museale Inszenierung erhöhte das Kriegserlebnis und lud es mit historischer Bedeutung auf, so als läge der gegenwärtige Krieg bereits in der Vergangenheit. Diese santizipierte Kommemoration`verlieh dem Gezeigten und damit auch dem Erlebten eine Wirkungsmacht, die die Popularität der Ausstellung und die Langlebigkeit ihrer Topoi erklärte.

Mit dem Fortschreiten des Krieges drangen die Moskauer Museumsdirektoren auf eine kontinuierliche Verbesserung der Arbeitsqualität ihrer Angestellten, was in einer Verwissenschaftlichung des Krieges mündete. Sie hatten die zunehmend größer werdende politische Rolle der Roten Armee erkannt. Während vor dem Krieg die Außenwahrnehmung der Sowjetunion auf dem Erfolg des wirtschaftlichen Aufbaus lag, kam es nach dem Krieg zu einer Glorifizierung der Roten Armee und ihrer Wehrhaftigkeit. Bei dieser öffentlichen Huldigung kam dem 
Armeemuseum als Bewahrer der »Heiligtümer« und als Expertin des Kriegswissens ein herausgehobener Platz zu. Für die Direktoren des Armeemuseums war die Chance gekommen, von einem Spartenmuseum zum Leitmuseum der Geschichte des »Großen Vaterländischen Krieges« zu werden. Dabei profitierten sie von der engen Zusammenarbeit mit den leitenden Stellen der Roten Armee, die die Ausstellungen und die Sammlungen des Museums mit den "frischesten« Exponaten von der Front füllten. Auch die Offiziere der Roten Armee hatten ein vitales Interesse an einer engen Zusammenarbeit mit dem Museum. Im Idealfall kommemorierten die muzejščiki die Heldentaten der Armeeverbände. Bei Kriegsende hatte sich das Armeemuseum gegenüber seinen Konkurrenten, den anderen $\mathrm{Mu}-$ seen und Institutionen, die Kriegsrelikte sammelten, durchgesetzt. Es hatte das Monopol auf alle Trophäen und Kriegsrelikte erhalten und wurde zur wichtigsten musealen Deutungsinstanz der Geschichte des »Großen Vaterländischen Krieges« in der Sowjetunion. ${ }^{541}$

In Bezug auf die grundsätzliche Frage der Formung und Ausgestaltung der frühen sowjetischen Kriegserinnerung lässt sich anhand des Moskauer Armeemuseums die Entwicklung von einer lokalen zu einer unionsweiten Meistererzählung nachvollziehen. Das Fallbeispiel zeigt, dass diese Entwicklung interessanterweise von den muzejščiki selbst vorangetrieben und nicht von einer übergeordneten Stelle diktiert wurde. Der Befund eines sautonomen< Handelns der Museen sollte jedoch nicht als absolut verstanden werden. Im Gegenteil, die muzejščiki handelten autonom nur im Rahmen ihrer Möglichkeiten und waren dabei diskursiv selbstverständlich nicht abgekoppelt von der sowjetischen Gesellschaft und schon gar nicht von den politischen Vorgaben. ${ }^{542}$ Der Krieg vereinte die Kulturinstitutionen zu Mitstreitern in einer Sache. Das Museum und seine Sonderausstellungen erschienen dabei als nicht zu vernachlässigende Akteure innerhalb des Kriegsdiskurses, die mediale Topoi aufgriffen und neue produzierten. Die Ausweitung der Moskauer Ausstellung zu einer chronologischen Überblicksausstellung zur gesamten Geschichte des »Großen Vaterländischen Krieges« war aus der Perspektive der muzejščiki die einzig sinnvolle Entwicklung.

Dass sie ihre Forderungen am Ende des Krieges durchsetzen konnten, spricht für die große Wirkung und Reichweite, die dem Museum seitens der GlavPURKKA

541 Die Objekte verleihen dem Museum auch heute ein Alleinstellungsmerkmal, das es beispielsweise von dem »Museum des Sieges« unterscheidet. Dieses wurde 1995 auf dem Poklonnaja Gora in Moskau eröffnet und zeichnet sich weniger durch die Ausstellung von Originalen als über seinen starken Event-Charakter (vertonte Dioramen, begehbare Schützengräben etc.) aus.

542 Zukünftige Studien müssten das diskursive Umfeld der Museen untersuchen und die Zusammenarbeit zwischen den medialen Akteuren (Presse, Rundfunk, Film, Theater, Literatur und Museum) stärker herausstellen. 
zugesprochen wurde. Ihre erfolgreichen Sonderausstellungen während des Krieges hatten dazu geführt, dass aus dem Museum als Unterabteilung des »Hauses der Roten Armee« am Ende des Krieges eine eigenständige Institution geworden war, die vom obersten Regierungsgremium zum Kriegsmuseum Nr. 1 befördert wurde, an dem sich von nun an alle Museen der Sowjetunion, die den »Großen Vaterländischen Krieg« ausstellten, orientierten.

Nach der Befreiung der belarussischen Hauptstadt im Juni 1944 hatte die unmittelbare Musealisierung der Besatzungserfahrung höchste Priorität für den ersten Sekretär des ZK Belarus Pantelejmon Ponomarenko. Das neue Museum basierte auf der Sonderausstellung der Belarussischen Historikerkommission, die diese im November 1942 im Moskauer GIM errichtet hatte. Das Minsker Kollektiv des neugegründeten Museums bestand aus jungen Männern und Frauen ohne historische oder museumsspezifische Ausbildung, die die dreijährige Besatzungsherrschaft bei den Partisanenverbänden oder im Untergrund überlebt hatten und selbst als historische Akteure die Ereignisse bezeugen konnten. Im Gegensatz zur Moskauer Ausstellung mussten sie dem Minsker Publikum keine Erklärungen zu der spezifischen belarussischen Kriegserfahrung geben. Die Ausstellungsmachenden und die Ausstellungsbesuchenden hatten den gleichen Erfahrungshintergrund, und die Ausstellung folgte dem Anspruch der Dokumentation, der Verewigung und der Verarbeitung. Zur Eröffnung des Museums im Oktober 1944 zeigten die muzejščiki eine Ausstellung zu den Partisanenwaffen und über die bolschewistische Untergrundpresse. Bereits einen Monat später wurde die Sonderausstellung »Belarus unter dem Joch der deutschen Besatzer« eröffnet, die das Leid der Besatzungserfahrung in den Mittelpunkt stellte.

Diese Sonderausstellung war eine Ausnahme in der Musealisierung des »Großen Vaterländischen Krieges«, da sie vermeintliche Leerstellen der sowjetischen Kriegserfahrung, wie zum Beispiel den Holocaust, ausstellte. Ähnlich wie die Historikerkommission, die sich im Moskauer GIM als Beispiel der >lebendigen belarussischen Kultur selbst musealisierte, hatten auch die Minsker muzejščiki eine Ausstellung inszeniert, die zum Teil ihr eigenes Kriegserlebnis wiedergab und sie beinahe unweigerlich selbst zu Ausstellungsstücken machte. Dabei konzentrierten sie sich nicht nur auf die klassischen heldenhaften Aspekte der Besatzungszeit, sondern stellten einen Widerstand aus, der aus Solidarität mit der jüdischen Bevölkerung (und den sowjetischen Kriegsgefangenen) entstanden war. Die Rettung jüdischer Kinder aus dem Minsker Ghetto von den belarussischen Frauen auf der anderen Seite des Zauns wurde als ein Aspekt einer vielfältigen Leiderfahrung ausgestellt. Das Schicksal der Kriegsgefangenen, der Zwangsarbeiterinnen und Zwangsarbeiter, der Internierten der "Todeslager « und die Vernichtung der belarussischen Wissenschaft und Kultur standen gleichwertig neben der Darstellung des Holocausts (wobei dieser Begriff nicht verwendet wurde). Der Besat- 
zungsalltag konnte beinahe ohne Einschränkungen (wie zum Beispiel der Aspekt der Kollaboration) ausgestellt werden, da die Umschreibungen oder vielmehr die Herausschreibungen von Holocaust und Zwangsarbeit erst später stattfanden (und dann Konsequenzen für die Ausstellungsgestaltung hatten).

Herauszuheben ist auch die Inszenierung der Sonderausstellung, die sich stark von den stalinistischen Ausstellungen sowohl der Vorkriegs- als auch der Nachkriegszeit unterschied. Während sowjetische Ausstellungen in der Regel als semantische Texte des Sozialistischen Realismus gelesen werden konnten, fehlte in der oben analysierten Sonderausstellung das in die Zukunft gerichtete Pathos, der Fortschrittsgedanke der Ideologie des Marxismus-Leninismus. Diese Wahrnehmung wurde von den poetischen Zitaten in der Ausstellung verstärkt, die das erlittene Leid betonten. Die Sonderausstellung war weder eine Mobilisierung zum Kampf noch zum Wiederaufbau. Sie erscheint ohne Vergangenheits- bzw. Zukunftsbezug wie ein Innehalten in der Zeit und diente dem Verarbeitungsprozess der gerade historisch werdenden Vergangenheit. Dieser Eindruck einer Momentaufnahme einer spezifischen Zeit an einem bestimmten Ort wurde von dem in der Ausstellung vorherrschenden Gebrauch der belarussischen Sprache hervorgehoben.

Diese lokalspezifische Ausrichtung der Sonderausstellung wurde den Minsker muzejščiki während der spätstalinistischen Säuberungen 1947-1949 zum Verhängnis. Der Vorwurf einer Überbetonung des persönlichen und regionalen Kriegserlebnisses traf auch sie. Die Ausstellungskapitel zum Partisanenkampf und zur Leiderfahrung der belarussischen Bevölkerung in der Zeit der deutschen Besatzung, die zwei Standbeine, auf denen das Museum während des Krieges gegründet wurde, mussten sich als stark verkleinerte Ausstellungskapitel einer Darstellung vom »Großen Vaterländischen Krieg« unterordnen.

Die Analyse der Sonderausstellung »Die Rolle Tscheljabinsks im Großen Vaterländischen Krieg«, die von April 1946 bis November 1949 im regionalwissenschaftlichen Museum in der Gebietshauptstadt gezeigt wurde, offenbart mehrere Phänomene der Museumsarbeit im Süd-Ural. Die Arbeitsfreiräume der muzejščiki während des Krieges waren möglicherweise in unbesetzten und von militärischen Kriegshandlungen nicht betroffenen Gebieten vergleichsweise groß gewesen. Der Tscheljabinsker Museumsdirektor hatte während des Krieges die Erfahrung gemacht, dass sein Engagement im Bereich der kraevedenie von gesellschaftlichem Nutzen war und von den Behörden nicht nur geduldet, sondern sogar ausgezeichnet wurde.

Vor diesem Hintergrund überrascht es nicht, dass der kraeved Gorochov die Sonderausstellung der Stadt »Die Rolle Tscheljabinsks im Großen Vaterländischen Krieg« an seine Vorstellungen anpasste. Dabei besetzte er die Rollen neu. Nicht die Panzer spielten den entscheidenden Part, sondern die Mineralien und Metalle des Süd-Urals. Indem er die Geologie seiner Region als Grundbedingung und Voraus- 
setzung für den Sieg über das Deutsche Reich inszenierte, integrierte er das lokale Narrativ scheinbar harmonisch in das entstehende unionsweite Narrativ des "Großen Vaterländischen Krieges«. Dabei waren die Mineralien nicht nur strategische Rohstoffe der Rüstungsproduktion, sondern materielle Zeugen und Vertreter der Region. In ihrer anschaulichen und haptischen Beschaffenheit verwiesen sie als quasi indigene Marker auf das Tscheljabinsker Gebiet. Sie wurden für das heimische Publikum zu einer konkreten Projektionsfläche ihrer regionalen Identität. Mit der Neubesetzung der Rollen sprach Gorochov der Region einen tatsächlich lokalspezifischen Kriegsbeitrag zu. Während die Panzer zum Großteil von evakuierten Arbeitern und Fabriken produziert wurden, waren die Steine des Süd-Urals ein Beitrag, der die Kraft der eigenen Region als entscheidenden Beitrag zum »Großen Vaterländischen Krieg« hervorhob und die Bevölkerung des Tscheljabinsker Gebietes integrierte. ${ }^{543}$

Auch die engste Mitarbeiterin des Museumsdirektors Vera Sur'janinova hatte die Arbeitsfreiräume im Krieg genutzt und eine Wertschätzung ihrer naturwissenschaftlichen Arbeit erfahren. Als die Lebensmittelknappheit $1947 \mathrm{zu}$ einer erneuten Hungersnot im Tscheljabinsker Gebiet führte, begegnete die Biologin der andauernden Not, indem sie der Bevölkerung mit ihrem Wissen über Heilkräuter und essbare Pflanzen half. Die Ausstellungen der Kuratorin standen exemplarisch für eine gewisse Autonomie, die der Bevölkerung in Krisenzeiten gewährt wurde. Der im Krieg geschaffene Raum für private Initiativen (wie individueller Gemüse- und Obstanbau) wurde offengehalten (und sogar partiell unterstützt), um die Versorgungskrisen der Nachkriegszeit besser zu bewältigen.

Die hier beobachtete Tendenz der muzejščiki, den Fokus des Museums auf die Themen ihrer Vorstellung von kraevedenie zu lenken, erstaunt in Anbetracht der zunehmenden thematischen Auslassungen des Krieges noch mehr. Die ideologischen Kampagnen der Nachkriegszeit kulminierten Ende der 1940er Jahre in einem Höhepunkt des Stalinkultes. Der Generalissimus des »Großen Vaterländischen Krieg«

543 Die hier festgestellte Umdeutung eines Ausstellungsauftrages war kein Einzelfall. Sie zeigt I. Gorochovs Haltung, die eigenen Freiräume auszuloten. Im Jahr 1947 mussten alle sowjetischen Museen ihre Ausstellungen einem historischen Ereignis von unionsweiter Bedeutung widmen. Die »Große sozialistische Oktoberrevolution« feierte ihr 30-jähriges Jubiläum. Gorochov erstellte eine Sonderausstellung über die Ceschichte der Stadt Tscheljabinsk. Während der sowjetische Außenminister Molotov in seiner Rede zu den Revolutionsfeierlichkeiten in Moskau die Verbindung zwischen der Oktoberrevolution und dem Sieg im »Großen Vaterländischen Krieg« herstellte und die Kriegsereignisse als zweite Etappe der sowjetischen Ceschichte deutete, präsentierten die sechs Themen der Tscheljabinsker Ausstellung die Gründungsgeschichte der Stadt. Ohne einen Bezug zum Krieg herzustellen, zeigte I. Gorochov die kulturellen und wirtschaftlichen Entwicklungen Tscheljabinsks bis 1947. OCAČO, f. R-627, op. 3., d. 402, I. 8-9. 
war im Tscheljabinsker Museum der Gewährsmann der einzigartigen Bodenschätze des Süd-Urals. Gorochov platzierte das Stalin-Zitat an prominenter Stelle: Im ersten Saal der Ausstellung sprach Stalin jedoch nicht als Kriegsherr, sondern als Herr der Ressourcen. Ähnlich still blieb es an den ersten Jahrestagen des Sieges im "Großen Vaterländischen Krieg«. Das Ausbleiben einer entsprechenden Aktivität des Tscheljabinsker Museums stand in Übereinstimmung mit einer landesweiten Tendenz. Mischa Gabowitsch wies darauf hin, dass die Überhöhung des Sieges im offiziellen Diskurs im Kontrast zu den bescheidenen Feiern anlässlich des Jahrestages des Sieges in der zweiten Hälfte der 1940er Jahre stand. Der Verzicht des Staates auf eine offizielle Gedächtnispolitik und die Entstehung einer Gedenkkultur »von unten« zeigten sich in vielen symbolischen Ereignissen und Nicht-Ereignissen der Nachkriegszeit. ${ }^{544}$

In den heterogenen Sonderausstellungen der Kriegs- und Nachkriegszeit zeigt sich eine regionalspezifische Erfahrung der Kriegszeit. Für die Moskauer muzejščiki und ihr Publikum war die Erfahrung des bedrohten Lebens in einer Frontstadt und der erfolgreichen Verteidigung der Hauptstadt zentral. Dementsprechend standen Trophäen im Zentrum der Inszenierungen. Die prägende Kriegserfahrung der belarussischen Bevölkerung war die des Sterbens und Überlebens. Die Minsker $m u-$ zejščiki dokumentierten diese Dimensionen anhand der Darstellung der geteilten Erfahrung des Leidens, die auch den Holocaust nicht ausschloss.

An der Tscheljabinsker »Heimatfront « war der Krieg durch die Erfahrung von Mangel und die Erkenntnis des Potentials ihrer lokalen Rohstoffe präsent. In Gorochovs Darstellung der Rolle Tscheljabinsks im Großen Vaterländischen Krieg waren die mineralogischen und pflanzlichen Ressourcen die einflussreichen Akteure.

Die Handlungsfreiräume der sowjetischen Museumselite in Moskau, Minsk und Tscheljabinsk schlossen sich aufgrund ähnlicher Motive jedoch zu unterschiedlichen Zeitpunkten. Die enge Kooperation mit der GlavPURKKA hatte die muzejščiki des Moskauer Armeemuseums zu Expertinnen und Experten gemacht, die die Reliquien des "Großen Vaterländischen Krieges« bewahrten. Die demonstrative Zurschaustellung dieses Status war die Ausweitung ihres Ausstellungsnarrativs, bei dem der Sieg in Moskau den Anfang einer Reihe von erfolgreichen Kämpfen darstellte, die zum endgültigen Sieg über den Faschismus in Berlin führten. Das Ideal eines Vorbildcharakters der neu aufgebauten Musterstadt Minsk führte im April 1948 zu einer politisch motivierten Säuberung des Ausstellungsinhaltes durch die Parteiinspektoren. In Tscheljabinsk scheint die parteipolitische Kontrolle schwächer ausgeprägt gewesen zu sein. Die Behörden erkannten das Engagement des kraeved an und begnügten sich mit Mahnungen. 
1956, vergleichsweise spät, wurde das Museum in der führenden Kulturzeitschrift des Landes öffentlich für seine lokalspezifische Ausstellung diffamiert. Der Museumsdirektor trat auf eigenen Wunsch zurück.

Diese Befunde weisen auf eine ambivalente und ortsgebundene Museumspolitik der spätstalinistischen Nachkriegszeit hin, die unterschiedlich verhandelt wurde. Bei diesen Aushandlungsprozessen, die innerhalb staatlicher Strukturen und auf der Ebene eines staatlichen Diskurses stattfanden, reagierten die muzejščiki im Rahmen ihrer individuellen Möglichkeiten. In Moskau nutzten die Kuratorinnen und Kuratoren ihre professionelle Erfahrung und die Nähe zu den militärischen Machthabern und schufen eine Ausstellung über den ersten Sieg im Krieg, die sie zur Interpretation der musealen Erzählung vom »Großen Vaterländischen Krieg« ermächtigte. In Minsk wurden diejenigen, die bei den Partisanenverbänden und im Untergrund die deutsche Besatzungszeit überlebt hatten, zu muzejščiki befördert. Als Museumslaien schufen sie eine leidzentrierte Ausstellung, die im Kontext der spätstalinistischen Repressionen zu Gunsten einer heldenhaften Erzählung der Roten Armee gesäubert wurde. In Tscheljabinsk erkannte ein Geologe das Potential der kraevedenie, um sein Museum durch den Krieg zu retten und eine naturhistorische Kriegssammlung anzulegen. Er gab seiner Kriegsausstellung eine lokalspezifische Prägung, die während der Nachkriegszeit in Ergänzung zu dem unionsweiten Narrativ des Krieges bestehen konnte. 